\title{
Connectivity and growth in Sub Saharan Africa : the role of communication satellites
}

Citation for published version (APA):

Mupela, E. (2011). Connectivity and growth in Sub Saharan Africa : the role of communication satellites. [Doctoral Thesis, Maastricht University]. Datawyse / Universitaire Pers Maastricht. https://doi.org/10.26481/dis.20110331em

Document status and date:

Published: 01/01/2011

DOI:

10.26481/dis.20110331em

Document Version:

Publisher's PDF, also known as Version of record

\section{Please check the document version of this publication:}

- A submitted manuscript is the version of the article upon submission and before peer-review. There can be important differences between the submitted version and the official published version of record.

People interested in the research are advised to contact the author for the final version of the publication, or visit the DOI to the publisher's website.

- The final author version and the galley proof are versions of the publication after peer review.

- The final published version features the final layout of the paper including the volume, issue and page numbers.

Link to publication

\footnotetext{
General rights rights.

- You may freely distribute the URL identifying the publication in the public portal. please follow below link for the End User Agreement:

www.umlib.nl/taverne-license

Take down policy

If you believe that this document breaches copyright please contact us at:

repository@maastrichtuniversity.nl

providing details and we will investigate your claim.
}

Copyright and moral rights for the publications made accessible in the public portal are retained by the authors and/or other copyright owners and it is a condition of accessing publications that users recognise and abide by the legal requirements associated with these

- Users may download and print one copy of any publication from the public portal for the purpose of private study or research.

- You may not further distribute the material or use it for any profit-making activity or commercial gain

If the publication is distributed under the terms of Article $25 \mathrm{fa}$ of the Dutch Copyright Act, indicated by the "Taverne" license above, 


\section{CONNECTIVITY AND GROWTH IN SUB SAHARAN AFRICA:

\author{
The Role of Communication Satellites
}

\section{PROEFSCHRIFT}

ter verkrijging van de graad van doctor aan de Universiteit Maastricht,

op gezag van de Rector Magnificus, Prof. Mr. G.P.M.F. Mols, volgens het besluit van het College van Decanen

in het openbaar te verdedigen op donderdag 31 maart 2011 om 16.00 uur

door

Evans Mupela 


\section{Promotor}

Prof. dr. Adam Szirmai

\section{Co-Promotor}

Dr. Adriaan van Zon

\section{Beoordelingscommissie}

Prof. dr. Luc Soete, voorzitter

Prof. dr. Théophile Azomahou

Dr. Thomas Ziesemer

Prof. dr. W.E. Steinmueller, SPRU, University of Sussex

This $\mathrm{PhD}$ research was sponsored by The Netherlands Organization for International Cooperation in Higher Education, NUFFIC. 
To my lovely wife Tamara and our children Ngosa, Munshya and Madalitso. 


\section{Acknowledgements}

This is probably the most difficult 'chapter' to write, not only because of its personal nature but also because it is impossible for me to list all the people who contributed to the successful completion of this dissertation. So half of me says name no names, while the other half says there is no way you can fail to mention the giants on whose shoulders you have been standing for the past five years and who have enabled you to see so far. The responsibility implied by the latter half is what I choose to honor in the next few sentences.

First and foremost I would like to thank the Senate of Walter Sisulu University (my employers) for having given me the time and support that I needed to complete this dissertation. I am particularly grateful to Prof Sisco Nakane, Prof Nomfundo Luswazi, Prof Sandile Songca and all my colleagues in the Computer Science Department.

My deepest gratitude goes to my supervisors Prof Adam Szirmai and Dr Adriaan van Zon for having worked with me through thick and thin but mostly for believing in me and seeing through my ideas so clearly. Words can not express how grateful I am to them but I sincerely hope they understand what I mean when I simply say "Thank you". I also extend my gratitude to the reading committee for their helpful and insightful comments on my original draft.

I am grateful to MERIT for offering me an opportunity to study there and to all the administrative staff who work tirelessly to ensure that all the pieces are in place.

I would like to mention my classmates from the class of 2005: Rhadika, Lina, Donatus, Sergey, Asel, Tina, Zakaria, Philip, Eze and my office-mate Alexis. It was not a joyride out there, but it was certainly a joy sharing the last couple of years with you guys.

Last but not least I thank Tamara and the children for their understanding and support throughout the whole journey. She gallantly kept our ship afloat and kept on believing, while the only complaint I got from the children was: "when are you going back?"

Though it has been a long and difficult journey, I have grown both as a person and as a scholar and hope that I will be able to meaningfully contribute to the African development agenda through my research. 


\section{Contents}

1 Introduction and Background 1

1.1 Introduction . . . . . . . . . . . . . . . . . 1

1.2 Origins of The Idea . . . . . . . . . . . . . . . . . . . 5

1.3 Outline of the Thesis . . . . . . . . . . . . . . . . . 7

1.4 Importance of this work . . . . . . . . . . . . . . . . 8

1.5 The Research Question . . . . . . . . . . . . . . . 9 9

1.5.1 Proposition 1 . . . . . . . . . . . . . . . . 10

1.5.2 Proposition 2: . . . . . . . . . . . . . . 10

1.5.3 Proposition 3: . . . . . . . . . . . . . . 10

1.5.4 Proposition 4. . . . . . . . . . . . . . . 10

1.6 Aims of the thesis ................ . . . 11

2 Satellite Fundamentals 13

2.1 Introduction . . . . . . . . . . . . . . . . 13

2.2 The Nature of Satellites . . . . . . . . . . . . . . . 13

2.3 Components of a modern Communications Satellite . . . . . 15

2.3.1 The Space Segment . . . . . . . . . . . . 15

2.3.2 Power Generation . . . . . . . . . . . . . . 16

2.3 .3 The Launch . . . . . . . . . . . . . . . . . . . 18

2.3.4 The Ground Segment . . . . . . . . . . . . 19

2.3.5 National Gateway . . . . . . . . . . . . . . . . 19

2.3.6 Tracking Telemetry and Control Earth Station . . . 19

2.3.7 Frequency Bands . . . . . . . . . . . . . . . 20

2.3.8 Transponder Capacity . . . . . . . . . . . . . . 21

2.4 The African Scenario . . . . . . . . . . . . . . . . . . 21

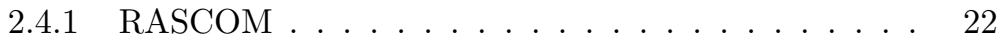

2.5 Summary ...................... 24

3 A Satellite-Based Endogenous Growth Model 25

3.1 Introduction ${ }^{1} \ldots \ldots \ldots \ldots . \ldots . \ldots 25$

3.2 The Model . . . . . . . . . . . . . . . 30

3.2.1 The demand for goods and Community welfare . . . 32

3.2.2 Connecting with another Community . . . . . . . . 34

\footnotetext{
${ }^{1}$ This chapter is based on the ideas of the author as implemented by Dr Adriaan van Zon appearing in the UNU-MERIT working paper series as Working Paper \#2010-001 (see bibliography van Zon and Mupela, 2010).
} 
3.2.3 Goods and Services Supply with Two Connected Communities . . . . . . . . . . . . . 35

3.2.4 Benefits from Additional Connections . . . . . . . 36

3.2.5 Optimum Network Expansion Rates . . . . . . . . . 38

3.2 .6 Network Expansion . . . . . . . . . . . . . . . . . . 39

3.2 .7 Parameter Constraints . . . . . . . . . . . . . . 40

3.2 .8 Transitional Dynamics . . . . . . . . . . . . . . . 42

3.2.9 Solving for the Transition Path Using Backward Integration . . . . . . . . . . . . . 44

3.2 .10 Sensitivity Analysis _ . . . . . . . . . . . 46

3.3 Concluding Remarks . . . . . . . . . . . . . . . . . . 64

3.4 Summary . . . . . . . . . . . . . . . . . . 65

4 Satellites and Communication Costs in sub-Saharan Africa 67

4.1 Introduction . . . . . . . . . . . . . . . . . 67

4.2 History of Telecommunications in Africa . . . . . . . . . 69

4.2 .1 Enter Satellites . . . . . . . . . . . . . . . . 70

4.2 .2 Optical Fibre versus Satellite . . . . . . . . . . . . . 73

4.2.3 Other Competing Technologies . . . . . . . . . . 77

4.3 International Settlement and Accounting Rates system . . . 79

4.4 ICT Services and satellites in Africa . . . . . . . . . . . . 83

4.4 .1 Fixed Telephony . . . . . . . . . . . . . . . . . . 83

4.4 .2 Mobile Cellular Telephony . . . . . . . . . . . . . . . 88

4.4 .3 The Internet . . . . . . . . . . . . . . . . . . . . . . 92

4.4.4 Television and Radio Broadcasting . . . . . . . . . . 97

4.5 Satellites and Communication Costs . . . . . . . . . . 99

4.6 Summary . . . . . . . . . . . . . . . . . . . 102

5 Communication Costs and Trade in sub-Saharan Africa 103

5.1 Trade and Growth . . . . . . . . . . . . . . . . . 106

5.2 The Gravity Model of Trade . . . . . . . . . . . . . . . . . . 109

5.3 The Empirical Model . . . . . . . . . . . . . . . . . . . . . . 114

5.4 The data . . . . . . . . . . . . . . . . . . . . . . . . . . . . . . . 119

5.5 Estimation Results . . . . . . . . . . . . . . . . . . . 120

5.6 Conclusion and Summary . . . . . . . . . . . . . . . . 124

5. A Data Summary . . . . . . . . . . . . . . . . . . 128

5.B Correlation Matrix . . . . . . . . . . . . . . . . . . . . . . . 129

5.C Descriptive Graphs . . . . . . . . . . . . . . . . . . 131

5.D List of Countries . . . . . . . . . . . . . . . 135

6 Telecommunications and Household Income in South Africa137

6.1 Introduction . . . . . . . . . . . . . . . . . . 137

6.2 Theoretical Conceptual framework . . . . . . . . . . . . . 142

6.3 Methodology . . . . . . . . . . . . . . . . . . . . . 143

6.4 The Empirical Model . . . . . . . . . . . . . . . . . . . 145 
6.5 Data Description . . . . . . . . . . . . . . . . . . . . 146

6.6 Regression results . . . . . . . . . . . . . . . . . . . . . . 149

6.6.1 Granger Causality Test . . . . . . . . . . . . 156

6.7 Conclusions . . . . . . . . . . . . . . . . . . . . 157

6.8 Summary . . . . . . . . . . . . . . . . . . . . . 158

6.A Data Disclaimer from Statistics South Africa . . . . . . . 159

6.B Data Summary . . . . . . . . . . . . . . . . . . . 160

6.C Correlation Matrix . . . . . . . . . . . . . . . 161

6.D List of Municipalities . . . . . . . . . . . . . . . . 163

7 Applications Case Studies $\quad \mathbf{1 6 7}$

7.1 Introduction . . . . . . . . . . . . . . . . 167

7.2 Worldspace Incorporated . . . . . . . . . . . . . . . . 168

7.2 .1 Introduction . . . . . . . . . . . . . . 168

7.2 .2 Early Days. . . . . . . . . . . . . . . . . . . . . . . . . . 169

7.2 .3 Competition . . . . . . . . . . . . . . 170

7.2 .4 The Business . . . . . . . . . . . . . . . . 172

7.2.5 Multichoice and World Space Compared . . . . . . 175

7.2 .6 The user's views . . . . . . . . . . . . . . . . . . 177

7.2 .7 Conclusions . . . . . . . . . . . . . . . . . . . . . . . 179

7.3 Telemedicine Projects . . . . . . . . . . . . . . . . . . 181

7.3.1 The Virtual Doctor Project ${ }^{2}$. . . . . . . . . . 183

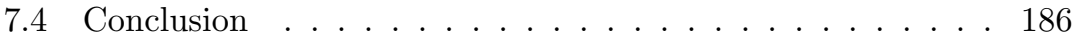

7.5 Summary . . . . . . . . . . . . . . . . 186

8 Conclusions and Recommendations 189

8.1 Introduction . . . . . . . . . . . . . . . . . . . . . . . 189

8.2 Major Findings. . . . . . . . . . . . . . . . . . . . . . . . 191

8.3 Regulation and competition . . . . . . . . . . . . . . . . 193

8.4 Recommendations . . . . . . . . . . . . . . . . . 194

\footnotetext{
${ }^{2}$ This section is based on a paper written by the author together with Paul Mustard and Huw Jones of the Virtual Doctor Project in Zambia. The paper appears in the UNU-MERIT Working Paper Series as Working Paper \#2011-002 due for publication in the Phiolosophy, Ethics and Humanities in Medicine Journal (see bibliography Mupela, Mustard and Jones, 2011)
} 



\section{List of Figures}

2.1 Geostationary Earth Orbit . . . . . . . . . . . . . . . . 14

2.2 The Three Axis Stabilized Spacecraft . . . . . . . . . . . . 16

2.3 The Spin-Stabilized Spacecraft _.. . . . . . . . . . . . 17

2.4 Launch Sequence of Communication Staellite . . . . . . . 18

3.1 The Phase Diagram . . . . . . . . . . . . . . . . . . 43

3.2 Sensitivity Results for Variations in $\sigma \ldots \ldots$. . . . . . 49

3.3 Sensitivity Analysis for Variations in $\theta \ldots \ldots \ldots$. . . . 51

3.4 Sensitivity Results for Variations in $\alpha \ldots \ldots \ldots$

3.5 Sensitivity Results for Variations in $\beta \ldots \ldots \ldots$

3.6 Sensitivity Results for variations in $\delta \ldots \ldots \ldots \ldots \ldots . \ldots 57$

3.7 Sensitivity Results for Variations in $\mu \ldots \ldots \ldots$

3.8 Sensitivity Analysis for Variations in $\bar{L} \ldots \ldots \ldots$. . . . 61

3.9 Sensitivity results for Variations in $\bar{l} \ldots \ldots$. . . . . . 63

4.1 Communication Costs Trade and Growth . . . . . . . . 68

4.2 Landing points of the Africa section of SAT3/WASC . . . . 74

4.3 Projected map of Fibre Connectivity in Africa, 2011. . . . 78

4.4 An Example of Accounting rates Based on US-Colombia Transactions in $1996 \ldots \ldots \ldots$. . . . . . . . 80

4.5 Internationla Fixed Outgoing and Incoming Calls for SSA . 82

4.6 A Typical Fixed Line PSTN Architecture . . . . . . . . . . 85

4.7 Cellular Network Topology _. . . . . . . . . . . . . . . 87

4.8 Mobile Subscribers and Mobile Service Penetration in SSA . 89

4.9 Cost of International Link via Two-Way Satellite . . . . . . 94

4.10 Comparison of Cost of Broadband between SSA and Other Regions . . . . . . . . . . . . . . . . 9 95

4.11 Satellite Home Antennas in SSA . . . . . . . . . . . 98

5.1 Cost of Export and Import Procedures in USD . . . . . . 105

5.2 International Call Charges between USA and AGOA Participating African Countries . . . . . . . . . . . . . . . . . 108

5.3 Distance from South Africa and Level of Exports . . . . . . 112

5.4 Distance from Zambia and Level of Exports . . . . . . . . 113

5.5 Level of Exports and International Calling Charges in SSA (2007) . . . . . . . . . . . . . . . 127

5.6 Level of Exports and International Fixed Calling Charges from RSA $2007 \ldots \ldots$. . . . . . . . . . . 132 
5.7 Level of Exports from Zambia and Fixed line charge in $\$$ US $/$ minute133

6.1 Telecommunications as an Enabler of Income Generation . 143

6.2 Percentage of Households Reporting Use . . . . . . . . . . 150

7.1 The WorldSpace Service Array . . . . . . . . . . . . . . . 170

7.2 Excerpt from Worldspace Consolidated Statement of Operations, $2008 \ldots \ldots \ldots \ldots \ldots \ldots$

7.3 Performance of $\$ 100$ Invested in WS compared with Nasdaq and the Russe IT Index Over One Year . . . . . . . . . . . 174

7.4 Multichoice Number of Subscribers in Africa as of Sept 2009178

7.5 Demographics of Respondents . . . . . . . . . . . 178

7.6 Cost Perceptions of Respondents . . . . . . . . . . . . . . . 179

7.7 Product Quality Perceptions of WS Users who Participated in the Online Survey . . . . . . . . . . . . . . . . . . . 180 


\section{List of Tables}

2.1 Radio Frequency Bands Commonly used For Satellite Applications ..................... 20

3.1 Parameter Constraints . . . . . . . . . . . . . . . . . 41

3.2 The Base-Run Parameter vector . . . . . . . . . . . . 46

4.1 Satellite Operators over Africa . . . . . . . . . . . . 72

4.2 Mobile Roaming Costs from Cell C South Africa to other Service Providers in Africa in 2009 (South African Rands/minute) 91

4.3 Internet Service Providers in Zambia and Access Type . . . 96

4.4 IXPs in Africa . . . . . . . . . . . . . . . . . 96

5.1 Variable Descriptions and Expected Signs . . . . . . . . . . 118

5.2 Determinants of Export Intensity: OLS Regression Results . 122

5.3 Determinants of Export Intensity: ML Regression Results . 123

5.4 Determinants of Export Intensity: Coastal Countries (OLS) 125

5.5 Determinants of Export Intensity: Landlocked Countries(OLS) 126

5.6 Data Summary for main Variables of the Model . . . . . . . 128

5.7 Correlation Matrix Table of main variables of the Model . . 130

5.8 List of Countries . . . . . . . . . . . . . . . . . 135

6.1 List of Variables and their Expected Signs . . . . . . . . . . 148

6.2 OLS Determinants of Per Capita Household Income in All Municipalities, 2001 to 2007 . . . . . . . . . . . . 152

6.3 OLS Determinants of Per capita Household Income in $\mathrm{Mu}-$ nicpalities without the Metropolitan Areas 2001-2007 . . . . 153

6.4 Random Effects Determinants of Per capita Household Income in All Municpalities, 2001-2007 . . . . . . . . . . . . . 155

6.5 F-test Results on Unrestricted Regression of Mobile and Fixed phones on Per-Capita Houehold Income . . . . . . . . 157

6.6 Data Summary . . . . . . . . . . . . . . . . 160

6.7 Correlation Matrix Table of main variables of the Model . . 162

6.8 List of Municipalities . . . . . . . . . . . . . . . . . . . . . . 164

6.9 List of Municipalities (Cont'd) . . . . . . . . . . . 165

7.1 Worldspace Corporation and Multichoice Compared . . . . 176 

1

\section{Introduction and Background}

\subsection{Introduction}

The idea of using communication satellites to foster African economic development is not new. As early as 1975, Philip Okundi proposed an African domestic satellite system (Okundi and Evans, 1975) and vigorously supported the establishment of a Pan-African Telecommunications network. The big idea was that having an own communications infrastructure would boost African development efforts and lead to higher growth rates and production levels. Ithiel de Sola Pool argued that international telecommunication was of great importance to the developing world and could

"bring deficient information facilities at a leap up to the best or its lack could lead to slipping further and further behind" (de Sola Pool, 1990).

Manfred Kochen proposed the large-scale use of computer conference facilities throughout the developing world to facilitate knowledge transfer and more efficient resource allocation (Kochen, 1982). These proposals and many others were based on the supposed benefits that a widespread telecommunications system brings to an economy in terms of expanded and improved contacts, trade opportunities, improved transport efficiency and regional development to mention but a few examples.

Support for these ideas in Africa gathered momentum in the eighties with the International Telecommunications Union completing a feasibility study in 1990 for a Regional African Satellite Communication project, RASCOM. This Pan-African satellite was supposed to usher in a universal telecommunication service for Africa that would cover both rural and urban areas alike. While the groundwork and finances for this overarching technology were in the pipeline, development and expansion of terrestrial telecommunication networks continued, driven by innovations in mobile and cellular network technologies in developed countries. Rapid integration of the electronic, computer and telecommunication industries took place in this period and it was not long before mobile and cellular network technologies appeared on the continent, providing a welcome alternative to fixed line technologies that were difficult to deploy and maintain economically over the African terrain. These technologies rapidly spread across the continent, because they were more suited to the rugged terrain and sparse population densities that have hindered the development of terrestrial infrastructure. The growth and uptake of mobile wireless communications in developing 
countries in the last decade has been phenomenal, with more than $50 \%$ of the population now covered by mobile services in most African countries for which data is available.

The boom in mobile telephony has taken most of the pressure off fixed line telecommunications companies to extend physical networks to rural areas and other hard to reach areas. It makes it worthwhile to study the social and economic effects and impacts of the boom in connectivity on the serviced population. Has mobile connectivity led to the creation of more wealth and a reduction in poverty or has the mobile connectivity boom been a result of wealth that has been created in other sectors of these economies? Simply put, do telecommunications bring prosperity and lead to economic growth, or is it economic growth that demands and necessitates growth in the telecommunications sector?

Alongside the boom in mobile phone usage on the continent has come the widespread use of computers and other related communications technologies in almost every sphere of economic and social endeavor, leading to the birth of a whole new paradigm commonly referred to as Information and Communication Technologies (ICTs). In the last decade these ICTs have come under the spotlight of many an economic study. The question of import again is the impact that these technologies are having on economic growth and development, especially in poor countries that have to grope with other more basic economic development hurdles. The general consensus is that ICTs can contribute considerably to development in poor developing countries although the nature of this contribution is still the subject of much debate and speculation.

What is the use and importance of a computer to a hungry and illiterate household in a remote African village with no access to electricity, telephone or mobile infrastructure, it is often asked. As useless as a computer may be to a hungry household without access to basic infrastructure, it is important to consider the benefits of the whole telecommunications access infrastructure, beyond mere computers, to the aggregate welfare of a whole region rather than the benefit to a single household. The cumulative and aggregate impact of access to connectivity devices in virtually connected regions on the inhabitants of these connected regions is what we seek to maximize. By spreading connectedness beyond the reach of only those who can afford to those who can not afford but are able to use and benefit from connectivity services, we increase the social welfare benefit for the whole economy.

Most developing countries are characterized by major differences between urban and rural areas. The urban areas are relatively economically vibrant areas with access to basic infrastructure like telephones, electricity, health facilities and so forth. The question in these areas is not the availability of basic infrastructure but rather the quality of service provided and the number of people able to make meaningful economic use of the infrastructure depending on the affordability of services. The rural areas are afflicted with 
lack of the basic infrastructure needed to provide ICT based services. This is usually due to distance from centrally located infrastructure in urban areas, rugged natural terrain that makes it difficult for providers to economically set up the physical infrastructure and of course the economic viability of operations in terms of returns to investment; the rural populations can not economically support the investment in terrestrial infrastructures.

All these factors make the economic spread and use of ICTs in African developing countries difficult and questions of priorities in allocation of scarce resources come to the fore. Some schools of thought propose that ICTs do not contribute that much to economic development of economically backward countries, which could do much better allocating the available meagre resources to more pressing health and poverty problems than to the development of ICT infrastructure (Gillespie and Cornford, 2001; Heeks and Kenny, 2001; Pohjola, 2001; Mayer, 2000; Garcia-Mila and McGuire,1992; Holtz-Eakin, 1993). Others hold that the general purpose technology characteristics of ICTs put them in an important position historically to provide a window of opportunity for economically backward countries to catch up (Freeman, 1996; Carlota, 1985; Reati and Toporowski, 2004; Castellaci, 2006).

This work takes its cue from the latter stance and argues that ICTs have the potential to profoundly influence the rate of improvement of the economic and social well being of economically lagging countries. It also draws from the old argument in the catch up literature of the 'advantages of backwardness' according to which developing countries may explore their backward position by imitating and implementing advanced foreign technologies created by the leader economies and by rapidly investing in the new technologies. Since in the new era catching up countries are less committed to the mass production technological paradigm prevailing in previous decades(investment in machinery and other physical infrastructure), they may find it easier to make the jump into the new technological system based on ICTs (Castellaci, 2006) ${ }^{1}$. Carlota Perez emphasizes the possibilities opened up for developing countries in the era of ICTs. For them she states,

'it is possible to attempt a direct entry without going through the technological stages it leaves behind.....'2

It is in this light that we examine whether satellite technology with its far reaching capabilities can be a vehicle for the acceleration of diffusion of ICTs and faster economic development in lagging African economies, when employed as an overarching technology for the creation of a publicly owned cyberspace network.

\footnotetext{
${ }^{1}$ Earlier work in this field by Alexander Gershenkron

${ }^{2} \mathrm{C}$ Perez, Microelectronics, long waves and world structural change: new perspectives for developing countries, World Development 13 (1985) pp29
} 
Over the last two decades, ICTs in developed countries have led to more efficient production processes and new and improved products and services by creating new product functions, incorporating skills and functions into equipment, automating routine work and making technical, professional or financial services more transferable. The transformational impact has therefore been seen in almost all sectors of the economy in keeping with General Purpose Technology (GPT) economic theory (Kline and Rosenberg, 2005; Richard, Lipsey and Bekar, 2005). In developing countries this transformation has not yet taken place but these technologies have arrived and are impacting development in slightly different ways and at a different pace than has been the case in more developed countries. We seek to contribute to the understanding of these processes in sub-Saharan Africa.

Theoretically satellites provide the window of opportunity for an instantaneous and widespread delivery of these ICTs. Satellites are, however, very expensive technologies and are beyond the financial, technological and human resource capacities of most governments and firms in sub-Saharan African countries. This prohibitive cost has made it difficult for governments and businesses alike to take advantage of the many possibilities that these technologies could offer ${ }^{3}$. We argue in this thesis that publicly owned satellites, shared by regional groups of African countries, providing cheap access at market rates lower than those offered by privately owned satellite operators would contribute in important ways to solving this problem, assuming that other bottlenecks such as human capital, e-readiness and complementary investments in information technologies are also dealt with. The rates can be kept low because the prices charged would reflect the social welfare benefit rather than the private benefit of access to telecommunications. This implies financing through government subsidies for satellite access. The low prices would result in better use of the satellite capacity and provide a challenge to existing oligopolistic practices in satellite capacity pricing.

Innovations in cheaper more accessible technologies for developing countries have been ongoing in many parts of the world. Viable over-the-air substitutes for satellites in poor countries have actually been developed and employed successfully. These include mobile cellular technologies and Wimax specifications. The wide implementation of these technologies for international connectivity and the spread of services to remote areas, however, still requires connection to the international gateway network which can only be achieved by satellite or optical fiber networks. These options will be discussed in Chapter Four.

The missing link in the literature has been the assessment of evidence from African economies of the direct and indirect benefits of satellite com-

\footnotetext{
${ }^{3}$ Satcom 2006 proceedings, Johannesburg, South Africa concluded that African countries were not taking advantage of the power and possibilities that satellites provide.
} 
munications to development in the region. We make the case for publicly owned satellite infrastructure through which private firms provide a variety of services and show how current practices have negatively affected both the variety and affordability of connectivity in Africa. We then show how a publicly owned satellite infrastructure can help reduce cost of services and promote inter-country trade in Africa thereby spurring growth. This is the subject of this thesis.

\subsection{Origins of The Idea}

This work is inspired by a long history of events that started when I worked as an IT Specialist for the Ministry of Health in Zambia. Our working group was given the task of implementing a country-wide Health Management Information System (HMIS) that could store and update all necessary primary and secondary health care data, needed for health center, district, provincial and national health research, planning and management purposes. The target system was supposed to update the central database as the data was being generated at the lowest level of the chain, the health center. This was quite a daunting task at the time (and still is) and a lot of time and money was spent equipping every health center in the 72 districts of the country with a computer as well as training health workers on how to record the data in the forms and consequently into the computer database. They then zipped up the file and sent it by health courier or post to the district office, which then aggregated for the district and sent a diskette to the provincial office. When the provincial office was satisfied with its reporting rates, they aggregated for the province and passed a zipped file on to the national office. After only one year of this store and forward method, the database at district level was already too big to be zipped onto a diskette and the provincial data was even worse. New measures had to be found to eliminate this daunting and irritating bottleneck of the 1.44MB diskette.

The next best approach at the time was to enable the health centers, districts and provincial offices to e-mail the zipped file after updating, using a dial up link through the one and only Internet Service Provider (ISP) then operating in the country then. This approach brought its own set of bandwidth and connectivity problems that proved insurmountable at the time. The ISP simply could not provide the bandwidth we were asking for. To make matters worse some of the health centers we were working with had no telephone networks and relied on two way radios for their urgent communication needs. The quick fixes were not working; the HMIS needed a long-term stable network solution in order to deliver and the answer lay in a wide area network covering the whole country with enough bandwidth for live updates directly from the health centre to the district all the way up to the national office. 
In October of 1999, the United Nations Economic Commission for Africa organized the first African Development Forum on the theme "Information Technology for Development" in Addis Abeba, Ethiopia. It was at this conference that the now world famous Ethiopian-born businessman Noah Samara gave a speech to launch his Worldspace satellite radio service business in Africa. Apart from the eloquence and intriguing statements of the man himself ${ }^{4}$, the demonstration of the technology was astounding and convincing. I immediately saw the solution to the problems we were struggling with at the Ministry of Health in Zambia. If this satellite technology could do what was being showcased at the conference i.e. continent wide CD quality radio and data broadcast, then all we had to do was get onto the satellite service and carry on with our business, eliminating the fixed-line telephone monopoly (ZAMTEL) and the ISP monopoly of the time (ZAMNET) in one single shot! This sounded incredible and almost too good to be true (as it eventually turned out to be) except for the fact that the demonstrations actually worked and were very convincing. I extrapolated beyond the radio service and saw unlimited possibilities that this satellite technology could bring not only to Zambia but to the rest of Africa as well.

Coming back from the conference I had the solution to our problems all worked out and was excited about drawing up an implementation plan. I was disappointed. The figures I uncovered in terms of cost and the general modus operandi of existing satellite services in Zambia and Africa as a whole led me to conclude that this technology was from outer space, as indeed it was, and not meant for the terrestrial mortal inhabitants of the African continent. The service was not free and as it turned out, neither was it accessible in terms of cost. So the satellite technology I thought would solve all our problems was practically too expensive a technology to implement for one project, even at national level.

Dismayed and disillusioned I left the Ministry of Health for an academic career in a University, which gave me more time to follow and think about developments in the satellite industry from an academic point of view.

What has become very clear over the last couple of years is the fact that satellite technologies can, and do actually provide very efficient, neat solutions for African connectivity and bandwidth problems. This is evidenced by the wide use of VSAT technology to connect multi-national bank branches across the African landscape and beyond as well as the provision of satellite television services across the continent ${ }^{5}$. What remains of great concern though is the cost of these services to the consumer, which is why they have so far been restricted to the banking industry and the more affluent elite of the African population. A way has to be found to cater for large

\footnotetext{
${ }^{4}$ Speech by Noah Samara http://www.uneca.org/eca_resources/Speeches

${ }^{5}$ Roger Chiume, Telkom SA -Vsat Services within the Africa Continent (2003), SPACESTREAM and INFOSPACE satellite based solutions.
} 
scale implementation of satellite based ICT strategic services at a fraction of the current cost, taking advantage of economies of scale made possible by the greatest advantage of satellite technologies over its terrestrial counterpart technologies i.e. its point to multi-point broadcast capabilities over very large coverage areas.

While a lot has been written about the benefits of ICTs to developing countries' economic growth potential (see section 6.1), no literature is available on the specific link between satellite technology and economic growth. This link is important to demonstrate given the heavy reliance of telecommunications services on satellites in Africa and the inherent capability of satellites to deliver services over very large geographic areas, easily linking terrestrial networks and spreading essential services to areas that would otherwise be excluded because of a lack of basic telecommunications infrastructure.

\subsection{Outline of the Thesis}

It is the objective of this study therefore, first to state the importance of the strategic application of ICTs to African economies, then to build a satellite based endogenous growth model that demonstrates theoretically the growth potential that mass connectivity, easily achieved with satellite technologies, holds for infrastructure-poor economic regions of the world. We then endeavour to empirically show the effect of communication costs on growth in Africa underlining the fact that communication costs are adversely affected by connectivity over international gateways dominated by satellites in Africa. The rest of the thesis is outlined as follows:

Chapter Two introduces the technology of satellites and takes a general outlook of the basic components of a satellite system. The chapter provides an overview of the sate of satellite technology in Africa

In Chapter Three we build a satellite based endogenous growth model on the premises that

1. regional connectivity matters for growth and that

2. satellite technology easily achieves widespread instantaneous connectivity between regions over very large geographical areas.

We review the literature on connectivity and growth and then build an endogenous growth model based on the provision of connectivity infrastructure. Communities become connected through communications and transportation infrastructure and get the possibility to trade in specialized goods and services. This trade leads to overall growth in the economy. In the model, provision of communication infrastructure is a necessary condition for growth to occur. This growth stems mainly from the assumption of 
boundless imitation capabilities in the connected regions and an increase in the number of varieties that members of a connected community can consume.

Chapter Four discusses the pros and cons of competing technologies on the continent and shows the practical advantages of connectivity by satellite that are assumed in Chapter Three. An evolutionary approach is taken starting with a brief history of international communications in Africa. Different ICT services are discussed, in each case emphasizing how these are affected by satellite connectivity in Africa. In addition a detailed comparison between satellite and fibre optic technology is carried out laying out the pros and cons of each and why one or other of the two technologies may not be the solution to connectivity problems facing sub Saharan Africa.

Chapter Five follows through with an empirical investigation of economic growth through trade in sub-Saharan Africa using a gravity model approach. Data on exports, telephone charges, monthly subscriptions for internet and number of outgoing calls from a country in 2007 are analyzed in the gravity setup. The results suggest that communication costs are important to trade and that these costs are negatively affected by satellite connectivity in Africa. This chapter demonstrates the negative effects that high satellite capacity charges have on communication costs in Africa and the negative knock on effect that this has on trade and growth.

Chapter Six investigates the relationship of telecommunications access in general to household income in municipalities in South Africa. Here we question the importance of access to ICT related variables i.e. radios, computers, television sets and telephones (both fixed and mobile) to per capita household income in municipalities in South Africa.

Chapter Seven shows how particular efforts to provide services in Africa using satellite connectivity have fared. We discuss the case of Worldspace Incorporated, a satellite digital radio service company and also have a look at various tele-medicine projects on the continent.

Chapter Eight wraps up with the conclusions and recommendations.

\subsection{Importance of this work}

It must be emphasized that satellites are not new to Africa and the African airspace. Satellites have been and are still being used to connect international gateway carriers for international voice calls, and lately cellular backhaul and internet connectivity. Satellite TV has been around for a while on the continent and all live transmissions of important world events and games would be impossible without it.

"Nearly all of Africa's international bandwidth is provided by satellite....As a result, African countries have a very high dependence on satellite, with the majority of countries' more than 
$95 \%$ of international traffic carried by satellite" 6

The problem is that the technology has mainly been used to support the local telecommunications companies' (Telcos) international signal delivery rather than to provide direct services to the population. In order to have this access the local Telcos have to foot huge international access bills to the private international owners of the satellite systems to route signals from Africa through Europe and America and back to Africa. The cost of this connectivity is inevitably passed on to the African consumers who end up with very high local and international telephone rates. African Telcos are simply not able to charge competitive prices for their international services partly because of the high cost in international satellite carrier subscriptions (there are also other factors associated with high cost of maintenance of outdated terrestrial network infrastructure coupled with frequent vandalism and security issues).

The importance of this research lies in the realization that in order for ICTs to make meaningful contribution to economic growth in Africa, there is a need to contain and reinvest resources in the sector on the continent. African Telcos and service providers need to curb the drain of meager resources to foreign satellite and fibre optic providers, so that they can compete favorably with international telephony pricing and extend their services to hard-to-reach rural areas as well, where services like tele-medicne have failed to take root and contribute positively because of high connectivity charges.

\subsection{The Research Question}

Questions examined in the thesis include the following:

Can the strategic and accelerated diffusion of ICTs in Africa lead to accelerated growth in key economic sectors leading to general economic growth and development in the region?

What is the role and effect of satellite technology, as the backbone of international communications in sub-Saharan Africa, on economic growth on the continent?

Do high communication costs actually affect trade outcomes in subSaharan Africa?

The employment of satellite technology as an overarching infrastructure backbone for strategic ICT applications in Africa has the potential to accelerate the diffusion of ICTs and contribute immensely to the economic growth and development of African economies. But satellites are expensive technology and African countries are currently dependent on international

${ }^{6}$ Sean Moroney \& Paul Hamilton, AITEC Africa 
satellite systems that charge very high premiums for their services leading to unaffordable ICT services on the continent.

The following propositions have guided our analyses:

\subsubsection{Proposition 1}

Connectivity over a shared satellite infrastructure can positively benefit the growth rate of connected regions. Satellites can be a useful infrastructure enhancement technology in infrastructure-poor regions of sub-Saharan Africa if they are implemented on a shared local basis to support the meagre terrestrial physical and wireless infrastructure in the region. The modeling exercise in Chapter Three examines this proposition of the potential positive contribution of satellite connectivity to growth in general.

\subsubsection{Proposition 2:}

The high cost of international calls in SSA is primarily caused by connectivity over satellite dominated international gateways and monopoly operated optical fiber international gateways that are owned by international business houses. This proposition is discussed in Chapter Four as a precursor to the empirical analysis in Chapter Five.

\subsubsection{Proposition 3:}

The high cost of international connectivity is a barrier to trade in subSaharan Africa. We assume that trade is positively related to growth therefore high costs of connectivity are indirectly an obstacle to growth. Our empirical research focuses on the relationship between connectivity costs and international trade in the region. For the relationship between trade and growth we rely on findings in the secondary literature.

\subsubsection{Proposition 4:}

Access to telecommunications has a positive impact on per capita household income in municipalities in South Africa. This proposition is examined in Chapter Six using census data from municipalities in South Africa for the years 1996, 2001 and 2007.

Scholars in developed countries have realized the opportunities available to economically lagging countries from the mass application and use of ICTs and have asked similar questions and suggested ways in which these countries can take advantage of this new growth paradigm. They propose that in order to take advantage of the ICT technological paradigm, African countries should make systematic policy efforts in acquiring, deploying and maintaining ICT backbone technologies in the region to support all sectors 
of private and public enterprise, as the benefits of the current wave of technology will not come automatically (Freeman, 2001; Carlota, 1985; Reati and Toporowski, 2004; Castellaci, 2006). As Burstein put it:As Burstein put it:

"Amid all the Info Highway enthusiasm, it is often optimistically asserted that digital technology will somehow bring wondrous benefits to the less developed world...the likely reality is probably the opposite. Without global policy intervention, the rich countries of the world, along with the high growth emerging markets, will use digital technology to get richer. The poorest countries of the world, meanwhile, will fall further behindalthough it may now be easier for their minuscule elites and middle classes to make cellular phone calls or check their portfolios in London and New York." (Burstein and Kline, 1985).

Given the expensive and highly technical nature of the technology, African policy makers should probably employ more innovative ways of acquisition, deployment and maintenance of the infrastructure. How can this be done? We propose that this can be achieved by building a public satellite infrastructure owned by regional groups of African governments. The consortium leases capacity off this satellite infrastructure at lower prices than private operators'. The prices charged reflect the social benefit rather than the private benefits of access and so the governments subsidize the cost of satellite access through tax receipts, while private firms operate normally as profit maximizing agents and are able to compete and make profits because they are not concerned about recovering the cost of building and maintaining the satellites in space. The case studies in Chapter 7 demonstrate this scenario with the case of Worldspace Incorporated and Multichoice Satellite TV. This lends to the argument that the economic benefits of ICTs will not come automatically but will only be realized as a result of deliberate sound policy planning and intervention strategies by African governments.

\subsection{Aims of the thesis}

We will endeavor to demonstrate that sub Saharan African countries can enhance trade flows and growth by reducing the cost of international and local communications. We propose that this may be achieved by the strategic, integrated use of satellite and terrestrial network technologies to bring down cost of network services and enhance both the infrastructure and the human capital component of the economic growth equation. It is further proposed that a public good model of cyberspace is the best way to achieve this strategic integration of network infrastructure, where the overarching 
infrastructure is satellite integrated with terrestrial high speed fibre and terrestrial wireless technologies. 


\section{Satellite Fundamentals}

\subsection{Introduction}

In this chapter we look at the nature of satellite technology and its relationship to terrestrial network topologies. A technical overview of satellite technology is given followed by a discussion of satellite projects in Africa. The overall objective of the chapter is to provide some technical insight into the nature and operation of communication satellite systems and bring to the fore the technical advantages of satellite communications and how they fit into the ever growing communications industry on the continent.

\subsection{The Nature of Satellites}

The basic idea of a satellite is that of a spacecraft loaded with communications devices going round the earth in much the same way that the moon does. A communication satellite is a specially designed spacecraft that receives and transmits microwave signals to and from points on the earth surface that may be some very large distances apart (this is the reason it is often referred to as a radio in the sky). Because satellites are hoisted into space above the earth, they are able to see large chunks of the earth surface at any given time and it is this property that gives them the special broadcast features that communications experts and engineers are interested in.

In his seminal 1945 paper in Wireless World magazine, Arthur C. Clarke (1917-2008) defined the idea of a special orbit in space, where a satellite could be able to maintain a constant relative position with respect to the earth surface, figure 2.1 (Clarke, 1945). This marked the beginning of a communications satellite revolution that has seen the number of satellites in this special orbit, now officially known as the Clarke Belt, rise from one in the early 1960's to more than 250 communications satellites as of May 2008.

The Clarke Belt is 35800 kilometers above the earth surface in the equatorial plane and a satellite in this orbit will complete one revolution around the earth in 24 hours and therefore appear to be in the same position relative to any point on the earth surface, geostationary. The strategic importance of this orbital slot makes it extremely attractive to satellite developers and the race to acquire slots in this orbital plane has had to be regulated 
FIGURE 2.1: Geostationary Earth Orbit

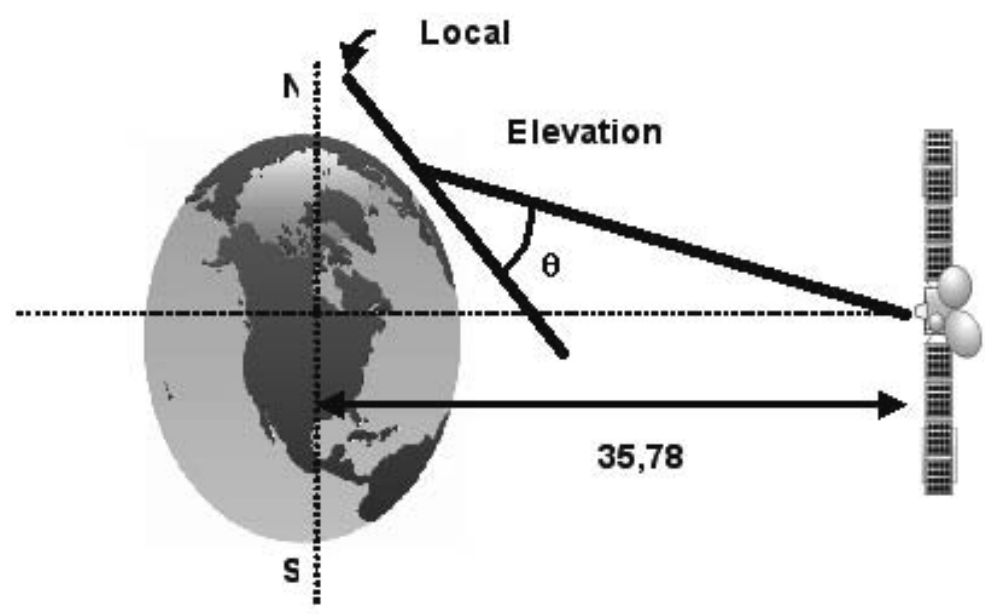

Source: Comsys itduk

by the ITU in order to bring some fairness and order to satellite launches in this all important orbital plane.

Not all satellites are launched in the Clarke belt (geostationary orbit) as the space is finite and in very high demand. Also the complexities of launching a satellite into the Clarke belt can be quite challenging and certain technicalities can be avoided by launching satellites into lower orbits called Low and Medium Earth Orbits (LEO and MEO), also commonly referred to as Non-Geostationary Orbits (NGSO). Though this may seem a plausible alternative these NGSO satellites present a different set of challenges which taken on the balance leaves GEO satellites as the most attractive alternative for Africa. LEOs are built in constellations that orbit the earth at the same time. The tracking, telemetry and control (TTC) of these satellite constellations becomes a lot more complex and expensive to maintain than tracking one satellite in GEO. The ground control stations are therefore a lot more demanding than GEO stations. There are also problems of space debris in lower orbits that can cause serious disruptions to the satellite fleet as well as the services provided.

Satellites may also be placed in what are called polar orbits, which are orbital slots above the poles. A Satellite in a polar orbit is able to see a large part of the earth surface as well 


\subsection{Components of a modern Communications Satellite}

A satellite system consists of two complementary parts, the space segment and the ground segment. The space segment is the part of the system that is lifted into space and carries all the communications devices needed to receive radio signals and retransmit them back to the earth surface. The ground segment consists of all the parts of the system that are required to control and maintain the satellite position in space as well as the receiving user devices of the consumers. The ground segment of the satellite system also includes ground station hubs, where signals are generated and transmitted to the satellite in space. This is called the uplink connection.

We will now describe the space segment in a bit of detail and outline the components and their technical characteristics.

\subsubsection{The Space Segment}

There are two main types of space craft, the three axis stabilized bus and the spin stabilized model. Figure 2.2 shows an outline example of the three axis stabilized model and the spin stabilized model is shown in figure 2.3. Both models are built out of lightweight aluminium to reduce both weight and cost of the bus structure. The structure is engineered to survive the rigors of the launch process including excessive vibration, stress, temperature variations and the shocks at separation from the launch vehicle.

The satellite carries on board communication devices also collectively referred to as the payload. This consists of repeaters/transponders and multiplexers that receive signals on the uplink from the ground stations called teleports and retransmit them back on the downlink to receiving devices on the earth surface. These may be user devices like TVs, radios, cell phones or another teleport that acts as a hub where the signals are rerouted to other receiving devices on the ground.

One of the most critical parts of the bus is the array of antennas and antenna reflectors that maintain the collection and redistribution of the microwave signals. The antenna reflectors are like huge mirrors that actually capture signals and reflect them back to earth. The reflectors generate what is called the foot print on the earth surface where signals can be uploaded or received. These footprints are characteristic of all communication satellites and form the actual area of influence of the satellite. The shape and size of the footprint determines the expanse of the satellite as well as the strength of the signals. 
FIGURE 2.2: The Three Axis Stabilized Spacecraft

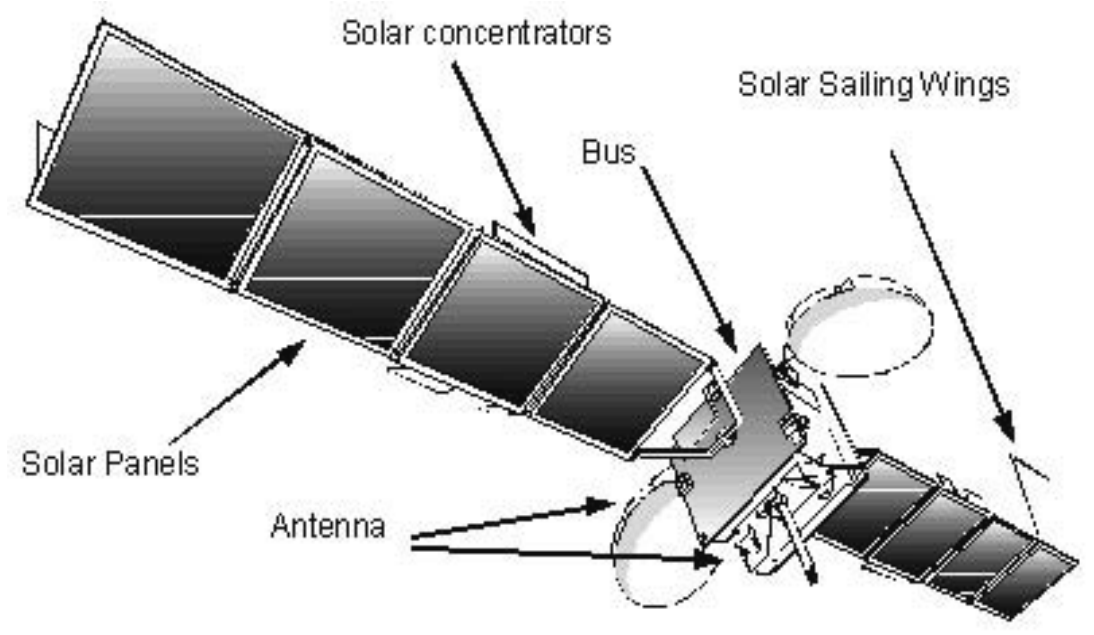

Soune: Comsys Ltouk

\subsubsection{Power Generation}

Most of the electrical power used for the motion and electrical needs of the spacecraft is generated by the solar panels. Flying with its solar wings aligned in the north-south direction, the three axis stabilized model rotates once in 24 hours in order to remain pointed at the sun. The rechargeable on-board batteries power the spacecraft when it is eclipsed from the sun by the earth once a day. Half of the power generated by the solar panels is transmitted back to earth as downlink RF powered radio signals. Modern satellites are able to generate about $20 \mathrm{kw}$ of power.

The common misunderstanding about satellite life-span is that the satellite ceases to produce power when it runs out of fuel. The on-board fuel carried by the satellite is used by the thrusters to maintain orbital position (station-keeping) and not to produce electrical power. This is the fuel that determines the life-span of the satellite and it typically can last for up to 15 years. The satellite will still be able to produce electrical power from its solar panels but will not be able to efficiently keep its position in orbit after its on-board fuel runs out. It is at this stage that it is fired out of orbit and destroyed.

The spacecraft could theoretically be re-fuelled but the benefits of refuelling in space could be thwarted by failing on-board electronic devices which would need replacement or service after fifteen years or more. 


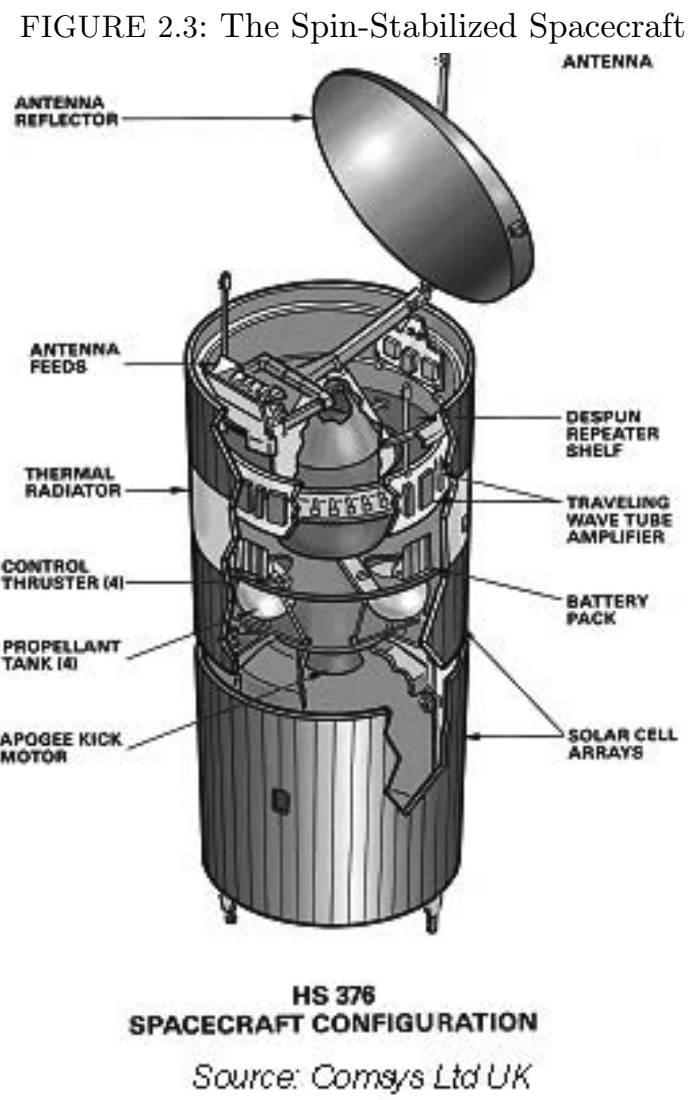


FIGURE 2.4: Launch Sequence of Communication Staellite

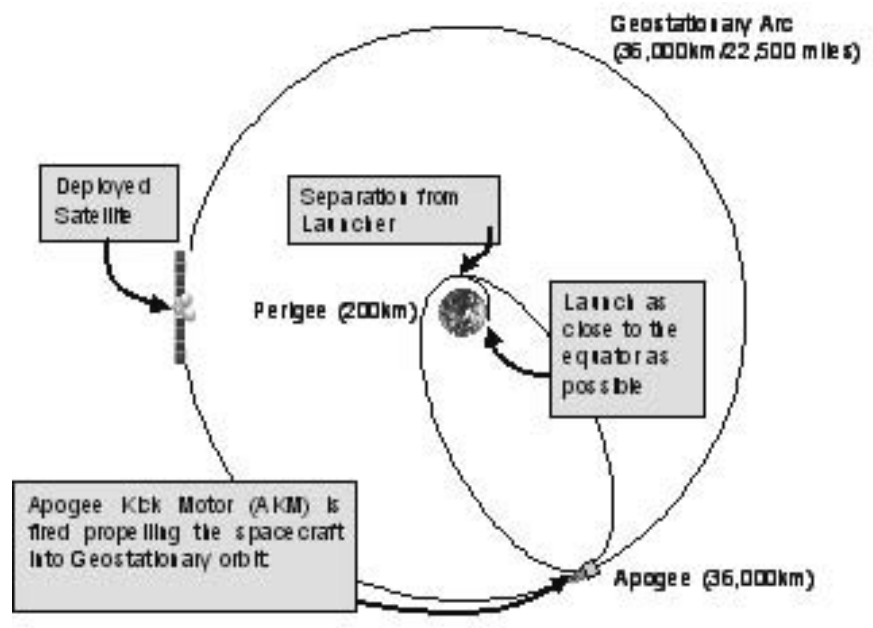

Source: Comsys itouk

\subsubsection{The Launch}

After the space craft is built it has to be launched into space. This is done by either the spacecraft manufacturer or a specialist launch agency like Sea Launch operated by Boeing in Long Beach California. There are a number of launch facilities around the world and all are built as close to the equator as possible to get some additional thrust from the earth's rotation. The launch rocket is usually fired due east with open space down range to minimize hazards in case of launch failure. The whole satellite is encased in what is called the payload fairing and loaded onto a rocket which fires it into space. The rocket delivers the load into the elliptical geostationary transfer orbit and separates itself form the satellite load. The Apogee kick motor is then fired to circularize the originally elliptical orbit following the launch, figure 2.4. From this point on the satellite is kept in its orbit by both gravitational forces and the telemetry, tracking and control center (TTC) on earth.

Once the satellite has reached its intended position in space it needs to maintain this in two planes:

1. the East/West station keeping, which is required to ensure that it does not interfere with other satellites in the GSO arc. The registered orbital slot must be maintained within $\pm 0.1^{\circ}$.

2. the North/South station keeping is less critical from a regulatory point of view, but North/South (up and down) excursions result in inclined 
orbit operation, details of which we will not discuss here, but suffice it to say that this is a situation that would rather be avoided.

\subsubsection{The Ground Segment}

The function of the ground segment is to access the repeaters on the satellite in space in the most efficient manner possible. The ground segment of the satellite system consists of what are called earth stations. The major categories of earth stations are National Gateways, Tracking Telemetry and Control Centres (TT and C), Very Small Aperture Terminals (VSATs), TV uplink hub and Direct to Home (DTH) antennas. The ground segment therefore is not a single entity. It is rather a diverse collection of facilities, users, applications and a wide variety of technical ground equipment. It is constantly changing and evolving, providing service when and where needed.

\subsubsection{National Gateway}

A national gateway is a major earth station interconnected to national telecommunications infrastructure on the ground. It is used for major telecommunication routing and international telephone routing as well as TV uplink and broadcasting. National gateways have traditionally been operated by Public Telegraph and telephone companies(PTTs) and are normally dedicated to a single satellite. The Mwembeshi satellite earth station in Zambia is an example of a national gateway that has provided major national communications functions to the government of the Republic of Zambia. It is connected to an Intelsat satellite and since 1972 has been the one and only legal gateway to route international traffic in and out of Zambia. Most of the countries on the continent have operated national gateways as monopolies run by the incumbent telecommunications parastatal (the PTT). But a recent drive in the privatization of these incumbent parastatal companies has also seen a relaxation of international gateway licensing regulations in Africa, giving choice and theoretically providing potential for lower prices of international services.

\subsubsection{Tracking Telemetry and Control Earth Station}

This is the ground resident part of the satellite system that actually controls and drives the spacecraft from the ground. Tracking and Telemetry (TT) earth stations use large powerful dish antennas to provide signal integrity and counter measures to fading and jamming signal effects. A TT earth station has to be manned 24 hours a day and 365 days a year as it is the lifeline of the services provided off the satellite. Any problems with the satellite are detected and corrected at the TT earth station and loss of 
the link between the TT earth station and the spacecraft in space usually means the end of all services provided off the spacecraft.

\subsubsection{Frequency Bands}

Satellite communications employ electromagnetic waves to carry information between the ground and space. Electromagnetic waves have frequencies measured in Hertz $(\mathrm{Hz})$. A particular range of frequencies is called a band, while the full range of frequencies from zero to infinity is called the frequency spectrum. The radio frequency $(\mathrm{RF})$ part of the electromagnetic wave spectrum allows the efficient generation of signal power, its radiation into free space and its reception at a distant point. The frequency bands of interest to satellite communications lie above $100 \mathrm{MHz}$, where the Very High Frequency(VHF), Ultra High Frequency (UHF) and the Supra High Frequency (SHF) reside. The SHF band has been broken down further into band slices designated by the letters L, S, C, X and K. This designation has a military background stemming from the use of radar systems in the army. These are the most popular frequencies for satellite communications. They range from $1 \mathrm{GHz}$ to $30 \mathrm{GHz}$.

The International Telecommunications Union (ITU) allocates and regulates the use of frequencies for various purposes to various groups of users around the world. The ITU consequently turned down a request by Wimax operators for $\mathrm{C}$ band to be opened up to Wimax operators as well (see section 2.4). The popularity of $\mathrm{C}$ band for satellite operations lies in its resilience to atmospheric attenuation (also called rain fade) especially in the congested rain forests parts of the earth. The higher frequencies in $\mathrm{K}$ and $\mathrm{X}$ band do not have this resilience but technology advances have made the $\mathrm{K}$ band usable by satellite applications with smaller dish antennas e.g. Direct to Home (DTH) TV reception is predominantly broadcast in K band (see table 2.1).

TABLE 2.1: Radio Frequency Bands Commonly used For Satellite Applications

\begin{tabular}{|l|l|l|}
\hline Band & Frequency & \multicolumn{1}{c|}{ Application } \\
\hline $\mathrm{L} / \mathrm{S}$ & $1-4 \mathrm{GHz}$ & Maritime satellite services, mobile satellite services \\
\hline $\mathrm{C}$ & $4-8 \mathrm{GHz}$ & Fixed Satellite Services (FSS), \\
\hline $\mathrm{X}$ & $8-12 \mathrm{GHz}$ & Military and experimental purposes \\
\hline $\mathrm{Ku}$ & $12-18 \mathrm{GHz}$ & DTH services \\
\hline $\mathrm{Ka}$ & $27-40 \mathrm{GHz}$ & Modern handheld devices \\
\hline
\end{tabular}




\subsubsection{Transponder Capacity}

A transponder is basically a transmitter/ responder ( or transmitter/receiver) thus the name transponder. It receives a signal on one frequency on the uplink and retransmits it on a different frequency (on the downlink) such that receiving and transmitting can actually happen simultaneously. A transponder is therefore not a single component in a satellite payload but rather a system of components that actually carry out reception and transmission of signals to and from earth stations. In satellite communications the number of transponders carried by a satellite is a very important measure of its capacity to deliver services. This is the unit that satellite operators use to sell or rent satellite capacity to users. Intelsat began to rent transponders to member countries in the early 1970s. These transponder systems are able to carry separate channels in different frequency bands (called hybrids) for different purposes e.g. TV, internet, radio etc. The current situation over the African airspace is that there is not enough transponder capacity to service the demand and hence we have seen efforts to increase this capacity through the launch of new satellites by both African and European operators (see Section 2.4)

\subsection{The African Scenario}

It is a known fact that Africa has been dependent on satellite services for a long time now and the cost of satellite transponder capacity has been the subject of many discussions. Transponder capacity is expensive but African countries have had no alternatives to using satellite until recent times with the advent of GSM and terrestrial wireless technologies like Wimax. The amount of fibre backbone cable has also grown steadily and continues to grow with new fibre projects recently completed or nearing completion (see section 4.2.3). These technologies however seek to share the same frequency bands allocated to satellite operators and the satellite operators are not willing to let go because Wimax in $\mathrm{C}$ band, for example, does cause interference with satellite $\mathrm{C}$ band operations. In an environment, where satellites are increasingly being viewed as expensive old technology, Wimax operators are seen as a welcome alternative and many African countries have given a go ahead to Wimax operators. At a recent World Radio Council (WRC) meeting, where the ITU distributes frequency allocations, the Wimax operators formally put in an application for access to the $\mathrm{C}$ band allocation, which was heavily opposed by the satellite operators. The ITU resolved to keep $\mathrm{C}$ band solely for satellite operations but this war is not over and the Wimax fraternity is not giving up. 
The significant growth in broadband bandwidth demand driven by internet growth, mobile cellular backhaul service demands and Direct to Home (DTH) pay TV has led to a serious shortage of bandwidth on the continent. Even though there about 100 transponders waiting to be added to the current capacity in Africa, the gap between supply and demand still exists and Africa continues to route most of its traffic through European and American satellites. Part of the problem is that the ITU has allocated orbital slots to companies that promise to launch satellites but never do. An allocation of an orbital slot in space lasts up to twenty years. Other satellite operators can not use that orbital slot until the allocation either expires or it is revoked and allocated to someone else by the ITU. This has led to an artificial shortage of orbital slots by companies operating what are now commonly referred to as 'paper satellites' and the ITU is currently reviewing this regulation to optimize the use of the limited orbital slots in space.

Nigeria and Algeria have contributed two satellites to the Disaster Management Consortium and Nigeria in 2007 launched Africa's first communications satellite Nigcomsat1 in partnership with a Chinese company. This being a progressive move for the African satellite industry it was announced in May 2008 that all the capacity on the Nigcomsat1 was already sold out. The euphoria was short-lived, however, as less than a year after launch, Nigcomsat has already lost track of the satellite and is in the process of recovering replacement costs from insurers. It will take another two to three years before the satellite is actually replaced. Some of Nigcomsat's customers were transferred to the ASTRA 2B Spotbeam operated by SES New Skies, which is not an African enterprise. SES New Skies itself lost a satellite built specifically to service the African continent on 30th January 2007.

\subsubsection{RASCOM}

The African Development Bank in cooperation with The New Economic Plan for African Development (NEPAD), launched an initiative in 1993 to build a satellite to service the African airspace through a private cooperation set up for this purpose called Regional African Satellite Communications company (RASCOM-QF). According to the RASCOM website ${ }^{1}$, this satellite was built by Alcatel Space of France and should have been ready for launch in June 2006. For some reason the RASCOM project failed to take off and has been in the final stages of implementation for close to five years.

The mission of RASCOM is:

"to provide to all the regions of African countries, efficient and

\footnotetext{
${ }^{1}$ http://www.rascom.org/
} 
inexpensive telecommunications facilities and meet their radio and television broadcast requirements, by having recourse to every appropriate technology, including a regional satellite communication system well integrated into existing and/or planned national networks with a view to facilitating the development of the countries of Africa." (ibid)

Put differently, the RASCOM project should enable a paradigm shift by Telcos in Africa from paying for international satellite carrier services to owning their own satellite carrier that will enable them to compete favorably in the international telecommunications industry and provide important broadband services to the African populace at competitive prices. It is this paradigm shift that will spell the success or failure of African countries to take advantage of ICTs for development and join the rest of the world in reaping the benefits of the information economy.

After more than ten years in planning due to lack of funds and political problems in the RASCOM community of countries, the first Pan African satellite RASCOM QAF1 was launched on 27 December 2007. This was supposed to be good news but unfortunately the life-span of the satellite was drastically reduced the expected 15 years to only three years because of a partial launch failure. The launch vehicle delivered the satellite into geostationary transfer orbit but the apogee kick motor that was supposed to steer it into its intended orbital slot in GEO failed. The fuel that was supposed to be used for station keeping for the next fifteen or so years was now used to steer the satellite into GEO. This was a disaster for the RASCOM outfit and for Africa as a whole because it meant that the waiting had all been in vain and anxious customers had to find alternative space channel capacity from the same European and American satellites they were trying to avoid.

Once again the African service providers were let down by a failed satellite infrastructure project. The failure of the Pan African RASCOM project has led these African countries with resources to think about investing in their own national satellite projects. The South African government recently announced acquisition of $60 \%$ share of the satellite company SunSpace to boost its control of satellite space channel capacity while the Angolan government has already contracted the construction of the Angosat satellite system for its own national needs. Outside sub Saharan Africa Egypt and Algeria already have national and private satellite projects. The proliferation of these national satellite systems is not a positive development as it goes against the very idea of a satellite system that is able to span national borders. but the failure of the Pan African project RASCOM also gives reason for second thoughts about large scale Pan African satellite projects and in the mean time life goes above the skies, with European and American satellites providing expensive satellite capacity that makes international communication in Africa the most expensive the world over. 
This discussion is developed further in Chapter Four.

\subsection{Summary}

In this chapter we have provided a technical overview of satellite technology without necessarily going into intricate details of how the technology works. We have emphasized the desirable features of this technology that makes it the technology of choice for broadcast services like television, live event transmissions etc. We have also discussed how African countries have tried to build their own infrastructure without success, this failure leaving them dependent on European and American satellite channel capacity for their local needs.

We next look at a how such an infrastructure might be used to achieve mass connectivity for a growing number of economic regions. We endeavor to theoretically demonstrate how such an infrastructure may contribute to the welfare and economic wellbeing of agents in connected regions. 


\section{3}

\section{A Satellite-Based Endogenous Growth Model}

\subsection{Introduction $^{1}$}

In this chapter we use the properties of satellites to build an instrustructure based economic growth model that heavily depends on communication and transport infrastructure. We use the property of ubiquity of satellites and ease of expansion over large geographic areas to support our assumption of a common ubiquitous communications infrastructure through which a central planner, who we will call the Great Connector, (GC) may add communities to the network of already connected communities. These 'communities' may in actual fact be countries (as we see in chapter Five) or regions within countries (as we see in Chapter Six with municipalities in South Africa). We first discuss the concept of infrastructure in general before looking at how communications and transport infrastructure in particular may affect growth. We then go into the details of the model itself.

Infrastructure generally is an important driver of economic growth. Some of the most prominent scholars in the field like Aghion and Howittt, Barro Sala-i-Martin, Agenor and Moreno-Dodson have modeled different ways in which infrastructure affects growth outcomes (Aghion and Howitt, 1998; Barro, 1991; Agenor and Moreno-Dodson, 2006).

The term infrastructure is usually used to refer to public capital with public good properties such as transport, communications, electricity, water etc. Of late research in communications infrastructure has taken prominence over other forms of infrastructure that were previously the focus of much research such as transport (cf. Fink, Matoo and Neagu, 2002; Hummels, 2002). In this chapter we investigate how communications infrastructure can enhance connectivity and lead to growth by formalizing the benefits of connectedness to trade flows between geographically separated communities. Infrastructure may impact growth both directly and indirectly. Directly, as covered by a production function approach, where infrastructure enters the production function as a third input alongside capital and labor, or as a factor augmenting total factor productivity (see Romp and de Haan, 2005).

\footnotetext{
${ }^{1}$ This chapter is based on the ideas of the author as implemented by Dr Adriaan van Zon appearing in the UNU-MERIT working paper series as Working Paper \#2010-001 (see bibliography van Zon and Mupela, 2010).
} 
In such a production function setting, infrastructure may have pure public good attributes, i.e. it produces services in a non-rival and nonexcludable way ${ }^{2}$. However, a growing part of infrastructure investments has happened through the market and has taken on standard private good characteristics of excludability. Apart from infrastructure as a direct productive input into the aggregate production structure, infrastructure services have indirect productivity effects as well, as they may positively influence the productivity/quality of other inputs. In this way investment in infrastructure lowers the cost of related intermediate inputs (transport, communication etc.) (cf. Fernald, 1999). Furthermore, due to the existence of strong complementarities, infrastructure development is an enabler of private investment made possible by providing access to previously unconnected areas through infrastructure networks, telecoms, electricity, roads etc. In short, infrastructure developments may enable further private investments in other sectors.

Infrastructure may also have an impact on growth through many indirect effects that include maintenance and adjustment costs, labor productivity, human development impact and economies of scale and scope. For example, a failure to maintain public infrastructure reduces the life-span of the infrastructure itself and implies higher operating costs for private capital such as trucks and computers that use the infrastructure, see (Romp and De Haan, 2005) for a full discussion of direct and indirect effects of public infrastructure.

From an economic geography aspect the forces of agglomeration and dispersion in the face of changing infrastructure scenarios are extensively discussed in Harris (1995), Krugman (1997), Venables (2001) and Spinanger (2001) to mention a few. Harris emphasizes the importance of communication costs to international trade while Krugman and Venables posit that coordination of geographically dispersed production processes are improved by communication networks. Spinanger identifies quality communication infrastructure as a key factor on FDI export decisions. We model international trade and specialization over an integrated communications infrastructure that enables economic agents to share both knowledge and the physical products of their innovative activities in space.

Some of the literature reviewed is unanimous about the positive effects that telecommunication infrastructure has on growth and also about the strong reverse causality between them (Roeller and Waverman, 2001; Yilmaz and Dinc, 2001). An increase in telecommunications investments, showing itself as an increase in number of users per 100 population (teledensity), is supposed to have both direct and indirect effects on the long term growth outcomes of countries and regions. Economic growth itself

\footnotetext{
${ }^{2}$ Note, however, that Barro and Sala-i-Martin (1995) have pointed out the possibility of congestion and therefore the potential rivalry associated with the use of infrastructure
} 
leads to higher demand for telecommunications services leading to higher investments in the sector, since, as Harris (1995) puts it:

'[a] ...reduction in communication costs... [results].... in a dramatic shrinking of time and space barriers that inhibit economic exchange over vast distances".

Fukushima and Kikuchi (2008b), study the role of competing communication networks in international trade and conclude that although the growth of communication networks is indeed a good thing, there comes a point when additional members to the network affect wages negatively and further expansion is undesirable.

"a network will not have the incentive to expand indefinitely, despite network externalities, since an exceedingly large number of member countries may cause the relative wage to drop" (ibid. pp 9).

This adds to the widely accepted view in network externality literature led by (Katz and Shapiro 1985), (Liebowitz and Margolis 1994) that discuss both positive and negative effects of boundless growth of networks. Thus the role of telecommunication networks and their organization has become an important aspect of modern economic study.

Another mechanism through which communication and transportation infrastructure may have an impact on growth is through its ability to facilitate the division of productive tasks as a source of productivity growth at the macro-level. In the presence of fixed set-up costs, the degree of specialization possible within a community depends directly on the size of the community itself. In his monopolistic competition model featuring increasing returns to scale, (Krugman 1991) shows that the integration of hitherto separate countries through international trade allows both communities to benefit from specialization and thereby induce economies of scale. However, such beneficial specialization patterns implicitly assume the existence of extensive information exchange and the consequent exchange of goods and services. Both exchange processes require the creation/extension of the corresponding networks through which such exchanges are usually taking place. In the model we are to present, we focus on the way in which communication and transportation network growth enables growth and the other way around. We therefore adopt a distinctly dynamic perspective on the specialization process that requires a high degree of connectedness between trading partners that is often assumed to exist a priori but does not have to exist in actual fact. Take rural areas in African developing countries, for example. Communities in such areas are often relatively disconnected from other communities, since both means of transportation like cars, trains, and complementary infrastructure (roads, bridges, railroads) and means of telecommunication are often lacking. This implies that such communities 
are to a large extent forced to be self-reliant If such communities are relatively small, which they usually are, then it may be difficult for them to attain a higher level of welfare through specialization in production activities that is attainable for larger communities.

We formulate a model of growth through specialization that relies on the provision of communication and transportation infrastructure for growth to take off. The growth in welfare is due to communities becoming connected through communication channels and through transportation infrastructure, providing the possibility of trade in goods and services. Hence, in our model, the provision of communication and transportation infrastructure is a condition sine qua non for growth to occur. We partly follow both (Fukushima and Kikuchi 2008b) and the network externality literature in trying to establish whether an optimal rate of expansion of the network exists from an infrastructure and cost perspective ${ }^{3}$. Our endogenous growth model therefore differs from other endogenous growth models in that we do not include the innovation process itself, but rather assume that the communities brought together by the infrastructure network engage in boundless and costless imitation. Our model thus illustrates the principle that increasing public infrastructure beyond one community's borders through inter-communal cooperation will have a positive growth effect due to increased access to other markets and an increase in the variety of products that the members of the connected communities have access to. The model is completely in line with (Harris 1995) who states that

'... The role of communication corresponds to defining the boundaries of firm's coordination abilities across space.'

In our set-up, the sharing of information and exchange of goods enables hitherto disconnected communities to specialize in a more narrow range of the variety spectrum and experience economies of scale in the process, leading to resource productivity growth at the aggregate level. We conclude that well connected markets with optimized cost of information exchange will tend to generate higher levels of welfare for their populations even under fairly weak parameter constraints and even when connectivity entails the use of scarce resources.

An important part of our model consists of the optimal inter-temporal allocation of scarce resources to cover the build-up of a common telecommunications infrastructure based on satellite technology. In principle satellite technology has the capability to cover entire continents, while the hardware is easily separated into a space segment and a ground segment (see Chapter Two), a fact we exploit in setting up the network expansion finance strategy

\footnotetext{
${ }^{3}$ In principle, the optimum rate of expansion that we find could be zero, and our model therefore provides exact information as to which particular structural parameter configuration would lead to networks that are of constant size.
} 
as it is well known that the use of an existing physical satellite network can be expanded at zero marginal cost. ${ }^{4}$ In addition to fixed communication costs, we also introduce transportation cost, because the latter are principally different from communication costs, in that transporting goods and services does require non negligible amounts of resources, whereas transferring a message does not ${ }^{5}$.

To find out how large the impact of the provision of such communication and transportation infrastructure is on economic growth, we formulate a model that is largely based on a stripped-down version of (Krugman 1979), except that we use it as a template for the description of how a community works when left on its own. Then we add an additional top-layer to the Krugman template in which we allow different communities to communicate and trade with each other. By allowing the 'local' community to go 'global' by being integrated into a communication and transportation network, all communities within the network can concentrate on their comparative strengths, and trade their surpluses. By explicitly introducing the costs of trading, and the costs of being connected, as well as the costs of extending the network, it is not self-evident that being connected pays off. Therefore, we try to find out how a benevolent central planner would have to play his role as the 'Great Connector' (further called GC) in such a way as to optimize the development over time of utility per head for all people brought together by the GC. We will show that under particular parameter constraints, the GC will want to connect more and more communities, because it is in the interest of the communities already connected to do so. We look into the steady state rate of the expansion of such connections, but also consider the corresponding transitional dynamics.

The model features an endogenous steady state growth rate of connectivity and its corresponding transitional dynamics. Performing a sensitivity analysis, we show that the steady state growth rate of the size of the network depends on the 'usual suspects' like the resource productivity of building ground stations (positive), the rate of discount (negative), the inter-temporal elasticity of substitution (positive/negative), but also on the elasticity of substitution between varieties/price elasticity of demand (positive/negative), and on community-size (positive). By contrast, steady state growth performance does NOT depend on the fixed cost of setting up a variety, or on variations in the cost parameters reflecting marginal production cost and transportation and communication cost. The transitional dynamics do depend on the latter cost parameters, though. We find that

\footnotetext{
4 "Satellites are still the most efficient means for providing truly global communication services .... satellite services can be provided at no marginal cost" Suzanne Hutchinson, Regulatory Council, Teledisc, 2005.

${ }^{5}$ According to Harris (1995, S.47), '. . the cost of communication is almost entirely if not solely a fixed cost; once a communication 'network' is installed, marginal costs of sending a message are very low'.
} 
a reduction in the cost of connecting new communities, greatly favors the growth of the number of connected communities, hence the growth in per capita utility within those communities, even if the latter entails a rise in the fraction of labor resources devoted to expanding connectivity, both in the steady state and during the transition. Lowering marginal transportation and communication costs also favors the rate of network expansion, but only during the transition. However, given the potentially long transition periods, cumulative transitional growth is not to be disregarded.

\subsection{The Model}

The model we present here demonstrates the importance of being connected among trading partners in regions that are not necessarily adjacent to each other but through road and telecommunications infrastructure are able to exchange goods and services.

We introduce the idea of a fixed telecommunications infrastructure through which connectedness may be achieved by acquiring appropriate devices. The communications infrastructure is thus divided into two segments:

1. a publicly owned common infrastructure, which we will assume to be given. This is the space segment of the satellite system and the corresponding ground equipment for satellite control and telemetry. Satellite systems are very expensive to build and deploy and it is economically inefficient for each region to build its own satellite system in order to get into the loop. Since satellites have the capacity to cover very large geographic areas, it is reasonable to assume this infrastructure as a given shared resource.

2. Each region acquires its own ground equipment to connect to the common satellite infrastructure. This is financed through a tax by the Great Connector (GC).

We would like to formally demonstrate the economic benefit that accrues when regions get connected. Does the addition of another region to the already connected regions of the trading model increase or decrease utility for both the new comers and these already connected? Theoretically we would expect this addition to increase the volume as well as the number of available varieties on the market and hence increase consumer utility all round. The objective is to formally present this result under a hypothetical setting of virtual connectedness through satellite systems. Satellite technology has the desirable and powerful property of being able to cover very large areas, so communication satellites become the overarching technology that binds all terrestrial physical networks together.

Since the process of exchange of goods and money happens across communication channels, the connectedness of trading regions will become more 
and more important as we add more regions. Transport and communication become limiting factors in the actualization of a trade transaction.

Addition of trading partners is financed by a tax on the connected population that is used to acquire ground equipment for connection to the common satellite. It is assumed that the satellite has infinite capacity and an infinite lifetime. This may seem unreasonable in the face of satellite capacity constraints in reality but comparing the amount of satellite capacity available today to that available twenty years ago coupled with integration of fibre optic cable infrastructure, it is reasonable to assume that technological change will continue to raise the amount of satellite capacity by continuous innovation in data compression technologies and radio spectrum efficiency.

The idea of a tax may not be very appealing but like all taxes it depends on what the resulting resources are used for. In this case the collected taxes are used to acquire ground equipment to connect to an already existing stock of traders, and as a result of a new entrant in the loop the utility per head per region actually rises.

The basic structure of our model is derived from Krugman's North South model of innovation and technology transfer (Krugman, 1979). Krugman models a trade relationship between Northern and Southern agents, where the northern agents have a special ability to produce new goods that is lacking in the southern territory. This ability to produce new goods enables northern producers to earn monopoly rents on new goods and pay higher wages. Contrary to Krugman we assume instead a relationship between southern agents whose capabilities to produce goods are exactly equal. New varieties of goods can therefore be produced in any territory and can flow freely in either direction and all connected regions would in principle be able to cover the same spectrum of goods as they would if they were self-reliant.

As in Krugman we assume a latent demand for new varieties of goods that enter the utility function symmetrically. At any given time the higher the number of varieties available, the higher the utility, i.e. consumers' utility rises with an increase in the number of varieties consumed, so at a given price and for a given budget a consumer will become better off just because she has access to more variety. We follow Krugman and assume only one factor of production, labor. We leave out Krugman's technology features and assume that the set of varieties of goods/services that could be imitated is so large and that people are so innovative that the rate of imitation is unbounded in principle, but for the existence of fixed costs in producing a particular variety. Finally, we drop the notion that countries are engaging in trade with each other, but rather adopt the view that it is organized communities of people that do the specialization and trading, and that there could well be many communities inside a country. As we want to expand the set-up with potentially infinitely many communities, we make use of the assumption that all communities are identical, except 
for the fact that they may be connected or not.

\subsubsection{The demand for goods and Community welfare}

We assume that if there are $\mathrm{N}$ different goods that could be produced by a community, then the utility, $\mathrm{U}$, that an individual belonging to that community could gain from spending a budget $\mathrm{B}$ on the consumption of these $\mathrm{N}$ varieties of $x$ is given by (3.1). The utility function is a standard CES function with equal contribution of all varieties to utility, which, by a suitable choice of units of measurement then boils down to:

$$
U=\left[\sum_{1=1}^{N}\left(x_{i}\right)^{\rho}\right]^{1 / \rho}
$$

Let's consider the above utility function with two groups of goods, imported goods and exported goods. Part of the export production is also consumed locally and we will differentiate this in the price of locally consumed goods which will differ from the price of the exported goods by the transport and communication and cost incurred in the latter.

Let $N_{x}$ be the number of exported varieties and $c_{x}$ the local consumption of export good $x$. Similarly let $N_{m}$ be the number of imported varieties and $c_{m}$ the level of consumption of the imported good. Our utility function becomes:

$$
U=\left(N_{x} c_{x}^{\rho}+N_{m} c_{m}^{\rho}\right)^{1 / \rho}
$$

Let the total budget of the agent be signified by $B$,

$$
B=N_{m} c_{m} p_{m}+N_{x} c_{x} p_{x}
$$

where $N_{m}, N_{x}$, are the cardinalities of the index-sets of imported and exported varieties of goods respectively in the region. $c_{m}$ and $c_{x}$ are the consumption levels of the respective good types and $p_{m}, p_{x}$ the respective price levels of imports and exports. The Lagrangian is given by:

$$
L=\left(N_{x} c_{x}^{\rho}+N_{m} c_{m}^{\rho}\right)^{1 / \rho}+\lambda\left(B-N_{m} c_{m} p_{m}-N_{x} c_{x} p_{x}\right)
$$

Taking the First Order Conditions (FOC) w.r.t. a single variety out of the two groups (in this case $c_{x}$ ) and solving for $\lambda$ gives

$$
\lambda=\frac{c_{x}^{\rho-1}\left(\left(N_{x} c_{x}^{\rho}+N_{m} c_{m}^{\rho}\right)^{\frac{1}{\rho}-1}\right)}{p_{x}}
$$

In the case of $c_{m}$, we get:

$$
\lambda=\frac{c_{m}^{\rho-1}\left(\left(N_{x} c_{x}^{\rho}+N_{m} c_{m}^{\rho}\right)^{\frac{1}{\rho}-1}\right)}{p_{m}}
$$


From the First Order Conditions we can construct the individual demand functions for both imports and exports and use the results to calculate $\lambda$.

The demand function for exports $c_{x}$ becomes:

$$
c_{x}=\frac{B}{N_{x} p_{x}+N_{m} p_{m}^{\rho(\rho-1)} p_{x}^{\frac{1}{1-\rho}}}
$$

The demand function for imports $c_{m}$ becomes:

$$
c_{m}=\frac{B p_{m}^{\frac{1}{\rho-1}} p_{x}^{\frac{1}{1-\rho}}}{N_{x} p_{x}+N_{m} p_{m}^{\rho(\rho-1)} p_{x}^{\frac{1}{1-\rho}}}
$$

The individual demand equations can be simplified to:

$$
\begin{aligned}
& c_{x}=p_{x}^{\frac{1}{\rho-1}} U \lambda^{\frac{1}{\rho-1}} \\
& c_{m}=p_{m}^{\frac{1}{\rho-1}} U \lambda^{\frac{1}{\rho-1}}
\end{aligned}
$$

Substituting these back into the utility equation and solving for $\lambda$ we get the familiar result for $\frac{1}{\lambda}$ as the price of a single unit of utility

$$
\lambda=\frac{U}{B}
$$

hence $\frac{1}{\lambda}=\frac{B}{U}$ is the cost per unit of utility, which is assumed to be unaffected by a marginal change in price, so domestic producers can then solve their profit maximization problem assuming that they are the only ones who can change prices (this is the normal ceteris paribus assumption underlying partial differentiation), i.e. the Lagrange multiplier equals utility per dollar spent on consumption in the consumption optimum.

If prices are identical for all varieties consumed, i.e. $\mathrm{p}_{i}=\bar{p} \forall_{i}$, then the level of consumption of each variety would be the same as well, $\mathrm{x}_{i}=\bar{x}$ $\forall_{i}$, and so the budget would have to be distributed evenly over all varieties, implying that:

$$
\bar{x}=\left(\frac{B}{N}\right) / \bar{p}
$$

(3.9) when substituted in (3.1) implies that:

$$
U=B / \bar{p} \cdot N^{1 / \rho-1}
$$

For $\rho<1$, i.e. an elasticity of substitution greater than one, equation (3.13) shows the impact of Love of Variety on utility: the greater $\mathrm{N}$, the greater total utility, ceteris paribus. Note that in equation (3.13), $\frac{B}{\bar{p}}$ actually represents the level of utility for $N=1$. 
Let $\bar{L}$ be the size of the total community in terms of the number of persons. Then the utility for the community, UC would be given by:

$$
U C=\bar{L} \cdot B / \bar{p} \cdot N^{1 / \rho-1}
$$

\subsubsection{Connecting with another Community}

Now assume that instead of all goods commanding the same consumer price, there are two groups of goods commanding different prices. The first group of goods will be thought to be produced within the community, while the second group of goods is obtained from a different source external to the community. These then are goods 'imported' into the community. The internally produced goods will in part have to be exported to the external community to pay for the imports.

Let $x$ now stand for domestically produced (and therefore exported) goods, and let $m$ be the common level of imported goods. Furthermore let $q$ be the corresponding price of $m$. In that case, the level of individual utility would be given by:

$$
U=\left(N_{x} \cdot \bar{x}^{\rho}+N_{m} \cdot \bar{m}^{\rho}\right)^{1 / \rho}
$$

where $N_{x}$ is the number of varieties that are domestically produced and exported, and $N_{m}$ is the number of varieties of imported goods. The corresponding budget constraint is then given by:

$$
B=N_{x} \cdot \bar{p} \cdot \bar{x}+N_{m} \cdot \bar{m} \cdot \bar{q}
$$

Maximizing (3.15) subject to (3.16) by choosing the individual levels ${ }^{6}$ of $x_{i} \forall_{i} \mid 1 \leq i \leq N x$ and $\mathrm{m}_{j} \forall_{j} \mid 1 \leq j \leq N m$, results in:

$$
\begin{aligned}
& \bar{x}=(\bar{p} \cdot \lambda)^{-\sigma} \cdot U \\
& \bar{m}=(\bar{q} \cdot \lambda)^{-\sigma} \cdot U
\end{aligned}
$$

Furthermore, when substituting (3.17a) and (3.17b) into (3.15) we find that

$$
\lambda=\left(N_{x} \cdot \bar{p}^{1-\sigma}+N_{m} \cdot \bar{q}^{1-\sigma}\right)^{-1 /(1-\sigma)}
$$

\footnotetext{
${ }^{6}$ To obtain the individual levels, the summations over $\mathrm{i}$ and $\mathrm{j}$ should be substituted back into the utility function, and the partial derivatives w.r.t. $\mathrm{x}_{i}$ and $\mathrm{m}_{j}$ should be evaluated first, and only then the symmetry assumptions $m_{i}=\bar{m}, x_{i}=\bar{x}, p_{i}=\bar{p}, q_{i}=\bar{q}$ should be substituted in the FOCS. However, in case of equations (6) and (7), both maximization w.r.t. individual x's and m's or w.r.t. average x's and m's would generate the same results, as the FOC's would be the same due to the cancellation of the $\mathrm{N}_{x}$ 's and $\mathrm{N}_{m}$ 's at both sides of the FOC's
} 
In addition, multiplying (3.17a) and (3.17b) by $N_{x} \cdot \bar{p}$ and $N_{m} \cdot \bar{q}$, respectively, and adding up the results would give us:

$$
\begin{aligned}
N_{x} \cdot \bar{p} \cdot \bar{x}+N_{m} \cdot \bar{q} \cdot \bar{m}=B=\lambda^{-\sigma} \cdot & \left(N_{x} \cdot p^{-1-\sigma}+N_{m} \cdot q^{-1-\sigma}\right) \cdot U \\
& =\lambda^{-\sigma} \cdot \lambda^{\sigma-1} \cdot U=>\lambda=\frac{U}{B}
\end{aligned}
$$

where we have used (3.18) to get rid of the bracketed term in (3.19). Equation (3.19) can be used to substitute for $\mathrm{U}$ in equations (3.17a) and (3.17b) leaving the levels of consumption of domestic and imported goods as a function of the available budget and the corresponding consumer prices and the Lagrange multiplier only:

$$
\begin{aligned}
& \bar{x}=\bar{p}^{-\sigma} \cdot \lambda^{1-\sigma} \cdot B \\
& \bar{m}=\bar{q}^{-\sigma} \cdot \lambda^{1-\sigma} \cdot B
\end{aligned}
$$

\subsubsection{Goods and Services Supply with Two Connected Communities}

The supply of each individual good can be modeled using the standard assumption that each individual supplier is of measure zero, i.e. his own actions do not affect the average cost of a utility (hence $1 / \lambda$, hence $\lambda$ ). So, from the perspective of an individual supplier, both the budget and the Lagrange multiplier are given in equations (3.20a) and (3.20b). For a profit maximizing supplier of domestic goods, the resulting profit function will therefore be given $b y^{7}$ :

$$
\pi=p \cdot x+q \cdot z-w \cdot(\alpha \cdot x+(\alpha+\beta) \cdot z+\bar{l})
$$

In equation (3.21), $\pi$ represents the profit flow for the local producer of each variety. This producer sells his produce on the domestic market at price $p$, but also to the external market at price $q$. The corresponding volumes sold are $x$ and $z$. These price/volume combinations have to be consistent with the respective demand equations, such as those given by equation $(3.20 \mathrm{a}, \mathrm{b})$. For the export volume $\mathrm{z}$, the corresponding demand for imported goods by the external community would function as the relevant demand constraint i.e. equation (3.20b) would be relevant, but then with the foreign budget,

\footnotetext{
${ }^{7}$ From now, we drop the subscripts indicating a particular variety, since we assume that the production technologies are symmetric as well.
} 
and foreign domestic prices and foreign import prices (i.e. the export price $r$ in this case), replacing $\mathrm{B}, \mathrm{p}$ and $\mathrm{q}$, respectively.

As regards the production technology, we have assumed that the production of a variety requires the input of labor at a wage rate $w$ to perform three different functions:

1) the production of each variety requires $\bar{l}$ units of labor as fixed set-up costs.

2) the variable cost of producing a variety amounts to $\alpha$ units of labor per unit of output.

$3)$ if a unit is shipped to an external community, then that requires $\beta$ additional units of labor per unit of output to cover per unit communication and transportation resource requirements. Note that for reasons of simplicity we assume that $\alpha$ and $\beta$ are independent of the variety and the community.

Maximization of equation (3.21) conditional on the demand constraints being met, then results in the profit maximizing prices given by:

$$
\begin{gathered}
p=\alpha \cdot w / \rho \\
q=(\alpha+\beta) \cdot w / \rho
\end{gathered}
$$

Note that, as usual, we need to assume that $0<\rho<1$, since otherwise profits would be negative.

\subsubsection{Benefits from Additional Connections}

Under the symmetry assumptions employed so far (i.e. same utility functions, same production technologies) and adding a further one by assuming that communities are of the same size, it must be the case that if we have $W$ connected communities, then the outside world to which each individual community is connected consists of $(W-1)$ communities in turn. In addition to this, if the local community exports $N_{x}$ varieties to the outside world, then, because of the symmetry assumptions made before, the outside world must be exporting $(W-1) \cdot N_{x}$ varieties to the local community in turn. This begs the question what the value of $N_{x}$ would be.

We can determine the value of $N_{x}$ by using the assumption of free entry up to the point that profits per variety drop to zero. To this end, we can substitute equations $(3.22 \mathrm{a}, \mathrm{b})$ as well as our observation that $N_{m}=(W-1) \cdot N_{x}$, into (3.18), while taking into account that the foreign budget equals $(W-1) \cdot B$, while the Lagrange multipliers in all communities must be the same, because of the symmetry assumptions made above. In that case, we find after some algebraic manipulation that: 


$$
\pi=\left(B \cdot(1-\rho)-\bar{l} \cdot N_{x} \cdot w\right) / N_{x}=0=>N_{x}=\frac{B}{(w \cdot \bar{l})} \cdot(1-\rho)
$$

Note that in equation $(3.23), \frac{B}{(\bar{l} \cdot w)}$ is the absolute maximum of the number of varieties that could be produced, because for this value of $N_{x}$ total expenditures B are just enough to cover the total set-up cost, leaving no resources to actually produce a strictly positive level of the $N_{x}$ varieties. Note moreover that if the elasticity of substitution between varieties would increase, i.e. if $\rho$ would go up, then the number of varieties supplied to the market would go down. This is because in that case the profit margin would go down, ceteris paribus. This would make it harder to recover the fixed set-up cost per variety.

Using (3.23), the total number of varieties, $V$ consumed by $W$ connected communities would be given by:

$$
V=B \cdot W /(\bar{l} \cdot w \cdot \sigma)
$$

where $\sigma=1 /(1-\rho)$.

It should now be noted that since profits are zero because of the free entry assumption, all income generated must be wage-income. Hence, the consumer budget in each community is given by $B=w \cdot \bar{L}$. Substituting this result into (3.24) then gives rise to:

$$
V=W \cdot(\bar{L} / \bar{l}) / \sigma)
$$

Again, $\frac{\bar{L}}{\bar{l}}$ is the absolute maximum of the number of varieties that each community would be willing to support. Hence, W times that quantity is the absolute maximum number of varieties that all communities could produce. Since $\sigma>1$, the latter number is strictly larger than the actual number of varieties produced by all communities taken together.

We can now obtain utility per capita (further called UPC) in each of the $\mathrm{W}$ connected communities by substituting the previous results into (3.15)

$$
\begin{gathered}
U P C=U / \bar{L}=[\bar{L} / \bar{l}]^{1 /(\sigma-1)} \cdot(\sigma-1) \cdot \sigma^{\sigma /(1-\sigma)} \\
\cdot\left(\alpha^{1-\sigma}+(W-1) \cdot(\alpha+\beta)^{1-\sigma}\right)^{1 / \sigma-1}
\end{gathered}
$$

Since we must have that $\sigma>1$, it follows directly that $\frac{\partial U P C}{\partial W}>0$, $\frac{\partial U P C}{\partial \bar{L}}>0, \frac{\partial U P C}{\partial \bar{l}}<0, \frac{\partial U P C}{\partial \alpha}<0$ and $\frac{\partial U P C}{\partial \beta}<0$, i.e. under these parameter values and symmetry assumptions, rational communities would have an interest in extending the number of connections with other communities. 
In addition, utility per capita would rise with the size of each individual community, while it would fall with the level of fixed set-up labor cost. Finally, a rise in transportation and communication costs would negatively affect utility per capita in all connected communities.

The analysis above still leaves the following questions unanswered:

a) Having established that $\frac{\partial U P C}{\partial W}>0$, does an optimum $\dot{W}$ exist that maximizes utility for all connected communities?

b) if an optimum $\dot{W}$ exists, how would it depend on the parameters of the model?

Finding answers to these questions is the subject of the next section.

\subsubsection{Optimum Network Expansion Rates}

Let us now assume that it takes some labor resources to connect thus far disconnected communities, by building ground-stations in the newly connected communities as well as transportation infrastructure ${ }^{8}$. As before, we make the simplest assumption possible, i.e. that the resources needed to make new connections are proportional to the number of newly connected communities. Thus we get:

$$
\dot{W}=\delta \cdot L_{w}
$$

In equation $(3.27), L_{w}$ are the total labor resources used for expanding the number of connected communities and $\delta$ is the productivity of this labor. Let each connected community contribute a fraction of its available labor force to this activity. Then we must have that $L_{w}=\tau \cdot \bar{L} \cdot W$, and consequently it follows from (3.27) that:

$$
\stackrel{\wedge}{W}=\delta \cdot \bar{L} \cdot \tau
$$

In equation (3.28), $\hat{W}$ is the instantaneous growth rate of the number of communities that is connected at any time.

If a fraction, $\tau$ of total real resources is used for connecting communities, then the new real budget available for spending on goods and services within each community must be equal to $(1-\tau) \cdot B$. This change in the real budget would not change optimum price setting behavior, but it would change both the supply of goods and services and the optimum number of varieties produced within each community. When we redo the analysis above, but with $(1-\tau) \cdot B$ replacing $B$, we find that the new number of varieties by community becomes a fraction $(1-\tau)$ of the old number of varieties:

\footnotetext{
${ }^{8}$ To keep things as simple as possible, we assume that there are only fixed set-up costs in doing this, so that the infrastructure is infinitely lived.
} 


$$
N_{x}=(\bar{L} / \bar{l}) \cdot(1-\tau) / \sigma
$$

According to (3.29), the introduction of the costs of connecting communities therefore reduces the number of varieties supplied by each community. Utility per capita would fall on that account, but for the fact that the number of communities connected (i.e. W) increases as well, and therefore also, potentially, the total number of varieties available to all connected communities (cf. (3.26)). Substituting (3.29) and (3.22a,b) into (3.15), while taking into account that $N_{m}=(W-1) \cdot N_{x}$, we find that the new expression for utility per capita becomes:

$$
\begin{gathered}
U P C=[\bar{L} / \bar{l}(1-\tau)]^{1 /(\sigma-1)} \cdot(\sigma-1) \cdot \sigma^{\sigma /(1-\sigma)} \\
\cdot\left(\alpha^{1-\sigma}+(W-1) \cdot(\alpha+\beta)^{1-\sigma}\right)^{1 / \sigma-1}
\end{gathered}
$$

It follows from (3.30) that $\frac{\partial U P C}{\partial \tau}<0$.

\subsubsection{Network Expansion}

We can now construct an optimum control problem in which the GC would want to maximize the present value of total utility in all connected communities, while using (3.30) in the objective function to be maximized. An alternative objective function would be the maximization of the utility per head of the community initiating the integration process of communities. As the communities are assumed to be symmetric, it should be the case that if for the initiating community it would be beneficial to expand the network of connected communities, then it would have to be beneficial for the newly connected communities as well. The corresponding Hamiltonian reads:

$$
H=\exp (-\mu \cdot t) \cdot U P C^{1-\theta} \cdot \bar{L} \cdot W /(1-\theta)+\psi \cdot \dot{W}
$$

In equation (3.31), $\mu$ is the rate of discount, while $\frac{1}{\theta}$ is the intertemporal elasticity of substitution and $\psi$ is the co-state variable associated with the state variable $W^{9}$. The control variable of the system is $\tau$. The corresponding FOCs to this problem are implicitly given by the requirements $\frac{\partial H}{\partial \tau}=0, \frac{\partial H}{\partial W}=-\dot{\psi}, \quad \frac{\partial H}{\partial \psi}=\dot{W}$ and the transversality condition that requires $\lim _{t \rightarrow \infty} \psi(t) \cdot W(t)=0$. Doing the algebra, results in a set of non-linear differential equations, that, under certain conditions, converges to a steady state when $W(t)$ approaches infinity. The system of differential equations is given by:

\footnotetext{
${ }^{9}$ Note that we disregard the case where $\theta=1$.
} 


$$
\begin{gathered}
\dot{\psi}=\psi \cdot A \cdot[W \cdot(1-\tau) /((W-1)+B)+C \cdot \tau-1] \\
\dot{\psi}=\psi \cdot\left[\begin{array}{c}
\hat{W} \cdot W /\{(1+C) \cdot(W-1+B)\}+ \\
+C \cdot \dot{\tau} /((1-\tau) \cdot(1+C))-\mu
\end{array}\right] \\
\hat{W}=A \cdot \tau
\end{gathered}
$$

with $A=\bar{L} \cdot \delta, B=((\alpha+\beta) / \alpha)^{\sigma-1}, C=(\sigma+\theta-2) /(1-\theta)$.

It should be noted that for $\mathrm{W}$ approaching infinity, the ratio $(\mathrm{W}-1) / \mathrm{W}$ will approach 1 , in which case the system becomes more manageable. Using the requirement that in the steady state $\tau$ must be constant (otherwise $\hat{W}$ can't be constant, cf. equation (3.28), it follows that in the steady state $\dot{\tau}=0$, implying that the steady state solution is given by:

$$
\begin{aligned}
& \bar{\tau}=\frac{(1+C) \cdot(A(2+C)-\mu)}{A \cdot C \cdot(2+C)} \\
&=\frac{(\sigma-1) \cdot(\bar{L} \cdot \delta \cdot(\sigma-\theta)-(1-\theta) \cdot \mu)}{\bar{L} \cdot \delta \cdot(\sigma-\theta) \cdot(\sigma+\theta-2)}
\end{aligned}
$$

$$
\begin{gathered}
\stackrel{\widehat{W}}{W}=\frac{(1+C) \cdot(A \cdot(2+C)-\mu)}{C \cdot(2+C)}= \\
=\frac{(\sigma-1) \cdot(\bar{L} \cdot \delta \cdot(\sigma-\theta)-(1-\theta) \cdot \mu)}{(\sigma-\theta) \cdot(\sigma+\theta-2)} \\
\bar{\wedge}=\frac{A \cdot(2+C)-(1+C)^{2} \cdot \mu}{C \cdot(2+C)}=\frac{(\sigma-1)^{2} \cdot \mu-\bar{L} \cdot \delta \cdot(\sigma-\theta)(1-\theta)}{(\sigma-\theta) \cdot(\sigma+\theta-2)}
\end{gathered}
$$

where a bar over a variable denotes the steady state value of that variable.

\subsubsection{Parameter Constraints}

The transversality condition requires that $\stackrel{\widehat{A}}{W}+\overline{\hat{\psi}}<0$ which gives rise to the following parameter constraint:

$$
\frac{\bar{L} \cdot \delta \cdot(\sigma-\theta)-(\sigma-1) \cdot \mu}{\sigma+\theta-2}<0
$$


In order to be able to have positive steady state growth in the number of connected communities, we require that $\stackrel{\overline{\hat{W}}}{\mathrm{~W}}>0$, which implies that:

$$
\frac{(\sigma-1) \cdot(\bar{L} \cdot \delta \cdot(\sigma-\theta)-(1-\theta) \cdot \mu)}{(\sigma-\theta) \cdot(\sigma+\theta-2)}>0
$$

In order to get the 'standard' results that the growth rate depends negatively on the rate of discount $\mu$, we require that:

$$
\frac{\partial \hat{\widehat{W}}}{\partial \mu}<0=>\frac{(\sigma-1) \cdot(1-\theta)}{(\sigma-\theta) \cdot(\sigma+\theta-2)}>0
$$

If, moreover, we want a rise in the productivity of connection resources to have a positive impact on the steady state growth rate, we should have:

$$
\frac{\partial \overline{\hat{W}}}{\partial \delta}>0=>\frac{\bar{L} \cdot(\sigma-1)}{(\sigma+\theta-2)}>0
$$

Since by assumption $\sigma>1$ and since $\bar{L}$ must be strictly positive, it follows from $(3.34 \mathrm{~d})$ that we must have $(\sigma+\theta-2)>0$. But then it follows from (3.34c) that the ratio $(1-\theta) /(\sigma-\theta)>0$, implying that either $\theta<1<\sigma$ (further called Case I) or $\theta>\sigma>1$ (further called Case II) .

The parameter constraints for the two cases are summarized in Table 3.1. It follows from the Table that Case II is the least restrictive case of the two in terms of choosing $\mu$. However, Case II also implies a lower inter-temporal elasticity of substitution than Case I, and hence a lower willingness (temporal) to divert resources.

TABLE 3.1: Parameter Constraints

\begin{tabular}{|c|c|c|}
\hline Constraint & Case I $(\sigma>1>\theta>0)$ & Case II $(\theta>\sigma>1)$ \\
\hline Transversality & $\mu>\bar{L} \cdot \delta(\sigma-\theta) /(\sigma-1)>0$ & $\mu>\bar{L} \cdot \delta(\sigma-\theta) /(\sigma-1)<0$ \\
\hline $\begin{array}{c}\bar{W} \\
W\end{array}$ & $\mu<\bar{L} \cdot \delta(\sigma-\theta) /(1-\theta)>0$ & $\mu<\bar{L} \cdot \delta(\sigma-\theta) /(1-\theta)>0$ \\
\hline $\begin{array}{c}\overline{\hat{~}} \\
\partial W / \partial \delta>0\end{array}$ & $(\sigma+\theta-2)>0$ & $(\sigma+\theta-2)>0$ \\
\hline $\begin{array}{c}\overline{\hat{W}} \\
\partial W \mu<0\end{array}$ & $(1-\theta) /(\sigma-\theta)>0$ & $(1-\theta) /(\sigma-\theta)>0$ \\
\hline $\bar{\tau}<1$ & $\mu>\bar{L} \cdot \delta(\sigma-\theta) /(\sigma-1)>0$ & $\mu>\bar{L} \cdot \delta \cdot(\sigma-\theta) / \sigma-1<0$ \\
\hline
\end{tabular}




\subsubsection{Transitional Dynamics}

The system of differential equations given by $(3.32 \mathrm{a}, \mathrm{b}, \mathrm{c})$ is non-linear in the variables $\mathrm{W}, \tau$ and $\psi$. By means of substituting out the differential equation for the co-state variable, we can reduce $(3.32 \mathrm{a}, \mathrm{b}, \mathrm{c})$ to a twodimensional system that is still non-linear, but that is saddle-path stable under certain parameter conditions (see table 3.1) and that features steady state growth. When we would introduce an auxiliary variable $\mathrm{Z}$ defined as $Z=W /(W+B-1)$ (cf. $(3.32 \mathrm{~b}))$, the quasi-state variable $\mathrm{Z}$ converges to 1 , for $\mathrm{W}$ goes to infinity. In addition, the growth rate of $\mathrm{Z}$ is given by $\hat{Z}=\hat{W} \cdot(B-1) /(W+B-1)$. Substituting these relations into $(3.32 \mathrm{a}, \mathrm{b}, \mathrm{c})$ and substituting out the growth rate of $\psi$, then leaves a two-dimensional system, with a constant steady state, given by:

$$
\begin{gathered}
\hat{Z}=A \cdot(1-Z) \cdot \tau \\
\hat{\tau}=\frac{-(\mu \cdot(1-C)+A \cdot(1+C+Z) \cdot(1+C \cdot(1-\tau))) \cdot(1-\tau)}{C \cdot \tau}
\end{gathered}
$$

The locus of combinations of $Z$ and $\tau$ for which $Z$ and $\tau$ are not growing is obtained by setting $\hat{Z}=0$ in (3.35a) and setting $\hat{\tau}=0$ in (3.35b), giving:

$$
\begin{gathered}
Z=1 \\
\tau=(1+C)\left[\frac{\mu}{A \cdot((1+C)-C \cdot \tau)}-1\right]
\end{gathered}
$$

The $\hat{Z}=0$-locus is given by (3.36a) and the $\hat{\tau}=0$-locus by (3.36b). The steady state value of $\mathrm{Z}$ is obviously equal to 1 , as it should be, while the steady state value of $\tau$ is given by (3.36b) after substituting (3.36a), which gives the same results as (3.33a), after substituting the definitions of $\mathrm{A}$ and $\mathrm{C}$ in terms of the structural parameters of the system. Note that under the assumptions of Case II, the $\hat{\tau}=0$-locus has a vertical asymptote at $\tau^{\prime}=\frac{(1+C)}{C}<1$, since $\mathrm{C}$ must then be negative, and $\frac{(C+1)}{C}=(\sigma-1) /$ $(\sigma+\theta-2)=\frac{(\sigma-1)}{(\sigma-1+\theta-1)}<1$, as Case II implies $\theta>\sigma>1$. Under the Case I assumptions the asymptote lies at a value of $\tau>1$, and we need a further constraint on the parameters to ensure the steady state value of $\tau<1$ (see also the last line of Table 3.1). Moreover, system (3.35a, b) can be shown to be saddle-path stable in both cases. The difference between the two cases is therefore that Case I is more constrained than case II, while in Case II, the inter-temporal elasticity of substitution between periods is 
FIGURE 3.1: The Phase Diagram

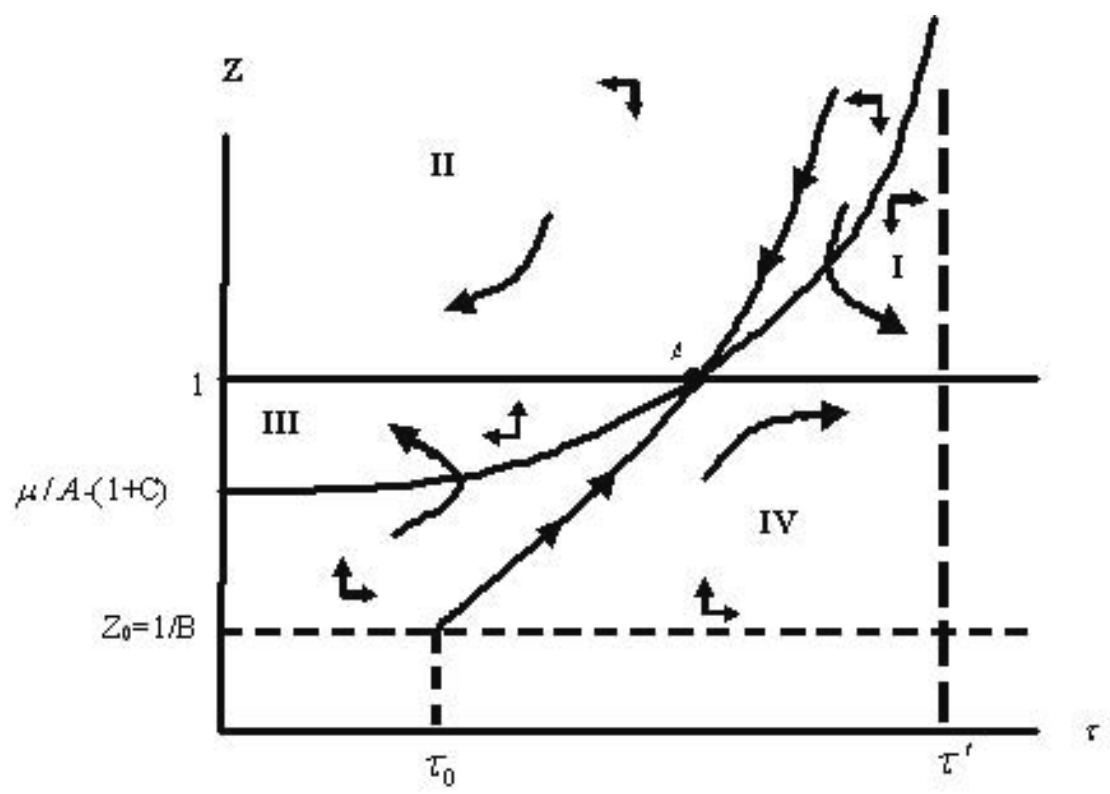

smaller than the elasticity of substitution between goods within periods. Henceforth, we will focus on Case II.

The saddle-path stability of both cases follows readily from differentiating (3.35b) with respect to $\mathrm{Z}$, giving:

$$
\partial \hat{\tau} / \partial Z=\frac{-A \cdot(1+C \cdot(1-\tau))(1-\tau)}{C \cdot \tau}
$$

It follows that $\operatorname{sign}(\partial \hat{\tau} / \partial Z)=\operatorname{sign}(-(1+C) /(C+\tau))<0 \forall_{\tau} \mid 0<\tau<$ $(C+1) / C$. Hence, if we would move vertically from a point on the $\hat{\tau}=0$ -locus for a given value of $\mathrm{Z}, \hat{\tau}$ would become negative, while the opposite would be the case if we would move downward. Note that this would hold for any value of $Z$, since $\partial \hat{\tau} / \partial Z$ is independent of $Z$. Note, moreover, that for combinations of $\mathrm{Z}$ and $\tau$ above the $\hat{Z}=0$-locus, the growth rate of $\mathrm{Z}$ becomes negative, while the opposite holds for points below the $\hat{Z}=0$ -locus. Consequently, the phase-diagram associated with $(3.35 \mathrm{a}, \mathrm{b})$ and (3.36a, b) looks like figure (3.1)

Point A in figure 3.1 represents the steady state. The four areas labeled IIV in Roman numerals show that under the Case II parameter restrictions, 
the model exhibits saddle-path stability. The horizontal solid line at $\mathrm{Z}=1$

is the $\hat{Z}=0$-locus, while the solid convex curve is the $\hat{\tau}=0$-locus. The saddle-path is the remaining solid curve. The horizontal dotted line is the value of $\mathrm{Z}$ at time zero. The $\hat{\tau}=0$-locus has a point of intersection with the vertical in the positive quadrant. It depends on the actual parameter values whether it is above or below $\mathrm{Z}_{0}$, but where exactly it is relative to $\mathrm{Z}_{0}$ doesn't make a qualitative difference. To keep the figure as simple as possible, we have drawn it as it is.

It follows from the figure that the optimum path for the allocation of communication resources and the corresponding path for the expansion of $\mathrm{Z}$ can relatively easily be obtained by means of the method of Backward Integration, i.e. obtain the time-path for $\mathrm{Z}$ (and $\tau$ ) by making time run backward, and starting at $\mathrm{Z}=1$ and decreasing to the moment in time when $\mathrm{Z}=\mathrm{Z}_{0}$. In that way we can obtain the corresponding initial value of $\tau_{0}$, and consequently the entire time-path for $\tau$ is thus easily obtained since the steady state value of $\tau$ is known (cf. Equation (3.33a)).

\subsubsection{Solving for the Transition Path Using Backward Integration}

Because of the non-linearity of $(3.35 \mathrm{a}, \mathrm{b})$, the solutions for the speed of connection and the corresponding resource allocation requirements can unfortunately not be obtained by analytical means. Therefore, in this section, we will use Mathematica to show how the adjustment path itself, but also the overall shape of the transition path changes with the parameters of the system. To do this, we use the method of Backward Integration (Brunner and Strulik, 2002). The method is suitable, since we know where the transition path ends (i.e. in the steady state), while we also 'know' where the quasi-state variable $\mathrm{Z}$ starts (i.e. at $\mathrm{Z}_{0}=1 / B$ ). Hence by integrating (3.35a) backwards in time and 'waiting' till $\mathrm{Z}$ hits the $\mathrm{Z}_{0}$-mark in figure 3.1 , we also obtain the corresponding initial value of $\tau$, i.e. $\tau_{0}$. The only problem is that when we would start integrating backward while being exactly in the steady state, we wouldn't be able to get away from there, since the speed of adjustment in the steady state is exactly equal to zero. Consequently, we need to move slightly outside the steady state, while being on the transition path, and then start the integration process. In order to do that we can draw a tiny circle around the steady state (with radius $\varepsilon$, thus defining a (circular) $\varepsilon$-region around the steady state) and pick the point of intersection of that circle with the transition path as the initial values for $\tau$ and $\mathrm{Z}$ in the backward integration process. This in turn requires that we linearize (3.35a) around the steady state, and obtain the Eigen values 
of the linearized system, which then can be written as ${ }^{10}$ :

$\left(\begin{array}{c}\dot{Z} \\ \dot{\tau}\end{array}\right)=\left(\begin{array}{cc}\frac{-(1+C) \cdot(A \cdot(2+C)-\mu)}{C(2+C)} & 0 \\ \frac{(1+C) \cdot \mu \cdot(A \cdot(2+C)-(1+C) \cdot \mu)}{A \cdot C^{2} \cdot(2+C)^{2}} & \frac{-A \cdot(2+C)+(1+C) \cdot \mu}{C}\end{array}\right) \cdot\left(\begin{array}{cc}Z & -\bar{Z} \\ \tau & -\bar{\tau}\end{array}\right)$

with corresponding Eigen values $\zeta_{1}=\frac{-(1+C)(A \cdot(2+C)-\mu)}{C(2+C)}$ (implying that $\left.\zeta_{1}=\frac{(\sigma-1((\theta-1) \mu+\bar{L} \cdot \delta \cdot(\sigma-\theta))}{(\theta+\sigma-2)(\theta-\sigma)}\right)$ and $\left.\zeta_{2}=\frac{-A(2+C)+(1+C) \cdot \mu}{C}\right)$, which implies that $\zeta_{2}=\frac{\bar{L} \cdot \delta \cdot(\theta-\sigma)+\mu(\sigma-1)}{(\theta+\sigma-2)}$. In order to have saddle-path stability, we need one of the Eigen values to be negative, and the other one to be positive. Since it must be the case that $(\theta+\sigma-2)>0$ (cf. $(3.34 \mathrm{~d}))$, this implies that under Case II, $\zeta_{2}$ must be the positive Eigen value, and hence $\zeta_{1}$ is the negative Eigen value provided that $\mu<\bar{L} \cdot \delta \cdot \frac{(\sigma-\theta)}{(1-\theta)}$, which is a parameter constraint that should hold in both cases anyway (see section 3.2.7 above, in particular the constraint associated with $W>0$ ). Under Case I the transversality condition implies that $\mu>\bar{L} \cdot \delta \cdot \frac{(\sigma-\theta)}{(\sigma-1)}$, which would make $\zeta_{2}$ the positive Eigen value again, and in order for $\zeta_{1}$ to be negative we would need that $\mu<\bar{L} \cdot \delta \cdot \frac{(\sigma-\theta)}{(1-\theta)}$, which was the requirement associated with

having $W>0$ in both cases. We conclude that the parameter restrictions outlined in section 3.2.7 imply the saddle path-stability of the optimization problem and that $\zeta_{1}$ is the negative Eigen value, with corresponding Eigen vector $\mathrm{v}$, where $\mathrm{v}$ is given by:

$$
v=\left(\left(\frac{\bar{L} \cdot \delta \cdot\left(\bar{L} \cdot \delta(\theta-1) \cdot(\theta-\sigma)-\mu \cdot(\sigma-1)^{2}\right) \cdot(\theta-\sigma) \cdot(\sigma+\theta-2)}{(\theta-1)^{2} \cdot \mu \cdot(\bar{L} \cdot \delta \cdot(\theta-\sigma)+\mu \cdot(\sigma-1)) \cdot(\sigma-1)}\right)\right)
$$

Consequently, the slope of the stable arm in the steady state is given by the top element of $\mathrm{v}$, the numerical value of which we will further call $\mathrm{s}$, for reasons of simplicity. Now consider a circle with radius $\varepsilon$ and center coordinates $\{\bar{Z}, \bar{\tau}\}$ in the Z, $\tau$-plane. Also consider a straight line through that center with slope s. The points of intersection of this line with the circle can be found by solving the simultaneous system $\left\{(Z-\bar{Z})^{2}+(\tau-\bar{\tau})^{2}=\right.$ $\left.\varepsilon^{2},(Z-\bar{Z})=s \cdot(\tau-\bar{\tau})\right\}$ giving as the relevant solution for our case with an upward sloping stable arm (see Figure 3.1):

\footnotetext{
${ }^{10}$ Cf. Barro and Sala-i-Martin (1995)
} 


$$
\begin{aligned}
& Z^{\prime}=\bar{Z}-\frac{\epsilon \cdot s}{\sqrt{1+s^{2}}} \\
& \tau^{\prime}=\bar{\tau}-\frac{\epsilon}{\sqrt{1+s^{2}}}
\end{aligned}
$$

The point $\left\{Z^{\prime}, \tau^{\prime}\right\}$ lies below and to the left of the steady state given by the point $\{\bar{Z}, \bar{\tau}\}$, since both $\varepsilon, \mathrm{s}>0$ under the parameter constraints outlined above. By choosing increasingly smaller values of the radius $\varepsilon$, we could get infinitely close to the steady state. The time spent during the transition from that point towards the initial point (or vice versa, which is what we really want) would become correspondingly longer. In the next section, we will present the results of the sensitivity analysis performed using the Backward Integration Method.

\subsubsection{Sensitivity Analysis}

The results obtained using the Backward Integration method for the transitional dynamics are associated with variations on the "base-run" parameter vector listed in Table 3.2 below. The values used for this vector are all consistent with the case II parameter constraints outlined in the previous section. They generate moderate but positive growth rates for the number of connected communities and transition paths that take several centuries before hitting the $\varepsilon$-region around the steady state.

TABLE 3.2: The Base-Run Parameter vector

\begin{tabular}{|c|c|c|c|}
\hline Parameter & Value & Parameter & Value \\
\hline$\alpha$ & 0.5 & $\bar{L}$ & 1 \\
\hline$\beta$ & 0.1 & $\theta$ & 2 \\
\hline$\sigma$ & 1.25 & $\delta$ & 0.1 \\
\hline $\bar{l}$ & 1 & $\mu$ & 0.05 \\
\hline
\end{tabular}

The parameters can be divided into three different groups. The first group consists of the production cost parameters $\alpha$ and $\beta$. As is clear from equations $(3.32 \mathrm{a}, \mathrm{b}, \mathrm{c})$ and $(3.33 \mathrm{a}, \mathrm{b}, \mathrm{c})$ these cost parameters do not influence the steady state itself, but affect the transitional dynamics only. The other structural parameters $\sigma, \delta, \mu, \theta, \bar{L}$ do have an impact on both the steady state and the corresponding transitional dynamics, whereas the fixed-cost parameter $\bar{l}$ does not influence either the steady state or the transitional dynamics. It does have an impact on welfare, though, since 
higher fixed labour costs imply lower numbers of varieties and hence lower welfare, ceteris paribus.

Using the parameter-vector above, we have performed a sensitivity analysis for all the elements in the vector separately. Each element has been varied over the range $c \cdot(1-x), c, c \cdot(1+x)$, where $c$ is the central value taken from Table 3.2, and $\mathrm{x}=0.5$ for the parameters $\alpha$ and $\beta$, and $\mathrm{x}=0.1$ for all the other parameters. These relative shocks are all still compatible with the case II parameter constraints. For the parameters $\alpha$ and $\beta$, the shocks are relatively high, because otherwise the effects on the transition path would hardly be visible. The corresponding results are depicted in the sensitivity analysis figures further below. In all the figures, we first see the variables $\mathrm{Z}, \mathrm{W}$, and $\tau$ graphed against time, and then the implied graph of $\mathrm{Z}$ against $\tau$, as in the phase-diagram in figure 3.1. A further plot holds the development over time of the present value of utility per capita (called PVUPC) along the transition path until the moment it hits the $\varepsilon$-region. The final plot shows the growth rate of W (called GW) along the transition path. In all plots, the graph associated with the lowest value of the parameter range is dotted. The central value graph is solid, and the highest value in the parameter range is associated with the striped graph. It should be noted that in the plot of $\mathrm{Z}$ against $\mathrm{t}$ (but also against $\tau$ ) there is a horizontal at $\mathrm{Z}=1$ (that corresponds to the steady state value of $\mathrm{Z}$ ). The other horizontals in the plot of $\mathrm{Z}$ against $\mathrm{t}$ are associated with the initial values of $\mathrm{Z}$ as given by $\mathrm{Z}_{0}=1 / B$. The horizontals in the plot of GW against $t$ are the steady state values of GW corresponding to each individual parameter vector concerned. 
In Figure 3.2, the results for a change in the elasticity of substitution $\sigma$, between varieties in the utility function are shown. Note that $\sigma$ also equals the (absolute value of the) price-elasticity of demand. A higher value of $\sigma$ would therefore lower profit margins, and hence would enable a community to sustain a lower number of varieties (see equation (3.25)), ceteris paribus. We see that a relatively low price elasticity of demand raises the transition path for Z. Higher values of $\sigma$ lower the transition path relative to the central value path. However, it should be noted, that the paths do actually intersect. This is most clearly seen in the plot for $\tau$. In addition to this, it can be seen from the position of the end-points of the transition paths in the plot for $\mathrm{W}$, that the length of the transition path for a low value of $\sigma$ is higher than that of the central value for $\sigma$. The same holds for the endpoint for the high-value of $\sigma$-path, suggesting the relevance of intertemporal trade-offs in a setting like this. For, as apparent from the plot of $\mathrm{GW}$, the growth rate of $\mathrm{W}$ is very close to its steady state value from the beginning in the low $\sigma$ case, while it is very low to start with in the high $\sigma$ case but ends higher than in the low $\sigma$ case.

From the plot holding the outcomes for PVUPC, it follows immediately that a lower value of $\sigma$ is relatively good news for the consumers that are all connected. There is some bad news as well, since the (steady state) growth rate $\mathrm{GW}$ is the lowest of the three. It follows from a comparison of the plots for PVUPC and GW, that having a high GW doesn't have to be a good thing per se. While the central value for $\sigma$ does generate the highest GW during the transition and in the steady state, the present value of utility per head is below that of the low- $\sigma$ case at all times. 
FIGURE 3.2: Sensitivity Results for Variations in $\sigma$
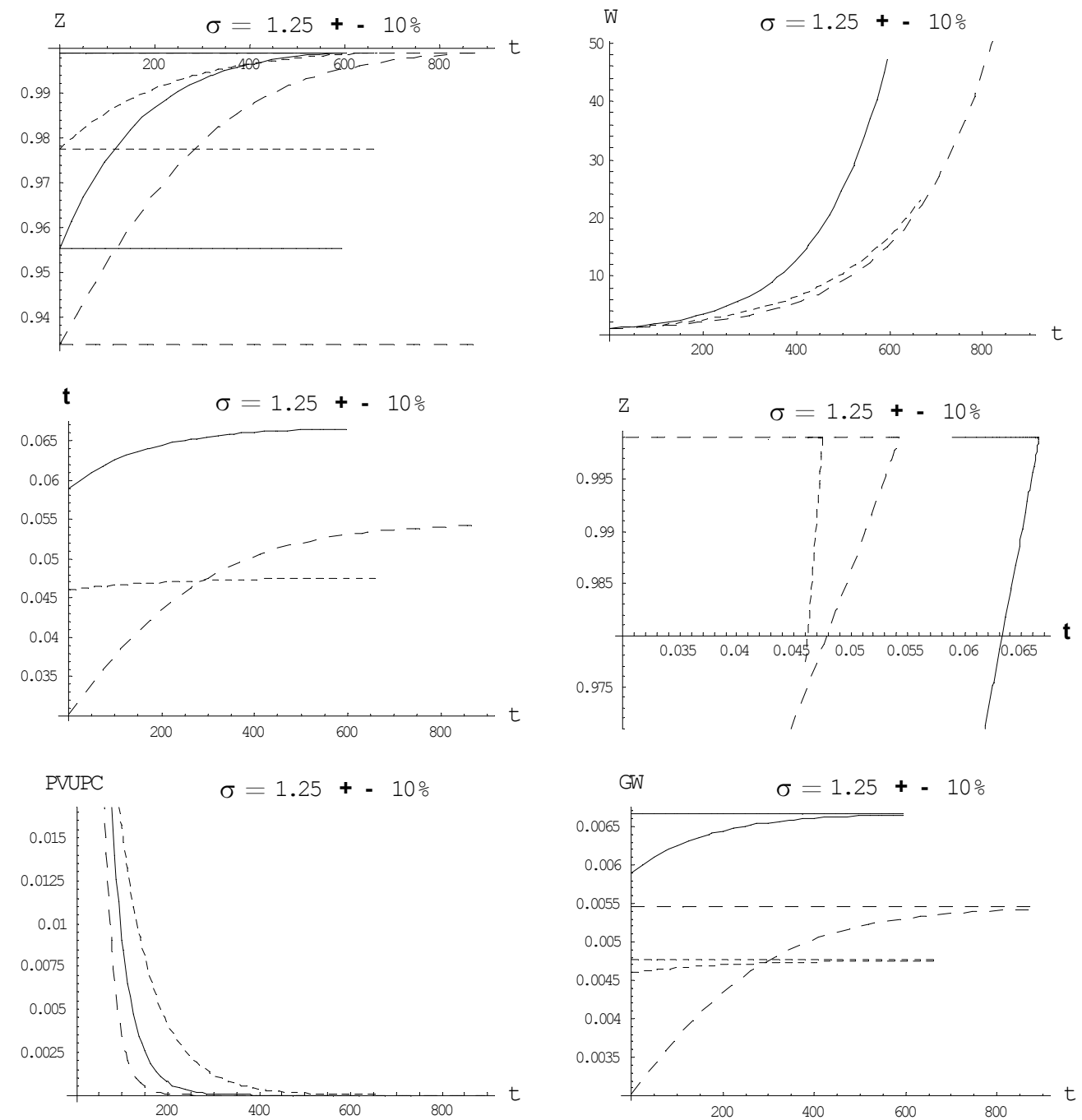
Figure 3.3 shows the results for variations in $\theta$, where $1 / \theta$ is the inter-temporal elasticity of substitution between (the utilities derived from) consumption at different moments in time. As with the variations in $\sigma$, we find that the central value of $\theta$ generates the highest growth rates, whereas the rest of the results are reversed, that is to say the highest value of $\theta$ now generates a steady state growth rate that falls below the one for the lowest value of $\theta$. This is what one would expect, since a higher value of $\theta$ implies a lower value of the inter-temporal elasticity of substitution and hence a higher willingness to give up resources now in exchange for higher returns in the future. We see therefore that the transition path for $\tau$ for the low $\theta$ case is indeed above the path for the high $\theta$-case at the end of the transition period and in the steady state itself. Also, it should be noted that a lower value of the inter-temporal elasticity of substitution (hence a higher value of $\theta$ ) would tend to cause a more uniform distribution of consumption over time, and hence a lower dispersion in transitional growth rates and lower steady state growth. This is exactly what can be observed from the plot of GW: the transitional growth dispersion falls as $\theta$ increases. However, the steady state value of GW is a hump-shaped function of $\theta$ around its central value, as apparent from equation $(3.33 \mathrm{a}, \mathrm{b})$, where the numerator of equation $(3.33 \mathrm{~b})$ is linear in $\theta$, while the denominator is a quadratic function of $\theta$. 
FIGURE 3.3: Sensitivity Analysis for Variations in $\theta$
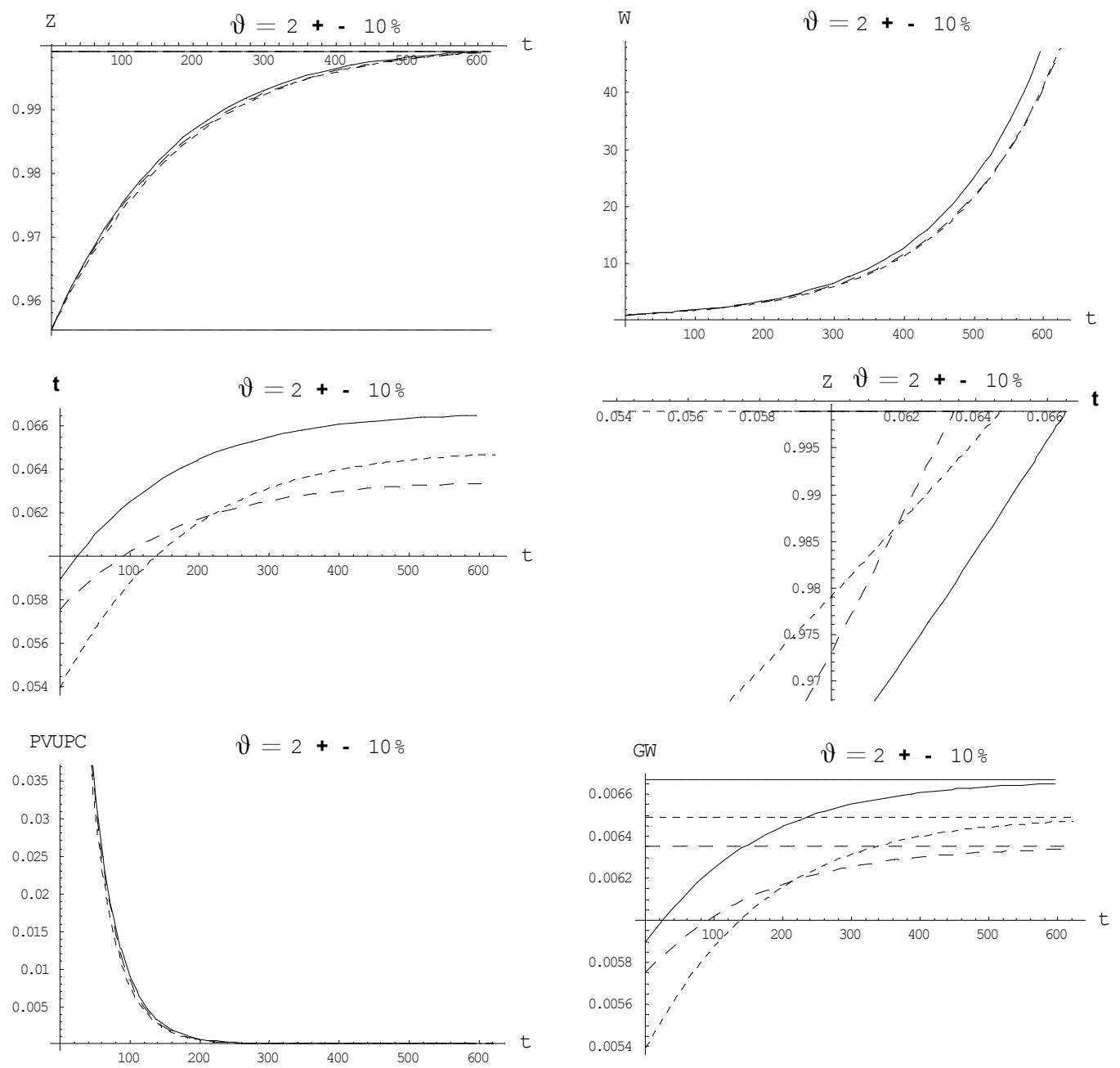
Figure 3.4 shows the results for variations in $\alpha$, the marginal production cost of each variety. As stated before, variations in $\alpha$ only affect the transitional dynamics, hence the levels of W, but not the steady state growth rate GW. Raising $\alpha$ from its low value to its high value leads to a shortening of the transition period on the one hand and to a rise in the transitional growth rate, while leaving the steady state growth rate untouched. Interestingly, higher values of $\alpha$ raise the relative contribution of variety to utility as compared to the contribution of quantity to utility. Hence for high values of $\alpha$, the incentive to increase the number of available varieties through raising connectivity increase as well. Consequently, we find higher transitional growth rates as $\alpha$ increases. Higher values of $\alpha$ also shift down the time path for the present value of utility per capita (PVUPC) as one would expect. This is because higher marginal production cost, would, for a given level of resources reduce (ex-ante) profits, and hence the number of varieties that can be sustained by a community. At the same time, for a given number of varieties, the volume of each variety must go down as well, reducing per capita utility on both accounts (cf. equation (3.26)). Note that, even though the time-paths $\mathrm{Z}(\mathrm{t})$ and $\tau(\mathrm{t})$ are clearly influenced, they are affected to exactly the same extent so that $\mathrm{Z}(\mathrm{t})$ plotted against $\tau(\mathrm{t})$ for all values of $t$ remains exactly where it was. This is easy to understand, since a change in $\alpha$ (or $\beta$ ) would only affect the value of $\mathrm{Z}_{0}$, i.e. the position of the horizontal $\mathrm{Z}=\mathrm{Z}_{0}=1 / \mathrm{B}$ in figure 3.1. Hence, when integrating backward, we would still follow the same trajectory along the stable arm from the steady state and down to the 'old' value for $\mathrm{Z}_{0}$, and then we would have to extend the stable arm from that point up to the 'new' value of $\mathrm{Z}_{0}$ (assuming the latter is below the former). 
FIGURE 3.4: Sensitivity Results for Variations in $\alpha$
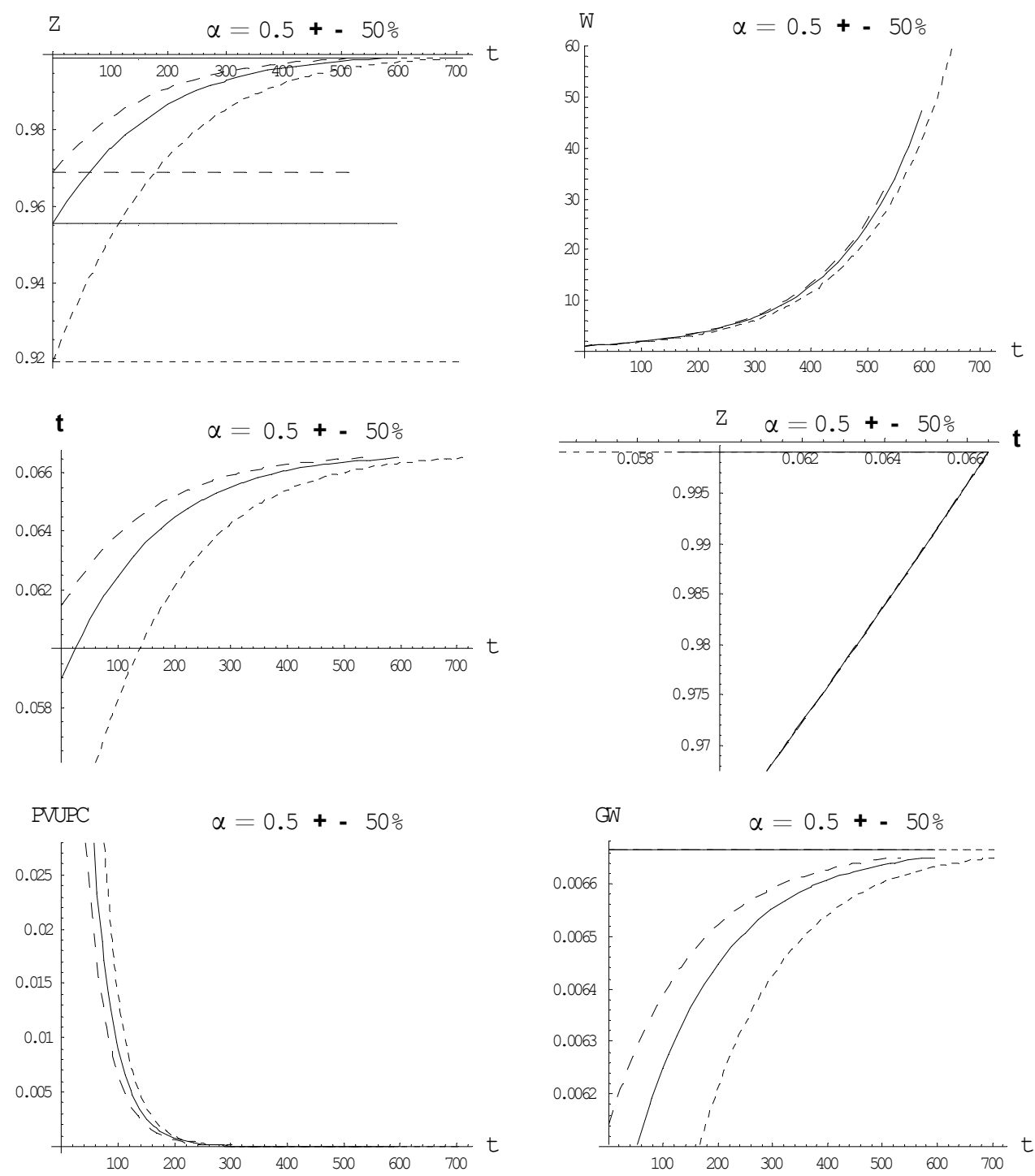
The results are qualitatively similar for variations in $\beta$, i.e. unit transportation cost, in the sense that only transitional dynamics are affected and not the steady state, see figure 3.5. However, now we find that an increasing value of $\beta$ will lead to lower transitional growth and longer transition periods, whereas a rising value in $\alpha$ would tend to have the opposite effect. Still, the effect on utility per head goes in the same direction as for variations in $\alpha$. The reason for the different impacts of variations in $\alpha$ and $\beta$ on utility per capita can be found in equation (3.26). As $\beta$ is associated with transportation costs, its impact on utility per capita becomes bigger the larger the number of connected communities is. Hence if $\beta$ rises, the direct impact on per capita utility will be negative, but that impact can be mitigated to some extent by reducing the rate at which $\mathrm{W}$ grows. 
FIGURE 3.5: Sensitivity Results for Variations in $\beta$
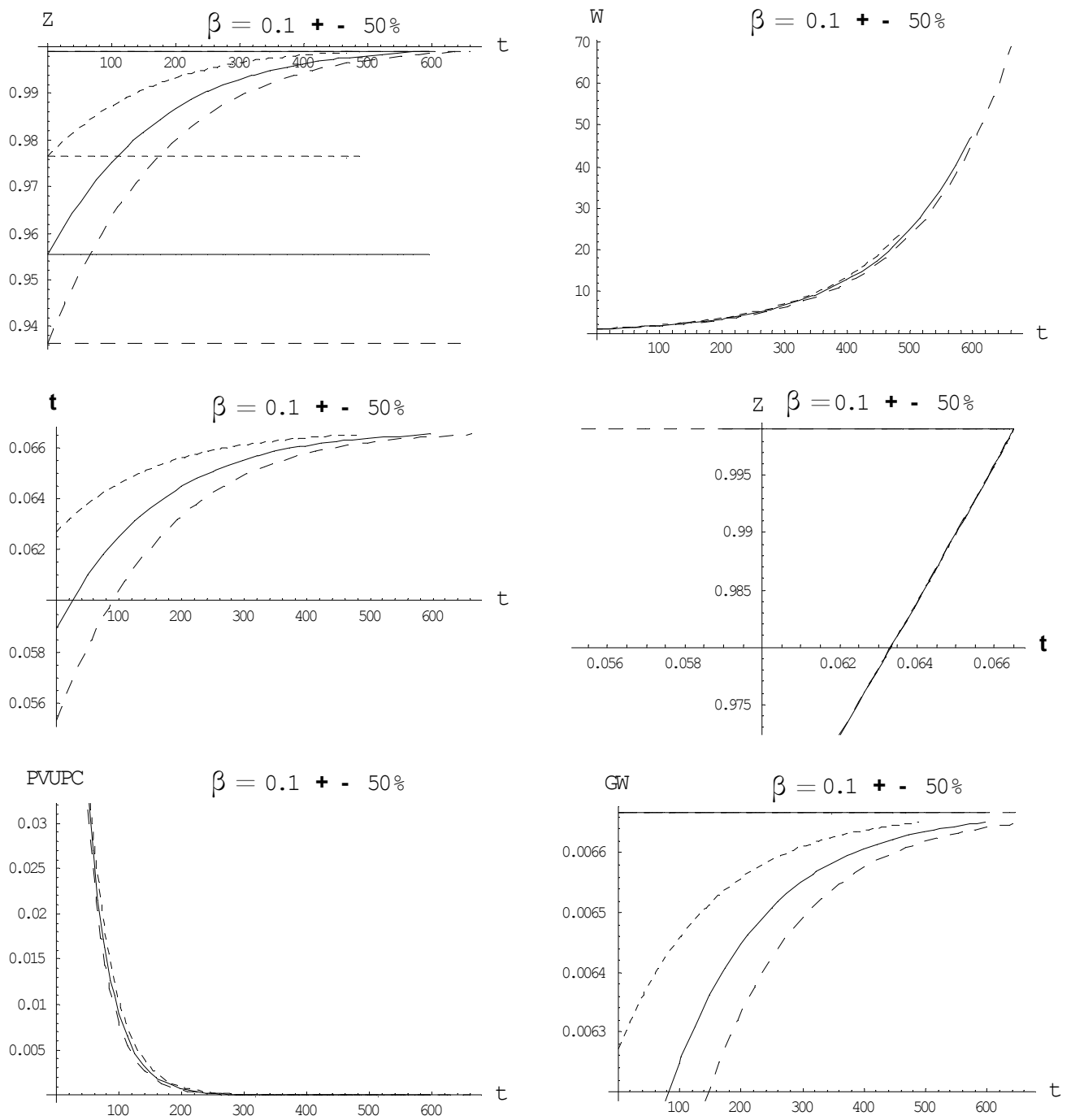
Figure 3.6 shows the results for variations in $\delta$. Note that the (labour) costs of extending the number of connected communities (by building ground stations for communication and transportation infrastructure) depend inversely on $\delta$. Hence low values of $\delta$ imply high costs of extending the number of connected communities, and we consequently see that the duration of the transition period falls as $\delta$ increases. We also see that the growth rate of W, i.e. GW, is positively affected, and quite significantly so, if $\delta$ increases. A rise in $\delta$ implies lower cost for creating new connections and the resources allocated to making those new connections actually go up. This follows from the fact that the steady state values of $\tau$ increase as $\delta$ rises. But even though $\tau$ increases, a rising value of $\delta$ has a positive net effect on the present value of per capita utility. 
FIGURE 3.6: Sensitivity Results for variations in $\delta$
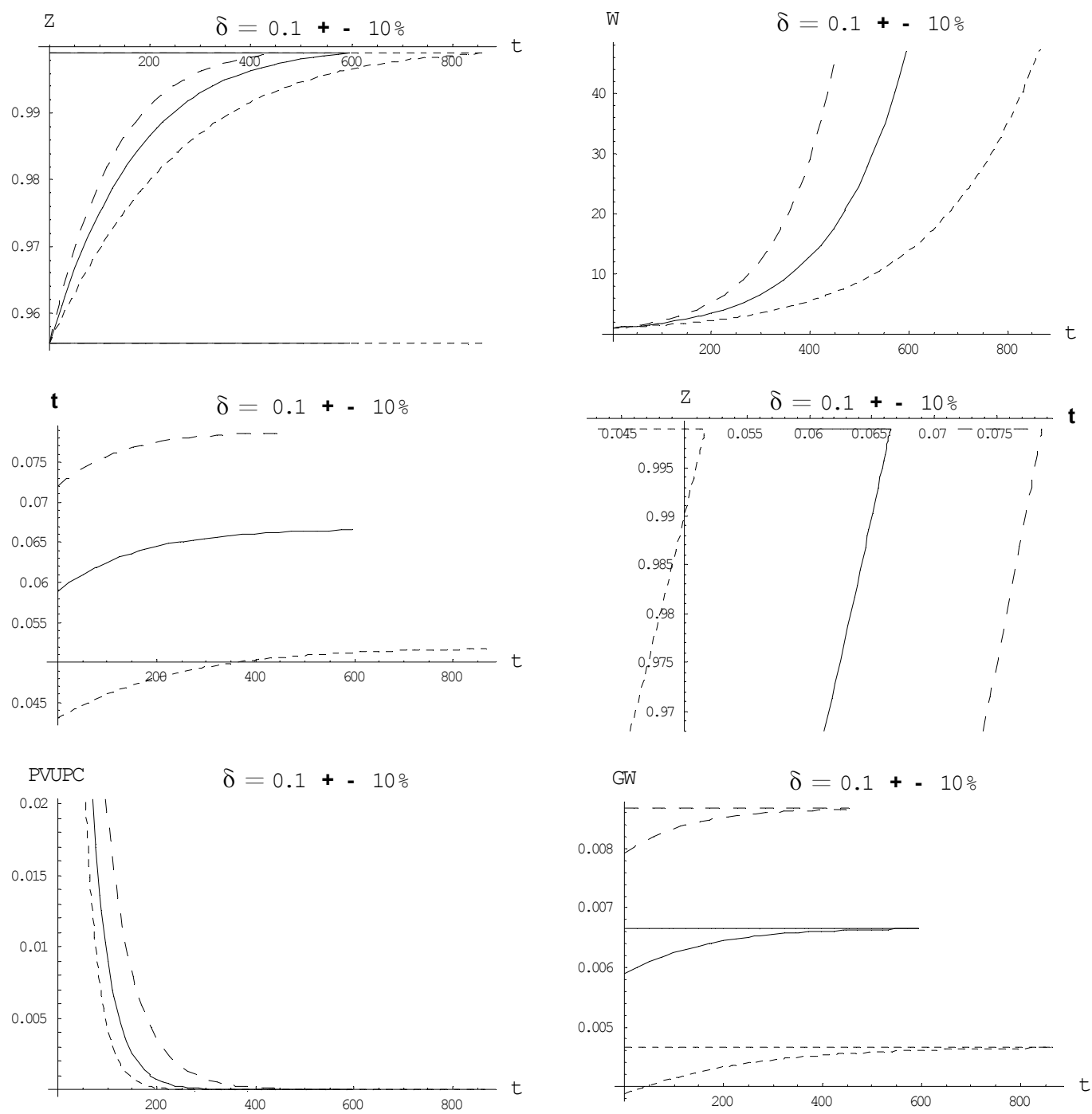
Figure 3.7 shows how the model reacts to variations in the rate of discount $\mu$. Basically, the results are opposite to those of variations in $\delta$, as a rise in $\mu$ would disfavor the execution of activities whose return would be in the future (like indeed extending the number of connected communities). Consequently we find lower growth in $\mathrm{W}$ and longer transitions as $\mu$ rises. As a consequence, the time-path for utility per capita also shifts downward as $\mu$ increases. 
FIGURE 3.7: Sensitivity Results for Variations in $\mu$
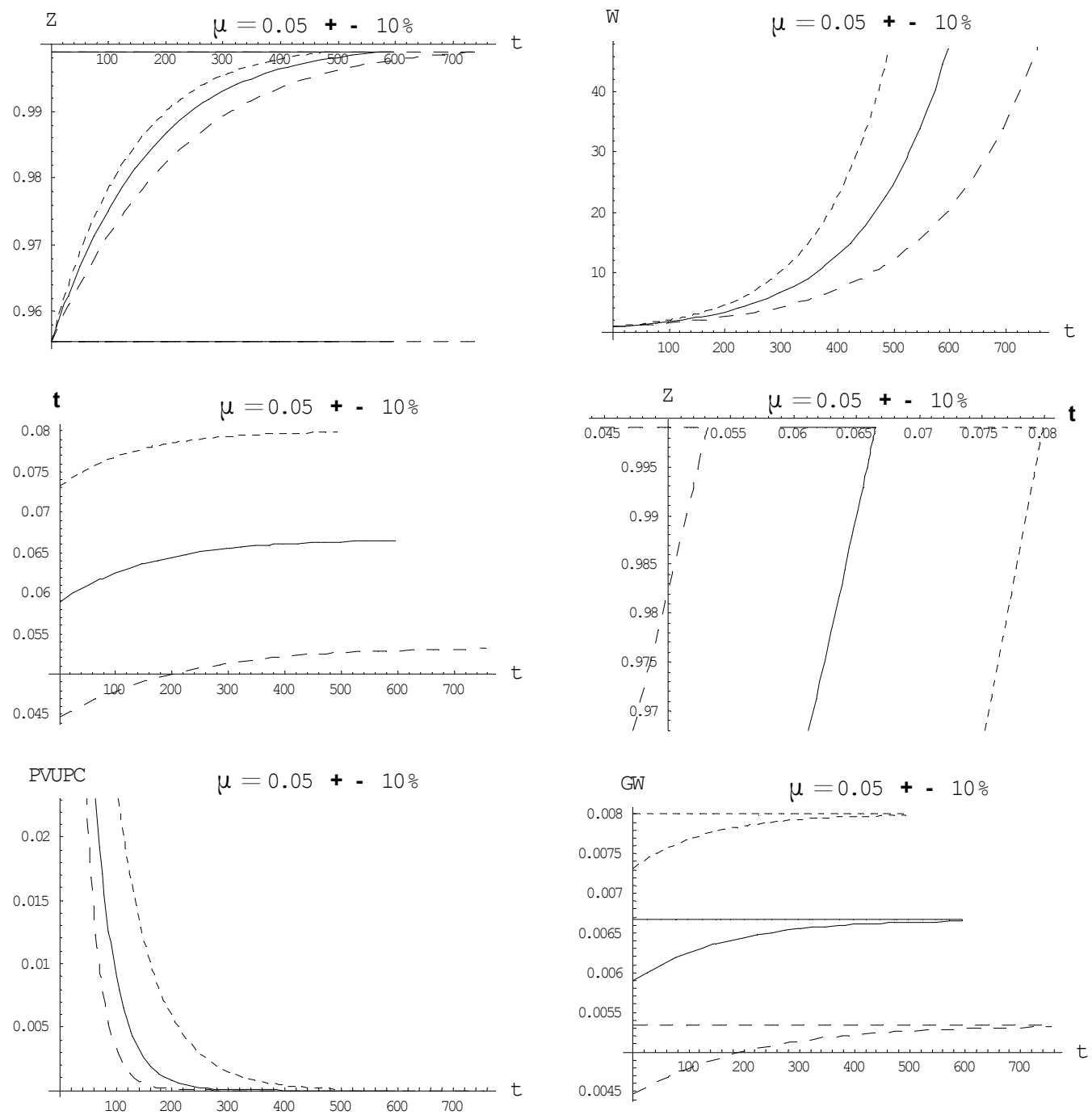
Figure 3.8 shows what happens for variations in the size of the communities $\bar{L}$. Increases in size would allow more varieties to be produced, before profits are squeezed to zero due to free entry. This means that the returns to connecting additional communities go up. Consequently, we observe a rise in both transitional and steady state growth as $\bar{L}$ increases, while the length of the transition period decreases. Because of the increasing returns to making new connections, we see that the resources allocated to doing that also increase for rising values of $\bar{L}$. 
FIGURE 3.8: Sensitivity Analysis for Variations in $\bar{L}$
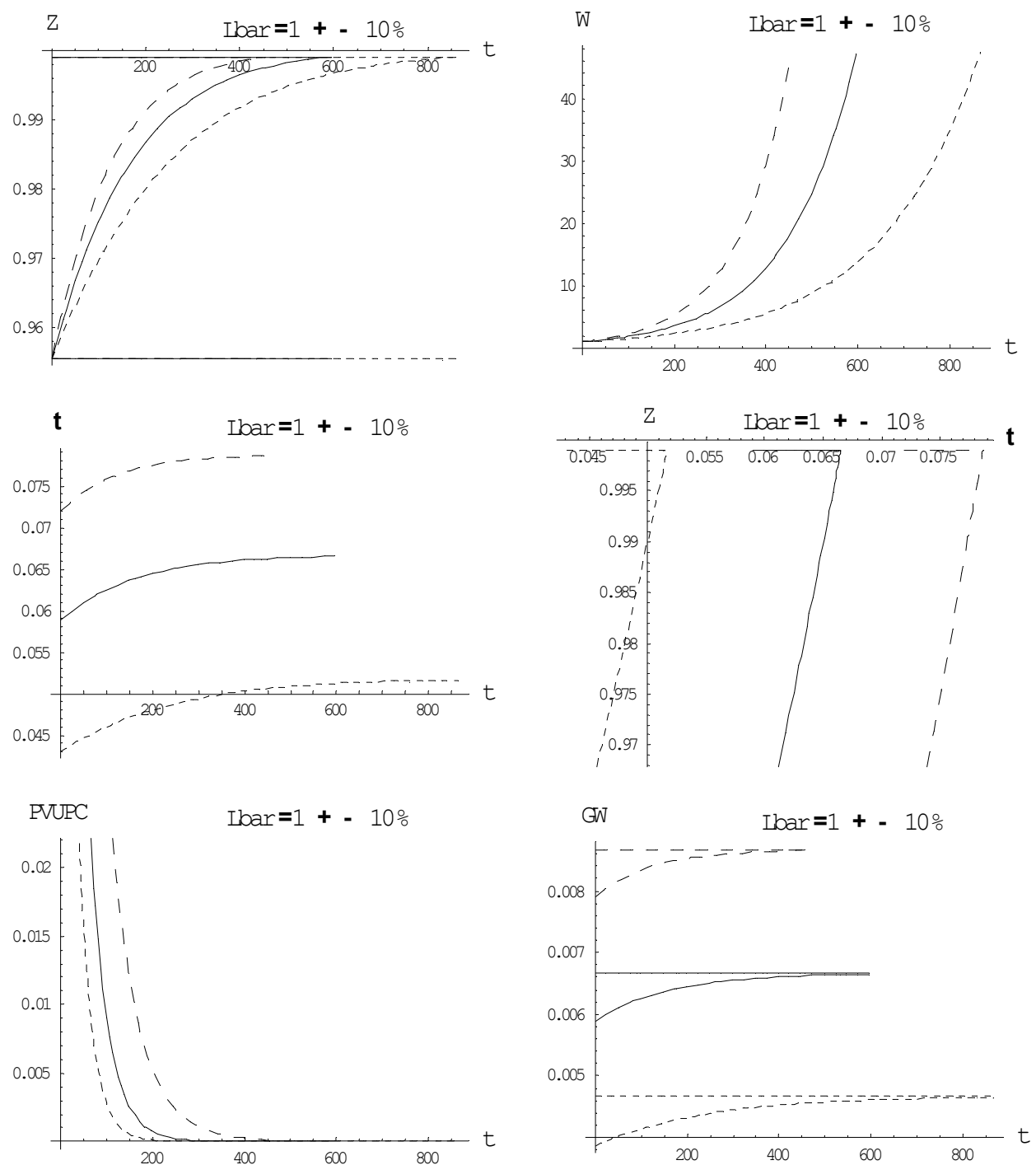
Finally, figure 3.9 shows what happens for variations in the fixed cost per variety $\bar{l}$, virtually nothing. As $\bar{l}$ only enters the per capita utility function in a multiplicative fashion, it follows that only the level of utility per capita will be affected, but not the way in which the relative contribution of $\mathrm{W}$ to per capita utility changes over time. Consequently, there will be no reason to change anything in the time-path for $\mathrm{W}$, and so all plots remain the same except for the per capita utility plot. Obviously, per capita utility falls if $\bar{l}$ increases, as each community can now support a lower number of varieties. 
FIGURE 3.9: Sensitivity results for Variations in $\bar{l}$
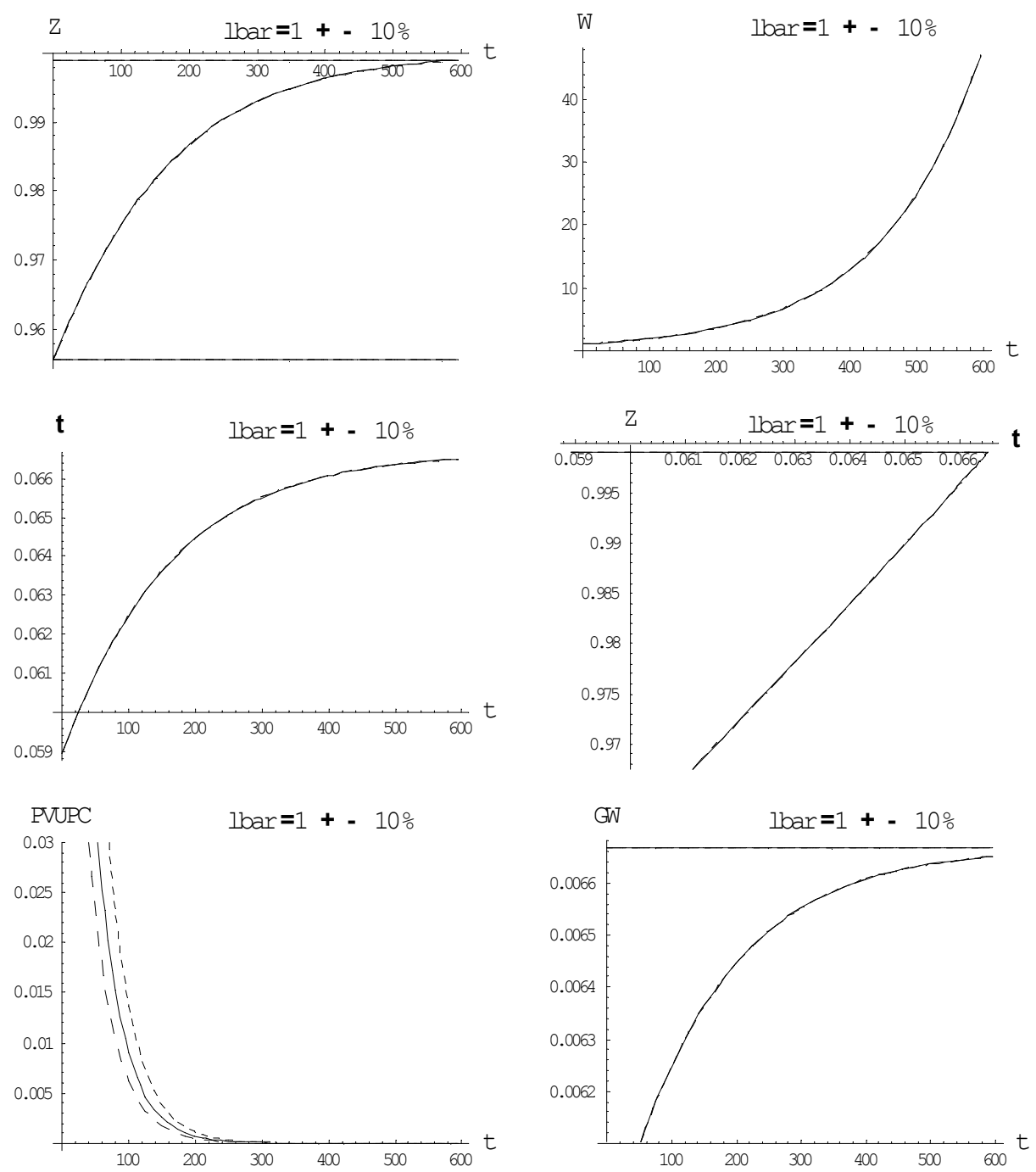


\subsection{Concluding Remarks}

In the previous sections we have shown that reductions in production costs but also in transport and communication costs have an immediate effect on the rate at which communities would want to become connected and trade with each other. We have shown that increasing production costs lead to faster transitions, while increasing transportation costs lengthen the transition towards the steady state. Both types of costs do not affect the steady state as such, but since the transition period is quite long, their different impact on transitional growth points at transportation and communication cost reductions in particular as a suitable vehicle to speed up growth.

The largest effect in growth-terms, however, can be observed for the case of reductions in the cost of making new connections. That has a relatively significant impact on both the steady state growth rate AND on transitional growth, while reducing the transitional period equally significantly. The same goes, mutatis mutandis, for changes in the rate of discount. Communities with lower rates of discount would have a higher incentive to connect/become integrated with 'the rest of the world'. This also goes the other way around; if the rate of discount in some community is low, the rest of the world has a relatively strong incentive to become connected to that community, since that community would be more willing to share in the common burden of maintaining and extending current and future connections.

We also showed that the population size of the communities (to be) connected strongly determines both the steady state growth rate and the transitional growth rates of all connected communities. The larger the communities are, the stronger growth will be, pointing towards a positive scale effect that arises out of the nature of the communication and transportation network itself, rather than out of a 'knife-edge' assumption about the functional form of the production function underlying the process of connecting communities. To some extent then, this scale-effect can be considered to be more 'real' than the one present in Romer (1990) or Aghion and Howitt (1992), for example. But even in the presence of a positive scale-effect, communities that are lagging behind in educational terms, would probably not be able to produce as many varieties as other communities of similar size but with a higher average level of education would be able to do. This would severely limit the benefits for other communities from being connected with low level education communities. It follows that to make such connections worthwhile for every community concerned, differences in educational levels shouldn't be too large. This again points to education as an important determinant of the growth performance of an economy, through its impact not just on the quality of labor per se (Lucas (1988) model), but on the size of the sub-spectrum of varieties that could be produced depending on average levels of educational attainment. 


\subsection{Summary}

We have shown in a very general model setup that trade under a publicly owned overarching satellite communication infrastructure is beneficial to growth and increases utility per capita of trading communities. In the next chapters we will investigate empirically the effects of connectivity on trade and income. In Chapter Five we consider the effect of cost of connectivity on countries and in Chapter Six we look at the effect of access to connectivity on regions within a country, municipalities of South Africa. We also investigate how exactly satellite connectivity is used in practice and how it affects cost of services and trade.

The commonly shared space segment of the satellite in the model is an important aspect of our approach as in practice this infrastructure is provided by international private businesses with a direct interest in maximizing profit more than social welfare benefits. The discussion in Chapter Four and the analysis in Chapter Five suggest that this arrangement has led to high cost of telecommunication services in Africa with negative effects on the cost of trading between countries on the continent. 



\section{4}

\section{Satellites and Communication Costs in sub-Saharan Africa}

\subsection{Introduction}

It was theoretically shown in Chapter three that growth can benefit from trade between connected regions. The model developed there assumed a virtual ubiquitous satellite public infrastructure where the trading communities only needed to acquire ground equipment in order to be connected to an existing pool of trading communities. The overarching satellite infrastructure was provided by the government, which can provide services at marginal cost while seeking to maximize welfare. This is not the case in reality where the satellite infrastructure is privately owned. This is a major difference because the private owners of the satellite infrastructure will naturally seek to maximize profits. In an oligopolistic market such as the satellite industry in Africa is, this leads to market failure and exorbitant charges for satellite capacity.

In the model it was demonstrated that transport and communication costs have a direct effect on the rate at which communities connect and trade with each other. Also in the model, the use of a shared space segment drastically reduced the cost of adding new users to the network. It is our view that approximating the organization of communication infrastructure used in the model will induce these positive effects in African economies. A publicly owned satellite infrastructure, subsidized by a group of cooperating African countries providing cheaper than usual broadband connectivity to private firms and individuals would be the real life equivalent of the model setup. Trading communities become any recognized group of human settlement, country in Chapter Five and municipality in Chapter Six.

In this chapter, we first take stock of the technological possibilities unfolding in SSA and compare efficiencies with cost where possible. The rivalry that is playing out in the international connectivity sector between satellites and undersea fiber optic cable is given special attention.

Various types of ICT services are discussed in light of their dependence on satellite infrastructure or lack of it. More importantly the cost of these services and the possible effects that these costs could have on trade in the region are emphasized. The services of interest are therefore those that would have an impact on trade. These are international calling services and internet connectivity. These services are directly linked to efforts that people make to gain information about products in other countries, disseminate 
FIGURE 4.1: Communication Costs Trade and Growth

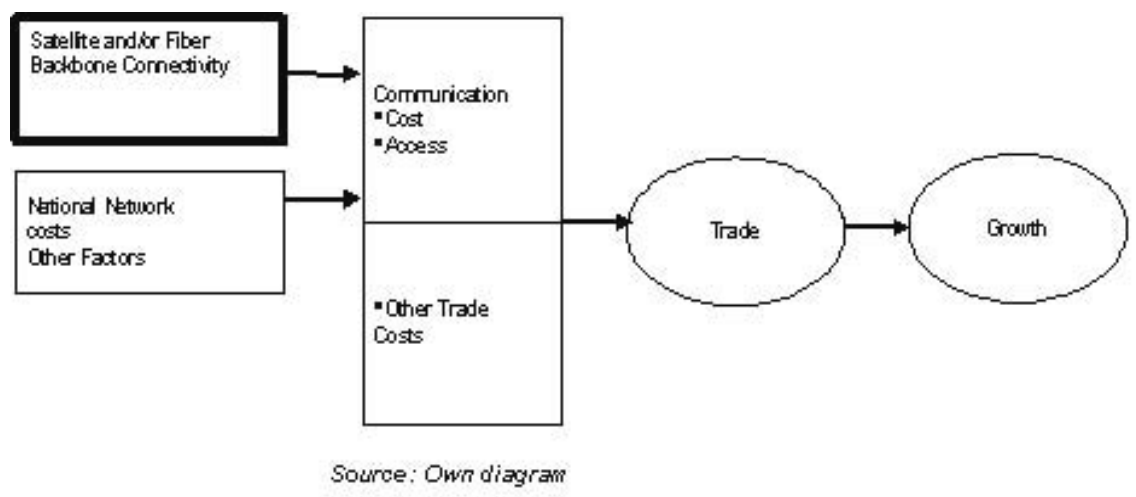

information about their own products and make connections with traders in other parts of the world. Television and radio broadcasting also have an effect on international trade through advertising and exposure to new products and services available in other countries. These are also discussed.

We want to find out how international connectivity over satellite affects international trade through its effect on international communications in SSA. It is proposed that international gateways dominated by satellite connectivity, affect the cost of communications. The potential of a common satellite infrastructure is to lower communication costs and provide instantaneous access to a very wide geographical area. However, in practice the private ownership of satellites has resulted in high communications costs. These communication costs in turn have a negative effect on overall cost of trade in the region, which negatively affect international trade in the region. International trade in turn has an important link to economic growth in SSA. This link is dealt with comprehensively in section 6.6 of this chapter. If trade is negatively affected by high communication costs the eventual impact of communication costs on growth of the region will also be negative. See figure 4.1 .

Our objective is not to determine causality per se between communication costs and volume of trade but to see whether the effect of communication costs is significant and whether it varies significantly between different country groupings. As obvious as the case may seem, it is important to make this distinction as we will be isolating and bringing to the fore one of the main factors affecting cost of international connectivity in SSA, foreign owned satellite and fiber gateways. Almost all the satellites that African service providers connect to are foreign-owned satellites. See Table4.1.

We first describe the history of international telecommunications and how it has affected the development of telecommunications infrastructure 
in Africa. A discussion of international settlement rates and their relation to telecommunications pricing practices on the continent follows. Various ICT services and their relation to satellite technology are then described concentrating on services that have a direct impact on international trade as explained above. Where possible, estimates of the cost of the services and how it is affected by satellite connectivity are given. The importance, or lack, of the satellite connection in each case is emphasized and alternative technologies are discussed wherever possible. We then summarize the potential benefits of satellite connectivity and the actual effects they have had on SSA communication costs. This leads us to the connection between communication costs and trade and the development of our empirical model in Chapter 5.

\subsection{History of Telecommunications in Africa}

The history of international communications is both a long one and a short one. Long, dating as far back as the history of the written word and coded script that was physically transported form one location to another by whatever means of transport dominated the day. From the use of trained pigeons to chariots across deserts to horseback all the way to modern air transport, moving messages from one place to another was once a physical activity that involved the transportation of a coded message from point $\mathrm{A}$ to point B.

With many inventors working on ways to transmit messages using coded electrical pulses over electrical mediums came the discovery of the telephone in the early 1800s, which together with the development of railways in the developed world led to the advent of the telegraph in 1845. Most of this activity was however cantered in the developed northern lands of Europe and North America. At this time in Africa the concept of countries as we know them today was almost non-existent. Communities were organized in tribes and kingdoms which needless to say had very vague boundaries.

Long distance communication was accomplished by the use of both audio and visual signals notably drums and smoke signals in Africa. Countries and states mushroomed all over Africa with the discovery of the African coast by European and American explorers and the colonizers brought with them the telegraph technologies developed in the mid-1800s mainly because they had to keep in touch with their lands of origin. Thus the combination of long distance ships to and from the Americas and Europe to the west, east and south coast of Africa and the internal development of the railway system in the new Africa brought electrical telecommunications to the continent.

Meanwhile long distance communication by telephone and telegraph in the northern lands was making fast progress with attempts to transmit electrical messages across the great ocean without the use of ships. After 
many failed attempts, the first transatlantic telegraph cable was laid and operated between North America and Europe on 27th July 1866. It took until 1879 for SSA to get connected to telegraph with the laying of the first telegraph cable from Aden in Yemen to Durban in South Africa. The west coast of Africa remained unconnected until 1885.

At the same time inventors were busy experimenting with wireless telegraph, radio and television technologies.

In 1876 Alexander Graham bell invented the telephone as we know it today and from then on developments in long distance communications took great leaps forward led by the laying of the first transatlantic telephone cable - the TAT-1 in 1956 from Scotland to Nova Scotia in Canada. Instant telephonic conversations were now possible across the Atlantic, but not yet on the African continent.

National telecommunications networks were built in the colonies on the continent, piggy backing on prior developments in long distance telephony in the North. These networks were important to sustain the heavy investments in settler mining and farming activities that had taken hold and continued to grow across the colonies in Africa.

The spin off for African telecommunications was that the basic local telecommunications infrastructure in the major cities on the continent was laid. International telephony however was still in its infancy worldwide. The successful laying and operation of TAT-1 laid the foundation for a booming industry in transoceanic telephone cables in the North, but not a single one to the African coastline until May 181968 when a telephone submarine cable was laid across the Mediterranean between Perpignan, France, and Tetuan on the northern tip of Morroco. This was the first direct dial facility between Africa and Europe.

It was the successful launch and operation of the first commercial communication satellite in 1965 that eventually brought mass international telephony to SSA.

\subsubsection{Enter Satellites}

The scene for the development of the satellite industry was set by Arthur C. Clarke in 1945 when he described the Geostationary orbit in his paper "Extra- Terrestrial Relays" (Clarke, 1945). This spurred a number of research projects on both fronts of the cold war mainly for "reconnaissance" purposes. The Russians were the first to launch an experimental satellite, Sputnik, in 1957, exactly a year after the first telephone cable was laid between North America and Europe.

By 1962 prolific research by NASA, the department of Defence and telecommunications powerhouse AT\&T eventually moved the US Senate to pass the Communications satellite Act of 1962 as a result of which Communication Satellite Corporation (COMSAT) was formed. By 1964 experimental and trial satellite missions TELSTAR, RELAY and SYNCOM 
had been launched and retired successfully. In 1965 COMSAT launched EARLY BIRD, the first commercial communications satellite. This was the beginning of the era of satellite communications. What followed was an unprecedented growth of satellite communications the world over, complementing the national copper and microwave national networks that had mushroomed all over the world including Africa. The International Satellite Organization INTELSAT, an offshoot of the COMSAT went on to launch a fleet of satellites that dominated the fixed satellite business and provided television, telephone, and later internet services to the whole of Africa. INTELSAT operated as a consortium of member countries who contributed according to their needs for satellite capacity. It eventually developed monopolistic tendencies and often imposed restrictions to new entrants into the industry supported by the US Federal Communications Commission (FCC).

A billion dollar industry had been spawned and calls for an even playing field could no longer be ignored. INTELSAT was privatized, but retained its dominant position in Africa to such an extent that to this day most SSA countries feed off and channel their services through INTELSAT satellites (see table 4.1). 


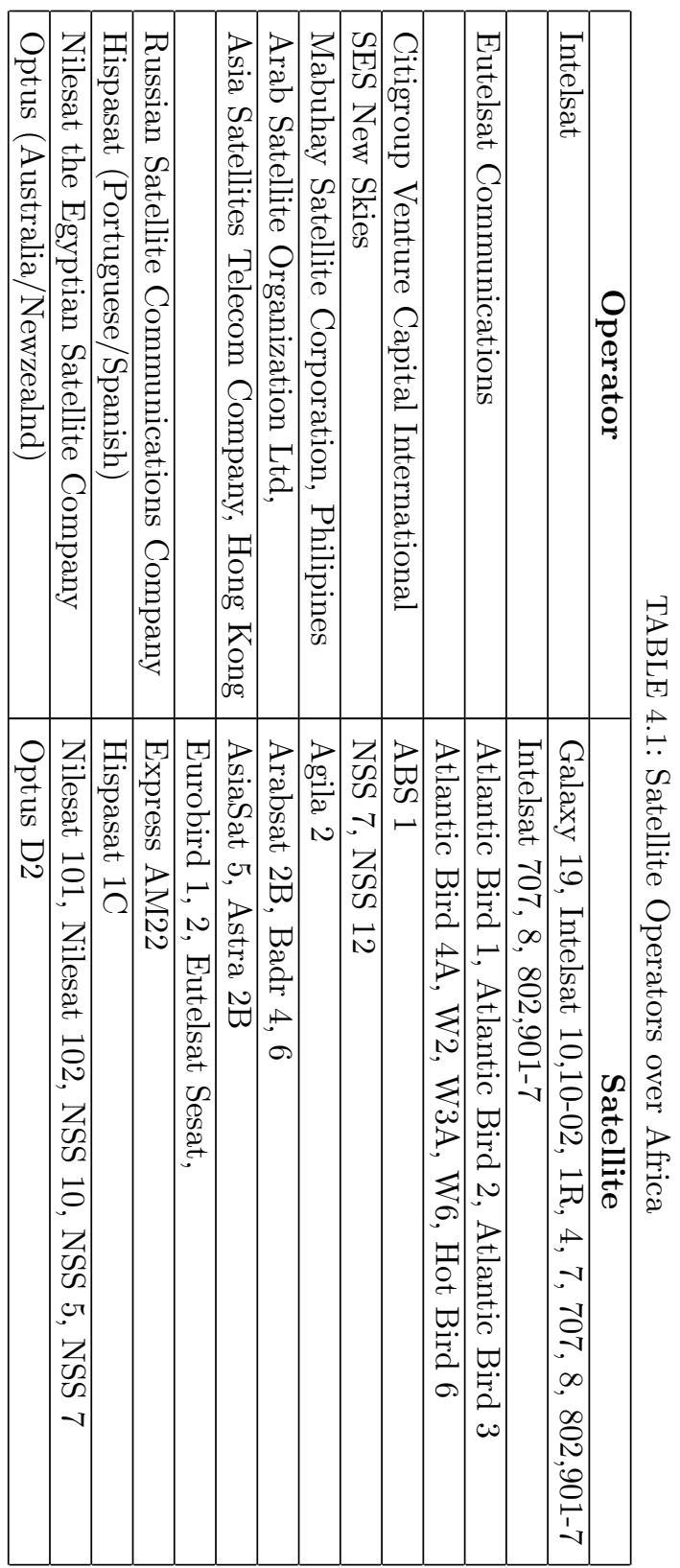




\subsubsection{Optical Fibre versus Satellite}

In 1988 AT\&T Corporation. completed the world's first transatlantic fiberoptic cable, TAT-8, which stretched more than 3,500 kilometers from New Jersey to Britain. The new fiber cable could carry close to 40,000 simultaneous phone conversations, five times more than the capacity of the best undersea copper cables at that time and comparable to all the trans-Atlantic voice traffic then handled by satellites.

Next up was a 17500 kilometer long fiber connection, Flag Telecom cable connecting Europe with North Africa, the Middle East, Southeast Asia and Japan in 1997.

Fibre optic had arrived as a better, faster, more efficient replacement for undersea copper cables but more importantly the amount of traffic it could carry easily competed and would soon outstrip the capacity of most modern satellite fleets at the time. Undersea fibre cable has since established itself as a viable competitor to satellite connectivity both in terms of capacity

and cost. It now has faster connectivity speeds than satellite because of the use of light instead of microwave signals as the transmission medium. It also does not suffer from signal losses and grey outs due to bad weather that satellites usually experience. But these advantages are dampened by the delicate nature of the fibre cable medium itself and the fact that it still has to be physically extended to an end user if it has to be used as the last mile solution. This is not a feasible solution for most African countries. This is the important advantage of satellite over fibre, the universal reach of the satellite connection. An end user does not need to be physically connected to the provider to get a signal, but receives her signal over the airwaves, wherever she may be under the satellite footprint. Also, the possibility of loss of service due to vandalism or accidental damage to infrastructure is higher for fibre cable than for satellite. For these reasons fibre cable is more suited for the provision of international connectivity as a backbone cable infrastructure than a last mile solution, while satellite can achieve both functions easily.

In SSA the first available optical fibre backbone was the SAT3/WASC fibre optic cable that was commissioned for commercial operation in 2002 on the west coast of Africa and runs from Sesimbra in Portugal through Dakar, in Senegal, all the way to Cape Town in South Africa(figure 4.2).

This was supposed to provide a potentially cheaper alternative to satellite connectivity for countries on the African west coast, but as Osiakwan reports, the presence of this fibre cable has not led to lower cost of bandwidth for countries on the west of Africa. The SAT3 fiber cable has had a negligible impact on improving broadband access in Ghana or lowering prices such that most customers continue to rely on satellite connectivity (Osiakwan, 2008). So the combination of liberalization of the satellite industry and the presence of the SAT3 fibre optic cable have not had the desired effect of lowering international voice and broadband costs and in- 
FIGURE 4.2: Landing points of the Africa section of SAT3/WASC
[1] Dakar, Senegal
[2] Abidjan, Côte d'lvoire
[3] Accra, Ghana
[4] Cotonou, Benin
[5] Lagos, Nigeria
[6] Douala, Cameroon
[7] Libreville, Gabon
[8] Cacuaco, Angola
[9] Melkbosstrand, South Africa

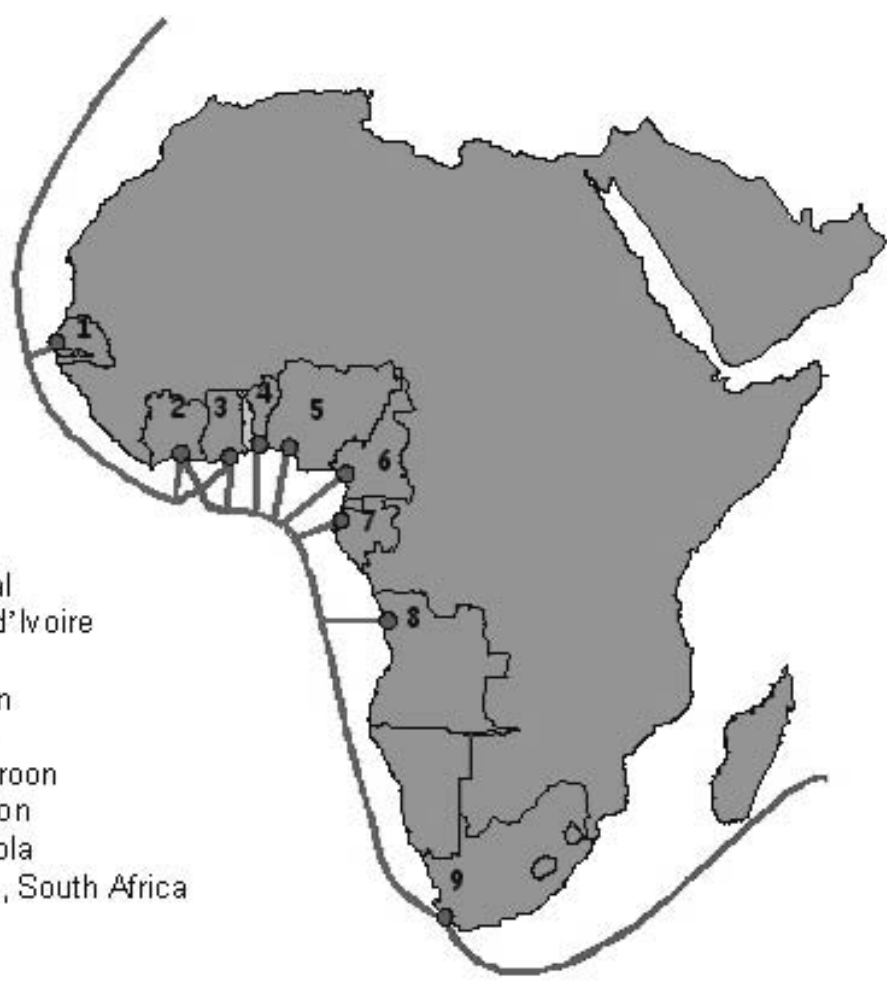

Source: Jagun, 2008 
creasing access on the west coast of Africa. This is mainly due to the fact that although the fibre cable is operated by a consortium of countries, the countries with landing ports on the coast have absolute control over who has access to the cable and at what cost. They are practically able to collect monopolistic rents for access. The charges collected for both satellite and fibre cable access are not related to the cost of providing the service as technology has advanced so much over the past two decades that the cost of providing these services has been falling steadily. This was first demonstrated in the ITU report Direction of Traffic using cost per voice path data up to 1995. But more recently in his book " Free: The future of a Radical Price" Chris Anderson discusses how the triple play of falling computer processor, storage and bandwidth cost will eventually drive the cost of providing bandwidth services to zero:

" Never in the course of human history have the primary inputs to an industrial economy fallen in price so fast and for so long...........In a world where prices always seem to go up, the cost of anything built on these three technologies will always go down. And keep going down until it is as close to zero as possible" (Anderson, 2009)

Namibia is a good example of a coastal country that does not have access to the SAT3/WASC cable. In spite of being a signatory to the SAT3 agreement, Namibia did not contribute enough to have a landing bay of the cable on its coast. So it is compelled to rent capacity off the Angolan or the South African facility. The charge for this access is however even higher than satellite capacity so Namibia continues to use satellite access instead of the supposedly cheaper fibre optic backbone. Another country with this problem is Lesotho in South Africa, which even has overland fibre cable connecting it to the fibre landing bay in Cape Town but still finds it cheaper to use satellite, because South Africa has monopoly control over its fibre landing bay at Cape Town. ${ }^{1}$

An Association for Progressive Communications (APC) report (Jagun, 2008) gives a breakdown of satellite capacity wholesale prices compared to optic fiber cable prices in Africa and shows that in effect as of 2008, satellite connectivity costs were even lower than fiber connectivity in the nine African countries that have access to the SAT3 Fiber cable on the West African coast. This is an anomaly, as one of the reasons for the construction of the fiber cable was to reduce dependence on the expensive satellites. The anomaly arises because the cable is under the control of the incumbent telecommunications provider in each of the member countries and this provider is a government controlled monopoly.

\footnotetext{
${ }^{1}$ http://fibreforafrica.net/main.shtml? $\mathrm{x}=4075283 \&$ als[MYALIAS6] $=$ What happens to landlocked countries?\&als[select $]=4051582$
} 
This situation is in the process of changing rapidly as more and more fibre optic projects come alive in Africa. There are currently many fibre optic projects underway in Africa ${ }^{2}$ intended to mitigate the lack of competition and introduce alternatives to satellite connectivity for African service providers (ibid). The following are some of the projects underway already (See figure 4.3 for a complete overview of these projects and their estimated time of completion)

1. Sea Communication (SEACOM) fiber project to cover South, East and North Africa was duly launched and commissioned in Mombasa, Kenya in July 2009. However the launch of SEACOM was already politicized by the launch a month earlier of TEAMS 9 (point 5), in which the Kenyan government apparently has an interest.

2. East Africa Submarine System (EASSy) fiber project 2010 to cover East and Southern Africa is due to be completed in 2011.

3. GLO-1 undersea cable, will be built by Globacom, the largest mobile operator in Nigeria, Ghana and Benin. This cable will connect Lagos in Nigeria directly to London. The special aspect of this cable is that it is fully owned by one private company unlike the other projects that are owned by consortia of companies or countries.

4. MainOne fiber project from Portugal to Nigeria and Ghana where they have a license and landing rights. It is also planned to go down south, providing competition to SAT3.

5. The TEAMS fiber project was commissioned on June 242009 and connects Mombasa in Kenya directly to The United Arab Emirates.

If all these projects succeed it will mean that, together with the SAT3/WASC and the North African fibre network, Africa will be surrounded by high speed fibre cable, which theoretically should lead to competition in the provision of wholesale broadband and normalization of the pricing structures. It should also lead to less dependence on satellite capacity and more and cheaper access to high speed broadband and international voice services. Unfortunately these effects may be more pronounced in the corporate world as the end consumer of services may still be faced with monopoly pricing by local service providers. Also the service providers may be locked in to long-term contracts with their current satellite providers and until they relinquish or terminate these, they may not be able to tap into cheaper broadband from the undersea cable, if indeed it becomes cheaper.

The launching of the SEACOM cable on the east coast was much appreciated and welcomed by both industry players and consumers continent wide, but it remains to be seen whether their operations will bring down consumer prices or whether they will also be drawn into predatory pricing practices like the SAT3/WASC cable on the west coast. There is already debate on how long and what it will take to deliver this bandwidth from

\footnotetext{
${ }^{2}$ http://www.afrispa.org/index.php?option $=$ com_content\&task $=$ view \&id $=61 \& I t e m i d=1$
} 
the coast to the hinterland where the users are.

Alongside these undersea fiber projects are a number of overland inland fiber projects all over the continent. Uganda, Zambia, South Africa, Lesotho, Congo all have inland fiber projects running to the nearest coast. This is a very positive and rosy outlook for the future of international connectivity in Africa. But is it as rosy as it looks? Are there caveats along the undersea fiber cable for Africa to be aware of?

What about satellites? Bringing the cable to the coast is the easy part. The difficult part is getting people connected to the fast bandwidth on the undersea fiber cable. This is where the challenge of these projects still lies and compared to satellites, they do not compete. While instantaneous access is possible for satellite connectivity, extensive inland infrastructure still has to be laid for the fiber cables to have a significant impact on service delivery. It is not practically feasible to 'fiber-up' every inch of the African continent, while it is practically feasible to cover every inch of the continent with satellite footprints. So in a perfect world, with perfect markets satellite connectivity would be a preferred technology over fiber for Africa given the limited inland infrastructure development and maintenance capacity.

But in the normal world, satellite technology is expensive as a technology (both on the technological and the financial fronts) thus the search for viable alternatives continues.

Inland fiber projects are also on the increase and depending on the ownership structure of these fiber networks, their existence may or may not remedy the dire need for cheaper international connectivity as these new foreign owners can still fix prices by forming cartels and colluding on pricing to speed up their returns on investment. Fiber cables have a life span of about 15 to 20 years and depending on maintenance and security, which are important issues for African physical infrastructure investments, this period could be drastically shortened. Vandalism and accidental destruction of buried cables is not a new thing in Africa and this could be a serious drawback for inland fiber projects as it has been for buried copper cables in the past

\subsubsection{Other Competing Technologies}

\section{Mobile Cellular Networks}

This is an over the air technology primarily designed to carry voice signals across limited geographic space between dedicated and specifically designed devices, small enough to be carried around. It was made popular in Africa through the use of the Global Services Mobile (GSM) specification, which has already gone through several upgrades from voice only transmission to digital voice and data transmission. More detail is provided in section 4.4.2. 
FIGURE 4.3: Projected map of Fibre Connectivity in Africa, 2011.

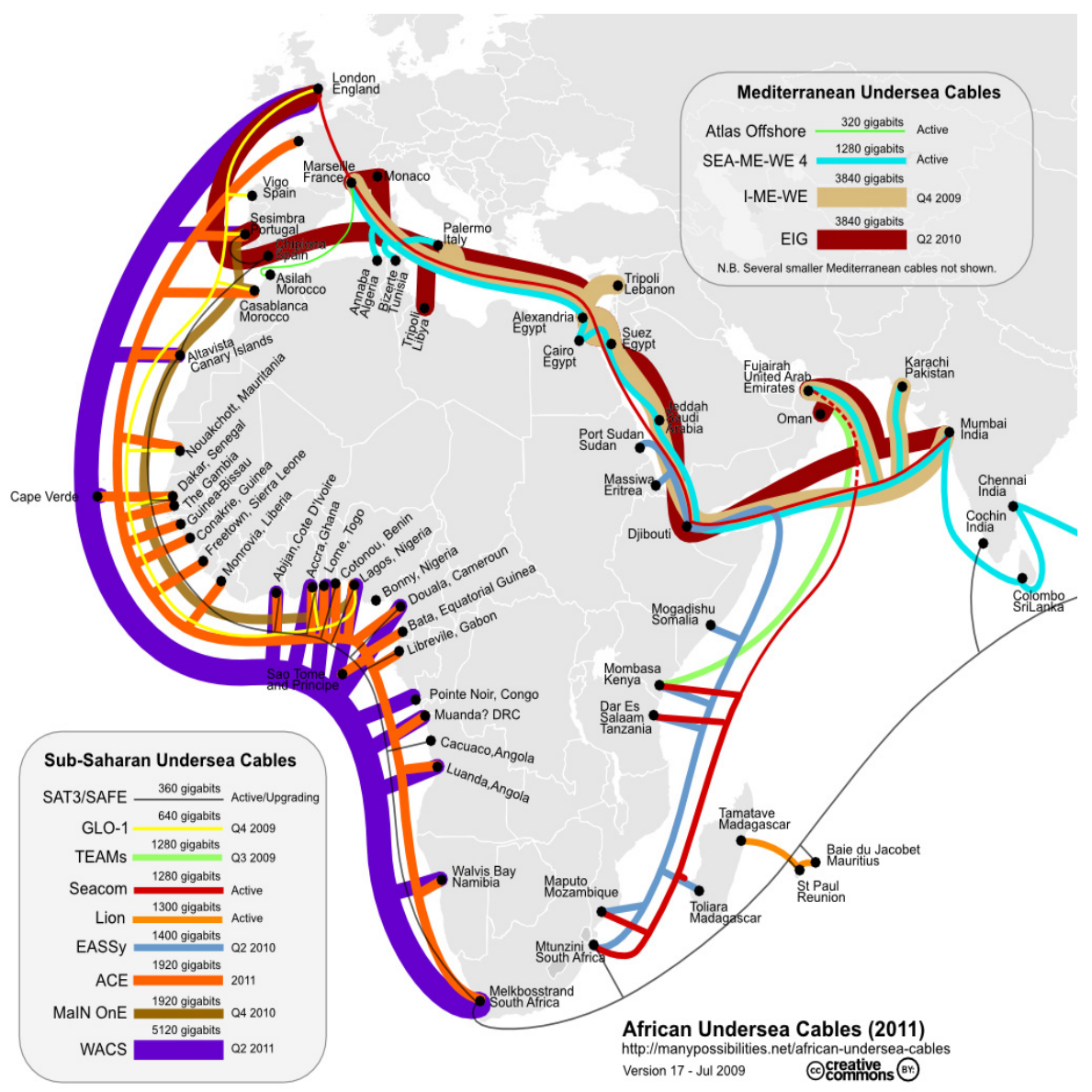


Wifi and Wimax Wireless Technologies

WiFi technology is a Wireless Local Area Network (WLAN) technology specified under IEEE 802.11. It is primarily designed to link up devices within a range of one base transmitting station usually inside a building, which led to it being referred to as technology for carpeted areas. So what Wifi does is really link up devices, receive and distribute services within a building. WiMAX (short for Worldwide Inter-operability for Microwave Access) on the other hand is designed to work over longer distances of 30 kilometers or more within a licensed frequency spectrum of 2 to $11 \mathrm{GHz}$. Base stations are either directly wired to the internet or are linked to other base stations that are linked to the internet either by satellite or optical fiber backbone. This frequency range is able to penetrate through walls to a certain extent and can bend over small obstacles. WiMax is therefore designed to create what are called Wireless Metropolitan Area Networks (WMAN).

The important thing to note about Wimax is that it has a real potential to compete with local loop fixed networks for delivery of the last mile in developing countries. But this technology still needs the satellite or fiber backbone to connect to the international backbone. So for as long as these backbone providers remain expensive, for whatever reason, consumer services off these networks will still be expensive and the over all effect on traffic flow will be negative.

\subsection{International Settlement and Accounting Rates system}

For more than 100 years countries' telecommunication incumbents have used a system called the Accounting Rates System to compensate each other for use of each others' equipment and facilities during international telephone transactions. This is because whenever an international call is placed the destination country has to use its equipment to make the call possible. Countries came up with a system whereby the country with a net sum of outgoing calls compensated the country which terminated the balance of calls. This rate payable was referred to as the accounting rate and the actual payment made to the country which terminated the most calls was referred to as the settlement rate. The settlement rate was usually half of the agreed accounting rate. This is the wholesale cost of providing international call services as opposed to the retail price which is actually charged to the customer making the call, also referred to as the collection rate. See figure 4.4

Developing countries incumbent telecommunications operators were net beneficiaries of this system as there are usually more incoming calls from 
FIGURE 4.4: An Example of Accounting rates Based on US-Colombia Transactions in 1996

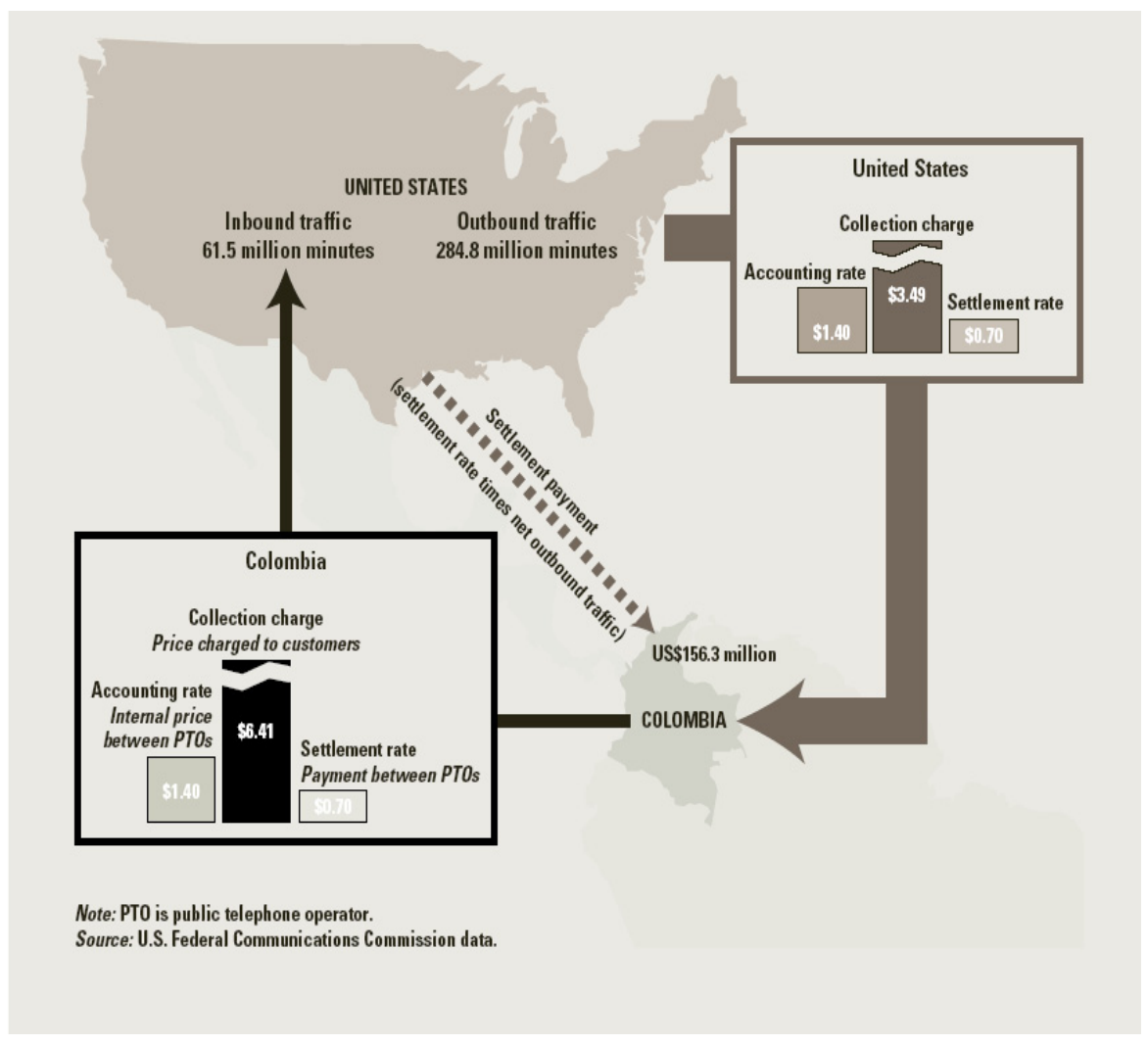

(Source: WB Public Policy for the Private Sector. Note N. 173 1999) 
the developed countries (figure 4.5) However no sub Saharan country featured in the top ten net beneficiaries of the Accounting Rates system, a list dominated by China, India, Latin American North African countries. Liberalization has however brought in more players in the telecommunications market and the accounting rates system is not that straightforward anymore. Most of the Post and Telecommunications operators in Africa started off as monopolies and have been monopolies until recently. Liberalization in the telecommunications sector, which has led to a boom in mobile telephony, has also led to many countries liberalizing their international gateway markets such that it has become easy for foreign operators to bypass the incumbent Telcos facilities and still be able to terminate international calls within a given country. This scenario complicates the international settlement rates system and definitely reduces income for the incumbents. New technologies have also been unrelenting and Voice Over Internet Protocol (VOIP), regulation or no regulation, is a reality in most African countries today. Lighter regulation controlling resale of international services over optical fiber and alternative satellite networks has also opened up the playing field and made it more difficult to track who is supposed to pay who as new entrants pay monthly charges for the bandwidth they need directly to an operator at both ends of a relationship ${ }^{3}$ who may not be the incumbent telecom provider.

${ }^{3}$ WB Public Policy for the Private Sector. Note N. 1731999 


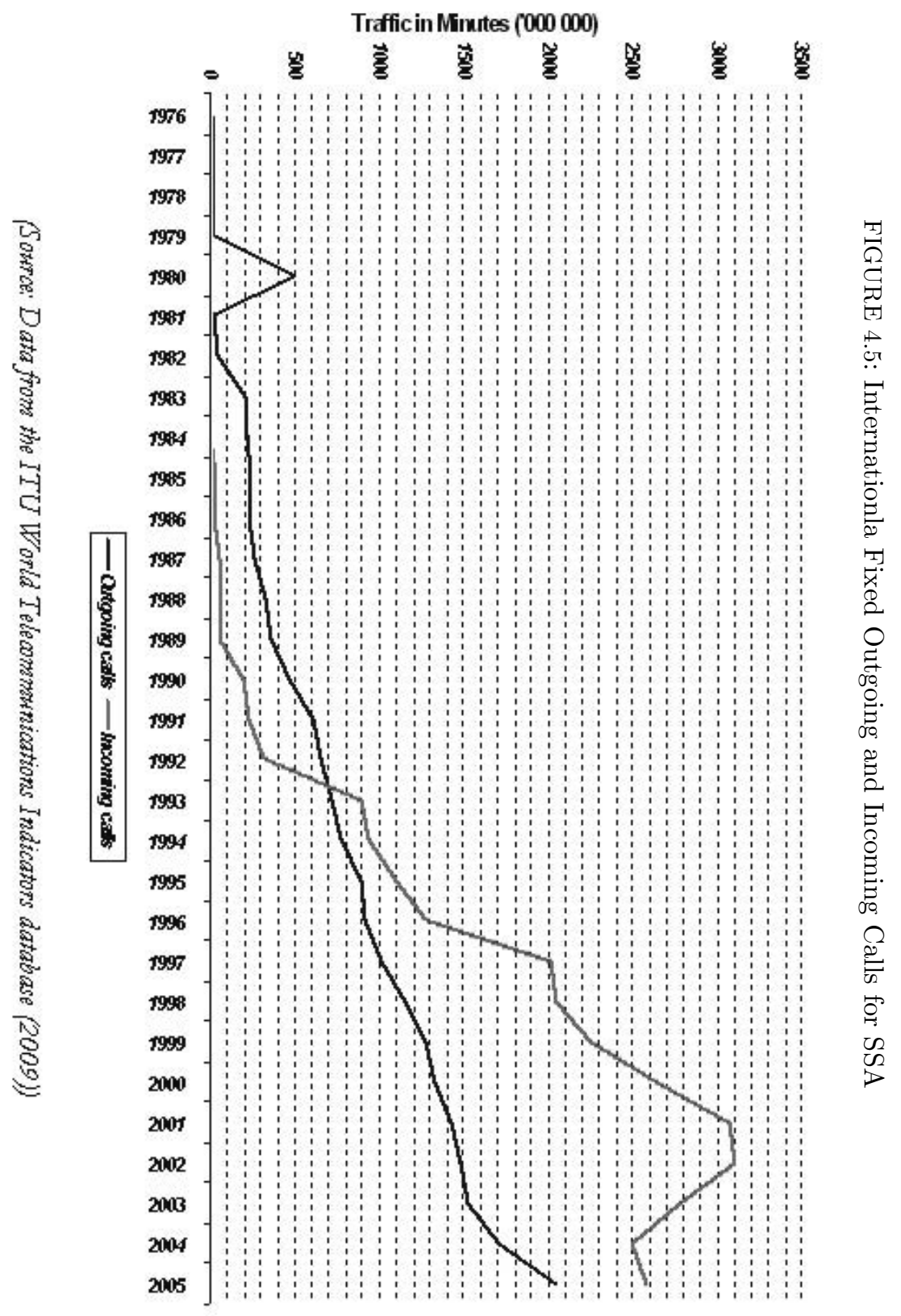


The International telecommunications Union (ITU) set up a dedicated working group whose objective was to reform this system in light of current global market conditions. Through its recommendations and due to pressure from net payers of accounting rates (the developed countries), the Accounting Rates system has since been largely replaced by cross-border interconnection, where Carriers directly negotiate rates to terminate traffic on a long- or short-term basis. These are pure business transactions and are likely to be linked to the true cost of servicing international traffic ${ }^{4}$.

Intuitively an incumbent telecom operator would have an incentive to deliberately inflate his charge for international telephone calls so that less users utilize the service, increasing the chances of being a net receiver instead of net sender at the end of the accounting period. This would bring in much needed foreign exchange from European and American partner PSTNs.

In a global cross sectional study on communication costs and trade flows, Fink, Matoo and Neagu (2002) found that the correlation between two calling prices at each end of a bilateral route was very weak despite the two countries facing the same accounting rate. This result was surprising to them at the time, but does not surprise us in this study. Rather it lends credence to our assertion that these accounting rates did not determine the cost of international calling services for consumers. Other factors are responsible for this. The cost of the international gateway over which international calls are placed is a far more important reason for the high cost of making international calls in sub Saharan Africa. The accounting rate was an administrative bilateral agreement and had no correlation with the cost of providing the service, whereas the cost of the international gateway to the national incumbent and other service providers has a direct effect on how much they charge for the services.

\subsection{ICT Services and satellites in Africa}

\subsubsection{Fixed Telephony}

Fixed telephony has traditionally been provided using terrestrial copper cable networks. The implication of this is that cables are physically run from the exchange points to the delivery site and connected to an enduser terminal. This entails having several exchanges at strategic locations of the service area from where leads are extended, using copper cable, for new users connecting onto the network. This is an expensive exercise and users are required to pay user connection fees to contribute to the cost of material and man hours involved. This infrastructure has traditionally

\footnotetext{
${ }^{4}$ ITU-D Study Group 12004
} 
been run centrally by most African governments under the Postal Services and Telecommunications Services Networks (PSTNs). 4.6 summarizes how most fixed telephone services are organized. 


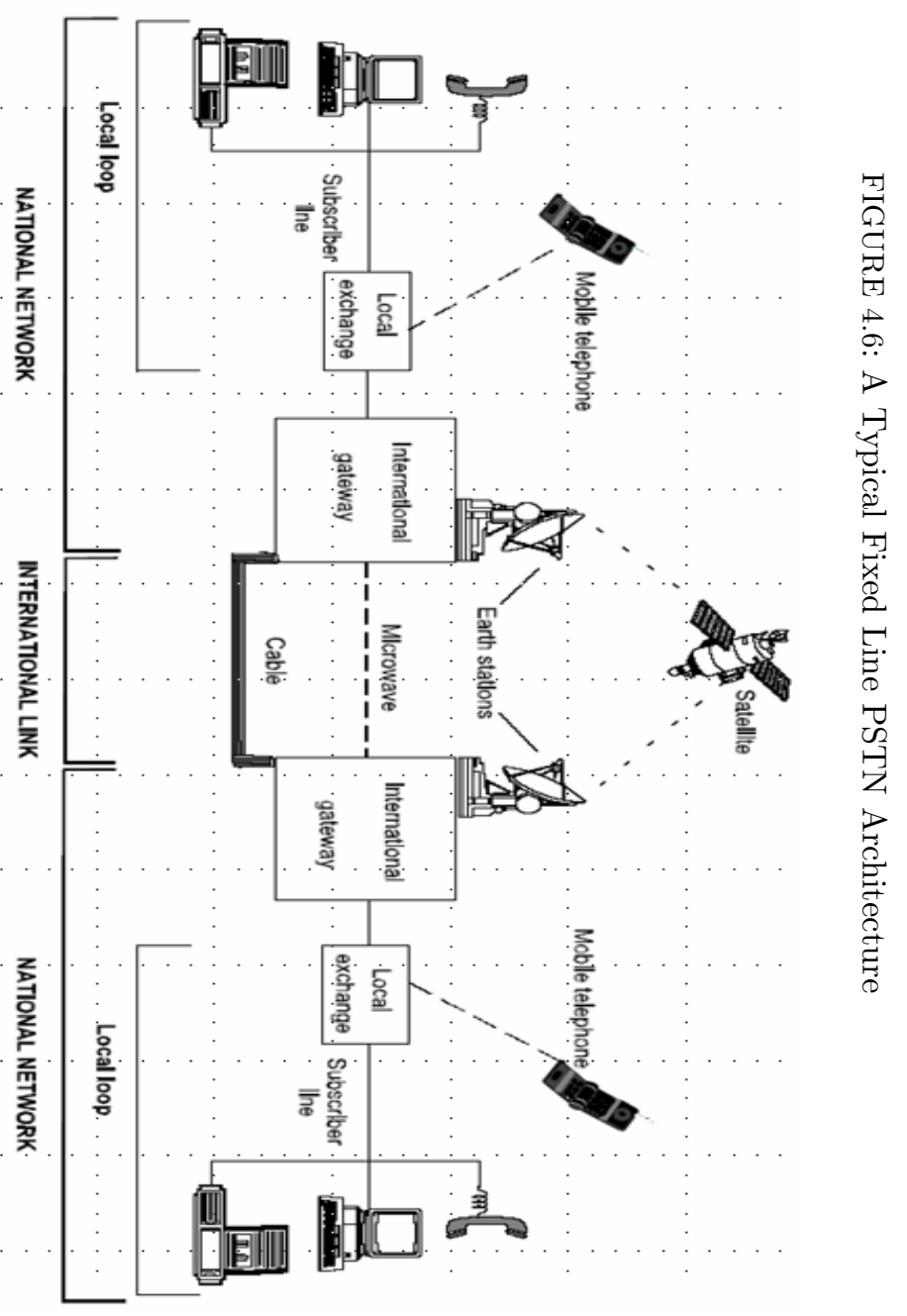


The 'local loop' represents the final connection to a subscriber, usually referred to as 'the last mile'. The further away you get from a local exchange point, the more expensive it becomes to implement the last mile. The connection of interest in this study, however, is the connection labeled 'international link', which is the connection linking two countries, neighboring or not, that need to communicate.

Due to the distances involved in links between countries, it is not economically and logistically possible to run cables to all countries in the world. So this link is usually implemented in three main ways

1. Using radio frequency waves usually for neighboring countries

2. using satellite microwave frequency to connect to the international backbone

3. using undersea fibre cable to connect to the international backbone

The reach of radio frequency waves is limited and that is why they are used mainly for connections to neighboring countries and long distance calls within a country.

Since the development of communications satellite technology in the early sixties, it became the standard technology for the implementation of the international link in Africa from the late sixties onwards. Until then, there was no international telephone communication on the continent. All international communications depended on the international telegraph network established by the colonial powers for swift communications with the motherland. An example of the Zambian situation is summarized by the following excerpt from the Zambia telecommunication Company official site ${ }^{5}$ :

"Zamtel has 15 direct routes for voice with partners in Europe, North America, the Middle East and Africa. These are France Telecom, Telecom Italia, Belgacom, British Telecom, IDT, Telco 214, Teleglobe VSNL, Verizon MCI, AT\&T, Gilat Satcom TelOne of Zimbabwe, Botswana Telecom, Tanzania Telecom and Telkom South Africa. The links to the neighboring countries are terrestrial while the rest are via Intelsat Satellites using the two operational Antennas at Mwembeshi Earth Station. "

However the satellites over which this link is implemented are foreign owned and operated and this has caused countless problems for African telecommunications, usually in the form of very high tariffs for both intraAfrican and international connections.

Undersea fibre cable is normally not available to landlocked countries as they have to run fibre cable over difficult terrain to get to a landing port in a country with coastal access and this is very costly and not always feasible. However optical fibre technology has become very popular in the

\footnotetext{
${ }^{5}$ www.zamtel.zm
} 


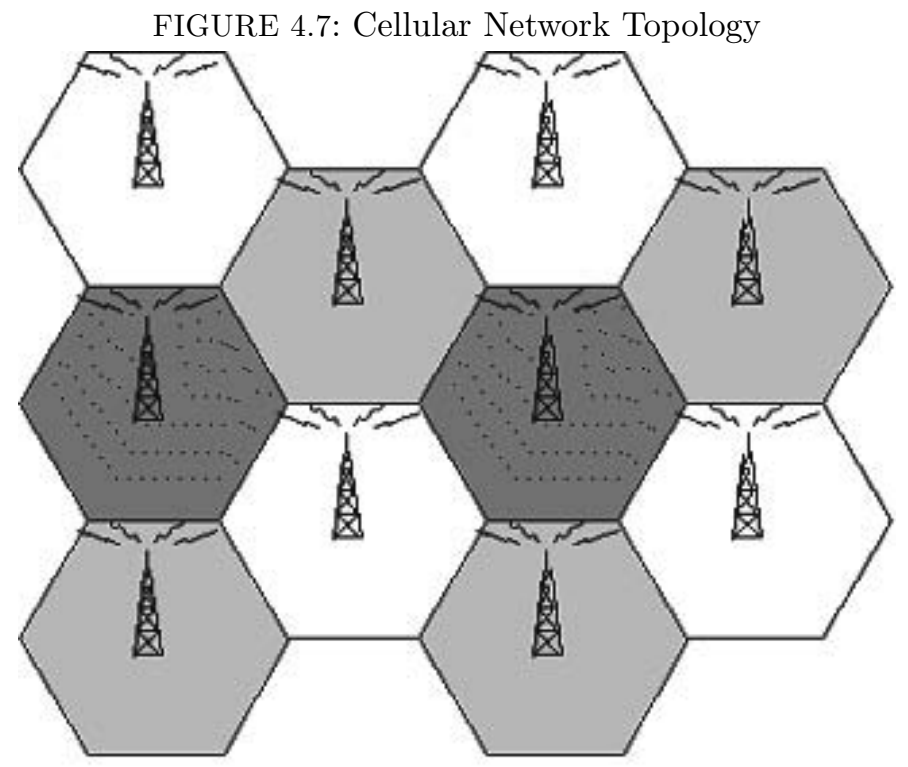

Source: http://Wwww wikipedia.com

implementation of the 'national network' (see figure 4) because of its higher bandwidth capabilities and faster connection speeds. Many African countries are currently replacing old copper cables with optical fibre cable on their national networks e.g. Democratic Republic of Congo, Zambia, South Africa etc. This should make internal communications on fixed lines more efficient and cheaper because optical fibre is able to carry more voice channels than electrical copper cables. The use of fibre cable for international connectivity is not without its own problems as discussed in section 4.2.2.

The advent of Voice Over Internet Protocol(VOIP) has brought a cheaper alternative to making international calls over fixed lines for those who can afford the internet, but as we will see in section 4.4.3, the cost of internet broadband in sub Saharan Africa is also on the high side, such that in order to get the benefit of VOIP one typically has to be able to cross the hurdle of a high internet broadband tariff first.

So, to this day international communications over fixed telephone lines are dependent on satellite connectivity for most countries on the continent. For countries on the west and east coast, a number of fibre optic projects are under way to mitigate the high cost of both fibre and satellite through competition (see section 4.2.2). 


\subsubsection{Mobile Cellular Telephony}

With cellular technology, geographical space is divided up into cells (see figure 4.7). Each cell carries a transmitter (or a base station that will normally be connected to an international backbone network) and receives and retransmits signals from source to destination devices within its reach. Line of sight is important for cellular transmitters, which is why they are usually mounted on elevated geographical locations. The problem is that not all adjacent transmitters are owned by the same cellular company. This leads to situations where one company's transmitter is requested to carry a competitor's signal-enter interconnection charges. Mobile phone companies charge each other for carrying each other's traffic and these costs are passed on to the consumer. This has led to situations where even local cell phone charges across different networks are abnormally high.

The advent of cellular connectivity in Africa has spread the availability of telephone services far and beyond what was previously possible by terrestrial traditional cable networks. $18 \%$ of Sub Saharan Africa is now reachable by cellular technology. The whole of the sub Saharan African region is serviced by several cellular companies bringing voice, video and data services to populations that previously could only access a voice service at a post office located several kilometers away (James, 2002).

This mushrooming of mobile and wireless services in the last decade has tremendously increased service delivery across the African continent, especially in the local voice telephony markets 4.8 . While mobile networks have enabled local connectivity, international connectivity still requires access to international gateways which, as we have seen before, are traditionally implemented over satellite or undersea cable. With the unfolding of mobile cellular technology networks over the African continent, however, we may see a situation where deregulation and the interconnection of different networks over the African landscape gradually reduces the dependence on international gateways for inter African connectivity. Signals will be transmitted over neighboring cells of different networks in different countries without ever having to hop onto an international gateway. The cost of the service would largely depend on how much different networks are willing to cooperate with each other to provide the inter-network connections. However, with the recent mergers and acquisitions in the mobile phone industry in Africa, a possible scenario that could arise is that a company's network becomes big enough to span across countries and the company is able to provide uniform call charges regardless of distance. With the presence of accessible fiber on the coast the necessity to route voice traffic over satellite would eventually fall away. This would require a lot more deregulation and free competition in the telecom sector in Africa. This possibility has already been touted by Zain Africa boss Chris Gabriel, who talking to the news giant Reuters declared that Zain was committed to establishing what 
FIGURE 4.8: Mobile Subscribers and Mobile Service Penetration in SSA

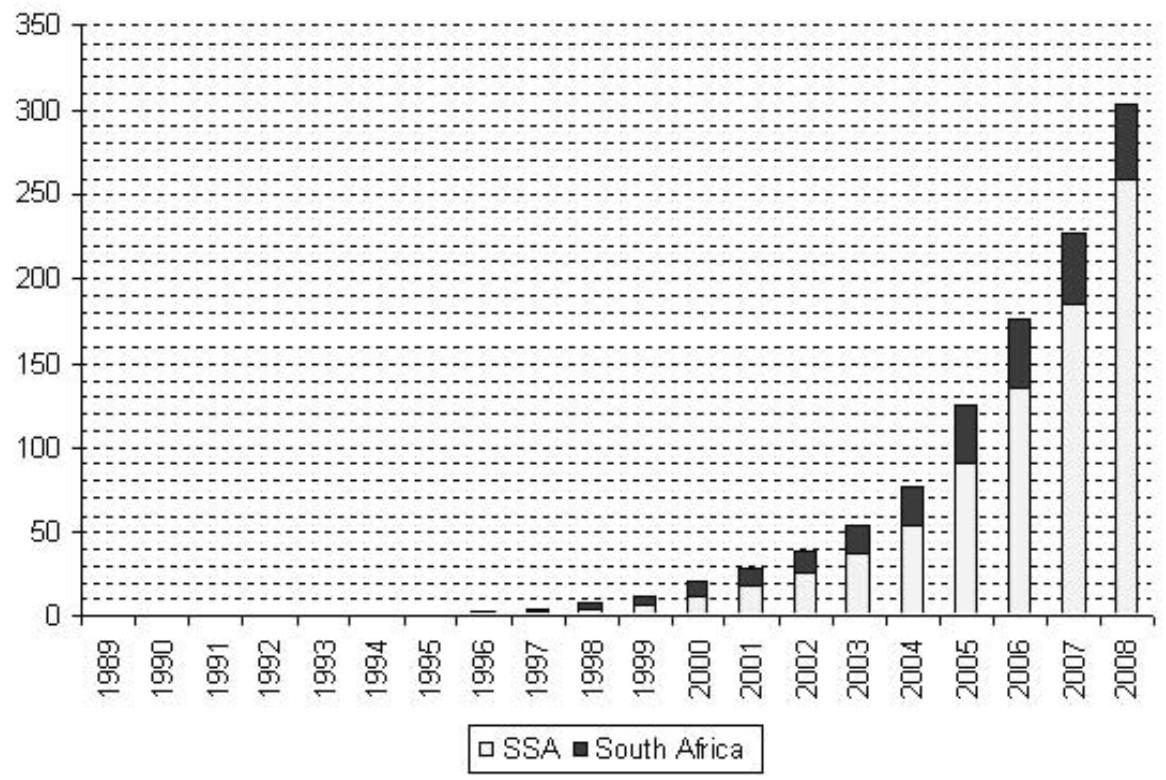

(Source Data fom ITU, Measuring the Intiomation Society 2009) 
it calls the "One Network" , where a flat rate will apply for all international calls. Zain has taken a step forward already by eliminating International roaming costs that other networks still apply in Africa ${ }^{6} 4.8$. Zain has taken over most of the initial mobile phone companies in Africa and is currently one of the biggest players in the market on the continent, the others being MTN, Vodafon and Orange. This is a promising prospect for international calls on the continent; however the concept relies heavily on the existence of monopolies (again!) or the enforcement of wide-based cooperation between mobile providers in the market. The alternative is to force operators to scrap interconnection charges but whether this sort of regulation can span across borders is a different problem altogether.

The rapid diffusion of mobile telephony has also had the desirable effects of increasing competition in the local voice markets and forcing considerable deregulation in the cellular technology industry. This has brought down the cost of mobile voice calls to unprecedented low levels in the last decade. The cost of mobile handsets has also dropped together with the cost of making calls on the same network. The number of mobile subscribers has soared, figure 4.8, raising the tele-density levels in Africa to levels far beyond most predictions. But a few things remain unchanged. Cross-network calling rates are still on the high side, and that includes mobile to mobile and mobile to land line and vice versa. Making an international call on a mobile phone, either to a land-line or another mobile phone in a different country is prohibitively expensive. So, typically international voice traffic on mobile phones is very low. Most mobile operators provide a service called 'roaming', where a user is able to receive calls on his mobile phone in a foreign country, away from his service provider's base. This is a useful service as it allows users seamless continuity of service wherever they travel on the earth surface. However the cost of roaming is very high. The user is billed for both receiving and sending calls from his mobile while he is roaming. A sample of the cost of roaming on a Cell C phone from South Africa in other African countries are shown in table 4.2. Again these high roaming charges are a result of international connectivity and interconnection charges.

\footnotetext{
${ }^{6}$ Western Union, Zain team up on Money Transfers, Georgina Prodhan, Reuters 23 June 2009
} 
4. Satellites and Communication Costs in sub-Saharan Africa

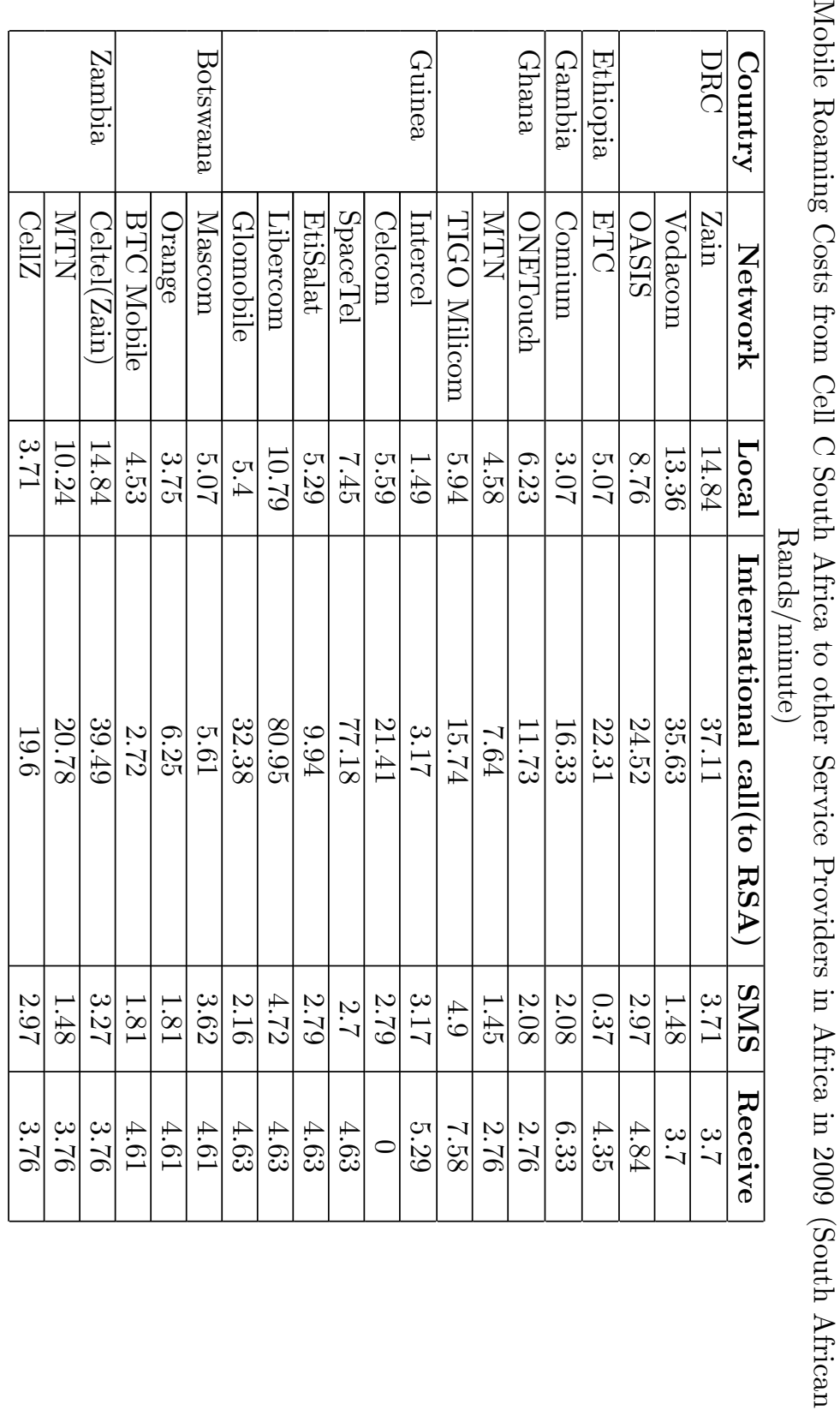


The factors affecting cross network connection charges are really mainly a result of rivalry and competition between service providers. While competitively lowering their charges for calls made on the same network, they hike their charges for calls to other networks so as to lure as many subscribers as possible to their network. Subscribers are tactfully 'coerced' into subscribing to networks where most of their associates already subscribe so as to take advantage of cheap rates from same network low rates. Unfortunately, for both the subscribers and the service providers, this dynamic is a hard one to practically enforce as a subscriber has no full knowledge of or influence over which network her associates will subscribe to. The Independent Communications Authority of South Africa (ICASA) recently passed a resolution and instructed all mobile phone providers in South Africa to get rid of the so called "interconnect charges" and significantly cut cross network cell phone charges. The cell phone providers are currently fighting this bill.

There are developments in this area that may eventually affect international dialing rates in Africa positively. But as of now the tremendous effects that mobile telephony has had on local telephone services have not yet spread to international calling services.

\subsubsection{The Internet}

Internet provision in SSA has come through various stages beginning from primarily dial up connectivity through local telephone lines to Digital Subscriber Lines (DSL) and wireless connectivity over Wi-Max, mobile cellular networks and direct satellite connections. Dial-ups are very slow and expensive to maintain as the user typically pays for the telephone connection to the local telephone exchange on top of her monthly subscription fee plus usage to the Internet Service Provider (ISP). The important thing for internet in Africa is not only how the last mile is delivered but rather how the local ISP connects to the global internet backbone as this is what eventually determines the cost to the user. The ISP has to connect to the internet backbone in order to deliver internet services to her clientele. This is usually done through an international gateway which, as depicted in figure 4.6, is usually over a satellite link. Satellite capacity is traditionally expensive because of the nature of satellites and the economics that govern their construction and operation. A wave of liberalization has swept across Africa relaxing rules for satellite connectivity and allowing users to purchase capacity from whoever they wish. This has made it possible for ISPs to connect to any satellite of their choice as opposed to being limited to the national earth station or gateway operated by the incumbent Postal Services and Telecommunications Network (PSTN). But as Osiakwan ${ }^{7}$ puts

\footnotetext{
${ }^{7}$ Is Africa in a Digital Quagmire? Eric Osiakwan November 2004. See also Daily Nation 12th November 2009 (Satellite Bandwidth currently costs $\$ 5,000$ per MB per month in Kenya)
} 
it:

"Until recently Africa has primarily received her long haul bandwidth through satellite. Liberalization and competition in the satellite industry has not affected internet cost as expected"

In August 2008 the telecommunications research firm BMI TechKnowledge reported that over $80 \%$ of African internet use was till being routed over satellite connections ${ }^{8}$. Figure 4.9 shows how this connection is realized and the costs involved. DC in the diagram stands for 'Developing Country'. What is shown in the figure is the cost of a $45 \mathrm{Mbit} / \mathrm{s}$ access channel. Typically PSTNs and ISPs do not buy the whole channel but use a portion of what they can afford according to their equipment specifications and traffic levels (typically 2MBps), which brings the cost to about 5000 Dollars per month. It is estimated that Africa pays about 500 million dollars annually in satellite connectivity fees to non-African satellite operators (ibid). These charges are paid to the international satellite operators and as of 2008 most African countries using international satellite exchanges used the Intelsat fleet of satellites, (see Table 4.1). Figure 4.10 shows clearly that cost of connectivity is highest in SSA.

\footnotetext{
${ }^{8}$ BMI TechKnowledge is based in South Africa and works on telecommunications research in over 40 countries
} 
है]

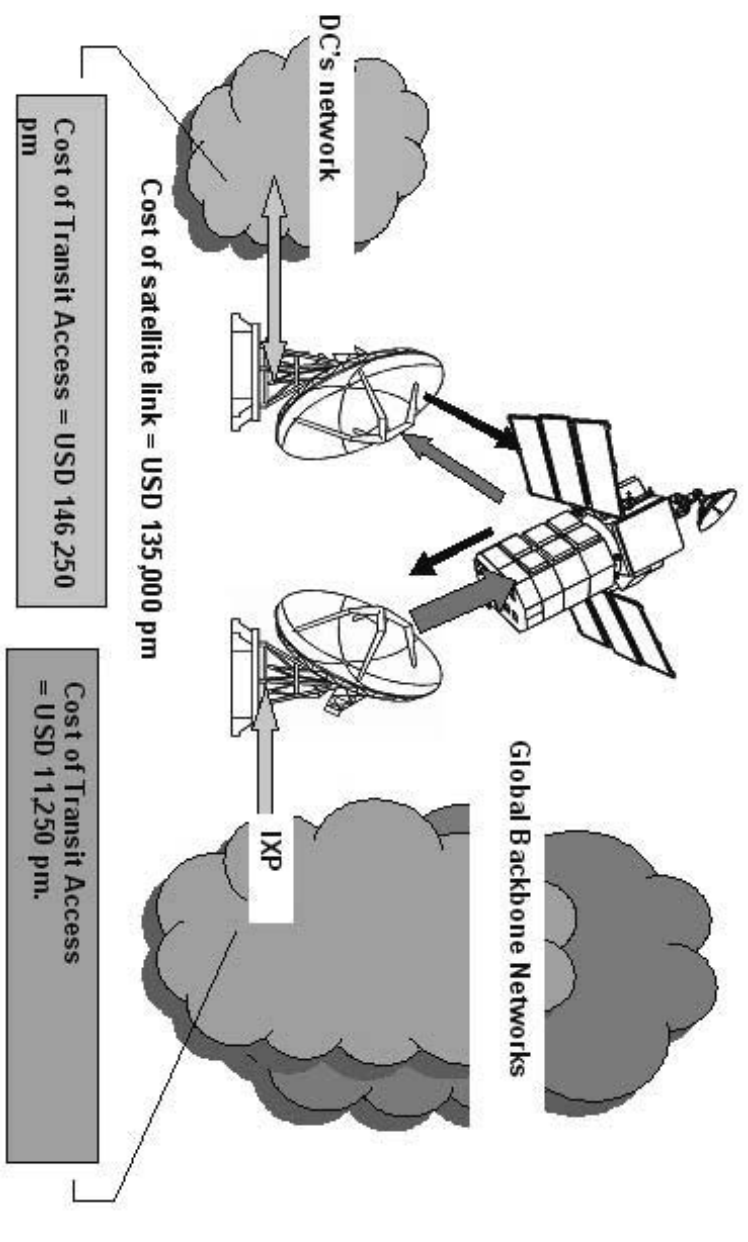

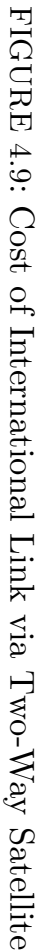




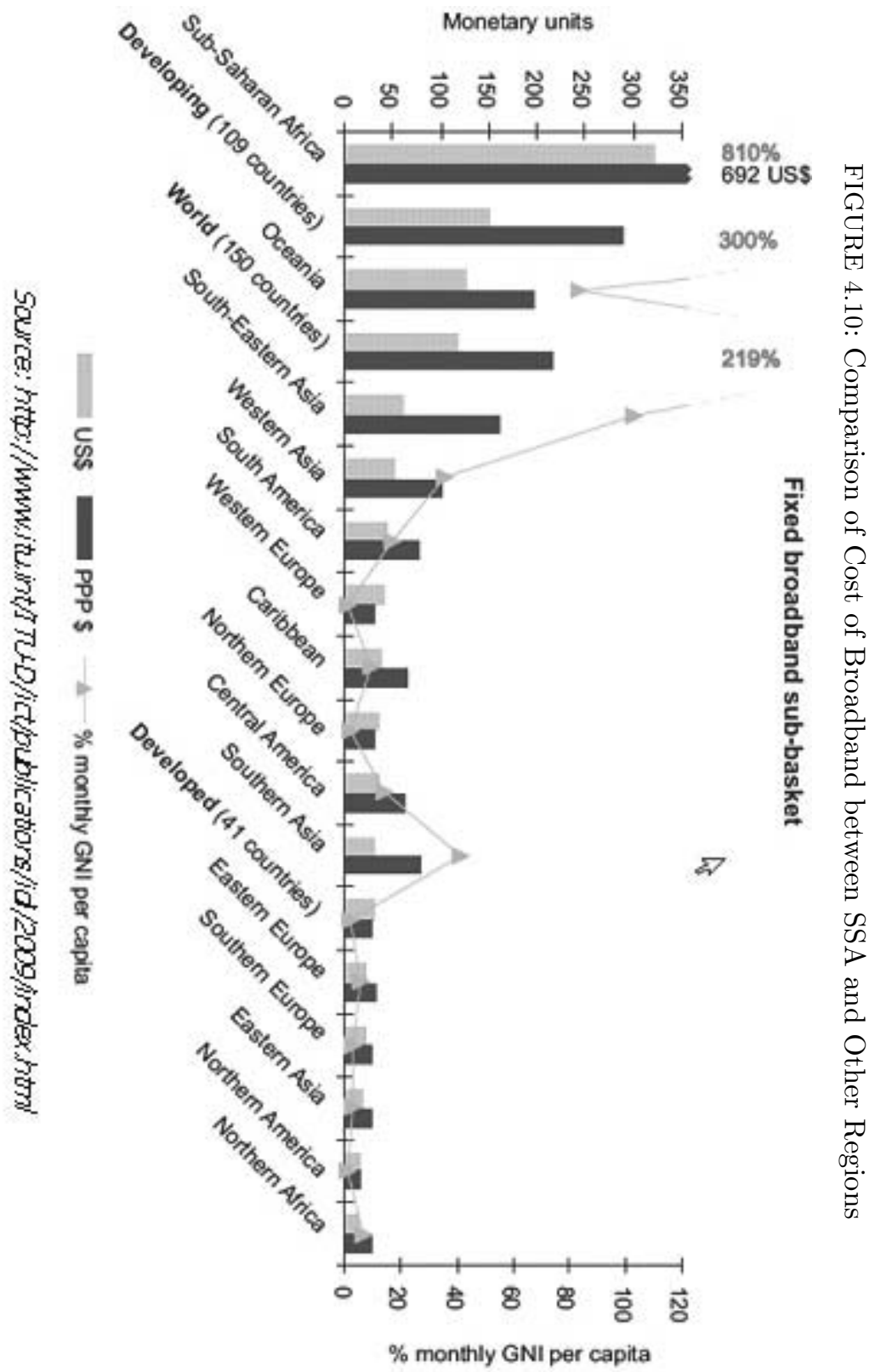


Table 4.3 shows the organization of five ISPs from Zambia and how they connect to the global internet backbone. The heavy dependence on satellite connectivity is typical of almost all landlocked countries in SSA.

TABLE 4.3: Internet Service Providers in Zambia and Access Type

\begin{tabular}{|l|l|l|l|ll|}
\hline ISP & Link Type & Bandwidth & Upstream ISP & \multicolumn{2}{|c|}{ POP Locations } \\
\hline Zamnet & Satellite & $3 \mathrm{Mb} / 1.5 \mathrm{Mb}$ & TaideNet & $\begin{array}{c}\text { Lusaka, Kitwe } \\
\text { L/Stone }\end{array}$ \\
\hline Zamtel & Satellite & $3 \mathrm{Mb} / 2 \mathrm{Mb}$ & BT/Teleglobe & $\begin{array}{c}\text { Lusaka, Kitwe, } \\
\text { Ndola }\end{array}$ & \\
\hline Microlink & Satellite & $5.5 \mathrm{Mb} / 1.5 \mathrm{Mb}$ & TaideNet & $\begin{array}{c}\text { Lusaka, L/stone, } \\
\text { Ndola }\end{array}$ \\
\hline Coppernet & Satellite & $3 \mathrm{Mbs}$ & IP Planet & $\begin{array}{c}\text { Lusaka, Kitwe, } \\
\text { Ndola }\end{array}$ & \\
\hline UUnet & Satellite & $3 \mathrm{Mbs}$ & & Lusaka & \\
\hline
\end{tabular}

The African business fraternity and telecommunications regulators have recognized these shortcomings and are moving fast to fill the gap. Internet Service Providers (ISPs) have formed local common transit points called Internet Exchange Points (IXPs), through which they can route local traffic so it does not have to be routed over international satellite or fibre backbone if it is intended for a local or another African destination. This greatly reduces connectivity costs for the ISP and leads to cheaper and more efficient connectivity for the end user.

The number of IXPs has risen and continues to rise within the continent due to the work of pressure groups such as the African Internet Service Providers Association (AFRISPA), table 4.4. AFRISPA pressures regulators and service providers to form peering IXPs where they can handle and route each others traffic thus doing away with third party operators and saving money for the continent.

TABLE 4.4: IXPs in Africa

\begin{tabular}{|l|l|l|l|l|l|}
\hline Country & City & Name & Date Started & Peers & Traffic(Mbps) \\
\hline South Africa & Johannesburg & JINX & Dec'96 & 15 & 45 \\
\hline Kenya & Nairobi & KIXP & Feb 02 & 13 & 8 \\
\hline Mozambique & Maputo & MozIX & Jul 02 & 7 & 4 \\
\hline DRC & Kinshasa & PdX & Nov 02 & 4 & 1 \\
\hline Egypt & Cairo & CR-IX & Dec 02 & 9 & \\
\hline Nigeria & Ibadan & IBIX & Mar 03 & 2 & 0.200 \\
\hline Tanzania & Dar es Salaam & TIX & Jun 03 & 10 & 1 \\
\hline Uganda & Kampala & UIXP & Jul 03 & 5 & \\
\hline Swaziland & Mbabane & SZIX & Jun 04 & 3 & 0.128 \\
\hline Rwanda & Kigali & RINEX & Jul 04 & 6 & 0.400 \\
\hline
\end{tabular}


So what is it that keeps international connectivity costs high in Africa? We identify three reasons from our discussion so far:

1. The use of non-African satellite operators to handle traffic within Africa, who operate an oligopoly over the African airspace and are able to collude on charges for the service.

2. The lack of competition in the operation of fibre optic infrastructure due to public monopolies at access points.

3. Marketing and distribution layers that take advantage of the huge profit gaps in the cost of the services owing to the fact that the cost of providing services over broadband has been falling and continues to fall with rapid improvements in hardware and software technology.

\subsubsection{Television and Radio Broadcasting}

\section{TV Broadcasting}

This is probably the most natural application of satellite technology because of its heavy dependence on point to multipoint broadcast. There are two main mechanisms that service providers employ to provide programming to their users. One is the use of satellite earth stations to uplink content to satellites in space which then distributes this content to several earth based transmission houses on the ground. These transmission houses then re-distribute the signal to all recipients within their area of reach to provide television reception. This is because terrestrial transmitting towers have a limitation on how far they can transmit. They also have to contend with natural and man made obstacles on the earth surface that interfere with transmission signals. Satellites elegantly solve this problem by literally having a bird's-eye view of the earth surface.

This is a service provision area where satellite outperforms fibre simply by the nature of its delivery mechanism. To provide wired fibre television service to all African households instantaneously is not possible given the huge physical infrastructure layouts and maintenance that this would entail. Satellite easily provides this service over the airwaves to the point where Free-to-Air television is now taken for granted in Africa. All one needs to do is buy a television set and power it up (various sources of power!). An assortment of antennae options are also available including indoor antennas.

The second method used is the so called Direct Broadcast used in Direct Broadcast Satellites. As before, programming content is sent to a satellite station in space on the uplink. The Direct Broadcast Satellite (DBS) then rebroadcasts this content on the downlink to all recipients within its 
FIGURE 4.11: Satellite Home Antennas in SSA

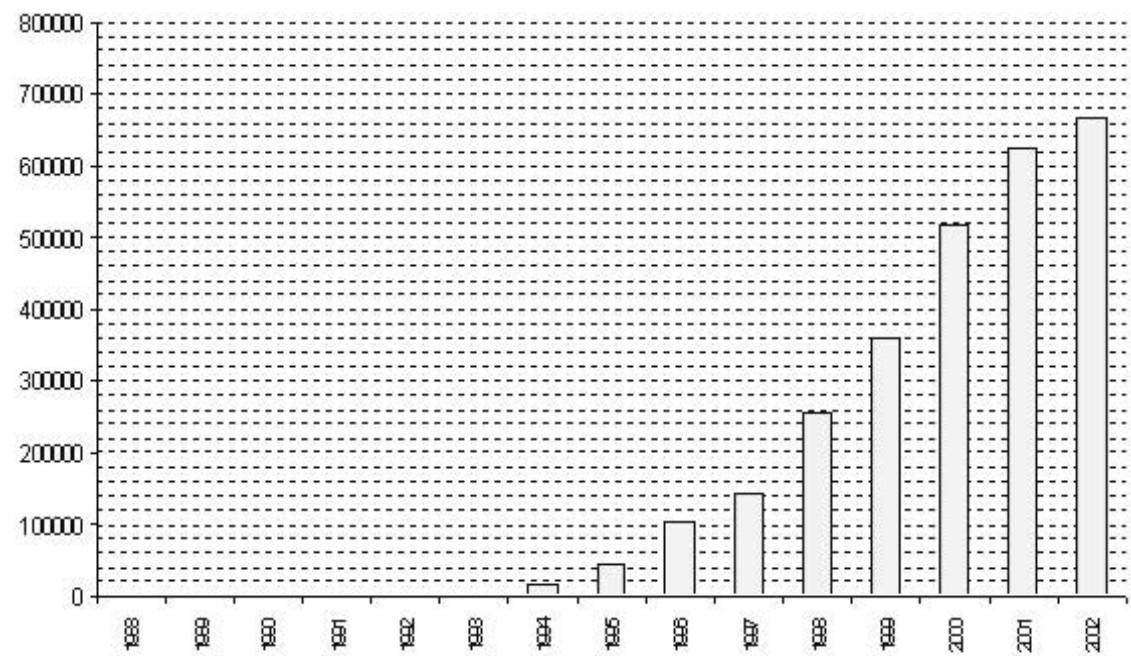

(Source: Data from the ITU World Teleconmunications Indicators database (2009))

satellite footprint with the correct receiving device. This signal is usually encoded and receivers have to subscribe and buy a set top box and appropriate antenna to decode the signal from the satellite, hence the popular name "decoder". A visit to any sub Saharan African country will reveal an array of very small aperture satellite (VSAT) dishes on rooftops in residential and business districts alike. The corporate world uses direct satellite signal for data connectivity across different branches of their businesses in different countries or between far flung areas in the same country. The banking sector has especially taken to VSAT technology and is one of the biggest users of the technology. The general population's fascination with Direct to Home (DTH) TV broadcasting has also spurred pay TV sales on the continent, figure 4.11

The figure shows the rise in the number of home satellite antennas in SSA. The biggest provider of DTH television in Africa Multichoice recently renewed their contract with the satellite company INTELSAT to beam content off their equipment for the next 25 years.

Radio broadcasting

The first attempt at direct satellite radio broadcast in Africa came with the launch of the Afristar satellite by Worldspace Incorporated in 1999. The service was intended to bring crystal clear radio content to the information poor of the continent assuming that they had enough money to buy the 
expensive receiver boxes and pay a subscription for the content as well. Needless to say this model did not work and the project was abandoned. Radio in Africa is perceived to be a free service and the idea of paying for radio content was new and did not appeal especially to the poor masses the project was trying to reach. To make matters worse the DTH TV provider Multichoice (a virtual monopoly in the business in Africa) threw in prime radio broadcasts as an added service to those who subscribed for their DTH services. So those who could afford subscription radio were already getting it for free on their DTH packages. Wordspace filed for bankruptcy and was taken over by SIRIUS who had similar radio subscription businesses in America and Europe. The Afristar satellite was redirected to provide service to India in a bid to recover investments costs. More details about this are provided in chapter 7 .

\subsection{Satellites and Communication Costs}

It has so far been made clear that international satellite connectivity is the most common type of access to the international backbone for most countries on the continent. The problem is that the connectivity costs are high and this leads to high charges for basic services like international phone calls and internet access. Service providers and users in Africa have no control over the operations of the international satellites that service the continent. Operators form cartels and are able to charge connectivity rates that have little to do with the cost of providing the service. This is shown clearly in figure 2 , where the marginal cost of providing a voice call over an Intelsat satellite and over Transatlantic submarine cable are shown to have been falling over the years to an extent where the ITU in its Direction of Traffic report concluded that the cost of the international link in actualizing an international connection is almost zero and should therefore have no bearing on the cost of an international call. The study provided evidence that the actual of cost of providing voice services over both satellite and transatlantic cable have been falling over a period of more than ten years and as of 2000 had stabilized around $\$ 2900$ for satellite and around $\$ 1000$ for cable. This trend coupled with technological advances in both the space and optical fiber industries makes it reasonable to assume that these costs should have fallen further since 2000. Unfortunately we see only marginal decreases in the corresponding cost of user services for international voice telephony and internet services. The result is relatively expensive connectivity charges passed down to the user of ICT services in Africa (Jagun, 2008) ${ }^{9}$ Another interesting and important spin off from this

\footnotetext{
${ }^{9}$ Abiodun Jagun The case for Open Access, APC "Issue Papers" Series 2008, p3
} 
difference between cost of providing the service and user costs, is that we now have re-seller businesses that buy bandwidth at wholesale prices and use it to resell services on the retail service markets at lower prices than official incumbent prices and mobile phone operators. The last ten years have seen a boom in the card calling business especially from rich countries to poor countries targeted at the migrant worker populations that need cheap constant contact with their families back home. There are cards on the market that promise "FREE" calling minutes to Africa and Asia for a minimum fee. What they do not advertise is the connection fee that they still have to pay when they hop onto carrier networks to complete the calls. These appear in the form of interconnect fees and usually take up more than the advertised share of the cheap connection. However these re-sellers still do make huge profits both from online services and digital switching services.

The cited ITU study concluded that what drives up the costs of cable and satellite systems are the distribution layers that mark up the price ${ }^{10}$. Are the levels of these prices justified for distribution alone if the cost of the link itself has been falling consistently with improved technology? We posit that while these distribution charges have an effect on the cost of bandwidth in Africa, they alone do not account for the high cost of bandwidth on the continent. Other factors mainly related to business practices and organization must be involved in pushing these prices to the high levels that they are at.

The importance of satellite connectivity, as has been emphasized is in its ability to deliver services to very large geographical areas and the possibility to expand the network at very low marginal cost. In practice this means that areas which would normally be without telecommunication services are serviced thanks to the far reaching capabilities of satellite connectivity. Mountainous regions, those cut off by natural disasters like floods or earthquakes, sparsely populated regions and other similarly disadvantaged geographical locations are able to access telecommunications services because of a satellite link.

However this remains a potential benefit of satellite connectivity because in practice satellite connectivity remains the most expensive connectivity solution on the continent, excluding millions from vital services that would otherwise be available if the satellite backbone connectivity were cheaper. In 2008 an NGO in Zambia reported a strong need for connectivity in order to provide much needed services to poor people and having tried all possible terrestrial and wireless options to their dismay finally turned to satellite connectivity. The problem was cost. A paraphrased account of the experience follows:

"I'm managing the computer network for a small NGO in Zam-

${ }^{10}$ see ITU Direction of traffic: Trading Telephone Minutes, 1998 
bia (Ndola) searching for cheap VSAT connectivity. We have tried several ISPs over the last few years in an effort to provide internet for the school and orphanage, all of which have resulted in poor connection speeds and high drop out rates. We have tried Wi-Max, microwave, GPRS technologies and in desperation are looking at VSAT but are finding the costs quite prohibitive." 11

These are examples of the effects of the high cost of satellite connectivity on use and adoption of ICT services for the public and commercial good. Whether these high costs translate into broader economic disadvantages for Africa is a question we ask and try to answer in Chapter Five by investigating the relationship between intra-African trade flows and communication costs.

In addition these high costs of international connectivity negatively impact on the intensity of international trade in Africa thereby stunting growth in the region. Services directly affected by the cost of international satellite capacity are international calling, both fixed and mobile, and internet connectivity, and television and broadcasting service

Particular efforts have been made to change the status quo and bring some African presence in the satellite operators' arena, see section 2.4.

These examples illustrate the desire by African countries to be free from foreign owned private communication satellites that have dominated the African airspace for so long. They also illustrate the need for regional cooperation between African countries to integrate their regional networks and construct common infrastructure for international backbone access. This is what has been attempted with the RASCOM project The problem is Africa does not have its own technological and financial capacity to implement space projects of this magnitude and will always rely on technical expertise and financial backing from developed countries in order to build this infrastructure. This is the paradox of African communications development; the owners of the communication satellites they are trying to replace are the same experts they turn to in trying to build their own satellite infrastructure.

Meanwhile high satellite connectivity costs and inadequate bandwidth capacity continue to hold African economies at ransom. According to Brian Hirlihy of Seacom:

" international bandwidth (in Africa) is so expensive that the market can only afford to purchase very little capacity at incredibly expensive rates in comparison to global communication rates" 12

\footnotetext{
${ }^{11}$ http:/ / forums.whirlpool.net.au/forum-replies-archive.cfm/1094567.html

${ }^{12}$ Via Satellite April 2009, p59
} 


\subsection{Summary}

In this chapter we looked at various services and how they are related to satellite connectivity. We have also considered how the cost of each service may be affected by satellite. In discussing international connectivity we have compared the advantages and limitations of fibre connectivity and compared them to the advantages and limitations of satellite connectivity. We have highlighted the high cost of connectivity over satellite and the efforts being made to mitigate this by bringing high capacity broadband through optical fibre on the east and west coast. In a nutshell, satellites affect the cost of international connectivity negatively. In the next chapter we specifically turn to this problem and show empirical evidence of the effect of these high communication costs caused by high cost of space channel capacity on exports on the sub continent. 


\section{Communication Costs and Trade in sub-Saharan Africa}

Communication costs are an important aspect of the barriers to trade often referred to as trade costs. These are costs that have to be overcome in order to actualize a trade transaction or more formally stated: Trade costs are "all costs incurred in getting a good to a final user other than the cost of producing the good itself" (De 2007). The higher these costs are, the more difficult it is to carry out trade and the less volume of trade you expect. Some of the more often researched barriers to trade are transport costs, exchange rates, freight charges and border related trade barriers. The impact of the cost of information gathering and transmission of messages has often been neglected or subsumed under transport costs or border related trade barriers. It is however important to model these costs separately as the share of services in world trade has increased dramatically over the last two decades and the advancement of information and communication technology (ICT) has made distance seem less important in the setup of trade transactions. A steady reduction in communication costs has resulted in a dramatic shrinkage of the time and space barriers which inhibit economic exchange over vast distances (Harris, 1995; Melvin, 1990).

These developments have led researchers to take communication costs more seriously and treat them differently from transportation costs, which largely constitute the costs involved in getting a finished product from point A to point B.

(Harris 1995) points out three reasons why communication costs are different from transport costs and why they should be treated differently. One of the major differences is that from a supply point of view, communication costs, as opposed to transport costs are almost always a fixed cost. This is in contrast to Samuelson's iceberg model used for transport costs, where part of the good is assumed to 'melt away' in the course of transportation because the marginal cost of transmitting a message once the network is in place is zero. Secondly, natural monopoly and public good properties present in communication networks are another reason to consider these costs seriously. Although the non-rivalry aspect of public goods is present in most communication networks, excludability is easily enforced by data encryption technologies and passwords. More importantly the presence of network externalities in communication networks is a defining difference between transport and communication. The concept of a network as a growing pool of links between a growing number of connected users makes it very 
distinct from a transport link between two points.

The new economic geography literature driven by (Krugman 1997) and (Venables 2003) has attributed the emergence of internationally distributed production networks to improvements in communication technologies that have made coordination of geographically dispersed production processes possible in more developed countries. Sub-Saharan Africa has seen very little of these dispersed production processes with most of the investments in the region heavily falling into extraction of primary resources and erection of retail outlets for finished products from more developed countries.

While earlier studies focused on the effect of country specific communication infrastructure on trade, they did not offer much evidence on how international communication costs affect trade flows. Fink, Mattoo and Neagu take an early lead in expressly investigating the effect of international communication costs on trade flows by assuming that communication costs affect trade primarily by influencing variable trade costs between nations. More recent literature has studied variations of the problem in relation to specific markets and products (Freund and Weinhold, 2004; Tang, 2006). We follow Fink, Mattoo and Neagu and investigate the effect of bilateral communication costs on trade flows in SSA by employing bilateral cost of communication between countries in an augmented gravity model setting.

Our contribution to this literature is that we go beyond Fink et al by linking high communication costs to international gateways and showing the effect of this on trade. We will demonstrate that the cost of communications is an important variable in the actualization of higher volumes of trade in sub-Saharan Africa. The affordability of communications facilities and services for both the corporate world and the general population has become an imperative for participation in the new global world order. The corollary and crucial question of interest then becomes the effect of more trade and openness to the world economy through affordable ICTs.

Our objective is to empirically investigate whether bilateral communication costs matter for trade in SSA. We then empirically test the hypothesis that communication costs in Sub-Saharan Africa have a negative impact on the volume of trade between countries. Communication costs in SSA are heavily influenced by the cost of access to international gateways dominated by satellites (i.e. the foreign privately owned 'public infrastructure'). If the hypothesis is confirmed this would be an indication that having a privately owned foreign 'public' infrastructure has negative economic effects on the economic effectiveness of Sub Saharan African (SSA) countries and a publicly owned infrastructure would be more beneficial as we found in Chapter Three.

What is the magnitude and direction of the effect of communication costs on trade in SSA? Shedding light on the existence and importance of this effect should provide justification for investment in communication infrastructure that reduces the cost of international connectivity. It should also provide guidance into the use of public funds for the construction 
FIGURE 5.1: Cost of Export and Import Procedures in USD

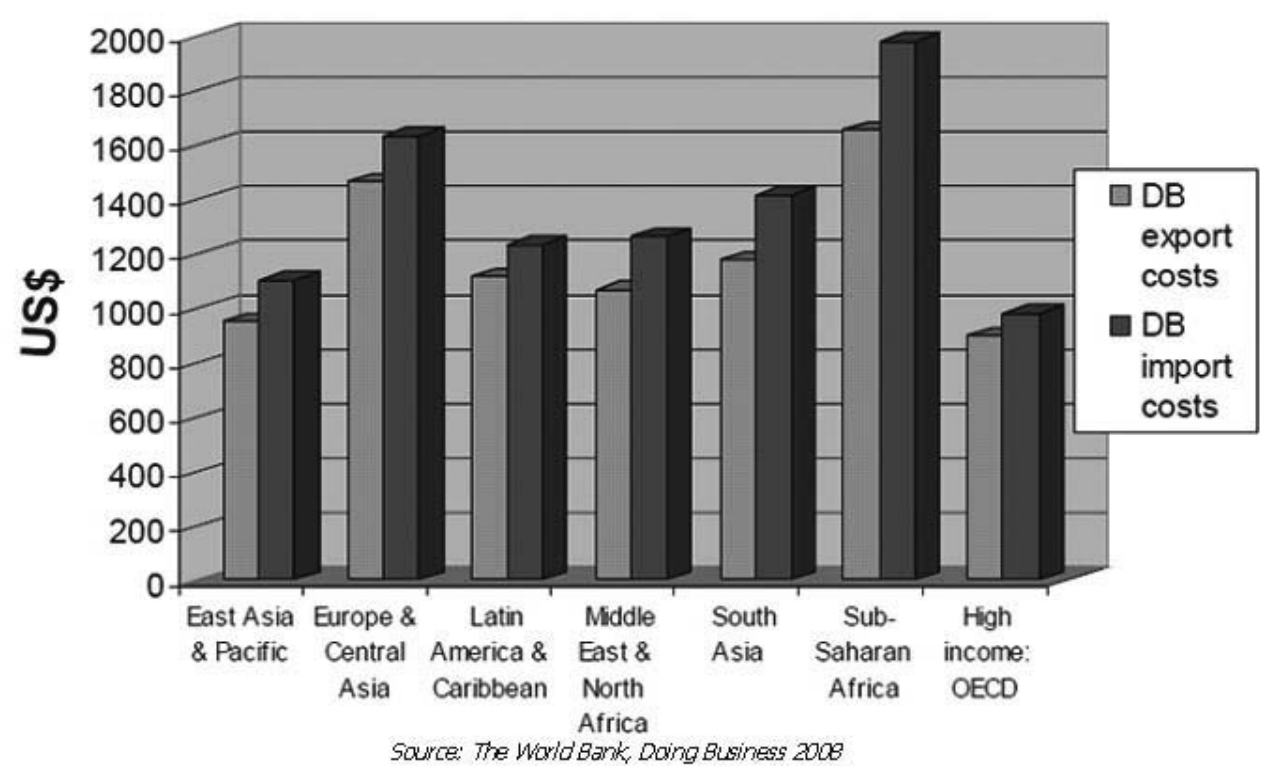

and management of such infrastructure as our theoretical growth model suggests (see Conclusion chapter 3), reducing trade costs and enabling more trade in the process.

World Bank research has established that the cost of doing business in Africa is among the highest in the world, (see figure 5.1).

We isolate the cost of communication and study its influence on overall trade performance in SSA. Communication cost cuts across all phases of the life cycle of a product, from initial product design to marketing and after sales services. This aspect of communication is almost always neglected in studies of trade costs in a bid to compartmentalize costs to broader categories that make them easier to study. An example of this is the study by (Anderson and Wincoop 2003), who find that $44 \%$ of trade costs in developed countries are due to border related barriers, a broad category that includes communication costs. We isolate communication costs in our study and look at the cost of gathering, transmitting and receiving information across international barriers through international telephone and internet services. These are represented by cost of broadband and the cost of making international phone calls. It is assumed here that the high cost of internet bandwidth and international calling rates are due to routing over 
international gateways dominated by satellites and monopoly operated fibre gateways on the west coast. We will use the cost of internet bandwidth and international fixed line calls to test this assumption. These are the communication costs that are likely to affect international trade. So in general we could say that international communication costs are a function of international calling rates and internet costs. International calling rates are measured in US dollars per minute while internet bandwidth is measured in dollars per Megabit per second (Mbps).

\subsection{Trade and Growth}

The foregoing discussion leads us to ask how much intra-African trade has contributed to growth in sub-Saharan Africa. If trade is important to growth and communication costs are important to trade then the factors that affect communication costs will, all else being equal, consequently affect economic growth. So we aim to show using the literature that there is a relationship between trade and growth and that more trade between countries in sub-Saharan Africa will lead to higher growth.

The direction of causality between trade and growth has been a question of interest for many researchers over the past decade. To what extent does trade cause growth and to what extent does growth itself cause trade? Some researchers have found a robust and moderate causality effect in the trade to growth direction (Levine and Renelt, 1992; Harrison, 1995). While the effects of trade on growth surely can not be negligible, it has also been shown that there is a two way link between trade and growth. Trade leads to growth (through specialization and spillovers) and growth itself leads to more trade. This is the basic premise of the gravity equation used in the empirical setting in section 5.2 Larger economies are likely to trade more than smaller ones ceteris paribus, because they have a larger variety of goods to exchange with connected communities. The larger the population, the larger the pool of specialization in the labor force from which more varieties could be produced (see section 3.2.10, figure3.9). But even more important in the gravity setup is the fact that a country's geographical position could have important effects on its trade patterns.

(Helpman 1988), Frankel and Romer (1999) give insights into the endogeneity problem between trade and growth while Frankel and Romer use the possible impact of geographical characteristics on trade to try and answer the important question of trade causing growth. They find that trade appears to raise income through spurring the accumulation of physical and human capital, but warn that though the results bolster the case for trade they do not provide decisive and irrefutable evidence for it.

One of the boldest policy initiatives to support and promote export-led economic growth on the continent is the American government's initiative, 
the African Growth and Opportunity Act (AGOA) of 2000 under President Bill Clinton. The act seeks to promote growth on the African continent by promoting trade between the world's biggest economy and the African continent. AGOA allows sub-Saharan countries to export products to the USA duty free among other benefits. During the period 2001 and 2008 exports from the continent to the US increased fourfold. What is interesting to note is that call charges between the AGOA participating countries and the US also dropped dramatically during this period, in most cases by more than $50 \%$. see figure 5.2. The figure shows a dramatic drop in call charges to the USA between 2000 and 2007 in all countries except Djibouti where they remained the same and Lesotho, where they actually increased. This does not necessarily mean that the drop in call charges led to higher exports but rather gives us further incentive to study whether this drop in communication costs contributed to the increase in trade volumes between the US and the AGOA countries. 


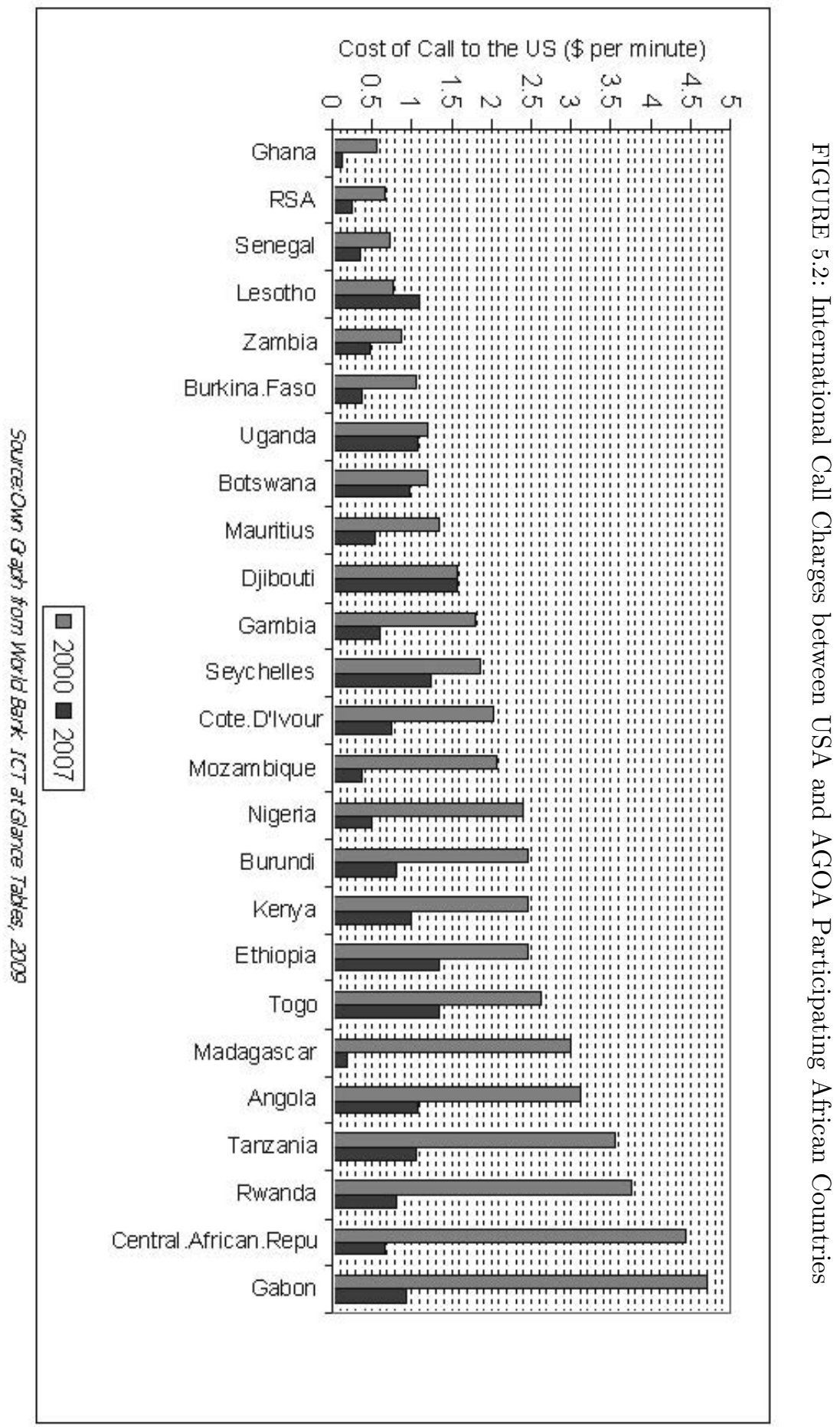


The literature suggests that a number of factors are involved in making trade work for the region (Baliamoune-Lutz and Leonce, 2007; Rodrik, 2003). While all the important variables may not be studied in one go, the ongoing research in the area points to an important coordination of factors that play to impede or promote positive growth effects of trade on the continent.

Theory suggests that trade liberalization and openness leads to growth through transfer of technologies and generation of foreign exchange reserves. Research however has found mixed results for the effects of liberalization but overall weak empirical evidence of the growth effects of liberalization and openness to trade (Easterly and Levine, 2003; Kraay, 2003). In trying to explain the modest impact of trade liberalization on trade, (Baliamoune-Lutz and Léonce 2007) find that institutions play an important role in enhancing the growth effects of trade. Countries with weak institutions are less able to take advantage of trade liberalization and openness while those with stronger institutions fare better.

A directed study into causality effects by (Njikam 2003) found that exports and growth were complementary in sub-Saharan Africa under an import substitution regime while under an export-led growth regime exports uni-directionally caused growth in nine out of the twenty one countries in the study.

(Noguer and Siscart. 2005) follow Frankel and Romer and (Rodriguez and Rodrik 2001) and use geographical instrumental variables on a bigger and more consistent database and find that trade has a large and positive impact on income even after introducing geographic controls, although their inclusion lowers the magnitude of the trade coefficient substantially.

So on balance research generally finds that trade has a positive effect on growth while openness and liberalization to the outside world have a positive impact on growth through trade. The direct impact of communications on trade through trade costs is our main concern in this chapter.

\subsection{The Gravity Model of Trade}

The gravity equation of international trade tries to predict international trade flows based on the size of the economy and the distance between trading partners. Simply stated the models posit that the amount of trade between two countries is directly proportional to the product of their economic sizes (GDP) and inversely proportional to the physical distance between them. The empirical use of this form is accredited to Walter Isard in his work on Regional Science although lots of other sources credit first use of the equation in economics to Jan Tinbergen (1962).

The equation takes the (generalized) basic form: 


$$
X_{i j}=A \frac{Y_{i}^{\alpha} Y_{j}^{\beta}}{D_{i j}^{\lambda}}
$$

where $\alpha, \beta$, and $\lambda$ are constant, positive parameters. $X_{i j}$ represents exports from country i to country j, $Y$ represents the economic mass of the trading partners $\mathrm{i}$ and $\mathrm{j}$, and $D i j$ the distance between them. $A$ is a proportionality constant. The log-linear form of equation 5.41 is

$$
\ln X_{i j}=\ln A+\alpha \ln Y_{i}+\beta \ln Y_{j}-\lambda \ln D_{i j}
$$

whose general empirical form is generally written as

$$
\ln X_{i j}=\beta_{0}+\beta_{1} \ln Y_{i}+\beta_{2} \ln Y_{j}+\sum_{m} \beta_{i j}^{m} \ln Z_{i j}^{m}+\varepsilon_{i j}
$$

,where $X_{i j}$ are the exports from $i$ to $j$ and $Y_{i, j}$ are the economic sizes of the trading partners and $m$ are all the barriers to trade variables, $Z$, between the countries $i$ and $j$ including the distance between them. $\beta_{0}$ is the constant while $\varepsilon_{i j}$ is the error term.

Despite the wide empirical success that this formulation has had in predicting bilateral trade flows between countries, the early literature criticized the gravity equation for not having any theoretical foundation in economics. This criticism led various authors to try and provide this justification. In 1979 James Anderson wrote "A Theoretical Foundation of the Gravity Equation" specifically to address some of these theoretical concerns. He demonstrated that the gravity equation could be derived from the properties of expenditure systems especially in countries where the structure of traded goods preferences is very similar. There were more theoretical justifications to follow. Helpman (1985)derived the gravity equation from the theory of monopolistic competition with increasing returns to scale. In a series of publications on the subject, Bergstrand developed a general equilibrium model of world trade, from which he derived the gravity equation under the assumption of perfect international product substitutability (Bergstrand, 1985; Bergstrand, 1989). He then followed this up with models based on monopolistic competition thus bringing together the two strands of literature on the matter, the product differentiation based literature and the monopolistic competition based models. Deardorf (1998) in proposing his two theories of frictionless and impeded trade notes that:

" I suspect that any plausible model of trade would yield something very like the gravity equation, whose empirical success is therefore not evidence of anything, but just a fact of life" 1

\footnotetext{
${ }^{1}$ page 12 in Chapter "Determinants of Bilateral Trade: Does Gravity Work in a Neoclassical World?" appearing in Volume entitled "The Regionalization of the World Economy" from the from the National Bureau of Economic Research
} 
(Harrigan 2002) provides an extensive review of the theoretical foundations of the gravity model of trade.

Another criticism of the gravity model is the usual log linearization of the basic form, which is then used to estimate elasticities, equation (5.43). (Silva and Tenreyro 2006) argue that the log linearization of the gravity model leads to bias by ignoring the zero trade pairs in the data. They propose alternative ways of estimating gravity equations without having to ignore zero-value trading pairs. This stems from the fact that the logarithm of zero is undefined and would therefore not make sense to have $\ln (0)$ in the regression. They propose that the gravity equation and all constant elasticity models should be estimated in the multiplicative form using pseudo maximum likelihood regression techniques, as they naturally take care of zero values. Another well-known trick around the problem of zero values is the arbitrary addition of the value one (1) to all export values, as all zeros would become ones and there is no problem with the logarithm of one $(\log (1)=0)$ in the regression. This is the approach we take in this study.

It is interesting to note the implications of the gravity formulation for sub-Saharan African countries. Most SSA countries have strong ties with their former colonial rulers and are more likely to have larger volumes of trade with these countries than with countries they share borders with. These relations however have become weaker over the years and countries with more access to telecommunications and other trade-enabling infrastructure have become more independent of their former colonial ties and are able to export their products to a wider variety of trading partners. A quick comparison of exports from Zambia and from South Africa from 2007 IMF Direction of Trade data reveals a strong gravity tendency for Zambia but a very weak one for South Africa (figure 5.3 and figure 5.4). 


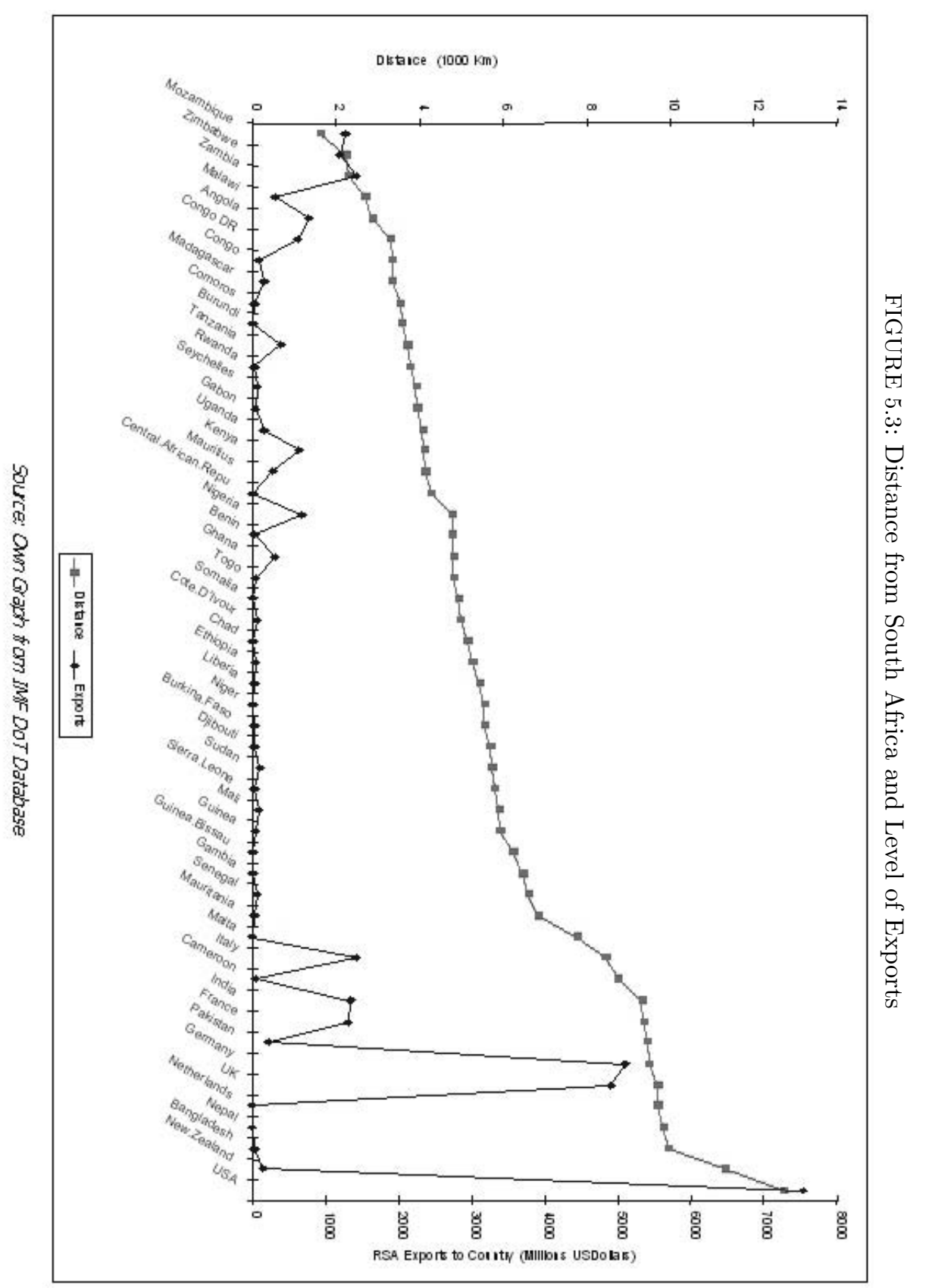


5. Communication Costs and Trade in sub-Saharan Africa

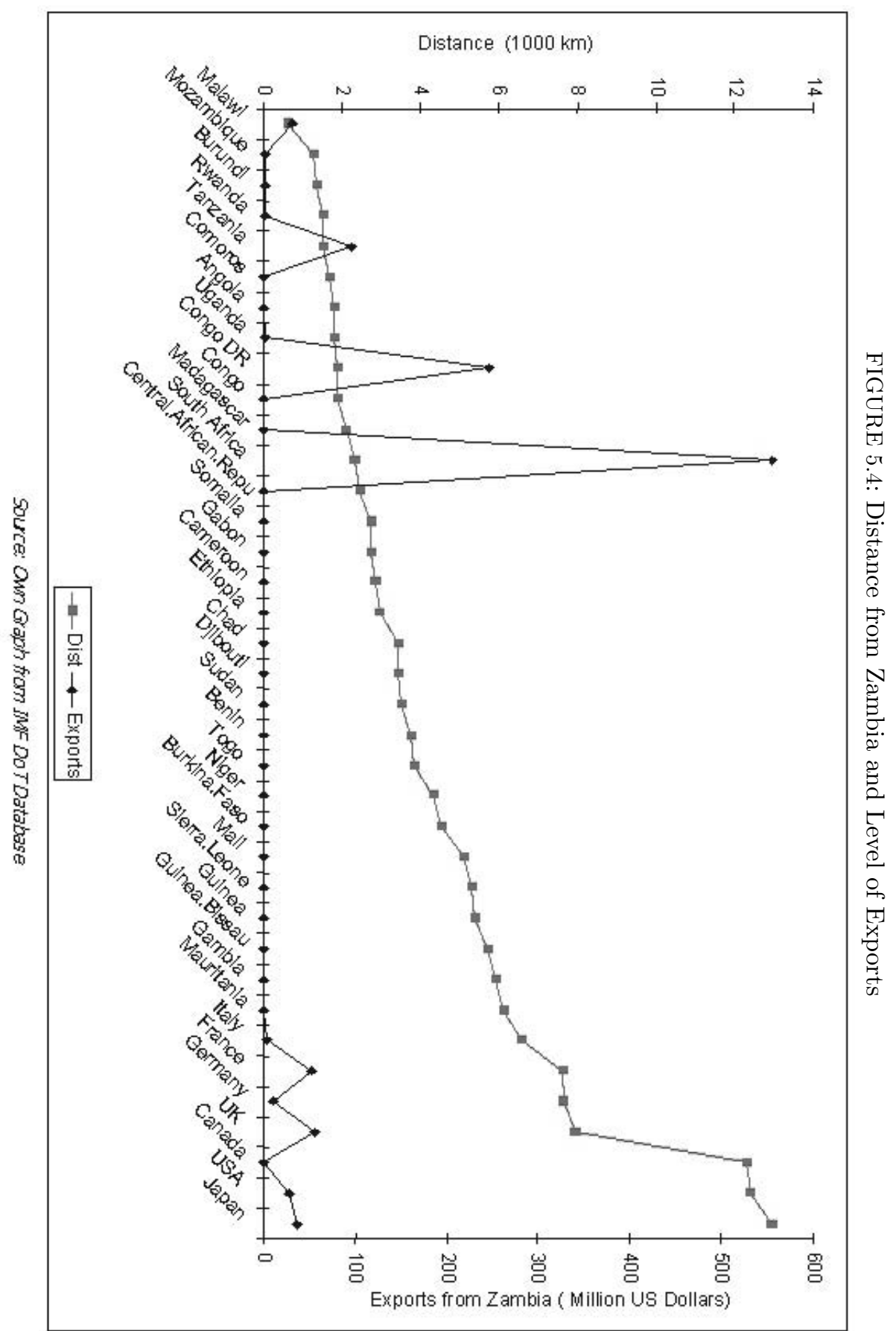


The figures show that although South Africa trades with its neighboring countries, its levels of trade with far away developed countries are far higher than its levels of trade with neighboring African countries. Exactly the opposite is the case for Zambia, which has its highest trade volumes for 2007 with its nearby trading partners. Could it be that, among other advantages, South Africa's easier and relatively cheaper access to international connectivity does help to facilitate its trade with far away countries? South Africa has direct access to undersea fibre cable, which until recently was not available to most countries in SSA (see discussion in chapter 4), which had to rely on expensive satellite capacity for their international connectivity. The case of South Africa may also be a special one in that South Africa has a more developed manufacturing sector and a wider range of export possibilities than most SSA countries. We test the statistical significance of this apparent advantage of access to cheaper telecommunications on level of exports in SSA, all things being equal.

\subsection{The Empirical Model}

We model the effects of communication costs on trade using an augmented version of gravity equation 5.43, which emphasizes the relative economic masses of the interacting countries as well as their access to international connectivity. The following is the multiplicative form of our empirical model:

$$
\begin{aligned}
& X_{i j}=A \cdot \frac{G_{D} P_{j}^{\beta_{1}} \cdot G D P_{i}^{\beta_{2}}}{\text { Dist }_{i j}^{\beta_{3}}} \cdot \text { Fixed }_{i j}^{\beta_{4}} \cdot \text { Bband }_{i}^{\beta_{5}} \cdot \text { MA_OTRI }_{i}^{\beta_{6}} \cdot \\
& \cdot \text { OTRI }_{j}^{\beta_{7}} \cdot \text { Outgoing }_{i}^{\beta_{8}} \cdot \text { Landlocked }_{i}^{\beta_{9}} \cdot \text { ComBorder }_{i j}^{\beta_{10}} \cdot \text { Satellite }_{i}^{\beta_{11}}
\end{aligned}
$$

Dividing both sides of equation 5.44 by $G D P_{i}$ and then taking logs gives us an intensity version of the dependent variable $X_{i j}, \ln$ Xintensity $_{i j}=$ $\ln \left(\frac{X_{i j}}{G D P_{i}}\right)$, where $X_{i j}$ is the total volume of exports from country $i$ to country $j$ measured in current dollar values for the year 2007. This results in equation 5.45 .

$$
\begin{gathered}
\ln \text { Xintensity }_{i j}=\beta_{0}+\beta_{1} \ln G D P_{j}+\left(\beta_{2}-1\right) \ln G D P_{i}+-\beta_{3} \ln \text { Dist }_{i j} \\
+\beta_{4} \ln \text { Fixed }_{i j}+\beta_{5} \ln \text { Bband }_{i}++\beta_{6} \ln M A \_O T R I_{i}+\beta_{7} \ln \text { OTRI }_{j} \\
+\beta_{8} \ln \text { Outgoing }_{i}++\beta_{9} \ln \text { Landlocked }_{i}+\beta_{10} \text { ComBorder }_{i j}+\beta_{11} \text { Satellite }_{i}+\varepsilon_{i j}
\end{gathered}
$$

This is the value of exports relative to the production size of the exporting partner. Along with the geographical variables of distance, landlockedness 
and sharing a common border we introduce the costs of bilateral communication and the cost of broadband in the exporter country into the equation. Only intra-African countries are taken into consideration.

We expect the export intensity in exporter country i to be correlated with the amount of information exchanged and exchangeable between traders in different countries. In this regard any variable that impacts the acquisition and transmission of this information in a country will also impact the volume of trade ${ }^{2}$.

$G D P_{i}$ and $G D P_{j}$ are the gross domestic products of countries $i$ and $j$ representing the economic masses of trading pairs measured in current 2007 dollars $^{3}$. Traditional gravity studies have consistently found that the economic masses of trading pairs matter, such that we expect bigger economies to trade more than smaller ones. We therefore expect positive signs on the coefficients of $G D P_{i}$ and $G D P_{j}{ }^{4}$. We retain $G D P_{i}$ as an explanatory variable in spite of the fact that it is accounted for in the dependent variable because we also need to account for the effect of GDP size of exporting country on export intensity separately.

Dist $_{i j}$ is the geographic distance between exporter country $i$ and importer country $j$, measured as the distance between their capital cities in kilometers. Distance has been used in gravity estimations as a proxy for cost of transport in trade models. It has traditionally been found to have a strong negative effect on trade flows and we expect a similar result ${ }^{5}$

Fixed $_{i j}$ is the cost of an international call from a fixed landline telephone from country $\mathrm{i}$ to country $\mathrm{j}$. This variable is critical information to our study as we have surmised generally that most international connections in SSA go over satellite or fibre cable gateways (sometimes even for neighboring countries). This variable, like distance, is a direct measure of communication related obstacles to trade and we expect its effect to be negative and significant.

InBband $_{i}$ is the cost of entry level DSL internet broadband subscription

\footnotetext{
${ }^{2}$ Taking into consideration that if the share of communication cost in trade costs is low but still impacts trade significantly, then communication costs could be capturing other factors that lead to poor communications e.g. poor infrastructure. Communication costs then become a proxy for the physical ability to make connections, which would work differently from a cost plus pricing setting.

${ }^{3}$ We tested the results using PPP Dollar GDP figures and found similar results. We show the results obtained using current dollar figures because these were more readily available in a consistent format than the PPP Dollar GDP figures.

${ }^{4}$ Note that both $\beta_{1}, \beta_{2}>0$ but not necessarily $\beta_{2}<1$ (cf. equation 5.45)and so finding a negative value for $\mathrm{GDP}_{i}$ would not necessarily be inconsistent with the basic assumptions of the gravity model.

${ }^{5}$ the fit could probably be improved by including measures of cultural distance such as language, religion, former colonila rulers etc. But it is hard to imagine that the inclusion of these concepts would qualitatively change the results since both spatial and cultural distance effects would a priori be expected to influence the results in the same direction.
} 
in country i. The cost of broadband in the exporter country is used as an additional indicator of the hurdles to communication that are likely to have a negative impact on trade. Its effect is expected to be negative, like that of fixed telephone calls.

ComBorder $_{i j}$ is a dummy variable signifying whether countries $\mathrm{i}$ and $\mathrm{j}$ share a common border or not. The common border category is related to the distance variable but refers to more than distance alone. It is expected that sharing borders will in most cases include sharing languages and cultures, common infrastructure etc., which together are expected to facilitate rather than hamper trade between country pairs. We therefore expect a positive sign on this variable.

Landlocked $_{i}$ is another dummy showing whether the exporting country i is landlocked or not. Landlocked countries are limited by not having access to the sea. In terms of communications, which is our prime concern, the fiber connection to the outside world, which is supposed to be cheaper than satellites, is not easily accessible from inland. This makes landlocked countries more dependent on satellite connectivity to the extent that all landlocked countries in Africa are dependent on direct satellite links for international connectivity. We expect a negative sign on this variable.

Satellite $_{i}$ is another dummy variable showing whether a country is dependent on satellite for international connectivity or not. It takes the value one for countries dependent on satellites and zero for countries not dependent on satellites. All landlocked countries are dependent on satellite connectivity but then so are some coastal countries that do not have access to the fiber cable or who prohibitive price structures from neighbors with fibre cable access. We expect this variable to also enter negatively into the model. Due to the high cost of satellite access, we expect the coefficient on this dummy to be negative and significant.

Outgoing $_{i}$ is the total number of outgoing international calls made in 2007 from country i to the rest of the world. We expect a positive sign on this variable assuming that a higher volume of outgoing calls from country $i$ in the face of high international calling costs indicates important business communications.

$M A \_O T R I_{i}$ is the Market Access Overall Trade Restrictiveness Index, which measures both tariff and non-tariff barriers to trade in country i. The original Trade Restrictiveness Index was constructed by the IMF in 1997 (IMF,2005; Nicita and Olareaga, 2006; Perez and Wilson 2008) and has been refined over the years to its current form ${ }^{6}$. We use this estimation to represent the obstacles that selected trade barriers offer to a country's access to outside markets. This index effectively accounts for tariff and nontariff barriers imposed by the rest of the world on each country's export

\footnotetext{
${ }^{6}$ See Review of the IMF's Trade Restrictiveness Index , 2005 on http://www.imf.org/External/np/pp/eng/2005/021405r.htm
} 
bundle. In order to capture obstacles posed by the receiving country $j$, we include a similar index, the Overall Trade Restrictiveness Index $\left(\mathrm{OTRI}_{j}\right)$, which is calculated differently to capture a country's protective policies' effect on its import bundle ${ }^{7}$. With this we basically capture trading partner j's resistance to country i's export efforts. We expect both variables to have negative signs.

We take care of the zero trade values by adding 1 to the Export $_{i j}$ series before calculating the export intensity, Xintensity $_{i j}$ series and taking logs, see (Linders Gert-Jan and F.Henri 2006).

The variables and expectations with regard to the signs of the coefficients are summarized in table 5.1.

\footnotetext{
${ }^{7}$ Details of how these indices are formulated and calculated can be found in Hiau Looi Kee, Alessandro Nicita and Marcelo Olarreaga's work in CEPR Working papers entitled "Estimating Trade Restrictiveness Indices" from 2006 and later revisions (www.cepr.org/pubs/dps/DP5576.asp)
} 


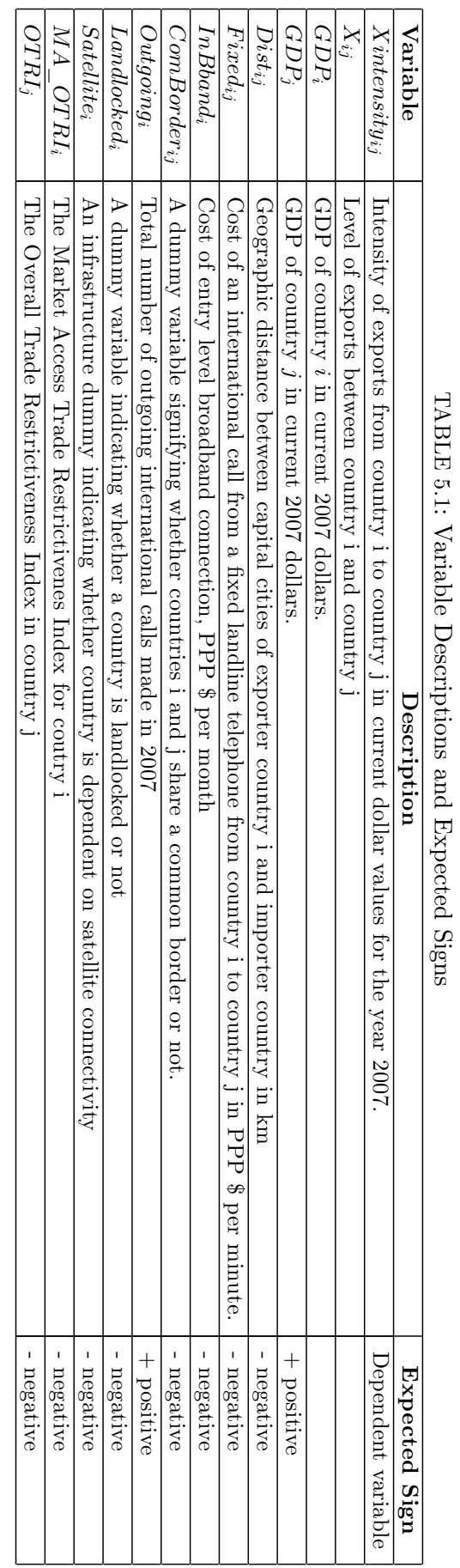


The next step is to look more closely at the differences between two groups of countries:

i. Coastal countries with access to undersea fiber cable and less dependence on satellite capacity for international routing.

ii. Landlocked countries with no access to undersea fiber cable and dependent on satellite for their international traffic.

As explained earlier (section 4.2.3), there would normally be a vast difference between the cost of satellite connectivity and the cost of fiber connectivity in favor of fiber. We expect the effect of communication costs on trade to be higher in landlocked countries than in coastal countries due to their dependence on more expensive satellite international connectivity. This would result in higher values of the coefficients of lnFixed and lnBband in the sub-sample of landlocked countries, than in the total sample of countries or the sub-sample of coastal countries.

The alternative scenario is the imperfect market scenario, where we have monopolistic rents being charged on fibre connectivity as well, due to the presence of monopolies along the SAT3 fiber cable operation. If the alternative scenario obtains, we should find no significant differences between the effect of communication costs in landlocked countries and in coastal countries.

Things are further complicated by the fact that not all countries along the coastline have access to undersea optical fiber cable. Countries along the coast without a fiber landing point will use satellite or will buy capacity from countries that do have a landing point. In the latter case they have no control over how much they pay. If the countries with landing points are able to charge monopoly rents in the alternative scenario, being on the coast does not necessarily guarantee cheap access to the international backbone. Again this will make for fewer differences between coastal and landlocked countries.

It remains to be seen, however whether the continuing roll out of more fibre optic cable along the East and West African coastline will change this dynamic in the near future in response to more competition.

\subsection{The data}

Several data sources were used to construct the main matrix of country pairs. Bilateral exports data was sourced from the IMF Direction of Trade database and the United Nations COMTRADE database. Distance data between countries' capitals was sourced from John Byers site chemical ecology $^{8}$. Another important source of data was the World Development Indicators database of the World Bank. Publications of the International

\footnotetext{
${ }^{8}$ http://www.chemical-ecology.net/java/lat-long.htm
} 
Telecommunications Union (ITU) provided most of the data for ICT indicators particularly the broadband cost in SSA countries. These included the 2009 publication "Africa Telecommunications Indicators 2008" and "Measuring The Information Society 2008 ITU". GDP figures were sourced from the Word Development Indicators database of the World Bank for the year 2007. These figures were matched with the corresponding 2007 levels of export and international calling prices. We used various sources for this data depending on availability. Most of it was sourced directly from different countries national telecommunications web sites, directories and Communications Authorities.

We used a cross section of 2007 data for 19 countries in Sub Saharan Africa mainly due to the fact that fixed telephony data was difficult to collect retrospectively. In certain countries like Nigeria for example, the incumbent fixed telephone operator was privatized and the ensuing state of transition made it difficult to collect any meaningful series of retrospective data. Another factor was the fact that in countries where time series data was available like Zambia, Togo, and Malawi, there was very little fluctuation, if any, in the price of international calls charged by the fixed service providers between successive years. Massive movements in price were evident in local call charges, mainly due to competition from cheaper local mobile cellular providers, but international call charges did not change much for successive years.

\subsection{Estimation Results}

Anderson and Wincoop (2003) show that estimation of the gravity equation in the presence of heteroskedasticity leads to biased estimates of the coefficients and this coupled with the omission of zero trade values (the so called zero omission bias) makes estimation of this model produce biased results. They propose a Pseudo Maximum Likelihood estimation of the equation and show that it gives more robust estimates and naturally takes care of the zero trade values. As explained earlier, in our analysis we add the value one (1) to all the export values in the series to avoid losing zero-valued export entries. We first do an OLS analysis and then compare the results with Maximum Likelihood (ML) estimates. We do not find much difference between the two approaches in the direction and significance of the variables. The magnitudes of the coefficients are however much higher in the OLS regressions than those in the ML regressions and we should be wary of interpreting elasticities with these. The ML regressions report a $12 \%$ increase in export intensity due to a one percentage drop in fixed line calling costs. This is still very high considering that this is a cross sectional analysis. The high elasticities may be indicative of switches from low economic mass partners to high economic mass partners, implying cross- 
effects between costs and mass not accounted for in the standard gravity specification. This is an aspect of the study we will investigate in further research with more spatially oriented techniques.

For the sub-samples of landlocked and coastal countries the Maximum likelihood regressions failed to run, probably because of limited sub-sample data. So we only show the OLS tables for the sub-samples of landlocked and coastal countries. Table 5.2 and 5.3 present the results of our econometric analyses of the full dataset.

Our OLS estimation results reveal the expected signs on all the variables. $\ln D i s t_{i j}$ is negative and significant at the $1 \%$ level. $\ln G D P_{i}$ and $\ln G D P_{j}$ both come out positive and significant at the $1 \%$ level as well. These variables all keep their signs and significance after more variables are added to the model. $\ln$ Outgoing $_{i}$ enters the model significantly but drops its

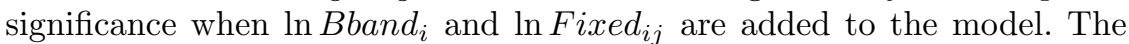
volume of outgoing calls was expected to be positively correlated with export intensity and negatively correlated with the cost of making a fixed call. We see from the correlation matrix in table 5.7 that this is actually so. $\ln$ Bband $_{i}$ is the cost of broadband connection in the exporter country and $\ln$ Fixed $_{i j}$ is the cost of making a fixed line call in the exporter country. These costs are expected to increase the cost of trade transactions between countries and are therefore expected to have negative coefficients. This expectation is consistently met in our estimation results for both OLS and ML approaches.

$\ln M A O T R I_{i}$ and $\ln O T R I_{j}$ are both negative and significant in the OLS regression, but $\ln M A O T R I_{i}$ comes out with the wrong sign in the ML regressions. This is not what we expected and the result is difficult to explain as the index is constructed to capture factors within country $i$ that work to reduce rather than increase trade. The common border dummy is positive and significant in both the regressions as we expected as sharing a common order in most cases also means sharing communication channels and other natural resources that facilitate trade between neighboring countries. The landlocked and satellite dummies also turn out with the expected signs in both regressions.

The standard errors in the ML regressions are generally smaller than these reported in the OLS regression. The ML regressions are therefore more reliable predictors in our case.

The results broadly confirm our proposition that costs of international connectivity is a limiting factor in trade in SSA. From the ML regression we see that an increase of $1 \%$ in the cost of international calling in SSA would result in a $12 \%$ drop in export intensity, which is very high. This being a cross-section analysis the large increase in exports due to a one percent drop in cost may imply a switch from a low economic mass partner to a higher economic mass partner pointing to cross effects between costs 


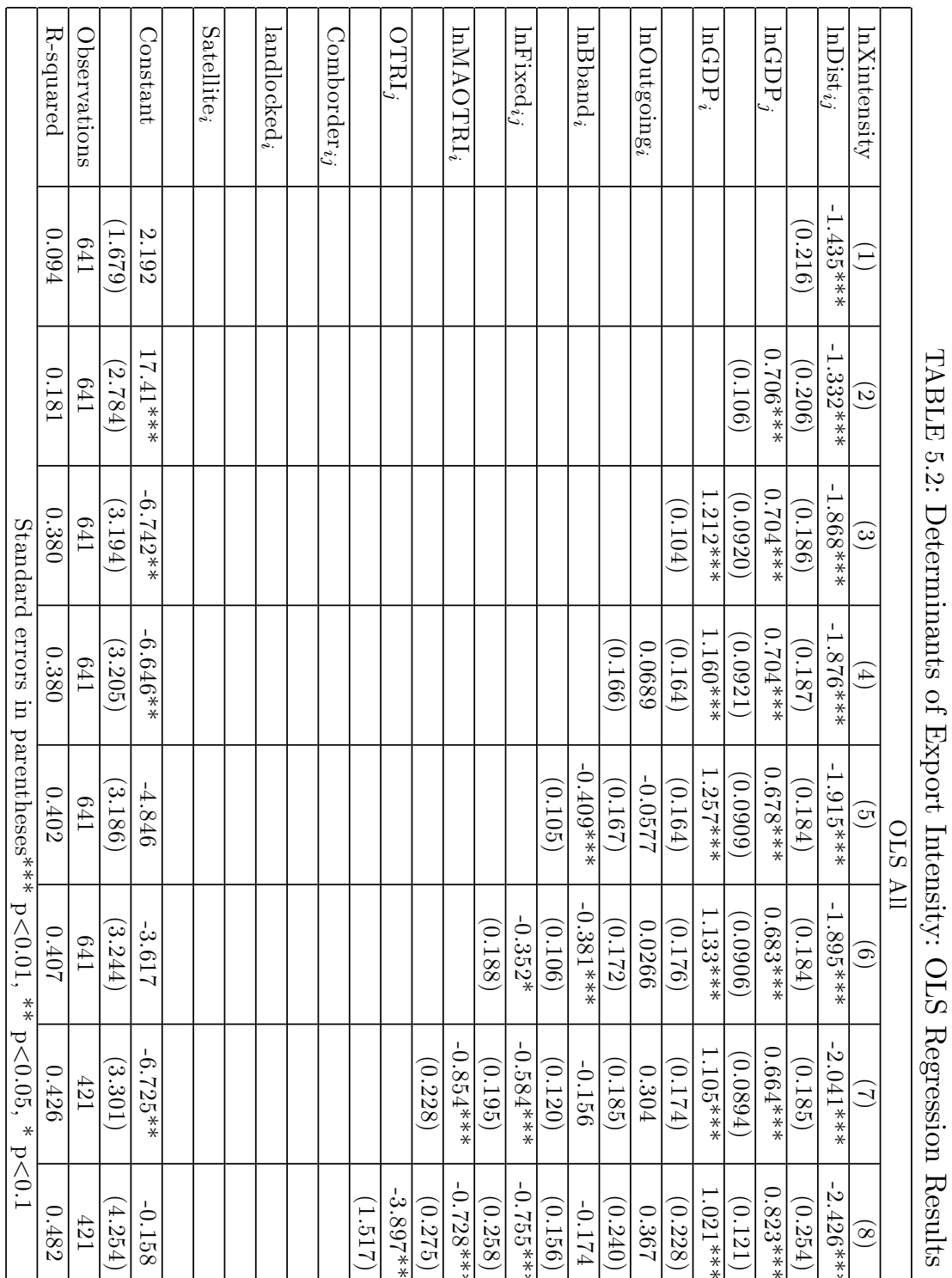

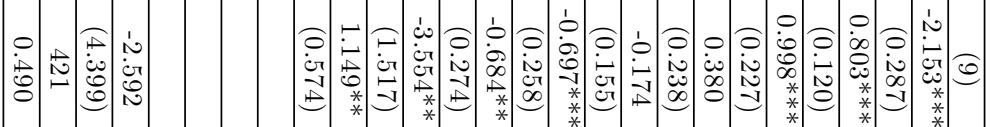

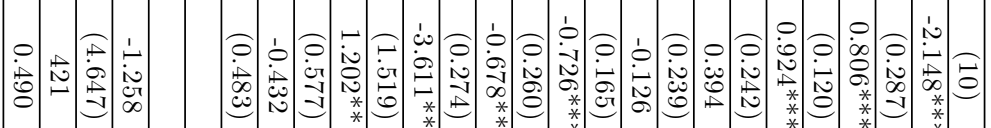

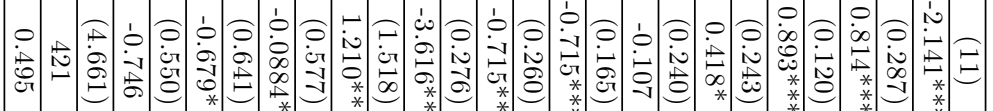




\begin{tabular}{|c|c|c|c|c|c|c|c|c|c|c|c|c|c|c|c|c|c|c|c|c|}
\hline & & 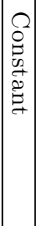 & 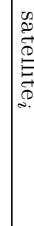 & & 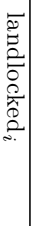 & & 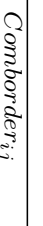 & $\mid \begin{array}{c}3 \\
0 \\
3 \\
3 \\
0 \\
0\end{array}$ & & 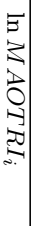 & 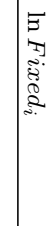 & & 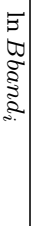 & 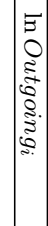 & & $\mid \begin{array}{l}z \\
8 \\
0 \\
0\end{array}$ & $\begin{array}{l}5 \\
0 \\
0 \\
0\end{array}$ & & & \\
\hline & 宫 & 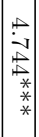 & & & & & & & & & & & & & & & & $\begin{array}{l}\dot{\partial} \\
\dot{\infty}\end{array}$ & & \\
\hline & $\begin{array}{l}2 \\
0 \\
0 \\
0 \\
\Leftrightarrow\end{array}$ & & & & & & & & & & & & & & & ב & $\left\{\begin{array}{l}0 \\
\dot{c} \\
\dot{c} \\
* \\
* \\
*\end{array}\right.$ & $?$ & & \\
\hline & 岂 & 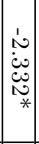 & & & & & & & & & & & & & 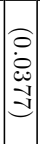 & 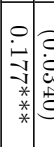 & 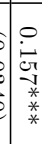 & 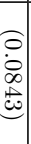 & & \\
\hline & 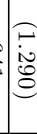 & 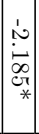 & & & & & & & & & & & $\$$ & 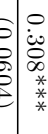 & $\mid \begin{array}{l}\hat{0} \\
0 \\
0 \\
0 \\
ن \\
ن\end{array}$ & $\begin{array}{ll}1 \\
\vdots \\
0\end{array}$ & 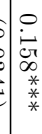 & 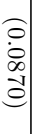 & $\begin{array}{l}\vdots \\
\vdots \\
\vdots \\
2 \\
* \\
* \\
*\end{array}$ & \\
\hline & 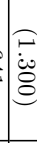 & 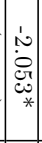 & & & & & & & & & & $\begin{array}{l}0 \\
0 \\
0 \\
0 \\
0 \\
0 \\
0\end{array}$ & 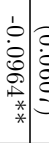 & 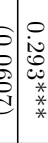 & 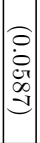 & 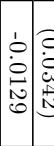 & 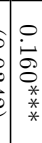 & $\begin{array}{l}\stackrel{\partial}{0} \\
\dot{0} \\
\text { जै } \\
\text { v }\end{array}$ & 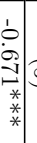 & $\widehat{c r}$ \\
\hline & تِنَ & $\begin{array}{c}\dot{1} \\
\dot{2} \\
\overrightarrow{2} \\
\sigma^{2}\end{array}$ & & & & & & & & & 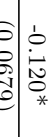 & 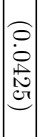 & 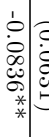 & 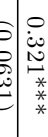 & $\begin{array}{l}\widehat{\partial} \\
0 \\
\dot{0} \\
0 \\
0 \\
0\end{array}$ & 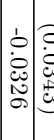 & 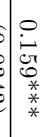 & 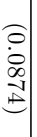 & 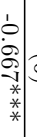 & \\
\hline & 瓶 & $\mid \begin{array}{c}c \\
0 \\
\rho \\
\rho \\
* \\
* \\
* \\
*\end{array}$ & & & & & & & 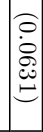 & 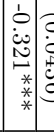 & 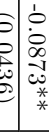 & 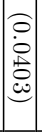 & 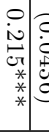 & 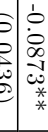 & 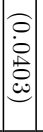 & 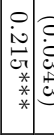 & 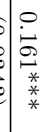 & 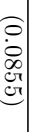 & & \\
\hline & & 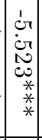 & & & & & 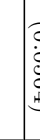 & 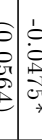 & 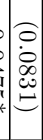 & 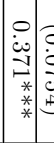 & 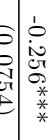 & 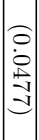 & 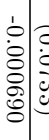 & 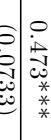 & 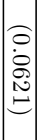 & 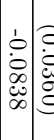 & 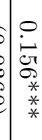 & 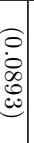 & & \\
\hline & نَ & 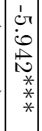 & & & & $\begin{array}{l}0 \\
\dot{0} \\
\dot{0} \\
\dot{\infty} \\
\end{array}$ & 惫 & 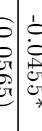 & 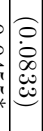 & 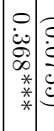 & 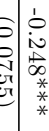 & $\left|\begin{array}{l}\partial \\
0 \\
0 \\
\vdots \\
0 \\
\infty\end{array}\right|$ & 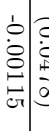 & 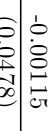 & 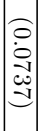 & 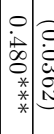 & 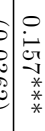 & 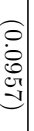 & 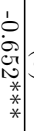 & 6 \\
\hline & 总 & $\mid \begin{array}{c}0 \\
0 \\
0 \\
0 \\
7 \\
* \\
* \\
*\end{array}$ & & 总 & i⿱ & 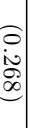 & $\begin{array}{lll}\circ & \\
* \\
*\end{array}$ & 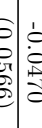 & $\begin{array}{l}\partial \\
\dot{0} \\
\dot{0} \\
\dot{0} \\
\dot{0} \\
0\end{array}$ & 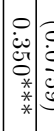 & 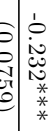 & 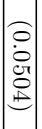 & 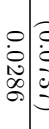 & 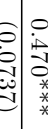 & 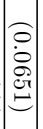 & 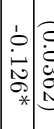 & 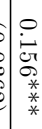 & $\begin{array}{l}\hat{0} \\
\dot{0} \\
\stackrel{0}{0}\end{array}$ & & $\widehat{E}$ \\
\hline & $\stackrel{\overrightarrow{0}}{\stackrel{0}{0}}$ & $\mid \begin{array}{c}0 \\
0 \\
0 \\
* \\
* \\
* \\
*\end{array}$ & & 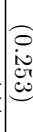 & 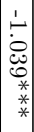 & ज̦ & 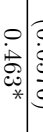 & 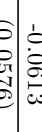 & 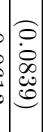 & 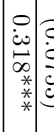 & 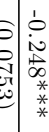 & 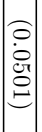 & 过 & 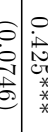 & \begin{tabular}{l}
0 \\
0 \\
$\dot{0}$ \\
$\stackrel{2}{8}$ \\
\hdashline
\end{tabular} & 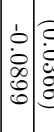 & 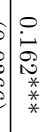 & 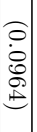 & 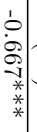 & $\vec{E}$ \\
\hline
\end{tabular}


and mass not accounted for in the standard gravity specification. This is another area for further investigation with more spatially oriented tools.

Most important for our study is the result that cost of international fixed line calling and cost of broadband are negatively associated with the intensity of exports from country of origin. We have associated high costs on international calling in Africa to the use of expensive satellite and fiber gateways. This result implies that any reorganization of these international gateways to bring down the cost of international calling and broadband connections should have a positive effect on exports within SSA.

We have run separate regressions for coastal and landlocked countries to see whether the effects of the price of connectivity is more pronounced in landlocked countries (see discussion in section 5.3). The results are shown in tables 5.4 and 5.5).

We find a strong negative effect of cost of broadband on coastal regions in spite of the presence of fibre optic cable on the west coast of Africa (see table 5.5 and 5.6). This would indicate that although the fibre optic cable is present it may not be as accessible as it is meant to be, leaving coastal countries with no option but to connect via satellite. On the other hand the effect of fixed lines calling cost on landlocked countries is much higher than in coastal regions, affirming our proposition that the cost of international connectivity in the interior must be more prohibitive than at the coast. The satellite dummy turns up negative and significant. Furthermore trade is generally higher in countries with lower connectivity costs.

Figure 5.5 shows the scatter plot for sub Saharan Africa. Exports are generally very low to countries with high calling rates per minute. The scatter plot shows a clear pattern of high bilateral call charges and low exports and a general trend of low bilateral calling charges and high exports. Although we have a lot of countries in the low calling cost/low export area of the plot, we do not have a single country in the high calling charge/high export area of the plot. This pattern is consistent with the regression results in table 5.2 and table 5.3, which show a negative significant coefficient for log of fixed call bilateral charge. These findings seem to suggest a strong relationship between affordable connectivity and export levels of a country ${ }^{9}$.

\subsection{Conclusion and Summary}

Adding variables representing the cost of international connectivity to a traditional gravity equation, we find that international communication costs

\footnotetext{
${ }^{9}$ Given the high frequency of low levels of trade as depicted in the figure, other models like the Threshold model could probably capture the relationship more accurately. This is an interesting avenue for further research
} 


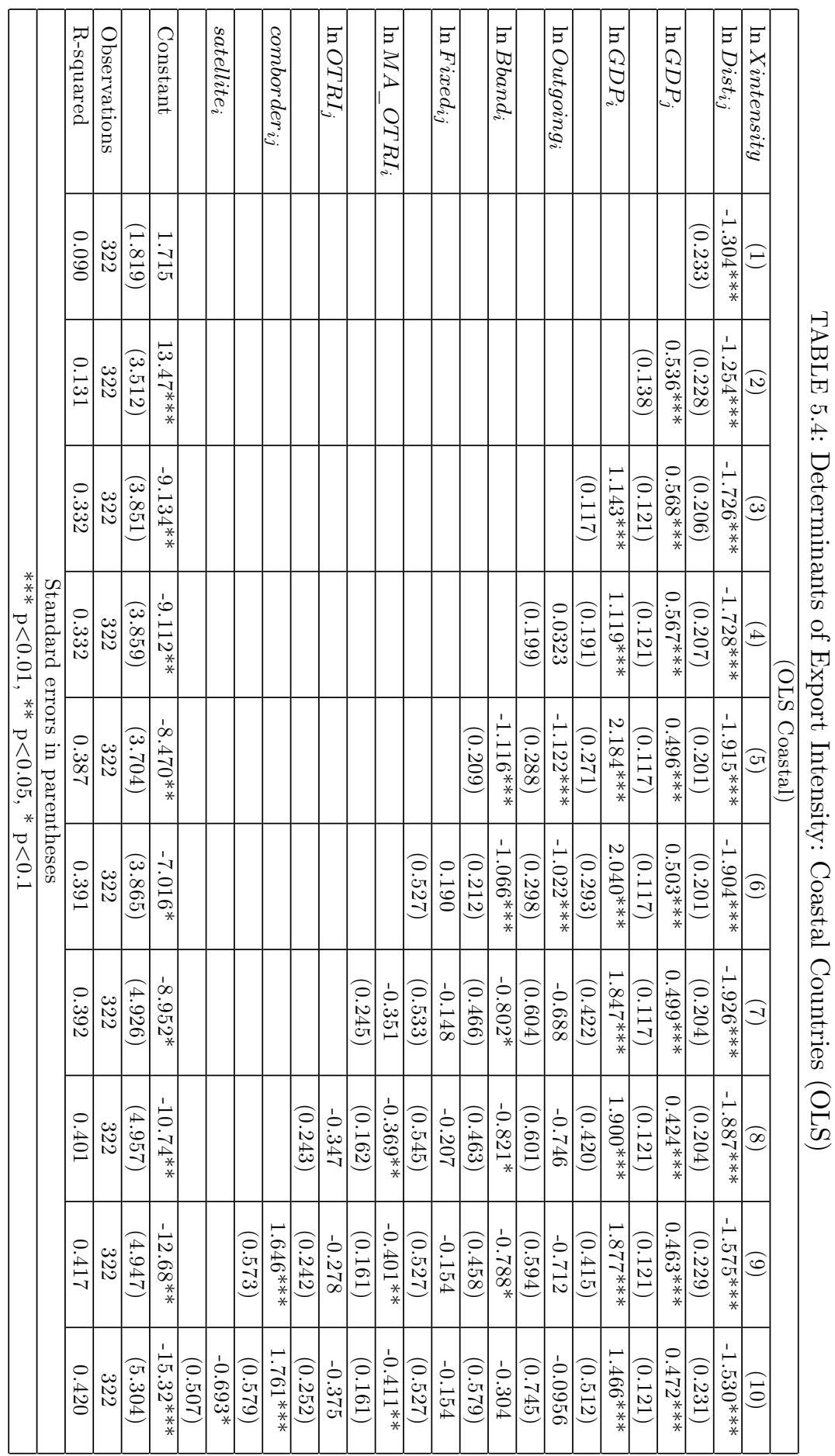




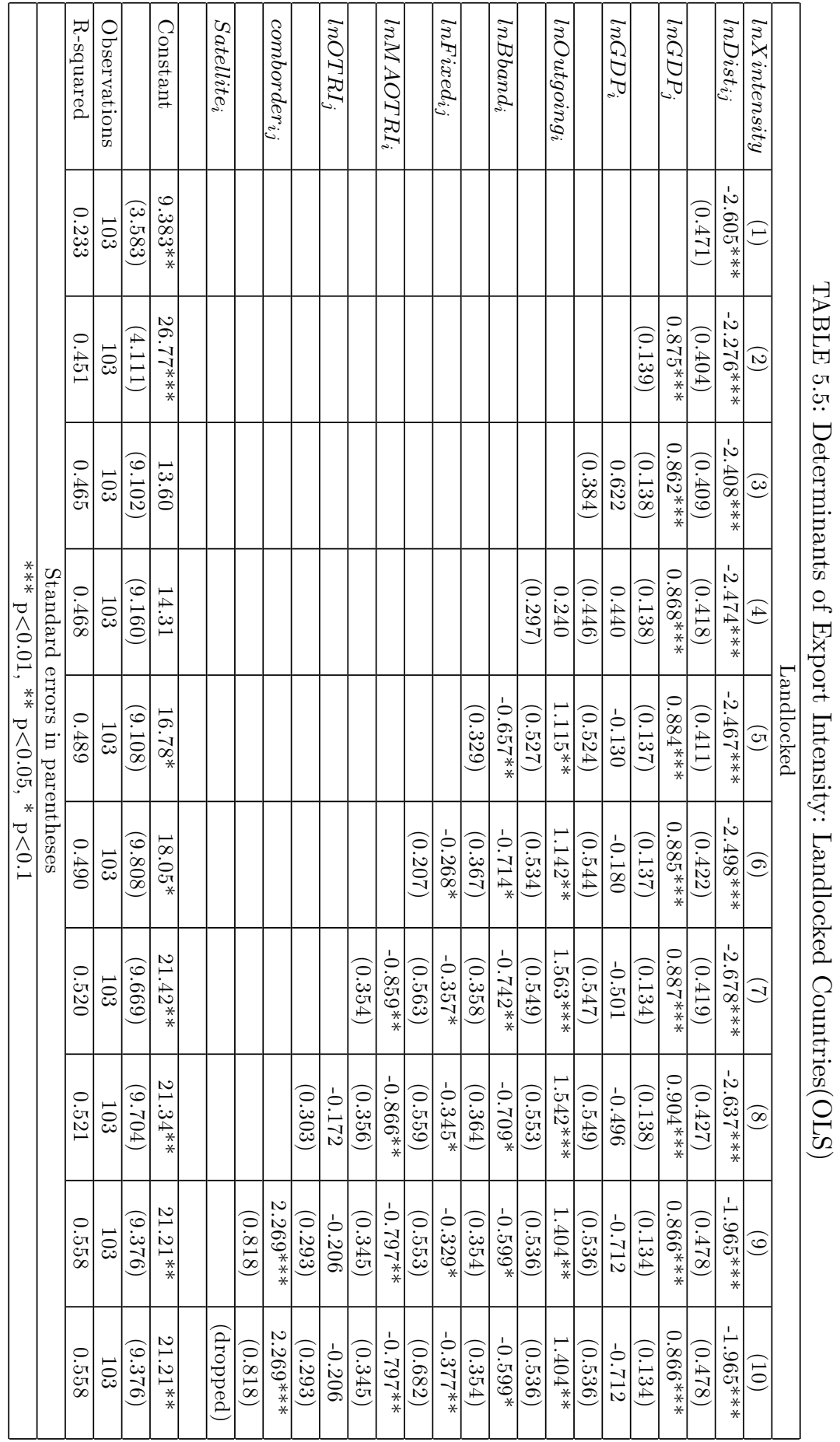


FIGURE 5.5: Level of Exports and International Calling Charges in SSA (2007)

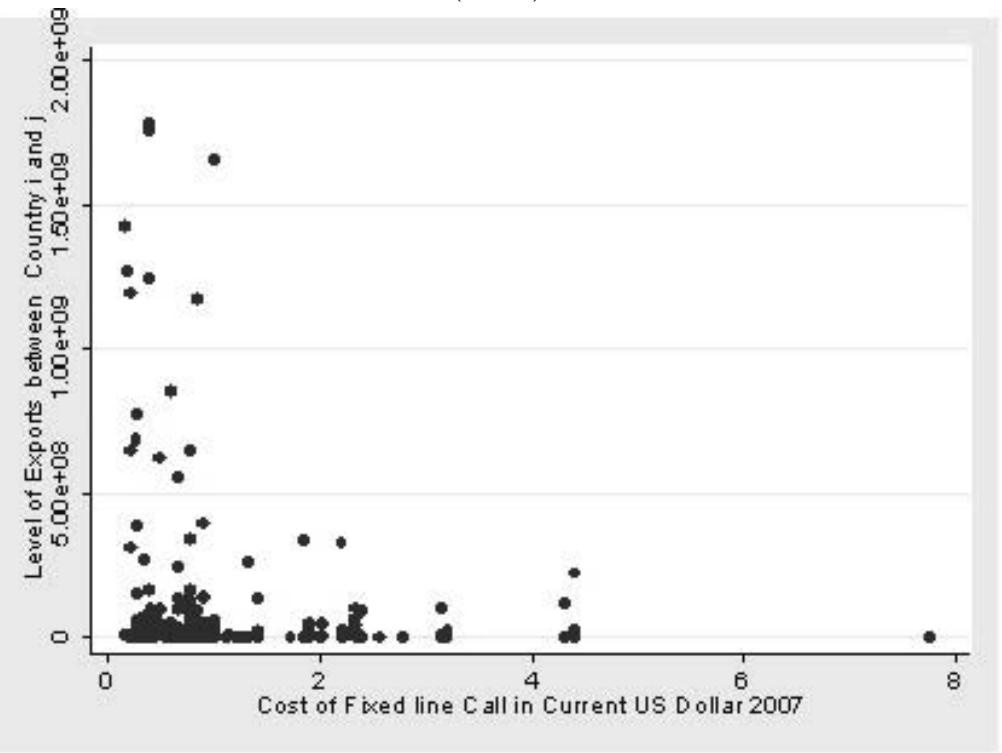

Saure: Own graph from the compied dota 
have a significant negative effect on the volume of trade in SSA. This implies that efforts aimed at reducing the cost of international communications in Africa will contribute to the reduction of trade friction and increase trade. A review of the secondary literature indicates that increased trade has a positive effect on growth. Thus expansion of trade through reduced communication costs will indirectly contribute to economic growth in sub Saharan Africa.

Given present market conditions, the indirect effect of the existing infrastructure of satellites and optical fiber gateways is negative because it results in too high international calling rates and broadband connectivity costs. Our results provide strong arguments for investing in both technologies and policies that will reduce international communication costs across the board in Africa.

\section{A Data Summary}

TABLE 5.6: Data Summary for main Variables of the Model

\begin{tabular}{|l|r|r|r|r|r|}
\hline Variable & Obs & Mean & Std. Dev. & Min & Max \\
\hline Xintensity $_{i j}$ & 641 & 0.0227435 & 0.464593 & 0 & 11.75579 \\
\hline GDP $_{i}$ & 641 & $3.36 \mathrm{e}+10$ & $2.01 \mathrm{e}+11$ & $5.75 \mathrm{e}+10$ & $7.35 \mathrm{e}+08$ \\
\hline GDP $_{j}$ & 641 & $1.73 \mathrm{e}+10$ & $4.00 \mathrm{e}+10$ & 797 & $2.83 \mathrm{e}+11$ \\
\hline Exports $_{i j}$ & 641 & $1.78 \mathrm{e}+09$ & $3.89 \mathrm{e}+07$ & 0 & $1.80 \mathrm{e}+08$ \\
\hline Fixedline $_{i j}$ & 641 & 1.404949 & 1.161086 & 0.1466667 & 7.764706 \\
\hline Bband $_{i}$ & 641 & 524.8855 & 766.7209 & 29.08 & 2674.25 \\
\hline Dist $_{i j}$ & 641 & 3291.001 & 2044.464 & 84.117 & 17578.84 \\
\hline Outgoing $_{i j}$ & 641 & $7.94 \mathrm{E}+07$ & $1.33 \mathrm{E}+08$ & 2256900 & $5.15 \mathrm{E}+08$ \\
\hline MA_OTRI $_{i}$ & 641 & 0.2019516 & 0.0993664 & 0.012 & 0.49 \\
\hline OTRI & 641 & 0.5667207 & 0.5845199 & 0.043 & 11 \\
\hline
\end{tabular}




\section{B Correlation Matrix}




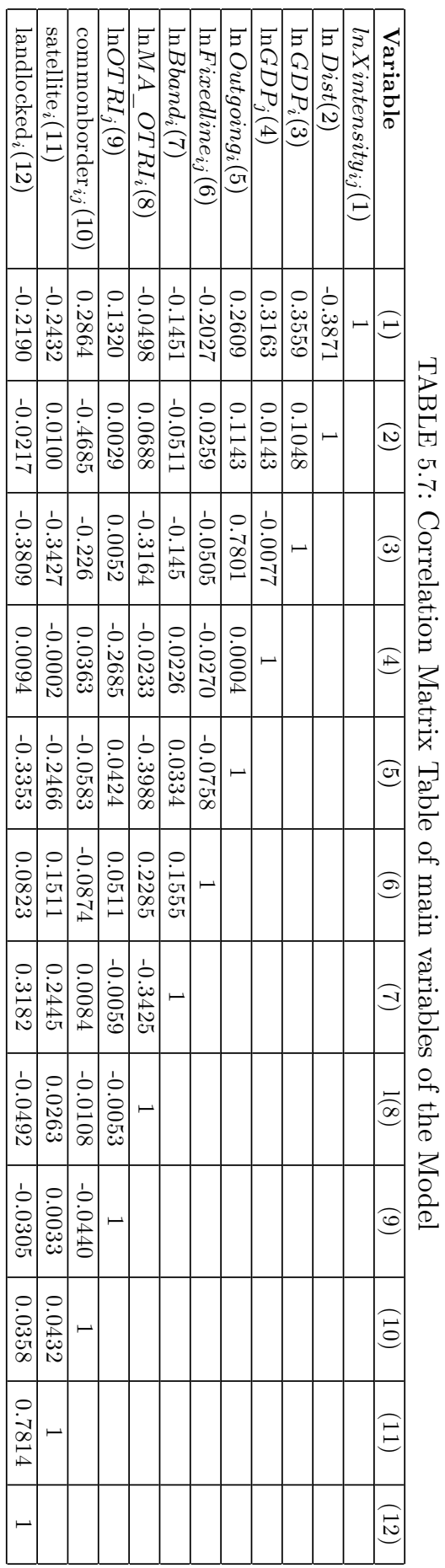


5. Communication Costs and Trade in sub-Saharan Africa

\section{C Descriptive Graphs}




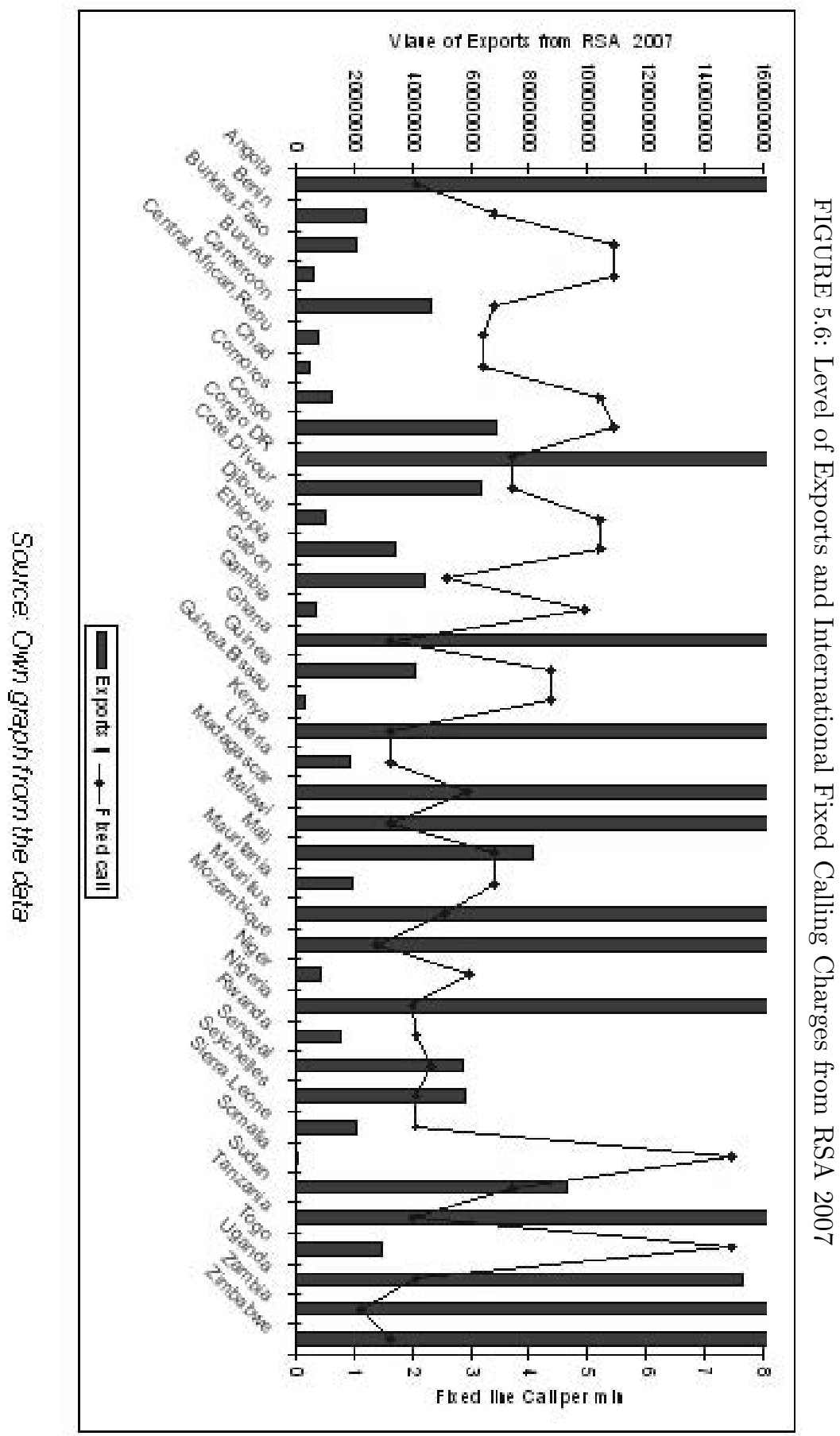


5. Communication Costs and Trade in sub-Saharan Africa

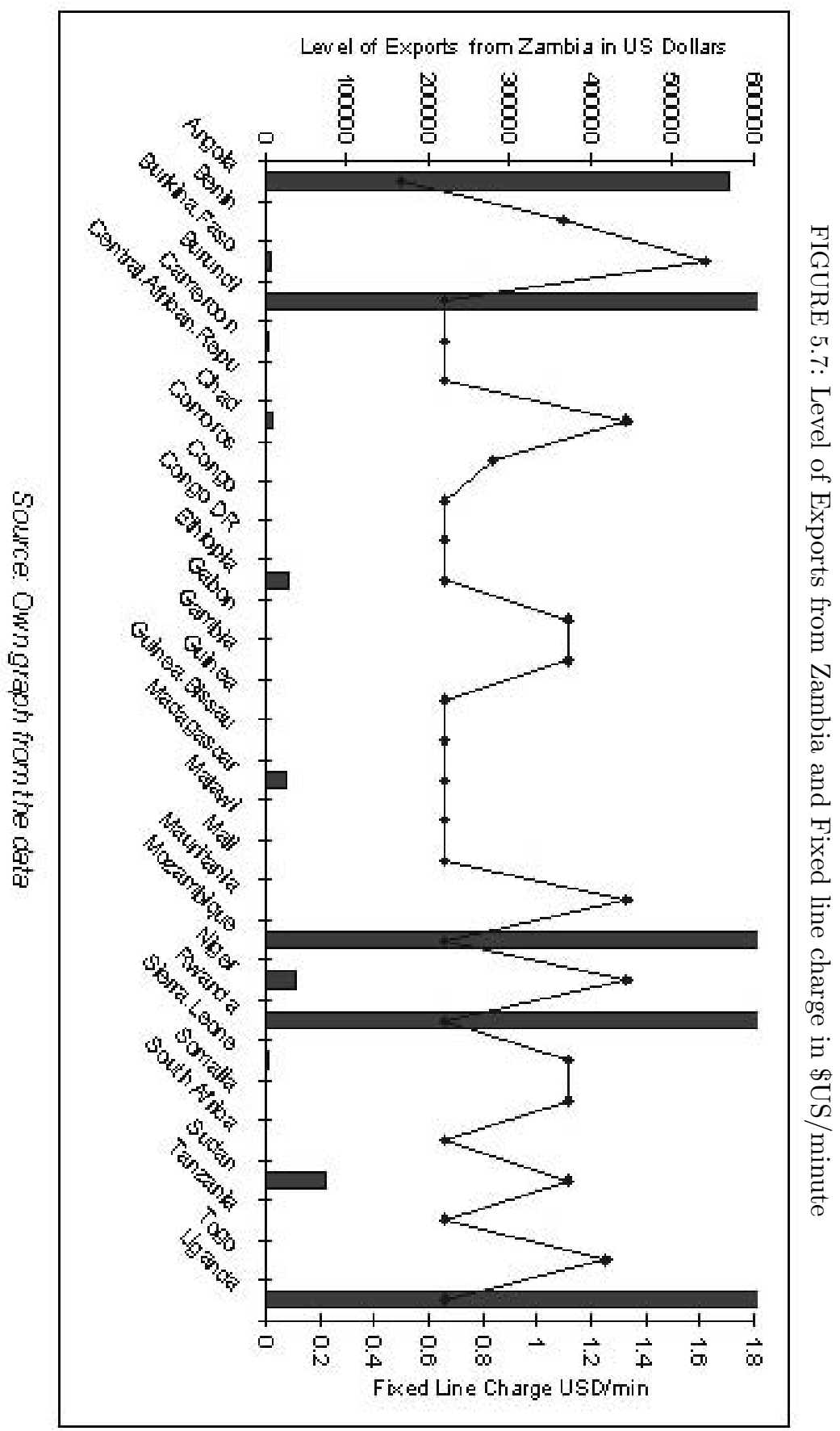


The graphs show the general trend with low exports from countries with high fixed calling charges. Only two graphs from South Africa and Zambia are shown. These graphs are given in support of the regression results in table 5.2. 


\section{D List of Countries}

TABLE 5.8: List of Countries

\begin{tabular}{|l|l|l|l|}
\hline Exporters & Importers & & Landlocked \\
\hline Angola & Angola & Mauritania & Burkina Faso \\
\hline Benin & Benin & Mauritius & Burundi \\
\hline Burkina Faso & Botswana & Mozambique & Central African Republic \\
\hline Burundi & Burkina Faso & Namibia & Chad \\
\hline Cote D'Ivoire & Burundi & Niger & Ethiopia \\
\hline Ghana & Cote D'Ivoire & Nigeria & Lesotho \\
\hline Kenya & Cameroon & Papua New Guinea & Malawi \\
\hline Liberia & Central African Republic & Rwanda & Mali \\
\hline Malawi & Chad & Senegal & Niger \\
\hline Mauritius & Comoros & Seychelles & Rwanda \\
\hline Mozambique & Congo & Sierra Leone & Swaziland \\
\hline Namibia & DRC & Somalia & Uganda \\
\hline Niger & Djibouti & South Africa & Zambia \\
\hline Nigeria & Equatorial Guinea & San Tome and Pricipe & \\
\hline Senegal & Ethiopia & Sudan & \\
\hline South Africa & Gabon & Tanzania & \\
\hline Tanzania & Gambia & Togo & \\
\hline Togo & Ghana & Uganda & \\
\hline Zambia & Guinea & Zambia & \\
\hline & Guinea Bissau & Zimbabwe & \\
\hline & Kenya & & \\
\hline & Liberia & & \\
\hline & Madagascar & & \\
\hline & Malawi & & \\
\hline
\end{tabular}



6

\section{Telecommunications and Household Income in South Africa}

\subsection{Introduction}

In this chapter we investigate the relationship between telecommunications and household income (HI) at municipality level in South Africa. We use telecommunication and household income figures for municipalities in South Africa from the Department of Statistics, StatsSA. A municipality is the smallest unit of democratically elected government in the country and lies one level below provincial government. Every province is subdivided into municipalities which have their own fiscal budgets for service delivery and every municipality is further divided into wards. We use national census data from 1996, 2001 and 2007. The 2007 data are not real census data as no census was conducted in this year, but a community survey was conducted to collect census-like data so as to keep track of trends. The exercise was called a mini census and was conducted on a sample of the population. The mini census data were adjusted so as to be comparable at municipality level with prior census data ${ }^{1}$.

Apart from the fact that telecommunications development is heavily linked to geographical considerations, the geographical component of the analysis is very important as it introduces the idea of connected regions (communities), which we developed theoretically in Chapter Three and further studied empirically in Chapter Five when we investigated the effect of communication costs on trade between countries. In this chapter we focus on the role of connectivity at regional level rather than at country level as in the previous chapter.

Connectivity here is represented by access to fixed and mobile phones, radios, television sets and computers. We treat these as variables representing private capital of citizens and firms in these municipalities and look at their interaction with public infrastructure variables, electricity, level of education of the population and fixed line telephone infrastructure. The key question is whether higher use and access to these private and public telecommunications infrastructure in a municipality induces higher

\footnotetext{
${ }^{1}$ See appendix A.1 at the end of the chapter for an excerpt of a disclaimer from Stats SA declaring the data comparable to previous census data.
} 
incomes or whether the higher income from other sources induce more access to telecommunications usage. It is worth noting that for the case of South Africa, which was undergoing massive expansion of telecommunications infrastructure in the period 1996-2007, there was a deliberate policy effort by the new government to expand access to telecommunications country-wide and especially in the previously disadvantaged areas of the country. We would like to find out whether these investments have actually contributed to better incomes in different municipalities of the country. Although South Africa may not be representative of the economic conditions in other African countries, it is still a useful place to start as the geographical factors and income dynamics of the poorer majority of the country are still very much like the rest of Africa.

Since the seminal work of (Hardy 1980), linking telecommunications in 60 countries (both developing and developed) to economic output, many studies have been done to establish the correlation and direction of the causality relation between telecommunications and economic development. In Hardy's work telecommunications was measured by the number of telephones and radios per capita and economic development by GDP per capita. The results of Hardy's work spurred interest in the effect of telecommunications as a new communications revolution was catching on. (Norton 1992) followed on with a study that estimated the effect of the average stock of telephones between 1957 and 1977 on the mean annual growth of output and found that output rises when telecommunications infrastructure is present. (Greenstein and Spiller 1996) found similar results in their investigation of telecommunications infrastructure on economic performance in the US. In their investigation of how telecommunications infrastructure affects economic growth, (Roeller and Waverman 2001) used time series data from 21 OECD countries over a twenty year period and found a significant and positive causal link between them. They also concluded that a critical mass of near universal access to telecommunications infrastructure must be present in order for this investment to have a positive effect on growth. (Oliner and Sichel 2000) found that Information Technology (IT) coupled with communications equipment was largely responsible for the upswing in productivity in the US in the 1990s.

Other corroborating research on developed country data show mixed results with one part of the literature following Roller and Waverman's findings of a strong bidirectional causal link between ICT and economic growth and another part finding little, biased or no such causal link between ICT and growth. (Gillespie and Cornford 2001) found that advanced regions in Europe may have benefited more from the rollout of telecommunications infrastructure than backward ones. (Heeks and Kenny 2001) found similar results, while (Pohjola 2001) and (Mayer 2000) argued that even studies that had found a historical link between ICTs and growth in developed countries failed to find such a link in developing countries. (Garcia-Mila and McGuire 1992) and (Holtz-Eakin 1993) dispute any positive contribu- 
tion of telecommunications to development, though they were writing at a time when positive results of the impact of telecommunications and the internet revolution were hard to quantify even in developed countries and debates on the "Productivity Paradox" were raging (see Brynjolfson, 1993) A more recent work tries to explain the alleged paradox by looking at micro transformations in organizations as opposed to macro country level studies (Turban and Volonino, 2008).

All the above studies use data from developed countries or a combination of both developed and developing countries. Few studies have been done on developing countries alone, let alone Africa. In order to fill this gap and take account of specific conditions prevailing in these countries, (Sridhar and Sridhar 2004) carried out a study centered specifically on developing countries using World Bank and ITU country data tables from 1990 to 2001. They estimated a model using all telephone connections (fixed lines and mobile phones) and find that total telephone penetration positively impacts aggregate output but at much lower levels than those found by Roller and Waverman (2001) for developed countries.

It is hard to find such studies on African economies and even harder to find intra-country studies that examine the effects of telecommunications on income and growth in regions within African economies. Would a concerted effort to realize universal access in African economies bring along the desired economic development and growth effects? This approach would assume that we have decided that causality runs from telecommunications to economic development. Primary research on the effect and direction of telecommunications impact on African economies is crucial for effective policy and investment related decisions in Africa especially as massive resources have already and are still being dedicated to improvement of telecommunications infrastructure on the continent.

It is our view that while cross country studies go a long way in shedding light on the relationship between telecommunications and economic development and growth, as evidenced in some of the aforementioned studies, they fail to capture the intra-country dynamics such as growing poverty gaps in the face of a growing middle class, rapid increase in access to technology in both rural and urban areas among others, that are crucial for the formulation of local investment and development policies. The gap in the literature, especially on sub-Saharan Africa, is still very wide and begs attention. Studies using local African data are needed to support or refute results obtained from developed countries. This is the gap we try to fill in this chapter.

South Africa is probably the only sub-Saharan country that participates in meaningful production of ICT products and services as well as consumption. As an exporter of ICT products and services to other sub-Saharan African countries, it makes an important and interesting case to see how these technologies affect its own local economies. The rest of SSA largely consumes and imports ICT products and services. This is not the case 
in most of the OECD countries that complement each other in terms of production of ICT products and services. This is important to emphasize because SSA countries as consumers rather than producers of ICT products have to make important policy decisions on the expenditure of their meager foreign exchange resources. There are other seemingly more important and more basic priorities that must be addressed before investments in ICT infrastructure can be accelerated. This said, it must be noted that African countries have already embarked on very expensive ICT projects to boost telecommunications and internet reliability on the continent. A more detailed discussion of this was presented in section 4.2.2 and 4.4.3.

The period since 1996 is an interesting period in South Africa as it is starts only two years after the fall of apartheid and the rise of a new democratic state. Radical policy changes took place in the country during this period and measures were put in place to specifically achieve some kind of redistribution of wealth to benefit previously disadvantaged groups of the South African population. Affirmative action, Black Economic Empowerment, the Employment Equity Act, 1998 and other similar policy initiatives were launched, which have substantially affected income distribution and development outcomes across regions and different population groups in the country. The telecommunications sector also grew rapidly with rural and previously disadvantaged regions seeing huge uptakes in connectivity. What contribution has the rapid growth of telecommunications in South Africa had on per capita household income in South African municipalities since 1996 ? We take an empirical look at this uptake in connectivity and see how much it has contributed to better income in municipalities in South Africa.

We will not study the effect of any one particular policy, but we will look at aggregate changes in household income and telecommunications connectivity across municipalities in the country between 1996 and 2007. Most of the economic activity in South Africa takes place around the prosperous metropolitan areas i.e. Cape Town, Ekhurleni Metro, Nelson Mandela Metro, Ethekwini Metro, City of Tshwane Metro (Pretoria) and Johannesburg. Three of these metros are in one province, Gauteng. This difference in natural endowment and geographical advantage of some municipalities over others is controlled for in the study by treating a sub sample of the data without the metropolitan areas in 1996 and 2007.

As mentioned above the justification for this approach lies in the fact that there were deliberate efforts to increase access to telecommunication over the said period as well as to raise the employment status of previously disadvantaged groups of the population. This indicates that we expect to see reasonable differences in the levels of income, connectedness, education, employment and access to basic infrastructure between 1996 and 2007 .

Using per capita household income and indicators of infrastructure availability in municipalities as proxy indicators for capital stock, we estimate the relative strength of the effect of telecommunication access on per capita 
household income in the municipalities. This effect should however be seen in the context of several important economic factors working together to produce income as it would be rather simplistic to assume that the answer to increasing household income in South African municipalities is to give everybody access to a phone.

While it stands to reason that regions within a country with higher income per capita, higher education levels and higher population densities will have higher access to ICT facilities and services, it does not necessarily follow that higher access to telecommunications results in higher incomes per capita. The relationship has to be demonstrated empirically and the channels through which telecommunications can help create income must be elaborately explored.

Furthermore, it has become imperative for African policy makers to understand what the effects of these new technologies are especially with regard to reducing the developmental gap that already exists between rural and urban areas in most African countries. W M Melody writing in 1985 noted that

"a major challenge for social policy will be to find methods to ensure that developments in the IC (sic) sector do not exacerbate class divisions in society and that the benefits are spread across all sectors of society" (Melody, 1985)

It becomes imperative for African policy makers and researchers to clearly understand what the cost, benefits and effects of Information and Communications technologies (ICTs) are, both on economic growth and consequently on the well being of citizens both in urban and rural areas. Our research contributes to the understanding of the economic effects of connectivity at a regional level in African countries and provides guidance in what forms of connectivity are more beneficial given the terrain and maintenance concerns of African infrastructure in general.

At a community development training workshop held in rural Mthatha in the Eastern Cape of South Africa, community leaders from Nyandeni municipality were asked to describe the benefits of ICTs to rural development as they understood it. Apart from appreciating the new technologies and the ease with which they could now communicate with family and friends in the city, they also pointed out the negative effects that the technology had brought, especially on their children. Children watch too much TV and learn a lot of 'bad manners' from foreign countries, was a common complaint; this they said is leading to moral degradation in their societies. Furthermore it was pointed out in the workshop that poor people in rural areas will not benefit much from TVs, phones and the internet if they continue to lack the basic necessities of a normal existence. It was emphasized by the participants that before ICTs can make any meaningful contribution to life in rural areas the basic necessities must be available and taken care 
of first. ${ }^{2}$

This seems to support the argument that economic development leads the way for ICTs to flourish, which is more than just a reasonable assumption as communication equipment and services all cost money. If disposable incomes are too low the population will not be able to afford the communications equipment and the services.

This also seems to hold for fixed telephone services. But as (Sridhar and Sridhar 2004) report from their study, traditional economic factors that explain the demand for fixed lines do not explain the demand for mobile phones. They find that price and income levels are not important for explaining demand for mobile services, which have grown exponentially in sub-Saharan Africa over the last two decades. Other micro-level variables are more important. These micro level variables may have to do with the fact that a family member's possession and use of a mobile phone actually generates income for the family, so being able to communicate in itself becomes economically profitable. This leads us to suppose rather that increased telecommunications use in developing countries is complementary to economic growth and contributes to growth as much as growth causes more participation in ICTs in a supply and demand matching process that leads to more efficient use of resources. It is this view that we investigate further in the rest of this work.

\subsection{Theoretical Conceptual framework}

Our theoretical framework hinges on the assumption that telephones, radios, computers and television shorten the distance between markets thereby providing access to pricing practices of competitors and rivals. The availability of this information leads to more efficient pricing of commodities in a region that would otherwise have to be accessed through physical relocation of economic agents in space, costing both valuable time and meager resources spent on transport, accommodation and daily subsistence. These technologies greatly reduce market uncertainty and traders are able to travel and deliver goods only when they are certain about prices and demand. The amount of guessing is greatly reduced of course depending on the reliability of the information sources accessed. A diagrammatic view of this framework is provided in figure 6.1.

In figure 6.1, use of telecommunications as an enabler of income generation activities acts through the reduction of transaction costs, reduction of market uncertainty, expansion of markets and a contribution to the overall positive development of institutions (more transparency for example).

\footnotetext{
${ }^{2}$ Workshop organized by The Rural Development Centre of Walter Sisulu University 19-23 November 2007
} 
FIGURE 6.1: Telecommunications as an Enabler of Income Generation

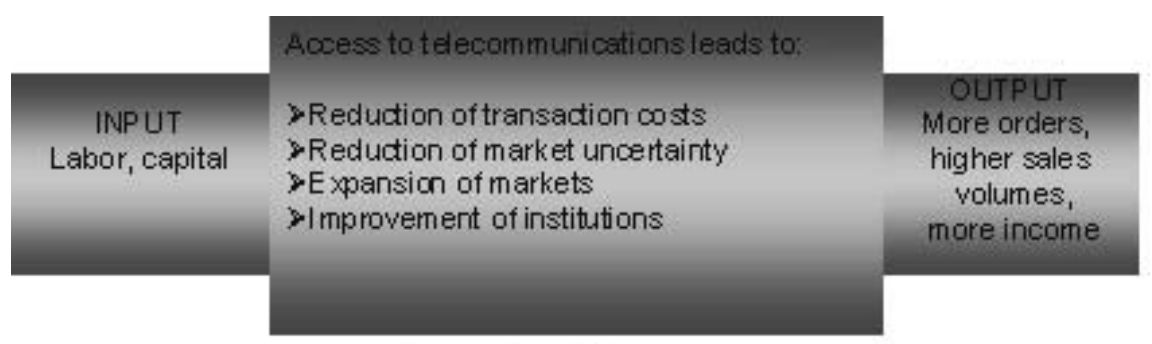

Soure: Own diagram

Households that have access to telecommunications benefit by having access to supplementary and more efficient ways of information gathering and less dependence on physical relocation just to gather information. Time costs are reduced and the frequency of information gathering is greatly increased leading to a virtual closeness to the market that is only possible because of the presence of telecommunication services. This in turn leads to higher and more regular incomes than those without access are able to realize.

\subsection{Methodology}

We follow a production function approach where total output in the municipality is represented by per capita household income (HI) and the labor input is represented by the number of people employed in the municipality. The capital input is represented by two types of capital infrastructure public and private. Level of education, access to electricity for lighting and cooking and access to fixed line telephones form the public infrastructure variables while the private capital variables are access to mobile telephones, television, radio and computer access.

Our unit of analysis is the municipality, the lowest level of local government in South Africa where decisions can be made on public infrastructure investments. The argument is that municipalities with access to more telecommunication, private capital and better infrastructure will be able to have easier access to markets and be able to generate more income from their efforts than those with less access. The access to timely information afforded by telecommunications will enable them to fetch better prices for their products and eventually lead to higher per capita household incomes than municipalities with less access to telecommunications facilities. The competitive advantage gained from previous investments in infrastructure would boost production and lead to an increase in the general level of income generated in the municipality. The total income in a municipality 
should therefore positively depend on its input of labor, capital and both public and private infrastructure. As we do not have data for production capital stock, we assume that all income is wage income and we can write

$$
Q=f(K, L, T)
$$

where $\mathrm{Q}$ is total output, $\mathrm{K}$ is capital stock, $\mathrm{T}$ is technology input and $\mathrm{L}$ is labor input

Assuming a Cobb-Douglas production function

$$
Q=A \cdot L^{1-\alpha} K^{\alpha} \cdot h(T)
$$

where $h(T)$ are private and public infrastructure and technology variables. Assuming perfect competition

$$
\frac{\partial Q}{\partial L}=\frac{w}{p}=(1-\alpha) \frac{Q}{L}
$$

where $p$ is price level and $w$ is wage rate. Total household income will therefore be total labour times wage rate

$$
H I=w \cdot L=(1-\alpha) \cdot p Q
$$

which is the total output value times a constant $(1-\alpha)$. $Q$ is still a function of labor, $L$ and capital stock, $K$. We do not have data for capital stock in in our dataset so we move to treat $\mathrm{K}$ out of the equation using accumulated investments over time. Suppose investments $I$ grows ata proportional rate $g$

$$
I=I_{0} e^{g t}
$$

then capital stock $\mathrm{K}$ can be written as

$$
K=\int_{-\infty}^{t} I_{0}^{g \tau} d \tau
$$

which for constant $g$ implies

$$
K=\frac{I_{0}}{g} e^{g t}
$$

Assuming that investments are directly proportional to output, we get

$$
I=\beta Q
$$

so capital at time $t$ is

$$
K_{t}=\frac{I_{t}}{g}=\frac{\beta Q}{g}
$$

substituting this in (6.2) gives 


$$
Q=A \cdot L^{1-\alpha}\left(\frac{\beta}{g}\right)^{\alpha} Q^{\alpha} h(T)
$$

so

$$
Q^{1-\alpha}=A \cdot L^{1-\alpha}\left(\frac{\beta}{g}^{\alpha}\right) h(T)
$$

giving

$$
Q=\left(A \cdot\left(\frac{\beta}{g}\right)^{\alpha}\right)^{\frac{1}{1-\alpha}} \cdot L \cdot h(T)^{\frac{1}{1-\alpha}}
$$

substituting (6.12) in (6.4) finally gives an expression of household income per worker HI without capital $\mathrm{K}$

$$
\frac{H I}{p \cdot L}=\left[(1-\alpha)\left(A \cdot\left(\frac{\beta}{g}\right)^{\alpha}\right)\right]^{\frac{1}{1-\alpha}} \cdot h(T)^{\frac{1}{1-\alpha}}
$$

Since we are interested in household income per capita and not income per worker as such and we have data for the proportion of labor in the municipality, we can transform (6.4) into an expression for household income per capita by multiplying it by $\frac{p \cdot L}{P}$ (this arises directly from the identity that $\frac{I}{P}=\frac{I}{L} \cdot \frac{L}{P}$, where $\mathrm{I}$ is income, $\mathrm{L}$ is labor and $\mathrm{P}$, population in general) giving

$$
\frac{H I}{P}=\frac{H I}{p \cdot L} \cdot \frac{p \cdot L}{P}
$$

which is an expression for household income per capita that we can now use in our empirical setting.

\subsection{The Empirical Model}

We derive our empirical model from the functional form of the relationship given in equation (6.14) as it can easily be re-written in the form

$$
\ln \frac{H I}{P}=\ln \frac{H I}{p \cdot L}+\ln \frac{p \cdot L}{P}
$$

by taking logs on both sides. Subtracting the second term on the RHS leaves us with an equivalent expression to equation 6.13 that we can estimate.

$$
\ln \frac{H I}{P}-\ln \frac{p \cdot L}{P}=\ln \frac{H I}{p \cdot L}
$$


The only problem is that we do not have data for the wage rate $p^{3}$.We assume this to be constant over the time period and allow it to be subsumed in our constant in the empirical formulation, giving us

$$
\ln H I \_P C-\ln \frac{L}{P}=\beta_{0}+\beta_{i} \sum_{i=1}^{N} \ln h\left(T_{i t}\right)+\varepsilon_{i t}
$$

where $H I_{-} P C$ is a label representing household income per capita $\left(\frac{H I}{P}\right)$ and $h\left(T_{i t}\right)$ the array of private and public infrastructure variables at time $t$ in the $\mathrm{N}$ municipalities as expressed in equation 6.13.

We do a similar transformation for all the variables using number of households and population so that all variables in the model enter as per capita terms. We end up with the following model which we estimate

$$
\begin{gathered}
\ln H I_{-} P C-\ln \frac{L}{P}=\beta_{0}+\beta_{1} \ln E d u c_{-} P C_{i t}+\beta_{2} \ln \text { Elect_PC } P C_{i t} \\
+\beta_{3} \ln \text { Mobile_PC } P C_{i t}+\beta_{4} \ln \text { Radio_PC } P C_{i t}+\beta_{5} \ln \text { Comp_PC } C_{i t} \\
+\beta_{6} \ln \text { Fixed_PC } C_{i t}+\beta_{7} \ln T V_{-} P C_{i t}+f_{i}+\varepsilon_{i t}
\end{gathered}
$$

where $f_{i}$ is the unobserved individual effect and $\varepsilon_{i t}$ is the error term

Hypothesis: Access to telecommunications has had a positive impact on per capita household income in municipalities in South Africa between 1996 and 2007.

\subsection{Data Description}

All the data used are from Statistics South Africa (Stats SA) databases,census South Africa 1996, 2001 and community survey 2007. Although we have three years in the dataset, data for employment, radios, computers and mobile phones are not available for 1996 and so we drop 1996 in the analysis except in the initial comparison of telephone usage in fig 6.2 . The census cycle in South Africa was changed from five years to ten years by a cabinet decision in order to provide for more lead time in preparation and adjustments to their survey instruments. This affected the next census which was to be held in 2007. A census was not done in 2007 but instead a community survey (mini census) was done to provide data on trends and updates on key census indicators. Massive changes came into effect in 2005 and a lot of municipalities either changed names or were moved from one province to another. As much as possible we have included municipalities

\footnotetext{
${ }^{3}$ This needs to be looked into more closely but we were not able to collect decent data on $p$ and trends in $p$. This is another area for further extension of this research effort.
} 
that have kept their identity and location intact especially between 2001 and 2007. All municipalities that had only name changes have been included in the analysis. Included in the analysis also are the metropolitan city areas: City of Cape Town, Ekurhuleni Metro (formerly East Rand), eThekwini Metro (Durban), City of Johannesburg Metro, Nelson mandela Metro (Port Elizabeth), and City of Tshwane Metro (Pretoria). These are relatively large municipalities with more advanced economic capabilities than the smaller municipalities. Three other municipalities are soon to be categorized as metropolitan city areas by virtue of their economic size: Buffalo City (East London), Mangaung (Bloemfontein) and Msunduzi (Pietermaritzburg). They are however not treated as metropolitan areas in this analysis. Because of the high household income in these areas they are treated first together with all the other municipalities and then they are removed from the analysis to isolate their collective effect on the outcome variable. The variables and their expected signs are listed in table 6.1. 


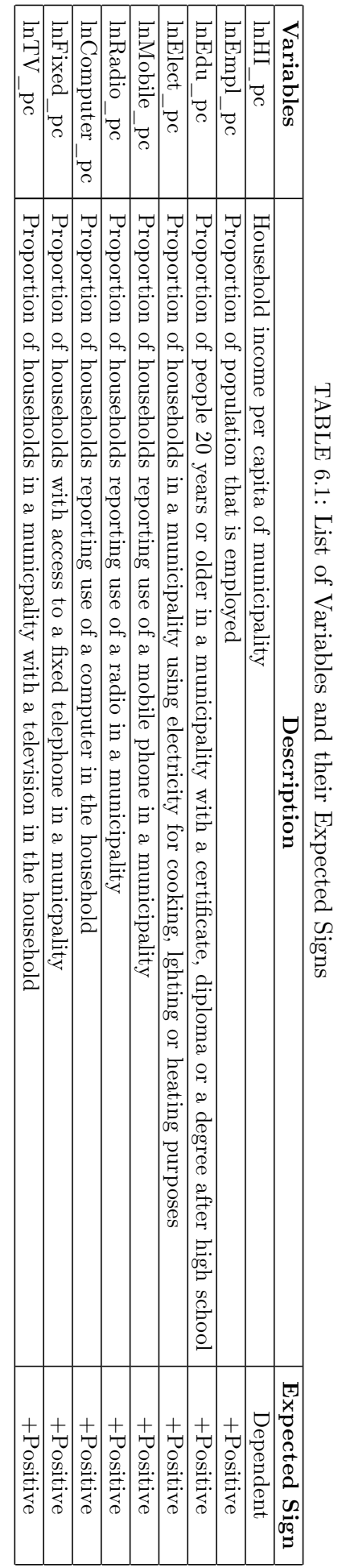


The variables of interest to our study are those showing access and use of connectivity enhancing technologies, mobile phones, fixed line telephones, computers, radios and TVs. We expect these variables to have a positive effect on income generation in the municipality through the increase of information availability, reduction of transaction costs, expansion of markets, reduction of market uncertainty and the general increase in transparency in the markets. Employment and education are also expected to contribute positively to household income in a municipality as employment generates wages and people are more likely to get higher paying jobs if they are better educated. A quick look at the data reveals that the proportion of households in all municipalities using fixed line telephones fell from 1996 to 2007.

Figure 6.2 shows an increase in fixed line usage between 1996 and 2001 but the level drops dramatically in 2007. This is consistent with observed trends since the introduction of mobile phones. There were very few mobile phone users in South Africa in 1996 and this data was not even solicited in the 1996 census. The dominant form of telecommunication was the fixed line phone. The penetration of fixed line phone infrastructure in SSA is however very low and before the uptake in mobile telephony this resulted in very low teledensity figures for South Africa, especially in the rural areas and previously disadvantaged areas of the country where the teledensity was as low as 0.1 per 100 population in $1997^{4}$. With the advent of the mobile phone many households did not see the need to keep their fixed line subscription and so many users actually opted to disconnect their fixed line access and maintain their newly acquired mobile connectivity. This effect is strongest in metropolitan areas where fixed line penetration was highest.

The data generally reveals higher per capita household income levels in municipalities with higher telephone access especially mobile phones. One obvious explanation for this as cited above is that most fixed line telephones were /are installed in metropolitan cities and richer municipalities rather than poorer ones, while mobile phones are practically almost everywhere.

\subsection{Regression results}

The results of the regression are shown in table 6.2, 6.3 and 6.4. Table 6.2 shows the regressions for all the municipalities in the dataset. All the variables show the expected positive sign except radio which comes out negative but not significant. $\ln E m p l \_p c, \ln E d u \_p c$ and $\ln E l e c t \_p c$ all enter the regression positive and significant at the $1 \%$ level. They retain the sign and significance level even after other variables are added to the regression. and $\ln$ Mobile_pc is positive and significant at the $1 \%$ level, but

\footnotetext{
${ }^{4}$ See Connecting the Globe: An African Initiative
} 
FIGURE 6.2: Percentage of Households Reporting Use

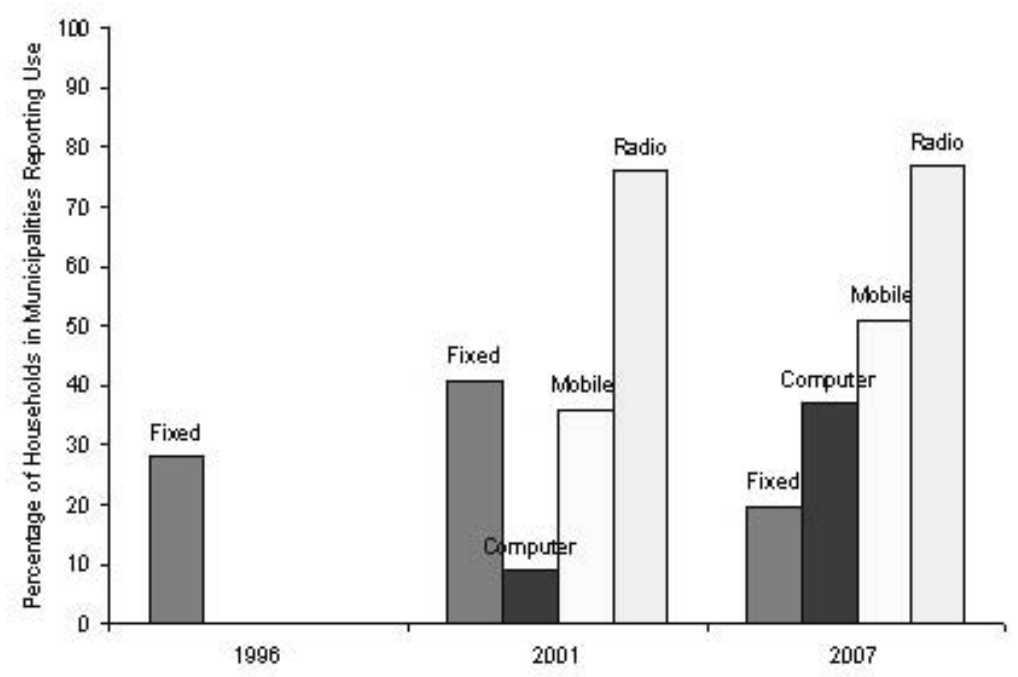

Source: Own graph from the data

drops to $10 \%$ significance level when $\ln$ Computer_pc and $\ln T V \_p c$ are added to the regression. In Fixed_pc, In Radio_pc, $\ln C$ Computer_pc and $\mathrm{TV}$ are all positive as expected but not significant.

The regression is repeated without the metropolitan cities. The metropolitan cities are the big business and industrial centers of South Africa and are likely to skew the result as they have better communication infrastructure than other parts of the country. The pattern of results remains much the same as in the first regression with all the municipalities included. This time ln Mobile_pc retains its significance level at $1 \%$ even after all the variables are added to the regression. 
We then ran the fixed and random effects regressions using the same stepwise technique. A Hausman test was run that showed that there was no difference between the random and fixed effects coefficients generated, so we accepted the null hypothesis that there is no systematic difference between the two approaches and reported only the random effects results. The results of the regression are shown in table 6.4 . About $9 \%$ of the change in per capita household income can be explained by mobile phone access in municipalities. Access to fixed line telephones is positive but not significant.

Our hypothesis that access to telecommunications is important to per capita household income in the municipalities seems to hold but we need to do more tests on the relationship, especially the significance of mobile phone access, in order to make a more definite statement about the magnitude of the influence. The aspect of mobile phone access would appear to be more important to income generating activities in poorer areas than fixed telecommunication access. This may be due to the mode of the telecommunication service delivery (over the air) but also to the higher access rate of mobile telecommunications compared to fixed telecommunication services. We perform a Granger causality test on the variables ln Mobile_pc, $\ln$ Fixed_pc.and $\ln H I_{-} P C$ to furtehr test the relationship. 


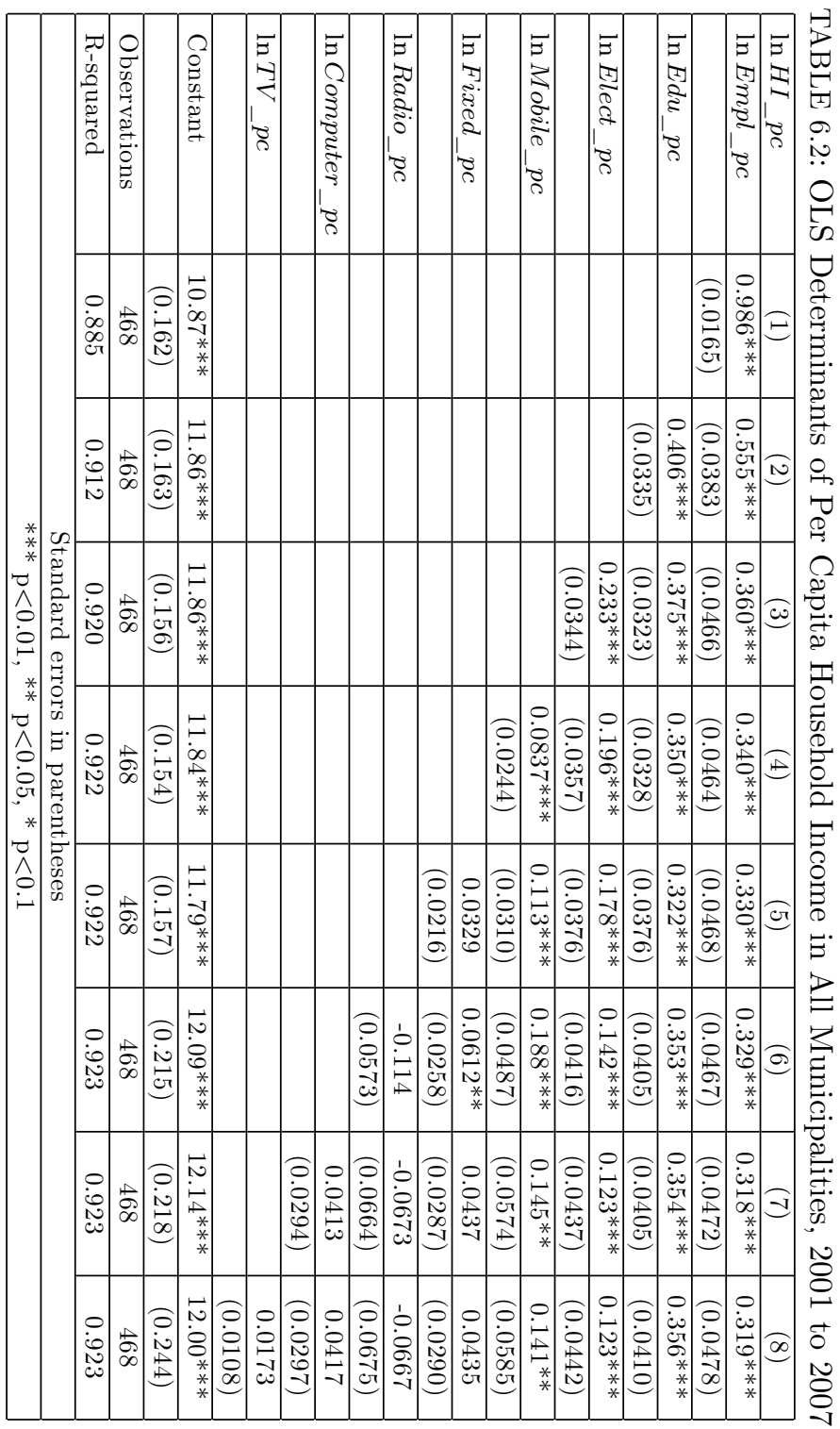




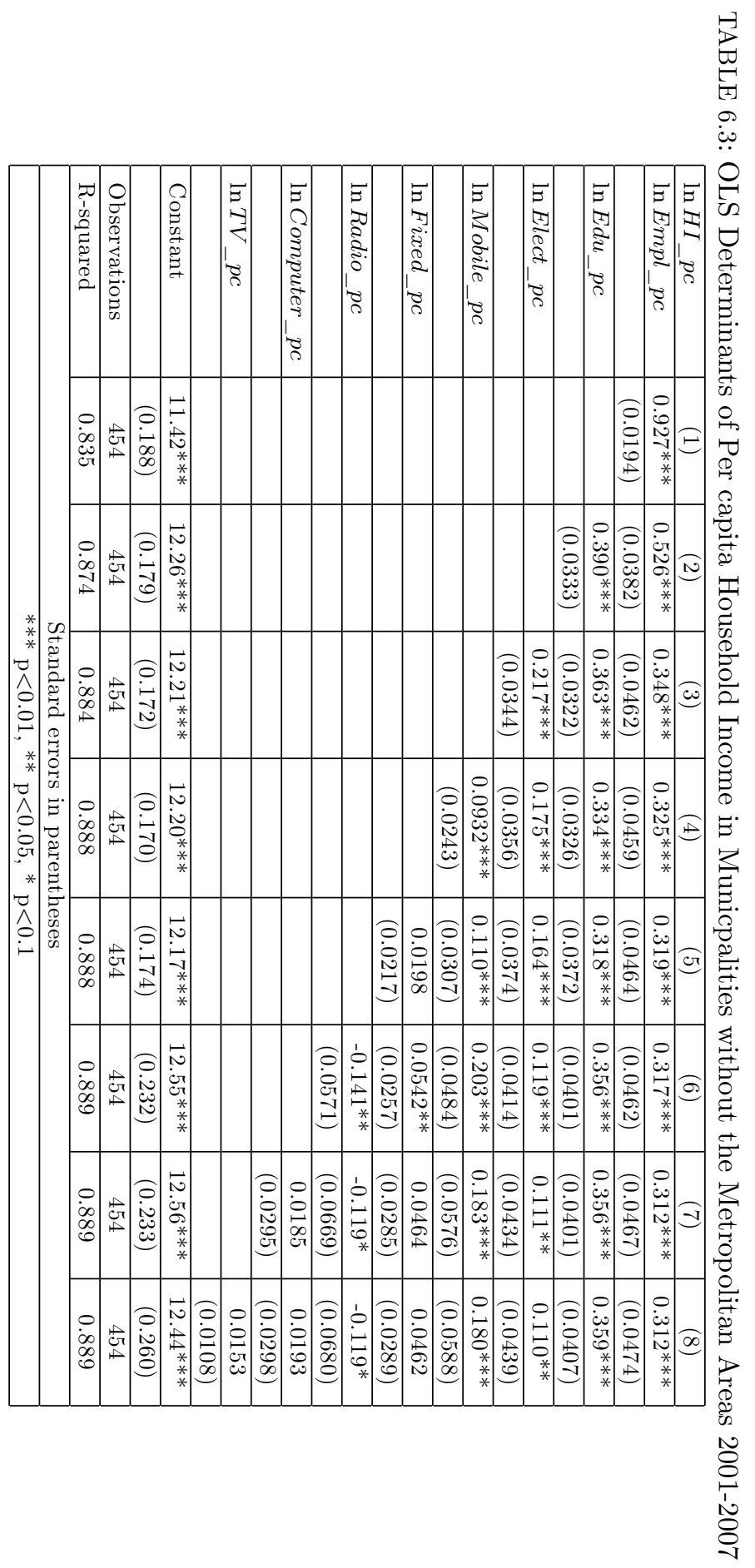


6. Telecommunications and Household Income in South Africa 


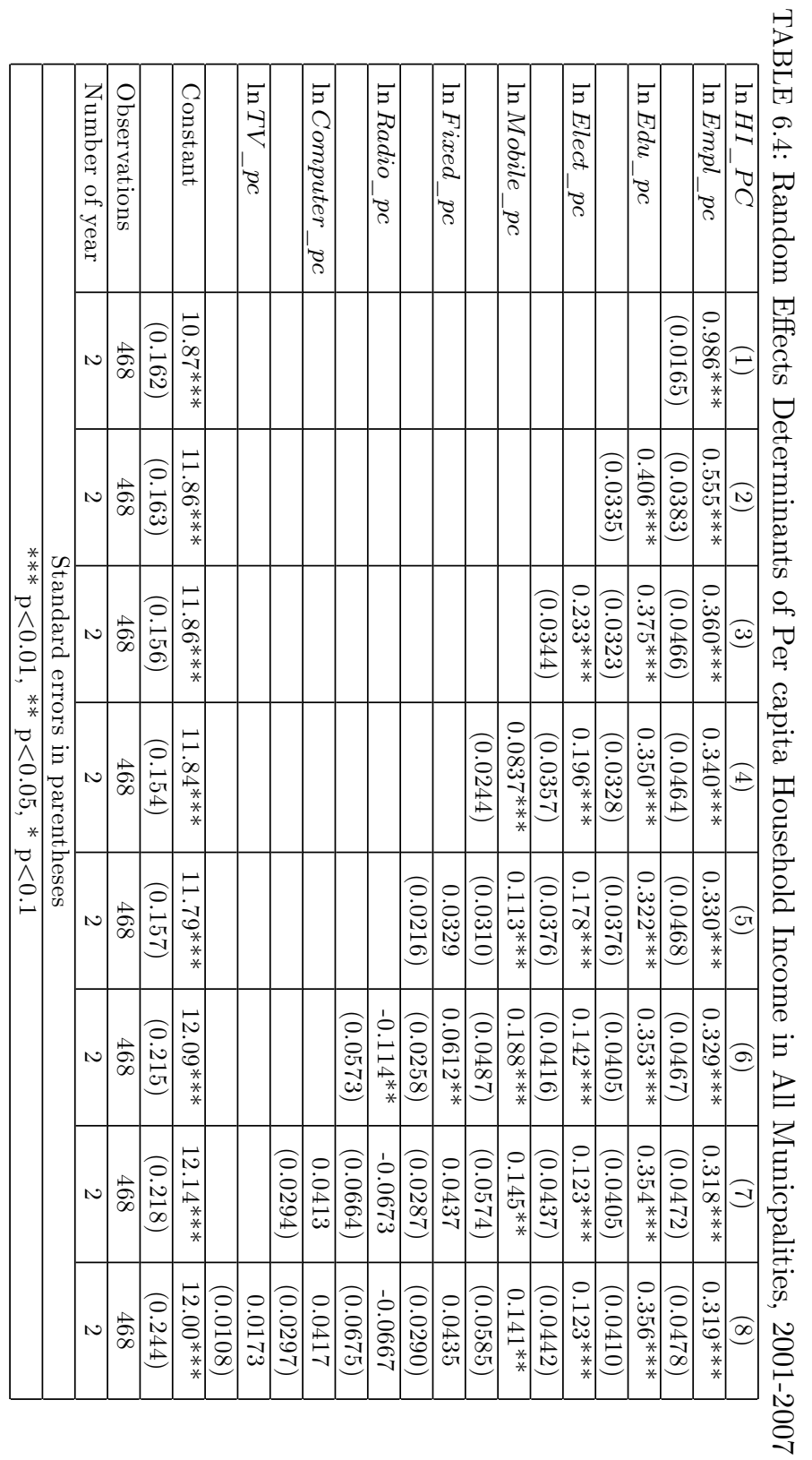




\subsubsection{Granger Causality Test}

Causality has always been a difficult topic in econometrics but always of great interest in most studies of social economic importance. The reason for this is not hard to see as knowing which social or economic factors lead to or seem to cause certain other social economic outcomes can be very useful information in the hands of policy advisers and governments. The basic idea employed in statistical causality tests is that the future can not predict the past, but we may be able to tell something about future events using past occurrences of other related events, hence the use of time series data in causality tests. We seek to ask whether higher per capita income in a municipality leads to higher connectivity or whether the higher levels of connectivity do induce higher per capita incomes in municipalities. These are data heavy operations in econometrics and as we do not have enough time series data we will resort to a more basic form of the investigation as referenced in (Gujarati and Porter 2009) and (Davidson and McKinnon 2004). For the case of connectivity over mobile and fixed phones and per capita household income, we estimate the following equations:

$$
\ln H I_{-} P C_{t}=\beta_{1} \ln \sum H I_{-} P C_{t-6}+\beta_{2} \ln \sum \text { Mobile_} P C_{t-6}+u_{1 t}
$$

$$
\ln H I_{-} P C_{t}=\beta_{1} \ln \sum H I_{-} P C_{t-6}+\beta_{2} \ln \sum \text { Fixed_PC } C_{t-6}+u_{1 t}
$$

$$
\ln \text { Mobile } P_{t}=\beta_{1} \ln \sum \text { Mobile } C_{-} P C_{t-6}+\beta_{2} \ln \sum H I_{-} P C_{t-6}+u_{1 t}
$$

$$
\ln \text { Fixed_PC } C_{t}=\beta_{1} \ln \sum \text { Fixed_PC } P C_{t-6}+\beta_{2} \ln \sum H I_{-} P C_{t-6}+u_{1 t}
$$

, where $t-6$ refers to the time span between the 2001 census and 2007 survey. We test HI_PC->Mobile and Fixed (read "per capita household income 'Granger-causes' Mobile and Fixed phones), Mobile and Fixed$>$ HI_PC (read Mobile and fixed phones 'Granger-cause' household income). In order to do this we pool the data and construct six-year lags for all the variables (we have one lag of six years, 2001-2007). We use these lagged variables to estimate the models in equation $6.19 \mathrm{a}, \mathrm{b}, \mathrm{c}$, d. After each estimation we run an F-test to check whether the lagged variables belong to the model or not. To do this we test the hypothesis

$\mathrm{H}_{0}: \beta_{1}, \beta_{2}=0$ both jointly and independently.

The results are shown in table 6.5. The null hypothesis reads that the coefficient on the $\beta^{\prime} s$ is zero, meaning that the variables do not belong in 
the model i.e. that Mobile and Fixed connectivity do not 'Granger cause' household income.

TABLE 6.5: F-test Results on Unrestricted Regression of Mobile and Fixed phones on Per-Capita Houehold Income

\begin{tabular}{|l|l|l|}
\hline Variables & F-Value & p-value \\
\hline lag_Fixed_PC & 115.39 & 0.000 \\
\hline lag_mobile_PC & 19.75 & 0.007 \\
\hline lag_HI_PC & 17.02 & 0.012 \\
\hline lag_HI_PC & 25.69 & 0.003 \\
\hline
\end{tabular}

The tests reveal that both mobile phones and fixed telephones "Granger cause" per capita household income and that per capita household income also "Granger causes" use of mobile phones and fixed telephones. The probability that the coefficient on lag_mobile and lag_Fixed is actually zero is very low, $0 \%$ meaning mobile and fixed line phones do belong to the model.

This result should however be interpreted with caution as the number of lags in these computations does matter and we have only one lag of six years in the model. However the results are consistent with our theoretical model where we had a virtual overarching technology connecting different regions as an enabler for growth in the connected communities.

\subsection{Conclusions}

We reaffirm that mobile and fixed phones are important to per capita household income in municipalities in South Africa, with mobile phones having a stronger effect than fixed line telephones. This is not a surprising result as the number of households using mobile phones for personal and business matters increased much more than the number of households using fixed telephones between 2001 and 2007. Since the uptake in mobile phone usage the number of people using fixed telephones has actually dropped even in the metropolitan areas (see figure 6.2). This result is in line with earlier results of cross country studies done in mixed economies as referenced in Section 6.1, where fixed telephony was found to contribute positively to GDP. The difference we see here is that over the air mobile telephony has a stronger effect than fixed line telephony in the municipalities. This would seem to demonstrate the advantages inherent in ubiquitous over the air connectivity technologies like mobile phones for the African communities lacking infrastructure. It is important to note that both mobile and fixed phones "Granger cause" per capita household income. So communication in itself is an important input in income generating activities but the more pervasive modes of communication, mobile phones would be more 
important in infrastructure poor regions of Africa.

We also find that education and employment are important for income generation in municipalities, as we would expect.

\subsection{Summary}

In this chapter we have considered the relationship between telecommunication access represented by electronic goods in the household together with other income enabling variables, electricity, educational and employment. We find a robust positive and significant effect of mobile phones on per capita household income in the municipality but no relationship with other telecommunication access variables computers, TV and radio. Education and employment are relatively more important to higher levels of per capita income in municipalities than fixed telephones, computers and radios.

What role do satellites have in enhancing these outcomes? As mentioned in section 5.4.2 satellites are an important link in providing backhaul services to both fixed line and cellular operators for all kinds of telecommunications services. They are crucial in linking different kinds of networks over difficult terrain and can easily spread services to remote areas that otherwise would be left without service. The use of a common African owned satellite service provider would bring service prices down to levels where even more public and private services can be provided on the continent through broadband. Government subsidized rates and free access for emergency and public services will also be easier to provide. Provision of health and educational services via satellite has been a failure in Africa mainly due to the high price of satellite broadband. In the next chapter we discuss two such cases, one involving radio and an ongoing tele-medicine project in Zambia. 


\section{A Data Disclaimer from Statistics South Africa}

\section{Cautionary Note}

The Community Survey results were released on 24 October 2007. After the evaluation of the data by the Stats Council, the Community Survey was found to be comparable in many aspects with other Stats SA surveys, censuses and other external sources. However, there are some areas of concern where Statistics South Africa is urging users to be more cautious when using the Community Survey data.

(To see the full text of the disclaimer go to www.statssa.gov.za.) 


\section{B Data Summary}

TABLE 6.6: Data Summary

\begin{tabular}{|l|l|l|l|l|l|}
\hline Variable & Obs & Mean & Std Dev & Min & Max \\
\hline $\ln H I \_p c$ & 468 & 10.73014 & 0.4150143 & 8.492703 & 12.3817 \\
\hline $\ln E m p l \_p c$ & 468 & -1.691147 & 0.6152505 & -3.633889 & -0.5506194 \\
\hline $\ln E d u \_p c$ & 468 & -3.549918 & 0.5816368 & -5.363993 & -1.657365 \\
\hline $\ln$ Elect_pc & 468 & 9.172453 & 1.231414 & 6.637258 & 13.84239 \\
\hline $\ln$ Mobile_pc & 468 & 9.095028 & 1.353527 & 4.905275 & 13.76503 \\
\hline $\ln$ Fixed_pc & 468 & 8.244076 & 1.42464 & 4.718499 & 13.27159 \\
\hline $\ln$ Radio_pc & 468 & 9.719713 & 1.113078 & 6.54535 & 13.76452 \\
\hline $\ln$ Computer_pc & 468 & 6.994605 & 1.521625 & 3.828641 & 12.6417 \\
\hline $\ln$ TV_pc & 460 & 9.045322 & 1.493473 & 2.833223 & 13.43 \\
\hline
\end{tabular}


6. Telecommunications and Household Income in South Africa

\section{C Correlation Matrix}




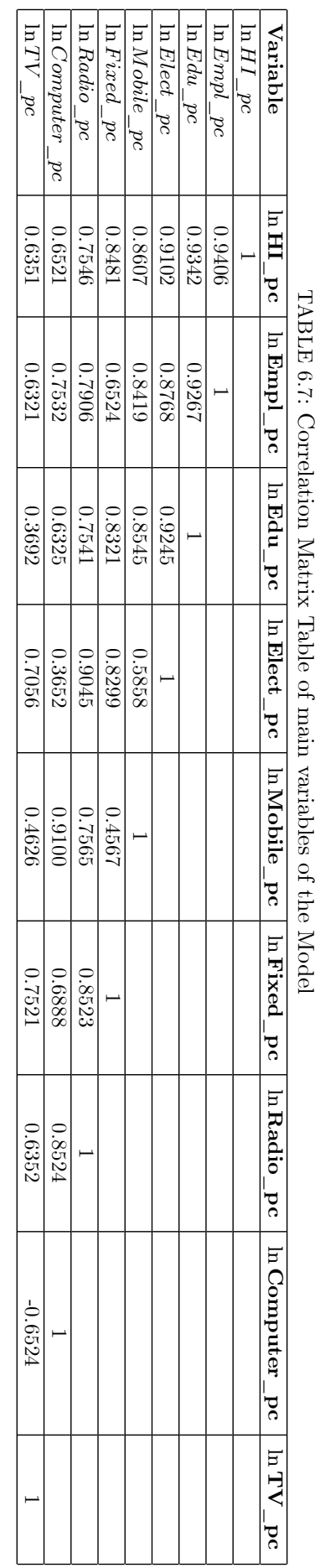


6. Telecommunications and Household Income in South Africa

6.D List of Municipalities 


\begin{tabular}{|c|c|c|c|c|c|c|c|c|c|c|c|c|}
\hline $\begin{array}{c}\mathbb{\sigma} \\
0 \\
0 \\
0 \\
0 \\
0 \\
0 \\
0\end{array}$ & 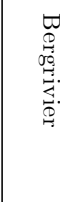 & 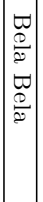 & 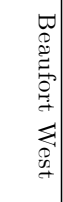 & 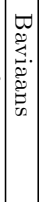 & 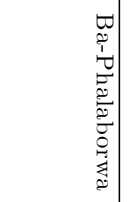 & 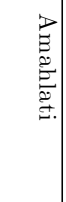 & 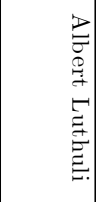 & 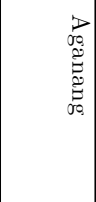 & 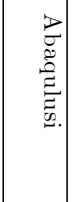 & 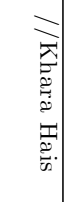 & 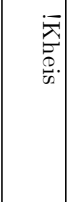 & 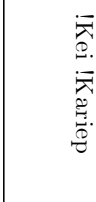 \\
\hline $\begin{array}{c}1 \\
0 \\
0 \\
0 \\
0 \\
0 \\
0 \\
0 \\
0 \\
0\end{array}$ & 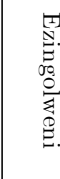 & $\mid \begin{array}{l}|r| \\
0 \\
0 \\
0 \\
0 \\
0 \\
0 \\
0\end{array}$ & 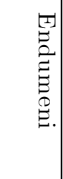 & 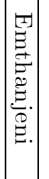 & 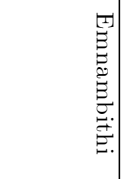 & 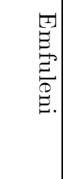 & 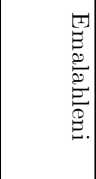 & 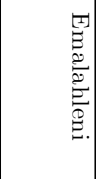 & 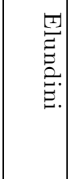 & 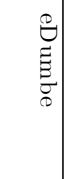 & 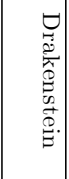 & 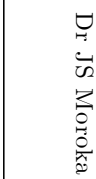 \\
\hline 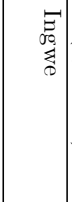 & 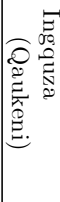 & $\mid$ & $\begin{array}{l}\bar{Z} \\
0 \\
0 \\
0 \\
0 \\
0\end{array}$ & 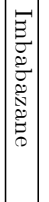 & 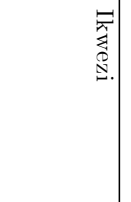 & 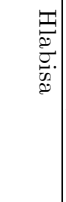 & 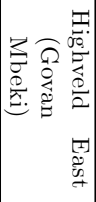 & 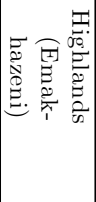 & 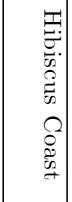 & 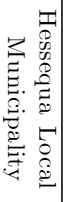 & 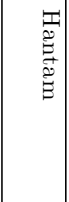 & 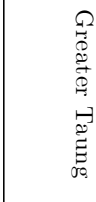 \\
\hline 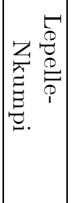 & 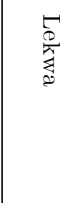 & 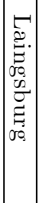 & 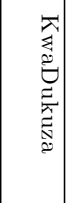 & 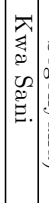 & 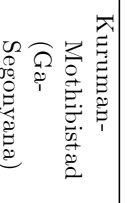 & 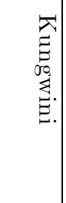 & 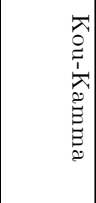 & $\begin{array}{l}\text { 저 } \\
0 \\
0 \\
00 \\
0\end{array}$ & 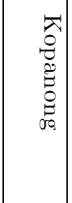 & 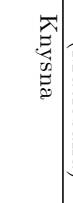 & 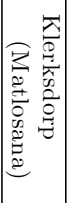 & 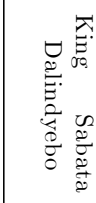 \\
\hline 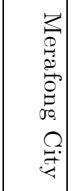 & 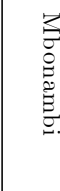 & $\left|\begin{array}{|c|}3 \\
\vdots \\
0 \\
0 \\
0 \\
0 \\
0 \\
0 \\
2\end{array}\right|$ & |ح. & 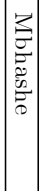 & 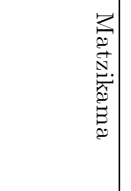 & 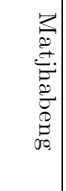 & 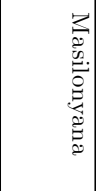 & 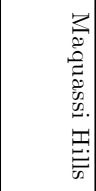 & 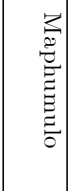 & 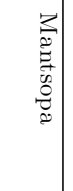 & 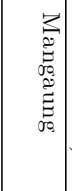 & 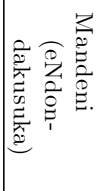 \\
\hline $\begin{array}{l}z \\
0 \\
2 \\
0 \\
2\end{array}$ & 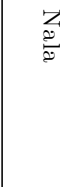 & 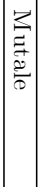 & 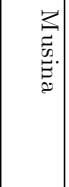 & 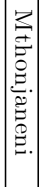 & 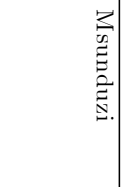 & 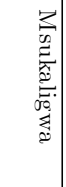 & 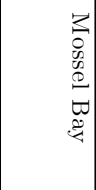 & 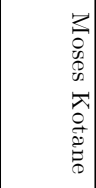 & $\begin{array}{l}3 \\
0 \\
0 \\
0 \\
0 \\
0 \\
0 \\
0\end{array}$ & 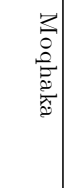 & $\begin{array}{l}3 \\
0 \\
0 \\
0 \\
0 \\
0 \\
8 \\
8 \\
0 \\
0\end{array}$ & 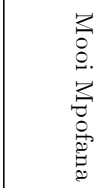 \\
\hline 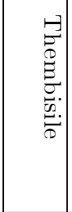 & 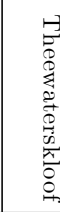 & 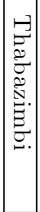 & 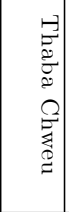 & 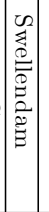 & 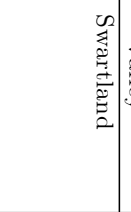 & 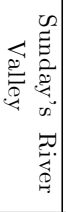 & $\begin{array}{l}\frac{y}{2} \\
0 \\
0 \\
0 \\
0 \\
0 \\
0 \\
0 \\
0\end{array}$ & 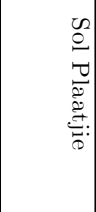 & 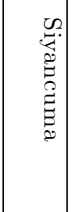 & $\begin{array}{c}02 \\
0 \\
w \\
0 \\
0 \\
0\end{array}$ & 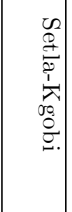 & 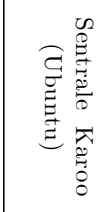 \\
\hline 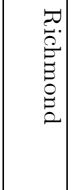 & 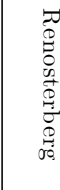 & 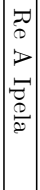 & 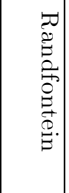 & 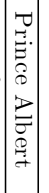 & 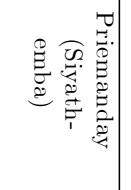 & $\begin{array}{l}7 \\
0 \\
0 \\
0 \\
0 \\
0 \\
0 \\
0 \\
0 \\
0 \\
0 \\
0\end{array}$ & $\begin{array}{l}0 \\
0 \\
0 \\
0 \\
0 \\
0 \\
0 \\
0 \\
0\end{array}$ & 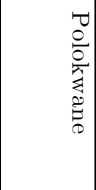 & 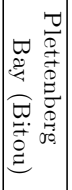 & 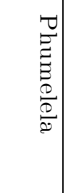 & 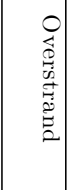 & 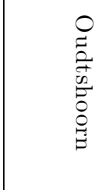 \\
\hline 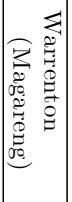 & 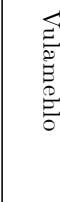 & 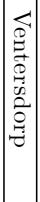 & 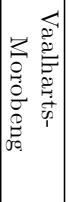 & 季 & \begin{tabular}{c|c} 
& \\
0 \\
0 \\
0 \\
0 \\
0 \\
0 \\
0
\end{tabular} & 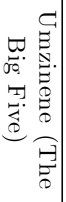 & 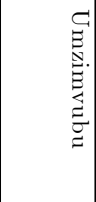 & 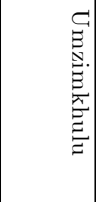 & 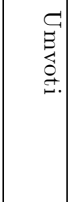 & 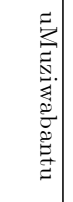 & 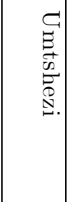 & 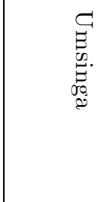 \\
\hline
\end{tabular}


6. Telecommunications and Household Income in South Africa

\begin{tabular}{|c|c|c|c|c|c|c|c|c|c|c|c|c|}
\hline 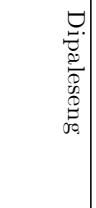 & 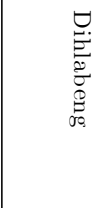 & 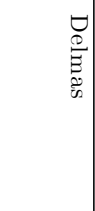 & 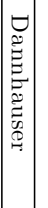 & $\begin{array}{l}\Omega \\
\stackrel{\Xi}{0} \\
\stackrel{:}{=}\end{array}$ & 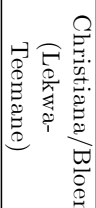 & $\begin{array}{c}2 \\
0 \\
2 \\
0 \\
0 \\
0 \\
00 \\
0.0\end{array}$ & 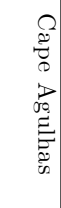 & $\begin{array}{l}0 \\
0 \\
0 \\
0 \\
0 \\
0 \\
0 \\
0\end{array}$ & 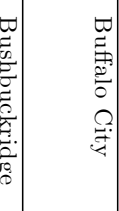 & 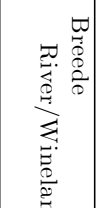 & 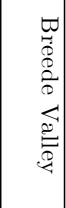 & 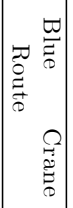 \\
\hline & 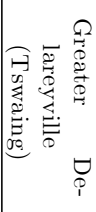 & 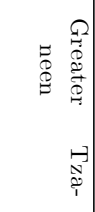 & 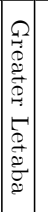 & 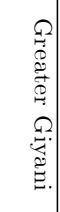 & 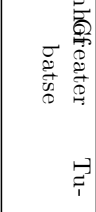 & 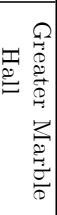 & 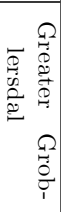 & 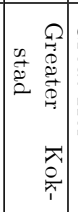 & $\begin{array}{l}\Omega \\
0 \\
0 \\
0 \\
0 \\
0\end{array}$ & 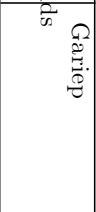 & 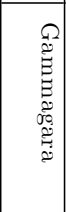 & 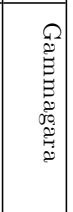 \\
\hline 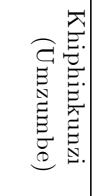 & . & 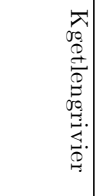 & 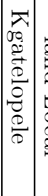 & 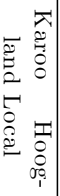 & $\begin{array}{l}7 \\
0 \\
0 \\
0 \\
0 \\
0 \\
0 \\
0.0\end{array}$ & 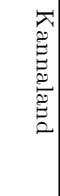 & 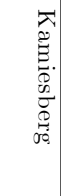 & 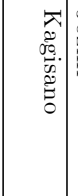 & 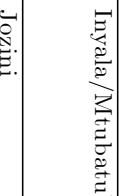 & 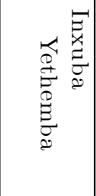 & 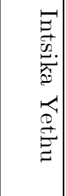 & 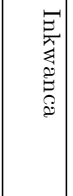 \\
\hline 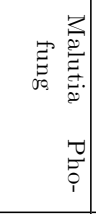 & 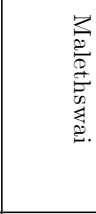 & 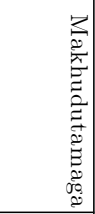 & & 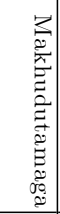 & 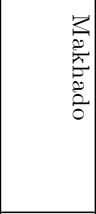 & 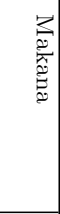 & 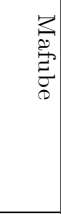 & 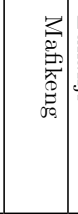 & 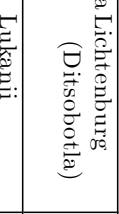 & $\begin{array}{c}5 \\
0 \\
0 \\
0.0 \\
0 \\
0 \\
0 \\
9 \\
0 \\
0.0\end{array}$ & $\begin{array}{l}\overrightarrow{0} \\
0 \\
0 \\
\stackrel{0}{*}\end{array}$ & 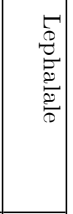 \\
\hline $\begin{array}{l}3 \\
0 \\
0 \\
0 \\
0 \\
0\end{array}$ & $\begin{array}{l}\text { 2. } \\
0 \\
0 \\
0 \\
0 \\
0 \\
0\end{array}$ & 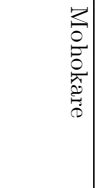 & 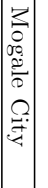 & 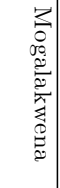 & $\begin{array}{l}3 \\
\vdots \\
0 \\
\vdots \\
0 \\
0 \\
0\end{array}$ & $\begin{array}{l}3 \\
\vdots \\
0 \\
\vdots \\
\vdots \\
\vdots \\
2\end{array}$ & $\begin{array}{l}\text { 完 } \\
0 \\
0 \\
\vdots \\
0\end{array}$ & 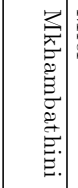 & |ح. & 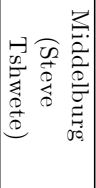 & $\begin{array}{l}3 \\
\vdots \\
0 \\
0 \\
0 \\
0\end{array}$ & $\begin{array}{l}3 \\
0 \\
0 \\
0.2 \\
0 \\
0 \\
0 \\
0 \\
0 \\
0\end{array}$ \\
\hline 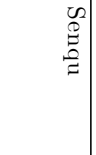 & 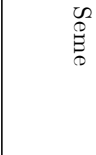 & 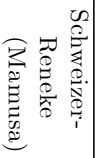 & $\begin{array}{l}z \\
\vdots \\
0 \\
\vdots \\
0 \\
0 \\
0 \\
0\end{array}$ & 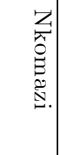 & 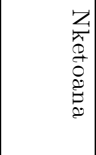 & $\begin{array}{l}2 \\
0 \\
0 \\
0 \\
2 \\
2\end{array}$ & 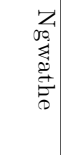 & $\begin{array}{l}2 \\
0 \\
0 \\
0 \\
0 \\
\vdots \\
\vdots \\
0\end{array}$ & $\begin{array}{l}2 \\
2 \\
\vdots \\
0 \\
0 \\
\vdots \\
0\end{array}$ & 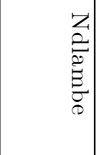 & 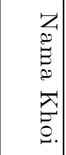 & $\begin{array}{l}z \\
⿱ 艹 2 \\
\stackrel{0}{0} \\
\stackrel{2}{2}\end{array}$ \\
\hline 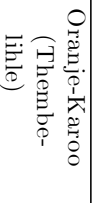 & 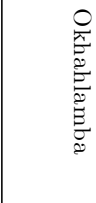 & 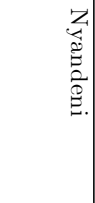 & 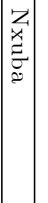 & 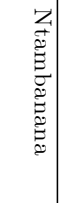 & 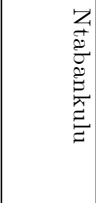 & 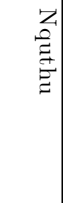 & $\begin{array}{c}2 \\
9 \\
5 \\
0 \\
0 \\
0 \\
0\end{array}$ & 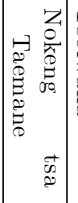 & 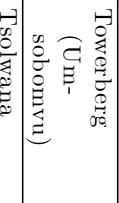 & $\begin{array}{c}0 \\
0 \\
0 \\
0 \\
0 \\
0 \\
0 \\
0\end{array}$ & 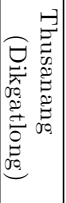 & 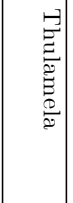 \\
\hline 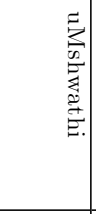 & 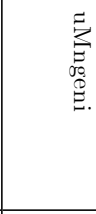 & 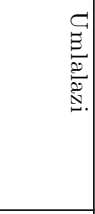 & 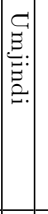 & 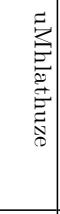 & 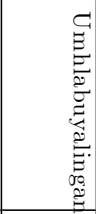 & 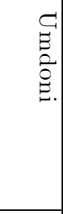 & 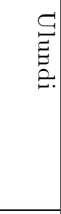 & $\begin{array}{l}\frac{7}{0} \\
0 \\
0 \\
0 \\
0 \\
0 \\
0 \\
0 \\
0\end{array}$ & 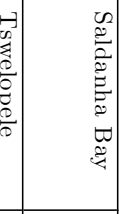 & 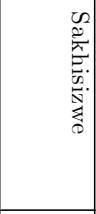 & 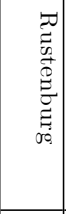 & 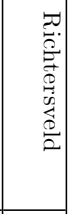 \\
\hline & & & & & & & & & & 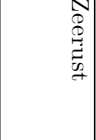 & $\begin{array}{l}3 \\
\vdots \\
0 \\
0 \\
0 \\
0 \\
0 \\
0 \\
0 \\
0.0\end{array}$ & 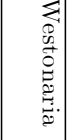 \\
\hline
\end{tabular}





\section{Applications Case Studies}

\subsection{Introduction}

Whereas we have demonstrated the potential of satellite technology in chapter three and the effect that satellite connectivity has on trade in chapter five, this chapter highlights cases of applications that have tried to tap into this potential for both public service provision and private business ventures. We present three cases of satellite technology applications, two of which were targeted at development through the provision of services to otherwise unreachable areas. These two cases were initiated to help deliver and share information to and from information-poor regions of Africa. Both cases are service oriented cases, where a service was envisaged to reach as many people as possible at a relatively low cost and provide access to a service that would otherwise be unavailable. We discuss WorldSpace Corporation (WS), a digital radio service provider and the Virtual Doctor project, a telemedicine not-for-profit project designed to help deliver basic health care over broadband by providing access to medical specialists who are otherwise physically unreachable due to distance and cost. Worldspace Incorporated is compared to our third case, Multichoice (MC), a very successful Direct to Home (DTH) satellite TV business in Africa. Multicoice provides DTH television channels across Africa on a monthly subscription basis using set-top boxes called decoders that users are obliged to purchase and connect to their existing TV sets.

The common denominator in the cases of WS and the Virtual Doctors is that they have both failed in one way or the other and the big promise of cheaper services for the rural poor by satellite has not been realized. This failure lends credence to our assertion that the current organization of satellite infrastructure has failed to deliver services to the wider information poor majority of the African population.

We first discuss WS and the problems it faced as a satellite services provider in Africa. We then present results of an on-line survey of users of the WS radio service that was done between November and December 2009. After that we discuss various tele-medicine projects around Africa and present the detailed case of the Virtual Doctor project. 


\subsection{Worldspace Incorporated}

\subsubsection{Introduction}

In this section we provide an overview of the WorldSpace Corporation and its intended mission in Africa and other under-served populations of the world. We first describe the origin of the company and its operation model, business strategy and competitive environment. We analyze its performance in Africa and Asia in particular and compare its performance to a satellite TV provider, Multichoice Limited. While WorldSpace has practically failed as a business venture and has been under chapter 11 bankruptcy, for the second time, since October 2008, Multichoice has had resounding success providing satellite TV to millions of households in Africa.

This comparison serves to highlight the fact that while satellite technology can deliver a service instantaneously and effectively to a wide geographical area (more than $80 \%$ of users polled thought the WS service either very good or excellent), the type of service provided and the mode of access to the satellite signal can significantly affect intended outcomes. It also highlights the importance of the cost of building and deploying satellite systems, which becomes a limiting factor in providing affordable services to infrastructure poor societies. While WS built its own satellites and deployed them to provide its own services, MC provides services from rented satellite space (INTELSAT). WS was able to mark down the price of its service and actually make it affordable to users at roughly 120 dollars a year because it owned the satellites that were beaming the signals. MC does not have this leverage and provided an expensive service from the start (approximately about 720 US dollars per year subscription). The problem for WS was how to recoup the sunk cost in infrastructure, while trying to keep the service affordable (most of the users polled actually thought the service was affordable see figure 7.6 ). So owning the satellite did enable WS to provide an affordable service. This perspective is important because none of the satellites servicing the SSA airspace are operated by African enterprises. It is difficult for African service providers to provide affordable services because they do not own the infrastructure they use.

This is the case with MC limited. They provide services from rented satellite capacity and the users have to pay a premium for it. But because the users are more interested in TV than in radio they are willing to sacrifice funds to gain access to more TV channels on MC than to gain access to a few more digital radio channels on WS. MC in appreciation of their customers' loyalty throws in free music and radio stations as part of the pricey packages they offer. This is the music and radio service that WS was trying to sell for 120 dollars a year from its satellites. So the nature of the services provided also become a critical determinant of success. 


\subsubsection{Early Days.}

World Space Corporation (WSC) Inc was founded in 1990 by Noah A. Samara, Chairman and CEO. He envisioned a worldwide service that would provide relevant information to the under-served majority of people on earth. The mission of the company was "to provide a variety of high quality programming through a subscription-based service that uses low-cost portable satellite radios and is available in under-served markets that lack programming choices ${ }^{* 1}$. Worldspace aimed to provide a combination of news, sports, music, brand name content multimedia and educational programming. The big idea was the creation of information affluence in Africa and Asia through this network by selling channel space on the satellite to content providers all over Africa and Asia and then selling specifically designed Worldspace satellite receivers to the individual and group users on the continents.

The company spent 750 million dollars on two satellites, the Afristar (launched on the Ariane V113 rocket on 28th October 1998) and Asiastar (launched on 21st March 2001) that form the space segment of their infrastructure. The ground segment of their infrastructure include end user devices that are built by independent electronics manufacturers on an OEM (Original Equipment Manufacturer) ${ }^{2}$ basis. Initially the manufacturers were Hitachi, Sony, Panasonic and Matsushita. These companies built customized radio sets that included a special chipset (STARCHIP) that could decode signals from the WorldSpace satellites. Together this infrastructure comprises the backbone of the Digital Audio Radio Service (DARS), which WorldSpace claims to have pioneered on a worldwide basis ${ }^{3}$. Figure 7.1 shows what WorldSapce hoped to achieve with its infrastructure.

The WS service was first launched in Africa in October 1999 on a Freeto-Air basis, where users only had to purchase one of the special radios in order to access WorldSpace programming from the satellites for life. The obvious question was how WorldSapce was going to make its money. Was there going to be enough radio sales in Africa to generate the return on investment and pay off the Afristar plus operating costs and still make a profit? By December 2006 WS had sold 200000 radios in Africa. The biggest business deal in Africa was with the Kenyan government, who are reported to have bought 5000 radios for use in a school radio program they were trying to reintroduce. The government also committed to buy

\footnotetext{
${ }^{1}$ see the company website http://www.worldspace.com

${ }^{2}$ Manufacturers who resell another company's product under their own name and branding. In reality they actually customize another company's product and sell it with their own warranty.

${ }^{3}$ (Sirius and XM Satellite have a subscriber based satellite radio business that operates only in the USA)
} 
FIGURE 7.1: The WorldSpace Service Array

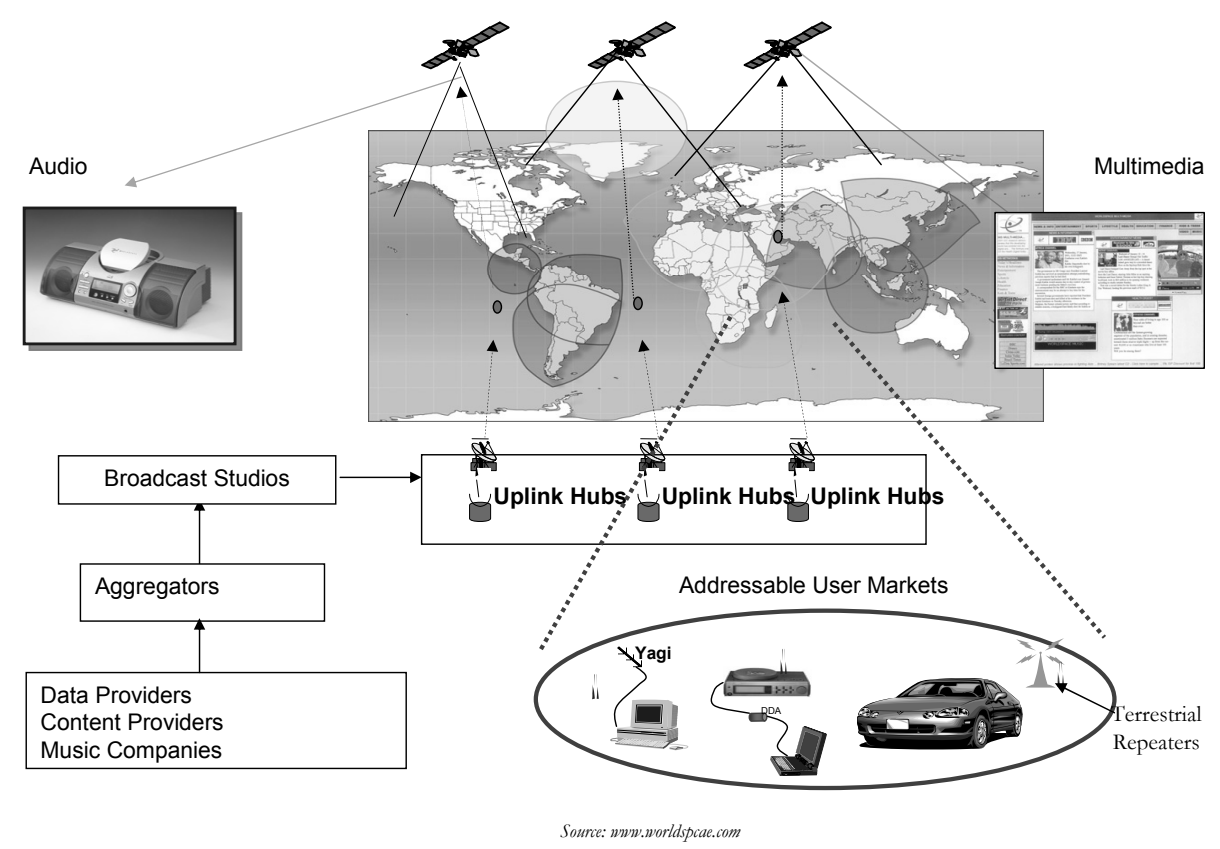

pre-paid subscription on a yearly basis. There is scant information about this deal and no one seems to know what happened to it after the initial announcements were made.

The Indian operation followed in 2001. Unlike Africa where WS entered with an initial free-to-air strategy, the Indian business was started as a subscription based business and users still had to buy the Worldspace receiver set for Rs.5,500. The Indian market reacted to this 'market aggression' as the whole idea of paying for radio service was new to them and the impression that this service was expensive quickly took hold. This attempt was unsuccessful and WS had to retract and make new plans for the business in India. They re-launched the product in 2005 with much more success than before as they slashed cost of radio devices from Rs.5,500 to Rs.1,999 including three months subscription. The subscriber base grew in leaps and bounds from 2,959 in 2004 to a healthy 66,239 in December $2005^{4}$.

\subsubsection{Competition}

Acknowledging that pay-radio is not a common concept in most of the markets they were trying to break in, WorldSpace identified the challenges

\footnotetext{
${ }^{4}$ WorldSpace Incorporated Fourth Quarter 2005 Results
} 
they were facing from competing technologies in their submission to the Securities and Exchange Commission of the US, where they are registered. Most important to note are the following points:

- WS is not able to offer local news content in local languages that AM/FM broadcasters with commercial advertising routinely offer their listeners for free. This is a limitation more of choice than anything else. WS chose not to do any live broadcasts of radio content but rather to concentrate on broadcasting pre-programmed content. This is a rather serious disadvantage as listeners and advertisers cash in on the prime news broadcasts. A listener in Africa would rather stick to his AM/FM radio than spend money to listen to 50 music channels of foreign music without any local news updates.

- There are technological shifts towards cheaper terrestrial digital broadcast systems that are able to provide digital audio. WorldSpace can no longer claim to have the only digital audio music platform, as cheaper options have become available with technological advances.

- Some DTH TV satellite providers include digital audio as an added freebie to their services. Multichoice in South Africa includes lots of digital audio channels free for full subscribers. If you can afford to buy the WorldSpace receiver plus a subscription, you can do one better by buying into Multichoice and get 80 TV channels, 3 interactive channels, $40 \mathrm{CD}$ quality digital audio channels and over 31 radio channels with local news bulletins, all in one. This is serious competition for WS especially in Africa where a booming movie industry has taken hold in the form of Nollywod, the Nigerian version of Hollywood, on the African Magic channel. This is one of the offerings on the Multichoice bouquet and it is a big selling point for their business in Africa.

- Internet Protocol (IP) based audio broadcast is becoming more and more accessible with the increasing availability of fibre optic cable. The quality of IP based audio services is just as good as those delivered directly by satellite if not better considering adverse weather interruptions on satellite signals. Worldspace gave out a license to a Chinese manufacturer to produce a PC card that carries the STARCHIP integrated circuit so that WS programming could be accessed via PCs through the card. But the same content could far more easily be routed via a server on the internet given the large file handling capabilities of fibre optic cables.

- Digital Multimedia Broadcasting (DMB) is now targeted at mobile phones. Mobile phone providers are routinely including digital media broadcast to mobile phone users, so the motivation to spend money 
on a Worldspace receiver plus monthly subscription fees is pretty low in most markets that can actually afford the service.

Apart from the above-mentioned competition issues, WS buys most of its content from content providers and other radio stations. They also spend a lot on marketing to acquire new subscribers. These expenses most definitely hike the operating costs and reduce their profit margins considerably.

\subsubsection{The Business}

Worldspace invested more than $\$ 1$.2billion in a for-profit venture that has so far fallen short of the expectations of the CEO and his partner investors. In 2004, WorldSpace reported revenue of $\$ 8.5$ million, down from $\$ 13$ million for $2003^{5}$. It posted net losses of $\$ 577$ million in 2004 and $\$ 217$ million in 2003. After an initial infusion of capital, WorldSpace finally ran out of money. These huge losses coupled with post 9/11 complications led to the introduction of a worldwide subscription model across the whole of its footprint. Its particular focus was on the expatriate workers in Africa and Europe who could easily afford a monthly subscription charge of $\$ 10$, in addition to the Indian operation. The company needed to restructure its debt and start making profits quickly to service its debts and recover its losses. The debts were rescheduled in 2004.After that Wordspace concentrated its efforts in India and China, where the middle class was bigger than in Africa and growing fast. The immediate effect of these changes were seen in the company's 2005 performance figures which showed a healthy increase in revenues compared to 2003. The subscription revenue grew more than three times from 2004 to 2005 and the equipment sales held steady (see figure 7.2 )

\footnotetext{
${ }^{5}$ WorldSpace Incorporated filing to the US Securities and Exchange Commission, Washington DC, 2005
} 


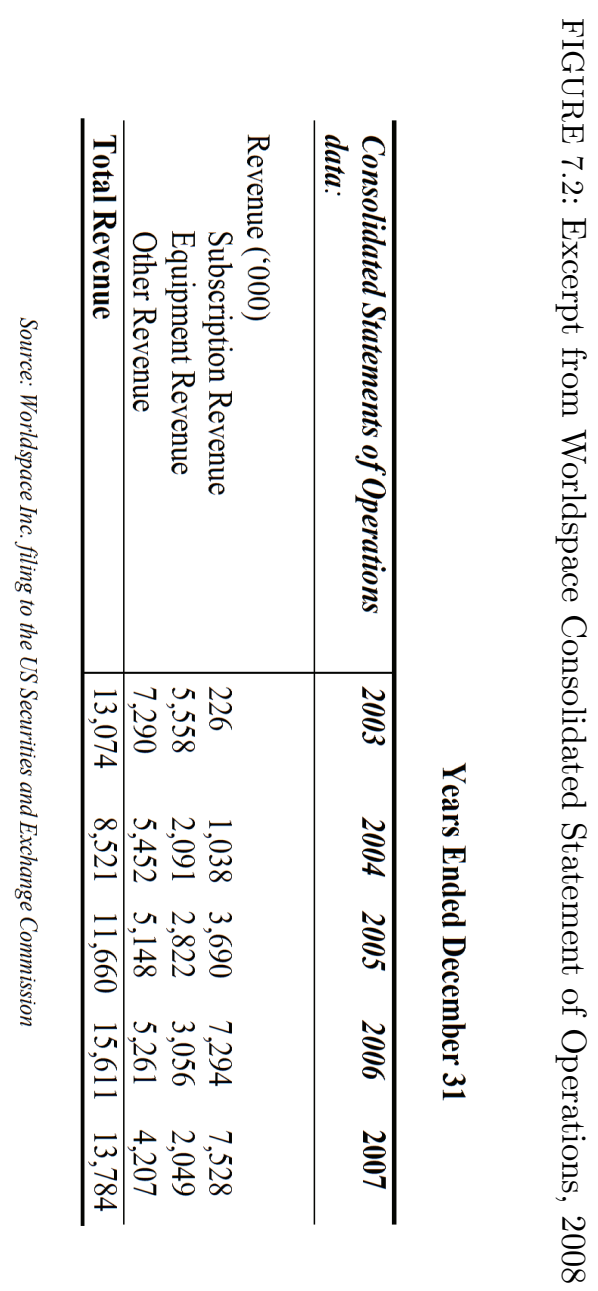


FIGURE 7.3: Performance of $\$ 100$ Invested in WS compared with Nasdaq and the Russe IT Index Over One Year

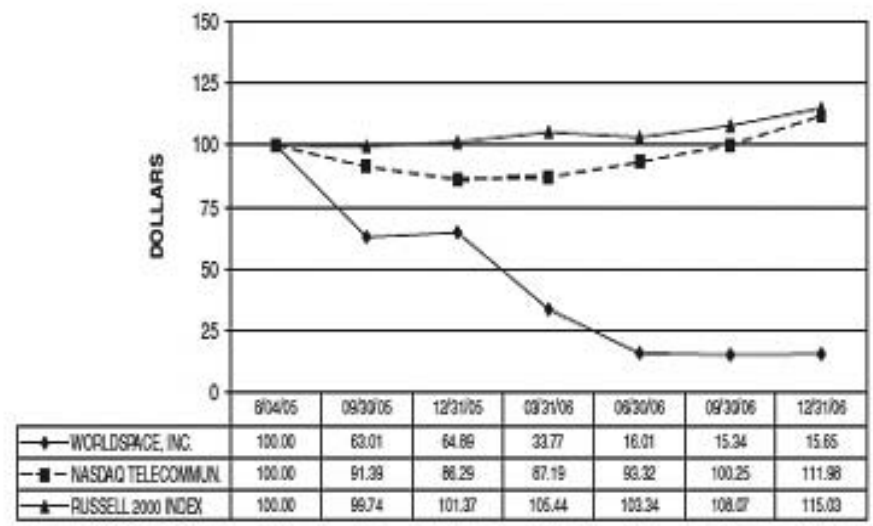

Source: Woridspace inc. Secunties and Exchnage Commission Fining 2008

In August 2005 WS began trading on the Nasdaq as a class A common stock. Figure 7.3 shows the performance of the Worlsdspace stock from the day it was listed till December 2006.

The graph shows a comparison of the performance of 100 dollars invested in three different stocks: Worldspace Inc, the Nasdaq ICT Index and the Russel Index. It is evident from the graph that in spite of general ICT stock performing reasonably well, the WS stock fell sharply losing almost all of its initial listed value. This performance angered investors and a civil Class Action lawsuit ${ }^{6}$ was brought against the corporation alleging that WS had inflated subscriber numbers and misled investors when it filed for its Initial Public Offering (IPO) on the New York Stock Exchange in 2005. Mounting marketing costs and operating losses coupled with the lawsuit finally drove WS to file for chapter 11 bankruptcy protection in October 2008. A buyer was identified for its India operation that was still doing very well and accounting for 95 percent of all WS subscribers. But the buyer pulled out at the last minute and WS is finally switching off the India operation as well. Satellite Today reported on 29th December 2009:

"WorldSpace's Indian operation will close down at the end of this year, the operator announced late last week. WorldSpace said the potential buyer of much of its global assets has decided

\footnotetext{
${ }^{6}$ The Class Action is being handled by the Rossen Law Firm P.A., Court Southern District Court of New York
} 
not to buy the WorldSpace assets relating to and supporting WorldSpace's subscription business in India. All customers in India will have their Satellite radio broadcast service terminated on Dec 31. WorldSpace, Inc. has been under bankruptcy protection since Oct. 2008"

The only reason given for this drastic measure are the problems that the mother company is having in the US and the fact that the buy-out deal fell through. WorldSpace remains firmly popular in India.

It is fair to say that WS has never made a profit since the inception of business in 1999 and is still struggling to break even two years before their satellites expire.

\subsubsection{Multichoice and World Space Compared}

A comparison of the business performance of WS Radio and the DTH satellite TV provider Multichoice (MC) reveals a startling difference of fortunes. While MC has been growing and making profits, WS has not turned a profit in 10 years of operation and its subscriber base remains pitifully small. Table 7.1 shows a comparison of WS and Multichoice. 


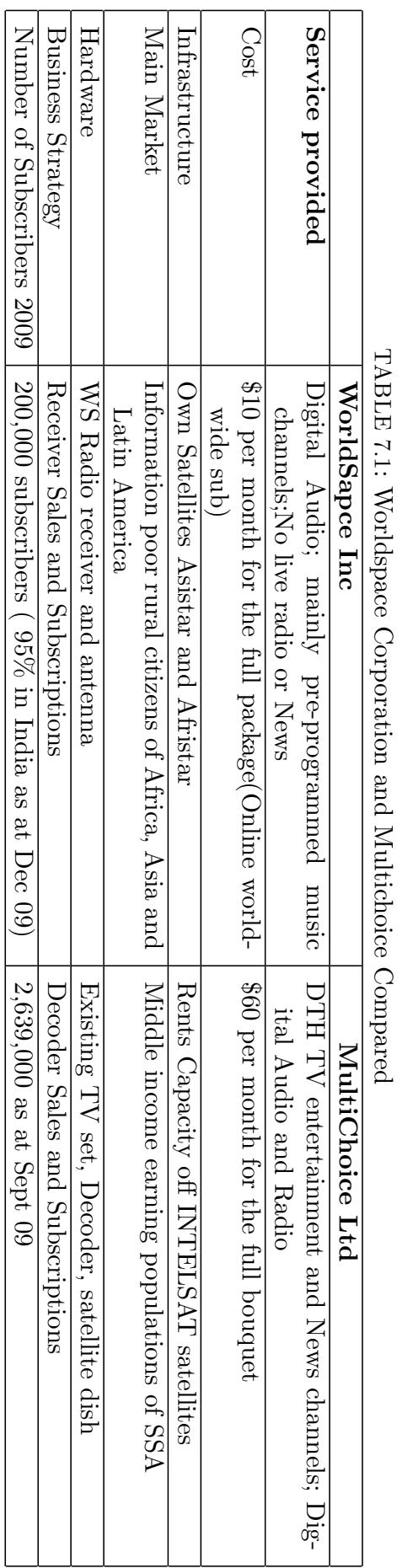


While WS served up digital audio signals on its own satellite platform, MC provides live world sports and other entertainment and news programs on rented satellite channels. Satellite space is expensive so MC subscriptions are also quite expensive at 60 dollars a month. This is much higher than the 10 dollars a month that WS charges for its premium package. Despite this obviously high subscription charge MC has acquired more than 2 million customers in SSA as of December 2008 and its subscription base keeps growing. Owning and displaying a satellite dish has become a status symbol in Africa and this can be seen from the numerous satellite dishes sticking out of balconies in shared apartment blocks or over townhouse rooftops in the suburbs. Figure 7.4 shows the growth in MC subscriptions

\subsubsection{The user's views}

We carried out an online survey of users over a period of two months (between November and December 2009). Users of the WS radio service were asked to respond to five simple questions regarding the service. This was not a comprehensive survey of the WS service as such, but an attempt to get an idea of the perceptions of the users as far as affordability, necessity and accessibility are concerned. As such users were asked online to respond to five simple questions about the WS service they were using. The obvious bias in this online survey is that the views of non-users were not solicited. Radio is probably the most common and most available channel of news in Africa and it is logical to assume that people who did not use WS radio either just never heard of it, or if they did thought it was too expensive. Another possibility is that they just did not see the difference between what they already had and what WS was offering. We are more interested in the views of these who actually had access to the service and so had an informed opinion about the service.

The survey was posted to the WS online user communities. Five questions were asked, 4 multiple choice and one open-ended question, where the users were asked to say what they would have done to make WS a successful business venture. The demographics of the respondents are shown in figure 7.4. It is clearly evident that the Indian operation was the most successful as $59 \%$ of all the respondents were Indian based subscribers.

Asked how they rated the WS service $81 \%$ of respondents thought the service either cheap or affordable. Only $19 \%$ thought the service was expensive. All the respondents from Africa thought the service was expensive. Asked about the quality of the radio service, $85 \%$ of respondents thought the service was either good or excellent. This shows that there practically was nothing wrong with the technology and the quality of the service delivered through it. The problem with WS' failure to make money both in Africa and in India, where they had a sizeable subscriber base was not the technology or the pricing of the product, as we see that most of their users thought it was affordable. The problem was rather how they could balance 
FIGURE 7.4: Multichoice Number of Subscribers in Africa as of Sept 2009

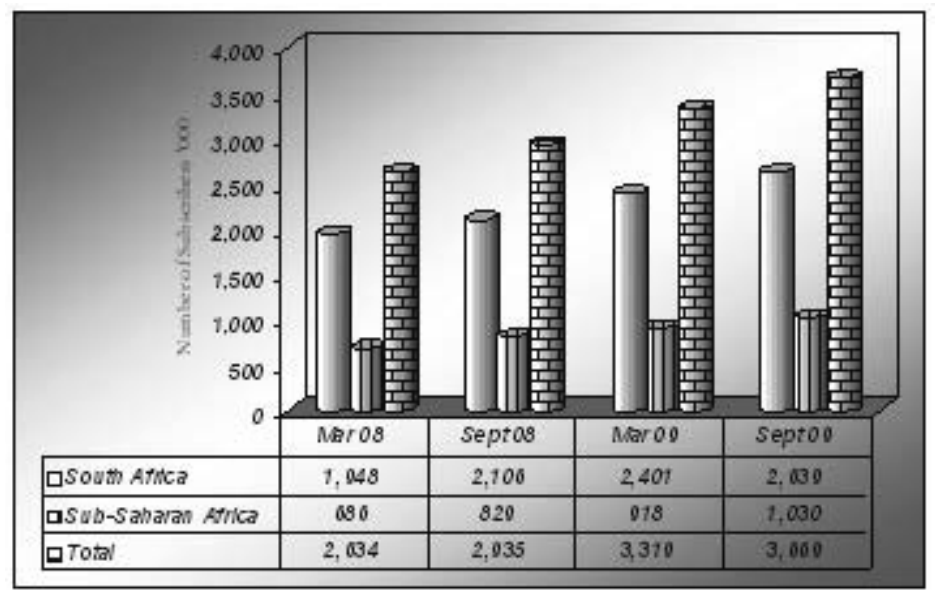

Source: Own Graph from Onine Survey Data

FIGURE 7.5: Demographics of Respondents

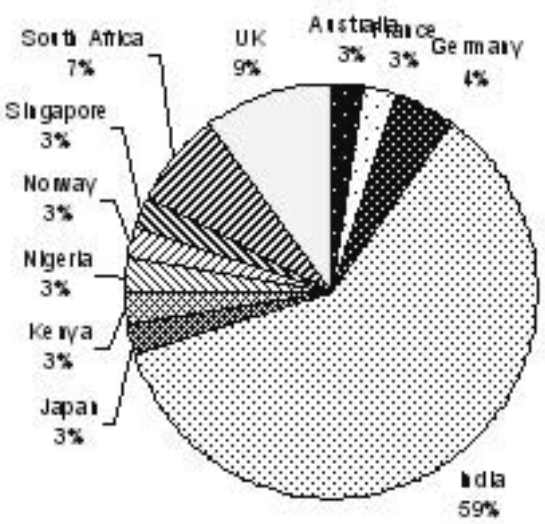

Source: Own Graph from Onine Survey Data 
FIGURE 7.6: Cost Perceptions of Respondents

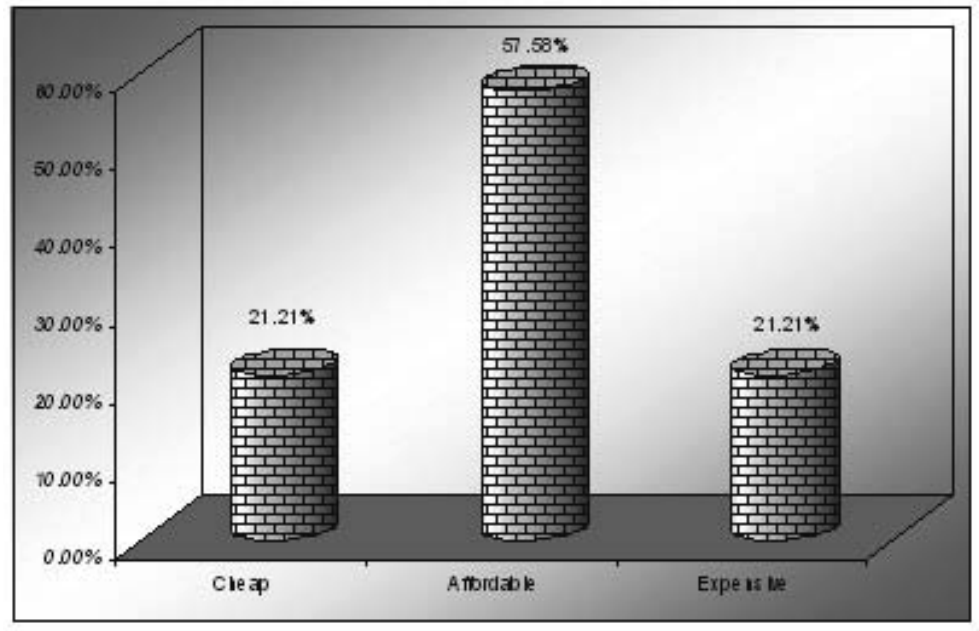

Source: Own Graph from Onine Surey Data

between providing an affordable service and recovering the sunk cost of owning the expensive satellite space infrastructure.

\subsubsection{Conclusions}

The comparison between WS and Multichoice gives reason to think that a 'Great Connector' model of satellite infrastructure (chapter 3) would have more social welfare benefits and be more efficient for the provision of services in poor developing countries than the privately owned infrastructure model. This, because owning the satellite infrastructure and charging little for the service did not benefit WS because their receiving devices were too expensive and this meant they could not profit from economies of scale. The sunk cost of building and launching the satellites had become too heavy a burden. This eventually disadvantaged users as the company closed down the free-to-air channels and implemented subscriptions for all, thus making the service inaccessible for many of the radio receiver owners on the continent, who had bought the radio receivers believing there would be no subscription fees. On the other hand Multichoice bought channel space from private providers and was able to provide prime services to a select middle class audience that could afford them. They did not have to worry about recovering an initial enormous investment in satellite infrastructure on a private basis, they used what was already there. The disadvantage in their case is that because the channel space is expensive their service remains 
FIGURE 7.7: Product Quality Perceptions of WS Users who Participated in the Online Survey

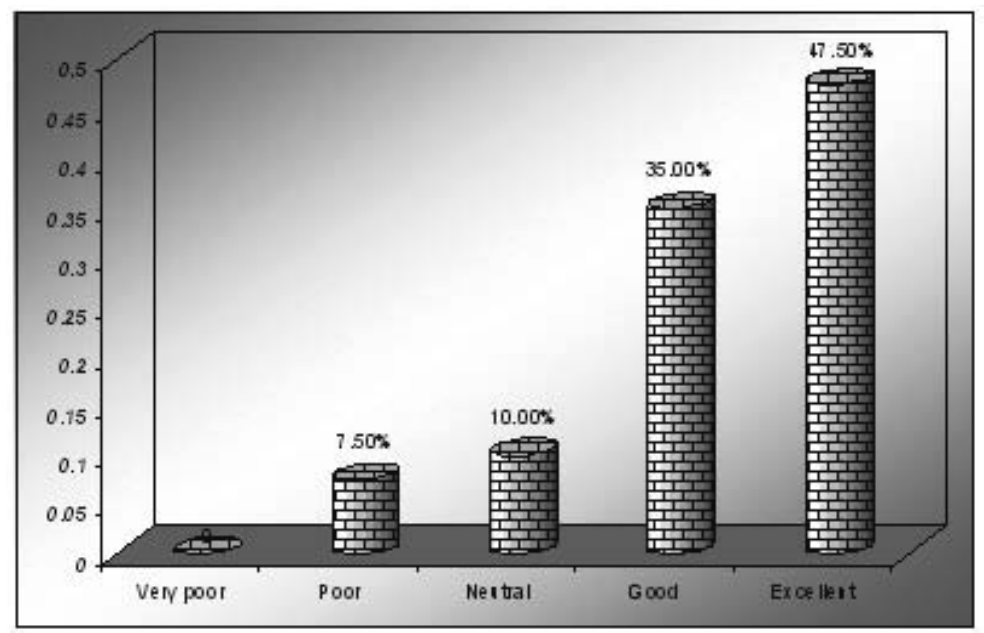

Source: Own graph from Onine Survey Data

exclusive and does not reach the mass of the poor in Africa. The result is an expensive service, which at present is the bane of satellite technology applications.

Although WS licensed the technology to a few brand names they could not cash in on economies of scale because these few radio brands were inaccessible to the bulk of radio users such that the customized radio was not the radio receiver of choice. As one of the respondents puts it:

" I would have included all the main national broadcasts from all countries in the target area so as to make WS the preferred way to listen to radio."

WS could have profited from economies of scale if they had simply licensed off the chip to all radio manufacturers, such that the WS radio feed becomes a premium for any user who buys any radio. More than anything else privately owning the satellite left them with the burden of recovering the sunk costs, which they could not easily do from the sales of the radio receivers and subscriptions. Making a profit would have been easier if they did not own the satellite space infrastructure (like Multichoice) but then that would have made their objective of reaching the poor people of Africa even harder as they would then have had to charge high prices for their service (like Multichoice). 


\subsection{Telemedicine Projects}

In this section we turn to an important application of ICTs in the health sector. Health practitioners have long realized the inherent advantages and possibilities that ICTs could bring in the delivery of health care services especially in helping to reduce morbidity and mortality rates in rural areas of poor developing countries. The central advantage and power of ICT is its inherent ability to deliver diverse information across large geographical spaces in relatively very short time periods. There is now a large stock of literature and project examples, which demonstrate how this concept, commonly referred to as tele-medicine, has been implemented for the benefit of poor populations in developing countries ${ }^{7}$.

Utilizing appropriate technologies can enhance the quality and the reach of ICTs thus empowering impoverished communities. Satellite technology has always been in the spotlight as the most suitable technology for spreading scarce medical expertise to poor distant areas in developing countries. A number of attempts have been made. Notable among these efforts is the Tele-medicine Network Project in French Speaking Western Africa (RAFT) pilot project in West Africa ((Geissbuhler A and L'Haire 2003)), where in 2003 tele-medicine centers were set up in eleven countries mainly with the aim of sharing information between northern European partners and their southern participants. One of the main conclusions of the pilot study was that there is a potential risk of the aggravation of the digital divide between urban and rural areas if these projects are set up mainly around main medical facilities in the cities. They proposed the

"deployment of internet access points in rural areas with the use of satellite technology, enabling not only tele-medicine applications but also other tools for assisting integrated multi-sectoral development...." 8

Reporting on the successes of the project the International Institute for Communications and Development (IICD) reports on its website that since the installation of a VSAT connection at hospitals in Timbuktu, Mopti, and

\footnotetext{
${ }^{7}$ World Bank, Information for Development Programme (Info Dev) (2005) 'Opportunities and challenges in using ICTs to improve public health'http://www.infodev.org/en/TopicBackground.6.html

Chief Advisors Office (CAO), Government of Bangladesh: 'ICT and Health Vision 2025', www.cao.gov.bd/projects/a2i/e-Health.doc

World Health Organisation (WHO), Department of Essential Health Technologies 'Taking basic health solutions to countries': Strategy 2004-2007 'eHealth for Health-care Delivery'http://www.who.int/eht/en/eHealtwfph_HCD.pdfWorld Information Technology and Services Alliance (WITSA) (2006) 'Health Care and Information and Communications Technologies: Challenges and Opportunities' http://www.witsa.org/papers/WITSA-HIT-final.pdf

8 ibid. pp3
} 
Gao hospitals the remote areas are now able to communicate better. They report that since the installation of the VSAT connection in April 2009, medical courses have been followed online and 39 tele-consultations have taken place in radiology, dermatology and other areas of medicine ${ }^{9}$.

The European Space Agency (ESA) and the German Fraunhofer-Gesellschaft have been involved in the drawing up of a reference model on the use of satellite communication within capacity development programmes. The FOKUS NET4DC project of Fraunhofer-Gesellschaft has set up another pilot project called Ubuntu Campus in Macha area in the Southern Province of Zambia, where specialists use bi-directional radio to connect to the existing satellite infrastructure. The experts from Fraunhofer FOKUS plan to use the network to test how reliable the technology is, what the life expectancy is likely to be, and what the maintenance requirements will be, given the prevailing climatic conditions ${ }^{10}$.

Another example is the national tele-medicine system in South Africa which was rolled out in 1999 using Integrated Services Digital Network (ISDN) at 256kbps. The initial applications were tele-radiology, tele-ultrasound, tele-pathology and tele-ophthalmology. This project went through several transformations from using dial up DSL connections to dedicated leased lines but had a lot of difficulties in acquiring the necessary bandwidth that they needed in order to efficiently carry out the consultations. They eventually moved on to try various over-the-air modes of connection utilizing satellite and mobile networks wherever possible.

In 2003 the Ministry of Health in Zambia set up a National Tele-medicine Steering Committee to study and implement tele-medicine initiatives in the country. The main objective of this initiative was to mitigate the shortage of skilled medical personnel in the country that was brought about by the massive emigration of personnel, leaving the country with very few skilled medical specialists. This meant that the few specialists available had to be shared in the most efficient manner and tele-medicine was seen as a possible solution to the problem. It is important to note that these initiatives were not meant to spread primary health care to the most remote areas of the country but rather sought to mitigate the shortage of specialist staff in the big hospitals in the country. As such most tele-medicine projects in Zambia are established around service delivery sites that already have the infrastructure and the capacity to utilize it but lack specialized medical personnel.

The survival of all these projects however depend on the cost of the satellite link and who is paying for it and for how long. These are donor dependent projects and experience has shown that the initiatives die off

\footnotetext{
${ }^{9}$ see the iicd website at http://www.iicd.org/articles/satellite-communication-solvesconnectivity-problems-in-mali

${ }^{10}$ The Times of Zambia 28 December 2009
} 
as soon as the donor funds run out and the situation reverts back to the undesirable beginnings. The arrival of fibre optic cable along most of the African coast will most certainly see a lot of migration of service providers from satellite to fibre. This should free up a lot of capacity on satellites currently serving Africa and if they are not able to sell this capacity it should be used for health connectivity initiatives on the continent. However the economic effect may be exactly the opposite in the sense that having lost most of their traditional customers to fiber, satellite operators may hike their space channel rentals to compensate for the lower number of customers.

Satellite operators losing big paying customers to fibre operators could use this as a selling point of their services to governments who are by the way, the biggest payers to private business in Africa. An offer of free bandwidth for health services could be bundled together with an offer for other paid-for services to African satellite users. Such models could help to reduce the amount of wasted satellite capacity being freed up by migrators to fiber and not being utilized just because it is too expensive. This however is not our preferred solution to the problem. We propose a public infrastructure owned by a group of African countries who are able to provide free and subsidized services off the public infrastructure because the social and long-term benefits are more important than recovering the sunk cost of the infrastructure (like building a road or a bridge, for example).

\subsubsection{The Virtual Doctor Project ${ }^{11}$}

The Virtual Doctor project is an effort to extend health care to the remote villages of Lundazi in the Eastern province of The Republic of Zambia by a charity organization, the Virtual Doctor project, using mobile clinics equipped with satellite communications hardware.

The whole concept is modeled around the traditional 'store and forward' mode of tele-medicine, where images and information are collected at remote health delivery sites and transmitted by E-mail to doctors based in distant locations. This system is supposed to enable these 'virtual doctors' to offer on-going diagnostic assistance to clinical staff on the ground. The mobile clinic travels between a number of village sites in four-wheel drive vehicles specifically equipped with appropriate technologies, setting up temporary clinics for several days at a time. The overall objective is to reduce morbidity and mortality rates of easily treatable and preventable diseases in hard-to-reach rural areas in addition to reducing the number of

\footnotetext{
${ }^{11}$ This section is based on a paper written by the author together with Paul Mustard and Huw Jones of the Virtual Doctor Project in Zambia. The paper appears in the UNU-MERIT Working Paper Series as Working Paper \#2011-002 due for publication in the Phiolosophy, Ethics and Humanities in Medicine Journal (see bibliography Mupela, Mustard and Jones, 2011)
} 
referrals to distant hospitals, which are already struggling to cope with the high numbers of local patients seeking medical attention.

This is a major departure from earlier tele-medicine projects which focused around centers with equipment and infrastructure ready to use. The Virtual Doctor Project has targeted areas without the basic facilities for provision of basic health care through mobile clinics. These mobile units have been used a lot in Zambia to reach the rural populations for massive immunization campaigns and sometimes just ante-natal and other primary health services. There has not however, been an initiative that has sought to combine mobile telecommunication access with specialist care at a distance as a main focus of the service. This is the special feature of the Virtual Doctor Project-the combination of mobile communication access with tele-medicine, making it possible for rural populations without telecommunications infrastructure and primary care facilities to both have access to primary care and specialist care through the mobile clinics fitted with ICT equipment.

\section{The Project Area}

Lundazi District is a rural area within the Eastern Province of Zambia. Rural areas are more afflicted with actual lack of basic infrastructure needed to provide basic services. For the health sector this means lack of primary health care facilities and difficult access to referral centres due to bad or no roads, poor or no telecommunications and in most cases lack of basic medicines. It also means lack of trained medical staff, who find it difficult to settle in these areas. At a national scale more than half of the Zambian trained medical staff have left the country for greener pastures abroad (Ngatia, 2008; Patel, 2003; Clemens and Pettersson, 2006). Such an exodus means that in Zambia, a country of 12 million people, there are only around 1200 registered doctors ${ }^{12}$ and they are mainly based in urban areas. This situation is common throughout sub-Saharan Africa.

There are about 40,000 people living in the remote areas of Mwanya, Chitungulu and Kazembe which lie in western part of Lundazi district along the Luangwa River. These are very isolated areas that often get cut off from the rest of the district during the rain season when the Luangwa river floods. Most of the communities in this area are subsistence farmers, relying on harvests of maize, millet, rice, and pumpkins for their livelihood. They often experience drought in the dry season and floods during the rain season, which lead to crop failure and periods of hunger ${ }^{13}$. Unfortunately these are periods when the population is also prone to many infectious diseases for which timely medical attention is of prime importance, both for treatment

\footnotetext{
${ }^{12}$ World Health Organisation Statistical Information Service (WHOSIS) (2008)

${ }^{13}$ World Food Programme

http://www..org/english/
} 
and prevention of further infections. The most common ailments recorded in the area are Malaria, Diarrhoea, Tuberculosis, Respiratory Tract Infections, and maternity complications. Animal and Snake Bites are also common occurrences. With such limited health care available, these complications often become fatal ${ }^{14}$.

As noted above it is a characteristic of areas like these that there is a critical shortage of medical staff in the area. This is compounded by a shortage of medicines and the lack of communications facilities. An added obstacle to patients getting treatment is also the distance required to travel to local clinics or regional hospitals. This journey can often take several days by foot or by bicycle even for healthy people. This usually means a loss of income and with many health centres poorly staffed and underequipped this effort may not guarantee any improvement in their condition. This means that often problems are not addressed until they become very serious. Early diagnosis and regular treatment becomes almost impossible in these areas. A typical scenario that captures the desperation for health services in the Lundazi district is one reported by the World Medical Fund operating mobile clinics in neighboring Malawi:

"Typically the tarmac road would be over $25 \mathrm{~km}$ away and the nearest health facility a further $40 \mathrm{~km}$. If the sick child made the journey, the choice would be between a government hospital where treatment, although free, is limited from chronic shortages of clinical staff and pharmaceuticals, or the mission sector where treatment is paid for, often beyond the means of the rural poor. The fact that the children's parents/guardians will travel for up to 2 days to be seen by our team indicates their lack of alternatives".

\section{Implementation}

The project was set to begin in operations in January 2010. Project implementation has been delayed because the communication component on which the project depends so much was hard to implement. The initial idea of using the B-GAN satellite connection was dropped because it was too expensive, so the second best option of using the local mobile phone network was adopted. But the project area was not yet connected to the local mobile phone network. The project therefore had to wait until Lundazi the project area was connected to one of the mobile providers in the country. This has also meant a scaling down of possible applications as the local mobile phone network has its limitations in terms of broadband capacity and speed.

\footnotetext{
${ }^{14}$ From an interview with Chisenga, A; Lundazi District Medical Officer: Ministry of Health Zambia $(\mathrm{MOH})$
} 
The Virtual Doctor project is also heavily dependent on charity donations and has very little sustainability built into it. The liaisons with the Ministry of Health, who recently bought mobile clinics to be used in rural areas of the country, is critical for success especially that the new mobile clinics do not have the communications component that the Virtual Doctor has proposed.

\section{Concluding Remarks}

We have seen here how the high cost of broadband connectivity over satellite and the lack of suitable alternative technologies in Lundazi district have played to delay the implementation of an important project in the area. If communcations technology can be used to improve the health and education status of the African population, then a way must be found to make it affordable to service providers and eventual end users. We propose free bandwidth for health services as a concept that should be adopted if these projects are to have any form of sustainability in Africa. One way to achieve this is to have all satellite operators provide a certain fraction of their capacity for health purposes.

\subsection{Conclusion}

We highlight the fact that satellites can be used to provide services that enhance economic success and contribute to social welfare in Africa as we have seen in Chapters Three, Five and Six. Health and Education projects enhanced by satellite connectivity can reach further in Africa than fibre cables and terrestrial wireless technologies alone. In order for these projects to have the desired positive effect in the long run, a cheaper mode of access to satellite bandwidth capacity is critical. Continuing to rent channel space from European/American space operators is definitely not one of the ways to do so.

\subsection{Summary}

In this Chapter we have looked at the case of a satellite radio service operated by WS corporation beamed from their own satellites to specialized radios receivers. We compared this with another satellite service providing television broadcast on rented channel space, Multichoice. Although the WS service is perceived as affordable by the bulk of users, it is not able to turn a profit because of a heavy sunk cost in infrastructure. Multichoice is able to turn a huge profit and keep its subscriber base growing in Africa. But for the mass of poor people this service is beyond their means. MC is also assisted by a lack of serious competitive options in the satellite 
TV sector in Africa. Meanwhile WS is still struggling to find a niche for its services worldwide and while its service is still popular in India it has been forced to switch off its Asiastar beam leaving subscribers with silent expensive radio receivers.

It would seem therefore, that such expensive infrastructure like satellites, is rather more efficiently owned and operated on a shared multinational basis and services run through them by private providers leading to less wastage of capacity and cheaper services for users and a wider distribution of risk among many countries instead of one private investor running the risk of defaulting on bank loans and abandoning a required and popular service.

Most Tele-medicine projects in Africa have failed to provide sustainable meaningful service to poor areas of African countries because of the high cost of satellite connectivity, which most of them have tried to utilize because of its obvious advantage over terrestrial networks. The dependence of these ventures on donor funds and the high cost of connectivity makes them very unsustainable and most of them close up after the money runs out. A shift towards land-based over the air technologies like mobile and Wimax will also end up the same way because of limited capacity and the need for market oriented profit margins on the part of operators. While these services have been around and are still being promoted, we argue for a shift towards free broadband capacity for tele-medicine operations in hard-to-reach areas in Africa. 



\section{8}

\section{Conclusions and Recommendations}

\subsection{Introduction}

We set out to investigate whether connectivity is important to growth in Africa and whether the reliance on international satellite infrastructure has a negative effect on connectivity pricing in sub Saharan Africa (SSA). We wanted to learn what effects, if any, satellite technology exerts on connectivity in SSA, because satellites have been the dominant international connectivity backbone in SSA. To do this we introduced satellite technology in Chapter Two and highlighted the technological advantages inherent in this technology compared to competing technologies. We then used these advantages to build the connectivity-based endogenous growth model in Chapter Three, where we studied the implications of communication and transport costs on growth rates of virtually connected regions, taking into account their contributions to the acquisition of ground infrastructure in order to join the pool of regions (communities) already connected through a public satellite infrastructure. This approach to demonstrate the effects of connectivity on growth has not been used before. The combination of a concrete connectivity mechanism, satellite, and a concrete connectivity finance mechanism in a formal model setup is the novelty in our work.

In Chapter Four we took stock of various forms of international connectivity and their delivery mode as well as cost to the end user. We particularly focused on cost of service to end users and what the determinants of this cost are. We identified two major delivery mechanisms of international connectivity in sub Saharan Africa, satellite and optical fibre and tackled the 'satellite versus fibre optic' connectivity debate. We concluded that SSA's quest for effective and affordable international connectivity is not a case of 'either satellite or fibre' but rather a case of innovative combinations of satellite, fibre and existing terrestrial fixed and mobile technologies combining to bring the benefits of international connectivity to the continent. We further established that the cost of access to these international gateways (both satellite and fibre based) is a major bottleneck in the delivery of affordable international connectivity services in Africa. As demonstrated in Chapter Three, a shared financing approach to the acquisition of satellite infrastructure could be beneficial to all under very reasonable parameter constellations.

The effect of the cost of communication was further tested empirically in 
Chapter Five, where we found its effect on exports in SSA to be negative and significant. This was done using a gravity model with bilateral data drawn from various sources. In Chapter Six, the regional effect of connectivity was examined using South African census data from 1996 and 2001 together with the mini-census Community Survey of 2007. The effects of ICT applications, mainly mobile and fixed telephony, computers, radios and television access variables on per capita household income from $238 \mathrm{mu}-$ nicipalities in South Africa were investigated. Here we found a significant and positive effect of mobile and fixed telephony on per capita household income in municipalities in South Africa, but found no such effect from television, computers and radios.

Lastly in Chapter Eight we looked at two cases of satellite applications in Africa: a failed satellite radio business venture and a promising telemedicine project for remote rural populations. The cases highlighted the need for integrated appropriate services in SSA with the involvement of governments combining resources to provide common infrastructure while private companies provide services via a publicly-owned common infrastructure, which is too expensive for any of them to put up individually.

We have demonstrated how telecommunication costs have a significant effect on trade in the region. One of our priorities for further research will be to examine the share of communication costs in trade costs as these costs could also simply be reflecting the difficulty to communicate due to poor infrastructure in the region. It has also been demonstrated how satellites, when used in conjunction with existing cable networks and operated on a shared regional basis, have the potential to drastically reduce the cost of communication in Africa and spur economic growth through trade. But so far their effect on communication costs in Africa has been to increase costs instead of reduce costs because the satellite access costs are too high in SSA due to the oligopolistic nature of the market and because SSA countries do not own the satellite infrastructure, so they can not dictate the terms of use. The situation is made more dire by the fact that all serviced communication satellites over Africa are owned by foreign operators. Connectivity fees being as high as they are, money flows out of the continent.

As we have seen, various attempts have been made to build African operated satellites: the RASCOM satellite failed to reach its intended GEO orbit, while the NigcomSAT tracking team lost contact with its satellite and had to abandon it. The third attempt to launch a dedicated African satellite by the Dutch company SES New Skies in December 2008 ended in disaster as the rocket blew up on launch and the payload was lost together with it. Angosat and the New Dawn project are satellite projects in the pipeline for Africa but the New Dawn project is basically an addition to the Intelsat fleet rather than a Pan African satellite as such. Satellites are expensive to operate as wholly private businesses in Africa and these that are in operation are expensive to access. They should rather be organized on a shared regional basis so that governments would be able to subsidize 
vital communication services and undercut the private satellite operators for the greater common benefit of cheaper broadband access.

We have also seen how fibre cable operators and countries with fibre cable landing points exercise monopolistic pricing on services for access. The implementation of new fibre projects is expected to bring more competition both on the west and east coast of Africa. This will hopefully bring an end to these monopolistic practices and might eventually bring connectivity prices down. However one should note that the fibre landing at the coast is only a first step in the broadband delivery supply chain and the more critical part is bringing this capacity from the coast to the hinterland. It is highly questionable whether in Africa this can be done by fiber all the way to the user. A combination of Satellite and terrestrial mobile technologies has the biggest potential to deliver this capacity inland. But in its current configuration of American and European private satellite infrastructure servicing the African airspace, service providers will always struggle with the cost of this connectivity resulting in high service costs. Terrestrial wireless technologies are filling this gap and if implemented coherently may add value to the existing terrestrial cable networks that have failed to provide connectivity in SSA.

The whole of this discussion is presented under the assumption that connectivity is important to growth, as modelled in Chapter Three. In Chapter Five we have only analyzed the relationship between connectivity costs and export volumes. For the connection between trade and growth we rely on the secondary literature. We present the main findings of the research and make some recommendations ensuing from these findings.

\subsection{Major Findings.}

From our theoretical model we found that reductions in transport and communication costs have an immediate effect on the rate at which communities connect and trade with each other. We found that increasing transportation costs lengthens the transition towards the steady state. Although transportation and communication costs do not affect the steady state as such, the transition period is lengthened by a rise in these costs and this directly implies that a reduction in transportation and communication costs would be a suitable method to speed up the effective rate of growth, since the transition itself may take quite some time.

The largest effect on growth was observed in reductions in the cost of making new connections, which has a relatively significant impact on both the steady state growth rate and on transitional growth, while significantly reducing the length of the transition period as well.

We also found positive scale effects on the size of the communities with the caveat that the quality of labor in the connecting communities 
should provide a positive incentive for other communities to connect to them. Differences in educational levels for connecting communities should therefore not be too large. This points to education as an important determinant of the growth performance of an economy, through its impact not just on the quality of labor per se (Lucas, 1988) model, but on the size of the sub-spectrum of varieties that could be produced depending on average levels of educational attainment. This observation is consistent with the empirical findings in Chapter Six, where the effect of education on household income in municipalities in South Africa was found to be positive and significant.

We also found that countries can experience higher growth dividends from higher connectivity levels and lower transport and communication costs on the continent.

In spite of the presented technological benefits of satellite technology, connectivity over satellite has had a negative effect on trade through high satellite capacity costs which have led to high international service costs. We found a strong negative effect of cost of broadband on coastal regions in spite of the presence of fibre optic cable on the west coast of Africa. This would indicate that although the fibre optic cable is present it may not be as accessible as it is meant to be, leaving coastal countries with no option but to connect via satellite. On the other hand the effect of fixed lines on landlocked countries is much higher than in coastal regions, affirming our proposition that the price of calling international in the interior must be more prohibitive than at the coast because of the dominance of satellite in the interior. Furthermore trade is generally higher in countries with lower connectivity costs. Countries with higher volumes of outgoing calls appear to trade more than countries with lower volumes. These findings seem to suggest a strong relationship between affordable connectivity and intensity of exports.

At the local regional level mobile phones are more important to household income in municipalities in South Africa than fixed telephones and computers. Fixed line usage in municipalities in South Africa has generally dropped while mobile usage has been on the increase. There is evidence to suggest that the cost of fixed telephony services in South Africa actually went up during the rollout of mobile services between 2001 and 2007 as the fixed telephony incumbent provider tried to salvage the loss of income brought about by customers switching to mobile services.

We also find that education and employment are important for income generation in municipalities, as we would expect. This result is consistent with the result of our theoretical model in Chapter Three, where we claimed that the communities with higher quality of labor would produce more varieties than those with lower quality labor of similar size making it more beneficial for communities to be connected with higher level education communities than with low-education communities. The major limitation in this study is the lack of time series data because we used census data and 
Statistics South Africa has only two comparable years so far. The 2011 census data will be incorporated in a future study to enhance these results.

It is important to note the implication of the significant negative outcome of the cost of fixed telephony on bilateral exports in Chapter Five in contrast to the positive outcome of fixed telephony for regional household income in Chapter Six. In the one case we looked at the cost of inter-country connectivity while in the other we considered access to intra-country connectivity. The result is important in the sense that it highlights the critical role of international gateways (both satellite and fibre) in international connectivity. The trend is towards more and more fibre to the end user and where this is not possible over-the-air Wimax and cellular mobile is employed. Satellites are being used more and more to provide the backhaul services where the reach of cable and Wimax fail.

\subsection{Regulation and competition}

The conventional argument in the telecommunication sector in Africa is that competition in the operation of international gateways will lead to lower tariffs for international services. Pressure has been piled on governments to deregulate international gateways and give out licenses to more operators. In South Africa service providers have a choice between satellite and optical fibre but the cost of international connectivity and broadband services are just as high. In Zambia, the government controls the only international gateway in the country that connects via Intelsat satellites. It is our view that liberalization in the international gateway business will not necessarily deliver lower connectivity charges to end users of telecom services in sub-Saharan Africa because the new operators will still have to contend with high satellite capacity charges inland. The cost of acquiring the international gateway license is another obstacle most service providers have to contend with. High licensing costs from the regulators have been an intentional barrier constructed by regulators to keep the competition at bay. Opening up the international gateway business must go hand in hand with lowering prices of the licenses and creating shared space capacity infrastructure, otherwise these costs will be passed on to users by the new operators and there will be very little change.

Going by the results of the foregoing research results we posit that having access to a Pan African satellite and fibre connectivity together with liberalization of the international gateway business is what will deliver cheaper international connectivity to sub Saharan Africa. This makes it important for African regulators to seriously look into reviving the badly managed RASCOM project that has practically failed to take off for close to twenty years. National satellite programs are not an option as most African countries have neither the technology nor the money to put up such expen- 
sive projects. Although a few African countries have satellite infrastructure projects (Nigeria, Angola and South Africa) underway, what we propose is a more regional based approach to mitigate the negative effects of expensive satellite connectivity.

\subsection{Recommendations}

An integrated telecommunication infrastructure that incorporates shared African-owned satellites and private and public terrestrial cable and mobile networks is the best way to bring about the growth benefits of connectivity which we have called the Great Connector effect. This over-arching infrastructure would form a 'common' cyberspace network, which every private and public data service provider in Africa can tap into for the purpose of transmitting data and information across the African continent and beyond. This is especially critical now that the world economy is going through a new technological paradigm, characterized by ICT diffusion, which presents an opportunity for fuelling the technological catch-up process of developing countries in Africa.

African governments and educational institutions should take advantage of the existing infrastructure to create information affluence in African populations and boost national economic development strategies. Governments across Africa should be committed to contribute to the creation of the common cyberspace network and transforming existing and future telecom investments for the good of the people of Africa. As alluded to in Chapter Six these investment decisions should be tempered with the reality that Africa's problems as regards food security, basic shelter, primary health care and basic education can in no way be overlooked or trivialized. The policy implications coming out of our analyses in this thesis can only have a meaning if they feed into the resolution of these basic problems that Africa still faces. In other words connectivity should contribute to the resolution of these problems as suggested in the telemedicine project in Chapter Seven. The cost of connectivity should not be a hindrance in its employment for the provision of basic education in rural areas; Connectivity should facilitate trade and should not be a cost burden to emerging entrepreneurs on the continent. Wholesale privatization of existing incumbent infrastructure is not the panacea for high cost of connectivity charges on the continent. It must be complemented with a Pan-African cyberspace super-structure through which vital communications can be channeled by both private and public institutions alike. 


\section{Bibliography}

Aghion, P. and P. Howitt (1992). A model of growth through creative destruction. Econometrica, Vol. 60, No. 2. , Pp. 323-351.

Anderson, C. (2009). Free: The Furture of a Radical Price. Hyperion,New York.

Anderson, J. E. and E. V. Wincoop (2003). Gravity with gravitas: A solution to the border puzzle. American Economic Review, March 2003, 93, 170192.

Baliamoune-Lutz, M. and N. Léonce (2007). The growth edects of open- ness to trade and the role of institutions: New evidence from African countries,. MPRA Paper 6189, University Library of Munich, Germany.

Belleflamme F, P. Picard. and J. Thisse (2000). An economic theory of regional clusters. Journal of Urban Economics . 48, 158.184.

Bergstrand, J. H. (1985). The gravity equation in international trade: Some microeconomic foundations and empirical evidence. Review of Economics and Statistics, 67(3), pp. 474-81.

Bergstrand, J. H. (1989). The generalized gravity equation, monopolistic competition and the factor Proportions Theory in international trade. The Review of Economics and Statistics, 71,pp.7-22.

Brunner, M. and H. Strulik (2002). Solution of perfect foresight saddlepoint problems: A simple method and applications. Journal of Economic Dynamics and Control 26, 737.753.

Brynjolfsson, E. (1993). The productivity paradox of information technology. Communications of the ACM, December

Burstein, D. and D. Kline (1995). Road Warriors :Dreams and Nightmares Along the Information Highway. E P Dutton.

Carlota, P. (1985). Structural change and assimilation of new technologies in the economic and social systems. Future, vol. 15, n. 5, October, pp. $357-75$.

Castellacci, F. (2006). Theoretical convergence? a critical review of evolutionary and new growth theories. Journal of Economic Survey

Clarke, A. (1945). Extra terrestrial relays:can rocket stations give worldwide radio coverage? Wireless World Magazine. 
Clemens, M. and G. Pettersson (2006). New data on african health professionals abroad - working paper 95. The Centre for Global Development (CGDEV).

Davidson, R. and J. McKinnon (2004). Econometric Theory and Methods. Oxford University Press.

Davis, D. and D.Weinstein (2005). Market Size, Linkages and Productivity: A Study of Japanese Regions. Oxford: Oxford University Press.

De, P. (2007). The importance of trade costs: A gravity model application. 3rdARTNeTCapacity Building Workshop: UNESCAP, Bangkok.

de Sola Pool, I. (1990). Technologies Without Boundaries: On Telecommunications in a Global Age. Harvard University Press.

Deardorf, A. (1998). Determinants of bilateral trade: Does GravityWork in a neoclassical world? J.A. Frankel, ed., The Regionalization of the World Economy. Chicago: University of Chicago Press, 1998, pp. 7- 32.

Dollar, D. (2008). Lessons from china for africa. Policy Research Working Paper, The World Bank.

Dollar, D. and A. Kraay (2003). Institutions, trade, and growth : Revisiting the evidence. Policy Research Working Paper Series 3004, The World Bank.

Easterly, W. and R. Levine (2003). New data, new doubts: Revisiting "aid, policies, and growth". Working Papers 26, Center for Global Development.

Fink C, A. Mattoo and I.C. Neagu (2002). Assessing the impact of communication costs on international trade. World Bank, Development Research Group, Trade : Washington, D.C

Frankel, J. and D. Romer (1999). Does trade cause growth? The American Economic Review 89 (1999):379-399.

Freeman, C. (1996.). Long Wave Theory. E. Elgar, Cheltenham.

Freeman, C. (2001). A hard landing for the 'SNew economy.? information technology and the united states national system of innovation. Structural Change and Economic Dynamics, vol. 12, n. 2, July 2001, pp. 115139.

Freund, C. and D. Weinhold (2004). The edect of the internet on international trade. Journal of International Economics 62, 171- 189.

Fujita M, P. Krugman and A.J. Venables (1999). The Spatial Economy: Cities,Regions, and International Economy. Cambridge, Mass.: MIT Press.

Fukushima, M. and T. Kikuchi (2008a). Competing communications networks and international trade. Unpublished. 
Fukushima, M. and T. Kikuchi (2008b). Competing communications networks and international trade: Competing communications networks and international trade.

Garcia-Mila, T. and T. McGuire (1992). The contribution of publicly provided inputs to states. economics. Regional Science and Urban Economics, 22, pp. 229,241.

Geissbuhler A, Ousman L, Lovis C, and J. H. L'Haire (2003). Telemedicine in western africa: Lessons learnt from a pilot project in mali. AMIA 2003 Symposium Proceedings, 249.

Gilles, D. and M. Turner (2008). Urban growth and transportation. University of Toronto Working Paper No. 305.

Gillespie, R. and Cornford (2001). Regional development and the new economy. EIB Papers, 6, pp. 109-131

Greenstein, S. and P. T. Spiller (1996). Estimating the welfare effects of digital infrastructure. National Bureau of Economic Research (Cambridge, MA) Working Paper No. 5770.

Gujarati, D. and D. Porter (2009). Basic Econometircs. McGraw Hill International.

Hanson, G. (2005). Market potential, increasing returns and geographic concentration. Journal of International Economics 67(1), 1.24.

Hardy, A. (1980). The role of the telephones in economic development. Telecommunications Policy, 4(4), pp. 278.86.

Harrigan, J. (2002). Specialization and the volume of trade: Do the data obey the laws. NBER Working Paper 8675.

Harris, R. (1995). Trade and communication costs. Canadian Journal of Economics 28: 46-75.

Harrison, A. (1995). Openness and growth: A time series, cross country analysis for developing countries. NBER Working Paper No. 5221.

Heeks, R. and C. Kenny (2001). Is the internet a technology of convergence of divergence? (Washington, World Bank), mimeo.

Helpman, E. (1988). Imperfect competition and international trade: Evidence from fourteen industrial countries. Journal of the Japanese and International Economics, 6281.

Helpman, E. and P. Krugman (1985). Market Sturcture and Foreign Trade: Increasing Returns, Imperfect Competition and the International Economy. Cambridge, MA: MIT Press.

Holtz-Eakin, D. (1993). State-speci.c estimates of state and local government capital. Regional Science and Urban Economics, 23, pp. 185,209. 
IMF (2005). Review of the IMF..s Trade Restrictiveness Index. Jagun, A. (2008). The case for open access. APC Issue Papers Series.

Katz, M. L. and C. Shapiro (1985). Network externalities, competition, and compatibility. The American Economic Review, Vol. 75, No. 3. (Jun., 1985), pp. 424-440.

Kline, S. and N. Rosenberg (1986). An Overview of Innovation in The Positive Sum Strategy. Landau, R. and Rosenberg, N. Editors. Na- tional Academy Press, Washington, D.C.

Krugman, P. (1979). Increasing returns, monopolistic competition, and international trade. Journal of International Economics 9: 469-79.

Krugman, P. (1991). Increasing returns and economic geography. Journal of Political Economy 99 483,499.

Krugman, P. (1997). Pop Internationalism. MIT Press, Cambridge, MA. Levine, R. and D. Renelt (1992). A sensitivity analysis of cross- country growth regressions. American Economic Review, 82 (4), 942-963.

Liebowitz, S. and S. Margolis (1994). Network externality: An uncom- mon tragedy. Journal of Economic Perspectives, American Economic Association, vol. 8(2), pages 133-50, Spring.

Linders Gert-Jan , F. De Groot, and F.Henri (2006). Estimation of the gravity equation in the presence of zero .ows. Tinbergen Institute Discussion Paper No. 06-072/3. Available at SSRN: http://ssrn.com/abstract$=924160$.

Lipsey R., G. Carlaw and C. Bekar (2005). Economic Transformations: General Purpose Technologies and Long Term Economic Growth. Oxford University Press.

Lucas, R. (1988). On the mechanics of economic development. Jouranl of Monetary Economics, 22, June 1988, 3-43.

Mayer, J. (2000). Globalization, technology transfer and skill accumula- tion in low-income countries. WIDER Working Paper No. 150.

Melody, W. (1985). Implications of the information and communication technnologies: The role of policy research. Policy studies 6. London Policy Studies Institute.

Melvin, J. R. (1990). Time and space in economic analysis. The Canadian Journal of Economics / Revue canadienne d.Economique, Vol. 23, No. 4 , pp. $725-747$

Mupela E, P. Mustard and H. Jones (2011). Telemedicine and primary health: The virtual doctor project zambia. UNU-MERIT Working Paper 2011-002 
Ngatia, P. (2008). Ways must be found to turn the global labour movement into a win-win situation. The African Medical and Research Foundation (AMREF).

Nicita, A. and M. Olarreaga (2006). Trade , production and protection 19762004. World Bank.

Njikam, O. (2003). Exports and economic growth in sub saharan africa: Is there a connection? (Unpublished)

Noguer, M. and M. Siscart. (2005). Trade raises income: A precise and robust result. Journal of International Economics.

Norton, S. W. (1992). Transaction costs, telecommunications, and the microeconomics of macroeconomic growth. Economic Development and Cultural Change,, 41(1), pp. 175.96.

Okundi, P. O. and B. Evans (1975). Afrosat: Proposals for an african domestic satellite communications system. Paper presented at the International Conference on Satellite Communications Systems Technology. London, April 1975.

Oliner, S. D. and D. E. Sichel (2000). The resurgence of growth in the late 1990s: Is information technology the story. Finance and Economics Discussion Series 2000-20, Board of Governors of the Federal Reserve System (U.S.)

Osiakwan, E. (2008). The case for "open access" communications infrastructure in africa: The SAT-3/WASC cable.

Patel, V. (2003). Recruiting doctors from poor countries: The great brain robbery? British Medical Journal. Education and debate.

Pohjola, M. (2001). Information Technology, Productivity and Economic Growth. Oxford, Oxford University Press.

Portugal-Perez, A. and J. S. Wilson (2008). Trade costs in africa: Barriers and opportunities for reform. The World Bank Development Research Group.

Reati, A. and J. Toporowski (2004). An economic policy for the fifth long wave. BNL Quarterly Review.

Rodrick, D. (2003). Growth strategies. Economics working papers 2003- 17, Department of Economics, Johannes Kepler University Linz, Austria.

Rodriguez, F. and D. Rodrik (2001). Trade policy and economic growth: A skeptic.s guide to cross-national evidence. Bernanke, B.S., Rogoff, K. (Eds.), NBER Macroeconomics Annual 2000. MIT Press, Cambridge, pp. 261-325. 
Roeller, L.-H. and L. Waverman (2001). Telecommunications infrastructure and economic development: A simultaneous approach. American Economic Review.

Romer, P. (1986). Increasing returns and long-run growth. Journal of Political Economy 94(5), 1002.1037.

Romer, P. (1990). Endogenous technological change. Journal of Political Economy, 98.

Rosenthal, S. and W. C. Strange (2003). Geography, industrial organization, and agglomeration. The Review of Economics and Statistics 85(2), 377.393 .

Silva, S. and S. Tenreyro (2006). The log of gravity. Review of Economics and Statistics, 88, 641-658.

Solow, R. (1957). Technical change and the aggregate production func- tion. Review of Economics and Statistics 39(3), 312-20.

Sridhar, K. S. and V. Sridhar (2004). Telecommunications infrastructure and economic growth: Evidence from developing countries. National Institute of Public Finance and Policy (New Delhi, India) Working Paper No. 14.

Tang, L. (2006). Communication costs and trade of differentiated goods. Review of International Economics Volume 14 Issue 1, Pages 54 - 68

Turban, E. and L. Volonino (2008). Information Technology for Man- agement: Transforming Organizations in the Digital Economy, 6th Edition. John Wiley Sons.

Venables, A. J. (2003). Spatial disparities in developing countries: Cities, regions and international trade. CEP Discussion Papers dp0593, Centre for Economic Performance, LSE.

Zon, A. V. and E. Mupela (2010). Endogenous economic growth through connectivity. UNU-MERIT Working Paper 2010-001. 


\section{Samenvatting}

In dit proefschrift wordt het belang onderzocht van de strategische toepassing van informatie- en communicatietechnologieën in economieën in SubSahara Afrika, met als doel het bevorderen van groeimogelijkheden in die regio. Het proefschrift onderzoekt de mogelijkheden die satellieten bieden om een gemakkelijk uit te breiden infrastructuur te bouwen. Die infrastructuur wordt gemodelleerd in een endogeen groeimodel dat op een theoretische manier het groeipotentieel laat zien van massacommunicatie in economieën die tot nog toe een dergelijke infrastructuur ontberen. Het proefschrift onderzoekt zulke effecten ook empirisch door de effecten van communicatiekosten op handel in Sub-Sahara Afrika te analyseren. Vervolgens bestudeert het proefschrift de effecten van toegang tot de telecommunicatie infrastructuur in Zuid-Afrikaanse gemeenten op het gemeentelijk welvaartsniveau. Het gemiddeld inkomen per huishouden wordt in deze studie gebruikt als een proxy voor de welvaart gegenereed in een gemeente.

Eén van de belangrijkste vragen van deze studie is of de strategische en versnelde diffusie van informatie- en communicatietechnologieën in Afrika zal leiden tot versnelde groei in belangrijke economische sectoren, en tot meer algemene economische groei en ontwikkeling in de regio. Om deze algemene vraag te kunnen beantwoorden, stellen we eerst enkele meer specifieke vragen met betrekking tot de betekenis van satelliettechnologie als de ruggengraat van internationale communicatie in Sub-Sahara Afrika. Het gebruik van satelliet technologie als een overkoepelende infrastructuur voor het gebruik van strategische ICT toepassingen in Afrika, biedt de mogelijkheid de diffusie van ICT's te versnellen en daardoor een belangrijke bijdrage te leveren aan economische groei en ontwikkeling van Afrikaanse economieën. Maar satellietcommunicatie is een kostbare technologie, en Afrikaanse landen zijn op dit moment afhankelijk van internationale's satellietsystemen die zeer prijzige communicatiediensten verlenen. Dit resulteert in relatief hoge kosten van ICT dienstverlening op het continent. Met de voortgang van de verspreiding van alternatieven voor satellietcommunicatie, is het belangrijk om na te gaan hoe de communicatiekosten zullen veranderen ten opzichte van de huidige kosten-niveaus. Dit leidt tot de vraag of hogere communicatiekosten feitelijk de handels uitkomsten voor de economieën van Sub-Sahara Afrika beïnvloeden, en of en inhoeverre de toegang tot de communicatie infrastructuur een positieve invloed heeft op inkomens genererende activiteiten beïnvloeden in lokale gemeenschappen. Hieronder volgt een hoofdstuksgewijze samenvatting van het proefschrift. 
Na een kort overzicht van de probleemstelling en de herkomst van het basisidee dat aan het proefschrift ten grondslag ligt in hoofdstuk één, volgt een behandeling van de belangrijkste eigenschappen van satelliettechnologie in hoofdstuk twee. Dat hoofdstuk biedt een overzicht van de staat van satelliettechnologie in Afrika en bespreekt de concurrentie tussen satellieten en andere communicatietechnologieën, in het bijzonder onderzeese glasvezel kabels.

In hoofdstuk drie bouwen we een endogeen groeimodel gebaseerd op satellietverbindingen, waarbij we de volgende veronderstellingen maken:

1. Regionale communicatieverbindingen zijn van betekenis voor groei;

2. Via satelliettechnologie kan gemakkelijk en onmiddellijk een uitgebreid netwerk van verbindingen worden gerealiseerd tussen regio's die geografische ver van elkaar afliggen.

We geven een samenvatting van de literatuur over communicatie en groei en construeren een endogeen groeimodel gebaseerd op de levering van communicatiediensten en de beschikbaarheid van een transport infrastructuur. Gemeenschappen worden met elkaar verbonden door communicatie- en transport infrastructuur en krijgen zo de mogelijkheid om handel te drijven in gespecialiseerde goederen en diensten. Deze handel leidt tot groei in de economie. In het model is de beschikbaarheid van een communicatie infrastructuur een noodzakelijke voorwaarde voor het optreden van economische groei. Deze groei komt voornamelijk voort uit de aanname van onbegrensde imitatiemogelijkheden in de gemeenschappen die met elkaar in verbinding staan aan de ene kant, en een stijging in het aantal variëteiten dat de leden van de grotere, met elkaar verbonden, gemeenschappen kunnen consumeren. Als resultaat vinden we dat een daling van de transport- en communicatiekosten zal leiden tot een hogere groeivoet in de verbonden gemeenschappen. Het grootste groei-effect treedt op wanneer de kosten van het maken van nieuwe verbindingen dalen. Dit resultaat onderstreept het belang van de omvang van het netwerk van verbonden gemeenschappen. We vinden ook dat de omvang van de individuele gemeenschappen belangrijk is voor groei.

Hoofdstuk vier bespreekt de voor- en nadelen van concurrerende technologieën op het continent en laat de praktische voordelen zien van verbinding via satelliet, zoals beschreven in hoofdstuk drie. We volgen een evolutionaire aanpak, waarbij we beginnen met een korte geschiedschrijving van de internationale communicatie in Afrika. Verschillende ICT diensten passeren de revue. In elk individueel geval benadrukken we hoe deze worden beïnvloed door satellietverbindingen in Afrika. Ook voeren we een gedetailleerde vergelijking uit tussen satelliet- en optische glasvezel kabel technologie, waarbij we de voor- en nadelen van elk van die technologieën bespreken, en nagaan waarom elk van deze technologieën uiteindelijk niet de oplossing biedt voor de verbindingsproblemen waarmee Sub Sahara Afrika geconfronteerd worden.

Hoofdstuk vijf bouwt hierop voort met een empirisch onderzoek naar de relatie tussen communicatiekosten en handel in Sub Sahara Afrika, waarin we 
gebruik maken van een verbeterd graviteits-model. Gegevens met betrekking tot exporten, internationale telefoontarieven, maandelijkse internetgebruikstarieven, en het aantal uitgaande telefoongesprekken uit een bepaald land in 2007, worden binnen deze graviteits-opzet geanalyseerd. De resultaten suggereren dat communicatiekosten belangrijk zijn voor handel, en dat deze kosten negatief worden beïnvloed door het ontbreken van voldoende satellietverbindingen in Afrika.

Hoofdstuk zes doet onderzoek naar de relatie tussen de toegang tot telecommunicatie in het algemeen en het inkomen van gezinshuishoudingen in gemeenten in Zuid-Afrika. We analyseren hier het belang van toegang tot ICT infrastructuur door middel van radio's, computers, televisie en telefonie (zowel vast als mobiel) in relatie tot de hoogte van het inkomen van gezins huishoudingen per hoofd in gemeenten in Zuid Afrika. We concluderen dat een betere toegang tot de telecommunicatie infrastructuur een positief effect heeft op het inkomen per hoofd van gezinshuishoudingen in gemeenten in Zuid Afrika.

Hoofdstuk zeven bespreekt een aantal specifieke initiatieven om satellietcommunicatie diensten te verlenen in Afrika. We analyseren de case van Worldspace Incorporated, een bedrijf dat via satellietverbinding digitale radio uitzendingen doorgeeft, en de case van Multichoice, een aanbieder van satelliet-tv . Ook kijken we naar verschillende"tele-medicijn" projecten op het continent in het bijzonder het "Virtuele Dokters"-project in Zambia.

Hoofdstuk acht geeft een samenvatting van onze bevindingen en biedt een aantal beleidsaanbevelingen en suggesties voor toekomstig onderzoek.

Het belang van dit onderzoek ligt in de ondersteuning van het groeiende besef dat ICT's alleen maar een significante bijdrage aan economische groei in Afrika kunnen leveren wanneer er voldoende middelen in de ICT sector worden geïnvesteerd. Afrikaanse dienstverleners moeten het beslag zien te beperken dat buitenlandse satelliet- en optische kabelaanbieders weten te leggen op hun beperkte middelen, zodat ze kunnen concurreren met internationale telefoontarieven en zo hun dienstverlening kunnen uitbreiden naar moeilijk te bereiken rurale gebieden waar dienstverlening zoals die op het gebied van "tele-medicijnen" mede vanwege de hoge verbindingskosten, niet goed van de grond is gekomen. 
